Структура подсистемы прогноза выбросоопасности многофункциональной системы безопасности угольной шахты
Крупномасштабные обвалы как геофизическмй процесс горного удара или внезапного выброса пород и газа

стр.21

Выпуск 2-2020 | Кемерово | ISSN 2072-6554 | DOI 10.26631/issn.2072-6554

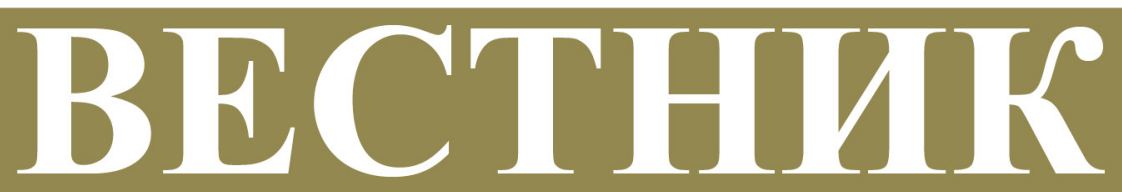

Научногоцентра по безопасности работ в.угольной промышленности

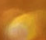
0

\title{
ПРОМБEЗОПАСНОСТЬ, ФAKTOP
} ПАНДЕМИИ И ПРОГРАММА

\section{РАВВИТИЯ ОТРАСЛИ.}

Слово редактора

стр 5

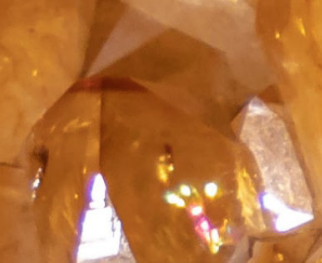

- АКТУАЛЬНО
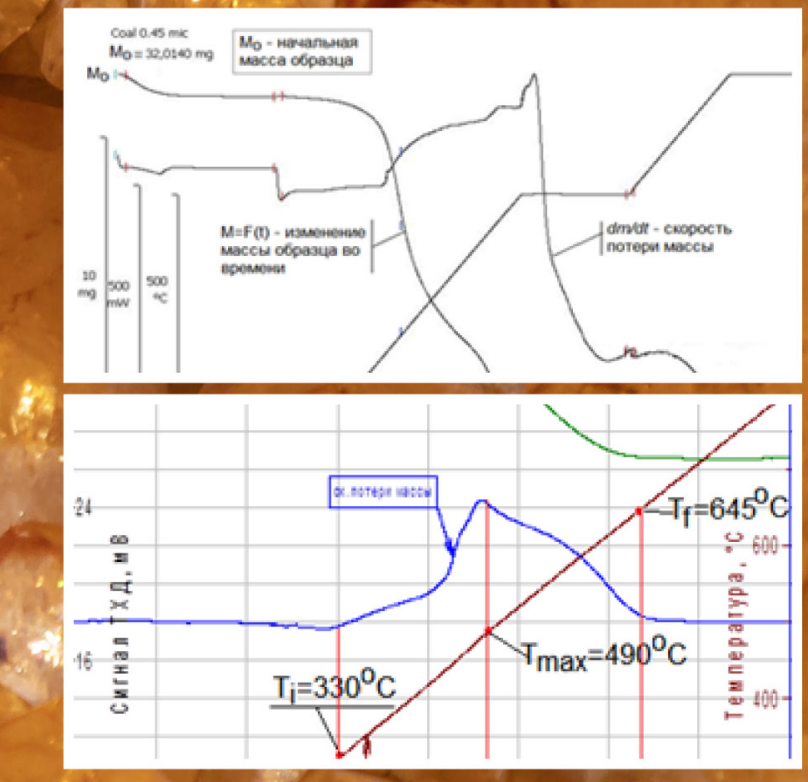

ТЕРМОГРАВИМЕТРИЧЕСКИЙ АНАЛИЗ УГОЛЬНОЙ ПЫЛИ и инертных добавок в системах пылевзрывозащиты стр. 6 


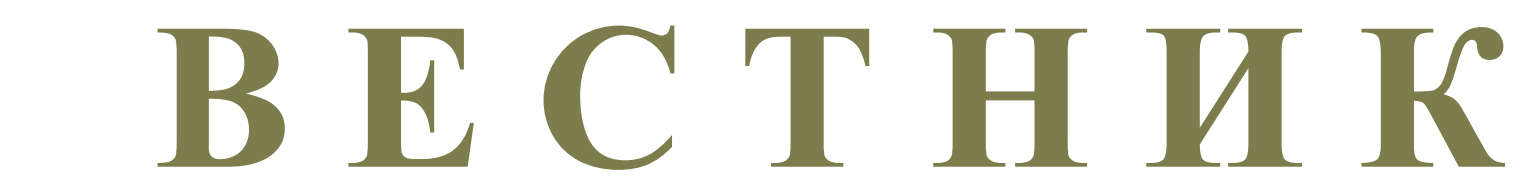

Научного центра по безопасности работ в угольной промышленности

\author{
Научно-технический журнал
}

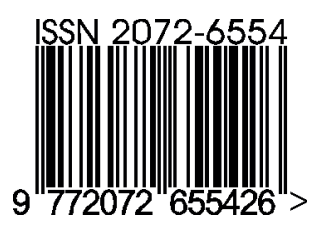

Кемерово 
ВЕСТНИК

\section{Научного центра}

по безопасности работ

в угольной промышленности ISSN 2072-6554

№ 2-2020
Выходит 4 раза в год

Подписной индекс

в Каталоге Агентства

«Роспечать» 2020 г. - 35939

\section{ЖУРНАЛ ЗАРЕГИСТРИРОВАН}

Федеральной службой по надзору в сфере связи, инфоормационных технологий и массовых коммуникаций.

Свидетельство о регистрации средства массовой информации ПИ № ФС77-71529 от 13.11.2017 г.

\section{ЖУРНАЛ ВКЛЮЧЕН}

в «Перечень российских рецензируемых научных журналов, в которых должны быть опубликованы основные научные результаты диссертаций на соискание ученых степеней доктора и кандидата наук», сформированный ВАК при Минобрнауки России

\section{Учредитель и издатель}

научно-технического журнала «Вестник...»: Общество с ограниченной

ответственностью «ВостЭКО»

(ООО «ВостЭКО»)

Адрес учредителя и издателя:

650002, Россия, Кемеровская область, г. Кемерово,

Сосновый бульвар, дом 1, кабинет 415

Адрес редакции:

650002, Россия, Кемеровская область, г. Кемерово, Сосновый бульвар, дом 1

Редакторы: М. В. Ярош, Л. С. Кузавкова, Д. А. Трубицына

Компьютерная верстка Д. А. Трубицына

тел. 77-86-62, 64-26-51.

e-mail: yarosh_mv@mail.ru dtrubitsyna@gmail.com

www.ind-saf.ru

Позиция редакции не всегда совпадает с точкой зрения авторов публикуемых материалов Автор фото обложкт - Grant Durr с pecypcaa Unsplash

В номере использованы материалы сайтов www.lori.ru, www.freelmages.com, www.unsplash.com и www.graphicriver.net

\section{$16+$}

\section{(C) 000 «ВостЭКО», 2020}

Главный редактор: Н. В. Трубицына

\section{Редакционная коллегия:}

Н. В. Трубицына - главный редактор, заместитель директора по научной работе ООО «ВостЭКО», д-р техн. наук

А. С. Ярош - заместитель главного редактора, канд. техн. наук

Д. В. Исламов - депутат ГД ФС РФ, кандт. техн. наук

А. А. Трубицын - консультант по научной работе ООО «Горный-ЦОТ», НАО «НЦ ПБ», д-р техн. наук, проф.

А. А. Васильев - заведующий лабораторией ФГБУН «Институт гидродинамики им. М.А. Лаврентьева СО РАН», д-р физ.-мат. наук, профр.

А. М. Брюханов - директор МакНИИ, д-р техн. наук

В. И. Клишин - директор Института угля Федерального исследовательского центра угля и углехимии СО РАН, чл.-корр. РАН, д-р техн. наук, проф.

3. Р. Исмагилов - директор Института углехимии и химического материаловедения Федерального исследовательского центра угля и углехимии СО РАН, чл.-корр. РАН, д-р хим. наук, проф.

А. В. Шадрин - ведущий научный сотрудник Института угля ФИЦ УУХ СО РАН, д-р техн. наук

В. Г. Казанцев - заведующий кафедрой «БТИ» (филиал) ФГБОУ ВПО «АлтГТУ им. И.И. Ползунова», д-р техн. наук

В. С. Зыков - заместитель генерального директора АО «НЦ ВостНИИ», д-р техн. наук, профр.

Д. А. Трубицына - выпускающий редактор ООО «ВостЭКО»

М. В. Ярош - редактор ООО «ВостЭКО» 


\section{INDUSTRIAL SAFETY}

Scientific-technical magazine

Kemerovo

2 - 2020

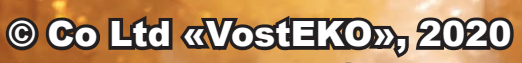

unuwhind-seffru 


\section{INDUSTRIAL SAFETY ISSN 2072-6554}

№ 2- 2020

\section{MAGAZINE IS REGISTERED}

by the Federal Service for Supervision in the Sphere of Communications, Information Technologies and Mass Communications. Registration cerificate of mass information means PI № FS77-71529 dated by 13.11 .2017 r.

\section{THE MAGAZINE IS INCLUDED}

into «The list of russian reviewed scientific magazines in which main scientific results of dissertations for scientific degrees of a doctor and a candidate of sciences must be published». The list is formed by Higher Attestation Commossion of RF Ministry of Education and Science.

\section{Promoter and publisher of "Industrial Safety» scientific-technical magazine: \\ Co Ltd "VostEKO»}

Address of the promoter and publisher:

650002 , Russia, Kemerovskaja oblast, Kemerovo, Sosnovyi bd., 1, office 415

Address of the editors:

650002, Russia, Kemerovskaja oblast, Kemerovo, Sosnovyi bd., 1

Editors: M.V. Yarosh, L.S. Kuzavkova, D.A. Trubitsyna Computer layout D.A. Trubitsyna

Tel. 77-86-62, 64-26-51.

e-mail: yarosh_mv@mail.ru dtrubitsyna@gmail.com

www.ind-saf.ru www.indsafe.ru

\begin{tabular}{l} 
The edition position not always coincides with the point \\
of view of authors of published materials \\
\hline Cover Photo by Grant Durr on Unsplash \\
\hline In the issue of the magazine materials of sites \\
www.lori.ru, www.freelmages.com, www.unsplash.com \\
and www.graphicriver.net are used
\end{tabular}

\section{$16+$}

(c) Co Ltd «VostEKO», 2020

\section{Chief editor: N. V. Trubistyna}

\section{Editorial board:}

N. V. Trubitsyna - chief editor, deputy director for scientific work of OOO «VostEKO», doctor of technical sciences

A. S. Yarosh - deputy chief editor, candidate of technical sciences

D. V. Islamov - deputy of the State Duma of the Federal Assembly of the Russian Federation, candidate of technical sciences

A. A. Trubitsyn - scientific work consultant, OOO "Gorny COT", NAO "NC PB", doctor of technical sciences, professor

A. A. Vasil'ev - Head of the Laboratory FGBUN "M.A. Lavrentyev Institute of Hydrodynamics SB of RAS, doctor of physical and mathematical sciences, professor

A. M. Brjuhanov - Director of MakNII, doctor of technical sciences

V. I. Klishin - director of the Institute of coal, Federal research center of coal and coal chemistry SB RAS, corresponding member of RAS, doctor of technical sciences, professor

Z. R. Ismagilov - director of the Institute of coal chemistry and materials chemistry, Federal research center of coal and coal chemistry SB RAS, corresponding member of RAS, doctor of chemical sciences, professor

A. V. Shadrin - Leading researcher of the Institute of Coal FIC UUH SB RAS, doctor of technical sciences

V. G. Kazantsev - chairman of «BTI» (branch) FGBOU VPO «AltGTU after I.I.Polzunov», doctor of technical sciences

V. S. Zykov - deputy general director JSC «ScC VostNII», doctor of technical sciences, professor
D. A. Trubitsyna - OOO «VostEKO» Commissioning Editor

M. V. Yarosh - OOO «VostEKO» editor 

которое в корне меняет привычное течение жизни всего человечества. Это, конечно же пандемия коронавируса COVID-19. Все последние месяцы он диктует нам свои "правила игры". Но мир ищет пути минимизации потерь от этой напасти. И ищет, подчеркну

резервы. И наша не исключение, ведь добыча угля — это энергетическая безопасность страны. К тому же экспорт твёрдого топлива на внешний рынок - одно из ключевых направлений экономической политики. Этим обусловлена особое внимание правительства к отрасли. И напомню, что буквально в середине июня премьер-министр Михаил Мишустин утвердил программу развития угольной промышленности России до 2035 года

Программа учитывает, что прочесс угледобычи "уязвим" тем, что в отличие от многих других сфер экономики горные работы на шахтах и разрезах обусловливает непрерывный цуикл производства. Остановка добычи твёрдого топлива даже на непродолжительное время оборачивается, как правило, больиими, а зачастую и невосполнимыми материальными потерями. Поэтому важно в условиях пандемии и после неё не обходить вниманием и поддержкой возрастающую роль промышленной безопасности, всех её составляющих в деятельности профильных структур и компаний. В одобренной программе подчеркивается, что сейчас актуализируется необходимость ускорения и динамичного внедрения прорывных технологий, обеспечиваюших требования промбезопасности и безаварийной работы предприятий, исключающчих какие-либо угрозы для жизни горнорабочих и специиалистов.

В нынешней ситуации возрос спрос на оригинальные и, может быть, даже неожиданные решения. Новый взгляд на порядок вещзей лищь подчёркивает их важность и социальную значимость. Поэтому не удивительно, что наши технологии напрямую востребованы в борьбе с коронавирусом. Это произошло с инновационной системой дезинфекции в зданиях и закрытых сооружениях. В аппарате, представленном инженерами и конструкторами группь компаний «ВостЭКО и «Горный-ЦОТ» используется "искусственный туман", создаваемый системой пневмогидроорошения, которая распыляет антисептические вещества в офисном или производственном помещении. Эта технология не только исключает контакты человека с химическими веществами, но гораздо эффективнее и в шесть раз быстрее ручной обработки. Эта разработка выходит за рамки одной отрасли, она необходима всем, везде и повсюду.

Сейчас во многих научно-производственных коллективах, занимающихся проблемами промбезопасности, идёт активное переосмысление вектора изысканий и корректировка практической деятельности. Это диктуют нам новые вызовы, перед которыми мы стоим, что называется, лицุом к лииу. Пандемия подняла планку нашей ответственности за здоровье и жизнь горняков намного выше. И это особо было подчёркнуто ещчё в мае на совещзании по состоянию промьиленной безопасности на угольных предприятиях Кузбасса в условиях санитарно-эпидемиологической ситуации, связанной с распространением COVID-19. Тогда, напомню, особо отмечалась актуальность дистанционного контроля за горными работами, поднимались вопросы ускорения оснащения предприятий отрасли новыми и модернизированными многофункциональныли системами безопасности технологических проиессов. На это ориентирует нас и одобренная руководством страны программа развития угледобычи.

Профильные структуры отвечают на запросы отрасли и общества. Достаточно открыть страниць с содержанием этого номера "Вестника". Публикации каждого тематического блока отражают различные направления деятельности компаний и научно-производственных коллективов. Уверена, что у каждого из материалов будет свой заинтересованный читатель. Назову только некоторые из актуальных проблем, поднимаемых авторами. Это пылевзрывозащчтта, точность прогнозов выбросоопасности, инновационные решения, возникающче при эксплуатации и консервации угольных предприятий, вопросы безопасной эксплуатации шахтного оборудования. Рассматривается также и "человеческий фактор", способствующий аварийным ситуациям. Авторы материалов наглядно демонстрируют достижения и конкретные результаты учёных и конструкторов в связке с инженерами и ведущчими спецчиалистами.

А редакиионная коллегия смотрит тем временем в будущчее и уже занимается формированием следующего номера. Здесь должна поблагодарить авторов и авторские коллективь. Благодаря вам, уважаемые коллеги, редакиионный портфель в этом году богат как никогда. У нас возникла своеобразная "очередь" на публикацию авторских работ. И это позволяет нам представить читателям и рассмотреть ту или иную проблематику всесторонне и основательно.

Свежий номер "Вестника" тоже тому пример. Дорогие читатели и друзья, главное, что мьл не стоим на месте, ищем новое и открыты для всего нового!

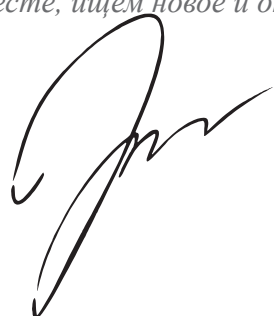

НЭЛЯ ТРУБИЦЫНА, главный редактор, д.Т.н. 

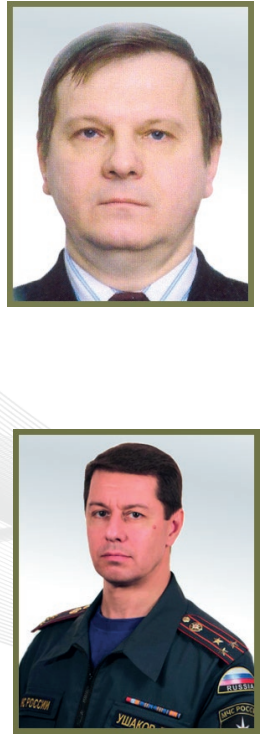

С.Б. Романченко //

S. B. Romanchenko romanchenkosb@mail.ru

д-р техн. наук, доцент, ведущий научный сотрудник ФГБУ ВНИИПО МЧС России, Россия, 143903, Московская область, г. Балашиха, мкр. ВНИИПО, д. 12 doctor of technical sciences, assistant professor, leading researcher of FGBU VNIIPO MChS of Russia, microdistrict 12, VNIIPO, Balashikha, Moscow Region, 143903, Russia

\section{Д.В. Ушаков // D. V. Ushakov}

начальник отдела ФГБУ ВНИ ИПО МЧС России, Россия, 143903, Московская область г. Балашиха, мкр. ВНИИПО, д. 12 head of department of FGBU VNIIPO MChS of Russia, microdistrict 12, VNIIPO Balashikha, Moscow Region, 143903 Russia

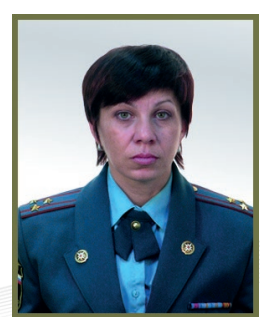

Е.А. Губина // Е. A. Gubina

начальник сектора ФГБУ ВНИИПО МЧС России, Россия, 143903, Московская область, г. Балашиха, мкр. ВНИИПО, д. 12 head of sector of FGBU VNIIPO MChS of Russia, microdistrict 12, VNIIPO Balashikha, Moscow Region, 143903, Russia

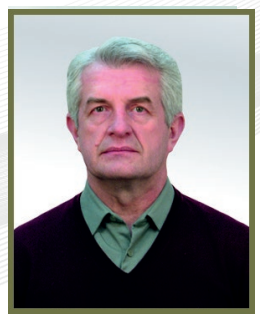

Ю.К. Нагановский // Yu. K. Naganowskiy канд. техн. наук, ведущий научный сотрудник ФГБУ ВНИИПО МЧС России, Россия, 143903, Московская область, г. Балашиха, мкр. ВНИИПО, д. 12 candidate of technical sciences, leading researcherof FGBU VNIIPO MChS of Russia, microdistrict 12, VNIIPO, Balashikha, Moscow Region, 143903, Russia

УДК 622.81

\section{ТЕРМОГРАВИМЕТРИЧЕСКИЙ АНАЛИЗ УГОЛЫНОЙ ПЫЛИ И ИНЕРТНЫХ ДОБАВОК В СИСТЕМАХ ПЫЛЕВЗРЫВОЗАЩИТЫ}

\section{THERMOGRAVIMETRIC ANALYSIS OF COAL DUST AND INERT ADDITIVES IN DUST AND EXPLOSION PROTECTION SYSTEMS}

В статье рассмотрены результаты термогравиметрического анализа (ТГ) образцов угля и инертной пыли на основе известняка. Показаны основные результаты статической и динамической термогравиметрии применительно к угольной пыли, данные совмещенных экспериментов «термовесы - анализ горючих газов» (ТГ-АГГ эксперименты), на основании которых определен интервал термодеструкции угля в соотношении стемпературным диапазоном выхода горючих газов. Представлены результаты термической деструкции инертной (сланцевой) пыли, применяемой в качестве систем пылевзрывозащиты. Обоснована практическая значимость интервала реакции и характерных точек процесса термодеструкции известняка для перспективного контроля качества осланцевания и определения участия смесей угольной и инертной пыли во взрывах.

The article considers the results of thermogravimetric analysis (TGA) of coal and inert dust samples based on limestone. The basic results of dynamic and static thermogravimetry in relation to coal dust, combined the data of experiments "termbase - analysis of combustible gases" (TG-AGG experiments), on the basis of which is determined by the interval of termodestruction coal in the ratio with temperature output range of combustible gases. The results of thermal destruction of inert (shale) dust used as dust and explosion protection systems are presented. The practical significance of the reaction interval and characteristic points of the limestone thermal degradation process for prospective quality control of shale and determination of the participation of coal and inert dust mixtures in explosions is substantiated.

Ключевые слова: ВЗРЫВ, ВЗРЫВООПАСНОСТЬ, УГОЛЬ, УГОЛЬНЫЙ АЭРОЗОЛЬ, КОНЦЕНТРАЦИЯ ПЫЛИ, ДИСПЕРСНЫЙ СОСТАВ, АЭРОЗОЛЬ, ТЕРМОГРАВИМЕТРИЯ, ВЫХОД ЛЕТУЧИХ ВЕЩЕСТВ, ТЕРМИЧЕСКИЙ АНАЛИЗ, ТЕРМОДЕСТРУКЦИЯ УГЛЯ, ТЕРМОГРАВИМЕТИЧЕСКАЯ КРИВАЯ, ТЕРМОГРАВИМЕТРИЧЕСКАЯ КРИВАЯ ПО ПРОИЗВОДНОЙ, ДИНАМИЧЕСКАЯ ТЕРМОГРАВИМЕТРИЯ, АНАЛИЗ ГОРЮЧИХ ГАЗОВ, СОВМЕЩЕННЫЙ ЭКСПЕРИМЕНТ.

Key words: EXPLOSION, EXPLOSION HAZARD, COAL, COAL AEROSOL, DUST CONCENTRATION, DISPERSION COMPOSITION, AEROSOL, THERMOGRAVIMETRY, VOLATILES YIELD, THERMAL ANALYSIS, THERMAL DEGRADATION OF COAL, THERMOGRAVIMETRIC CURVE, THERMOGRAVIMETRIC CURVE BY DERIVATIVE, DYNAMIC THERMOGRAVIMETRY, ANALYSIS OF COMBUSTIBLE GASES, COMBINED EXPERIMENT. 
$\mathrm{B}$

ВЕДЕНИЕ

В области пожаровзрывобезопасности веществ и материалов методы термического анализа широко применяются с 70-х годов XX века [1]. Методами термического анализа исследуется пожарная опасность веществ и материалов, проводится идентификация веществ, выделяющихся из исследуемых образцов при нагревании [2-5]. При этом в области исследований угля применяются крайне ограниченные по информативности методы изотермический нагрев в муфельной печи (или статическая термогравиметрия) в рамках отнесения угольной пыли каждого шахтопласта к взрывчатой [5]. При изотермическом нагреве $T=900^{\circ} \mathrm{C}$ в муфрельной печи в течение 7 минут определяется выход летучих веществ $V^{d a f}, \%$ ( по ГОСТ Р 55660-2013 - как величина потери массы образца, выраженная в процентах) и масса зольного остатка.

Исследование динамики процесса термодеструкции угля, определение характерных точек, температуры начала и окончания процессов выхода летучих веществ, диапазон реакции и ряда других показателей в муфельной печи невозможно.

Указанные вопросы решаются применением динамической термогравиметрии (TГ) - метода термического анализа, при котором в специальных устройствах - термовесах проводится нагрев и измерение массы образца с шагом времени (как правило - через 1-2с), контролируется температура и строится ТГ кривая - зависимость массы образца, как фрункции температуры:

$$
M=F(T),
$$

где $T$ - температура нагрева образца $\left({ }^{\circ} \mathrm{C}\right)$.

Поскольку в динамической термогравиметрии температура образца изменяется во времени по определенному закону, то фактически исследуется сложная функция $M=F(\varphi(t))$, где независимой переменной является время. Наиболее часто применяется равномерное увеличение температуры во времени от начального значения $25^{\circ} \mathrm{C}$ до максимального значения $900^{\circ} \mathrm{C}$. В математической форме рост температуры образца задается в виде функции от времени $[1,2]$ :

$$
T=\varphi(t)=T_{0}+A \cdot t,
$$

где $T$ - температура $\left({ }^{\circ} \mathrm{C}\right) ; T_{0}$ - начальная температура образца $\approx 20-25^{\circ} \mathrm{C} ; A$ - скорость нагрева (град/мин.); $t$ - время (с).

Наиболее распространенным значением параметра $A$ (скорости нагрева) при исследовании угля принято $A=20$ град/мин, максимальная температура нагрева - до $900^{\circ} \mathrm{C}$.

Кроме $T Г$ кривых экспериментально получаются ДТГ-кривые по методу термогравиметрии по производной. В этом случае строится кривая скорости потери массы $(d m / d t)$

$$
d m / d t=f(T)
$$

В современных исследовательских комплексах, включающих термовесы, анализирующие одновременно до 16 образцов материалов со встроенными функциями анализа химического состава выделяющихся газов, возможно задание функции измерения температуры по более сложной, чем (2) зависимости [7]. Типовой при-

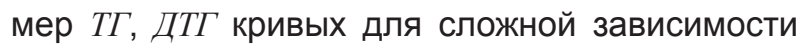
нарастания температуры приведен на рисунке 1.

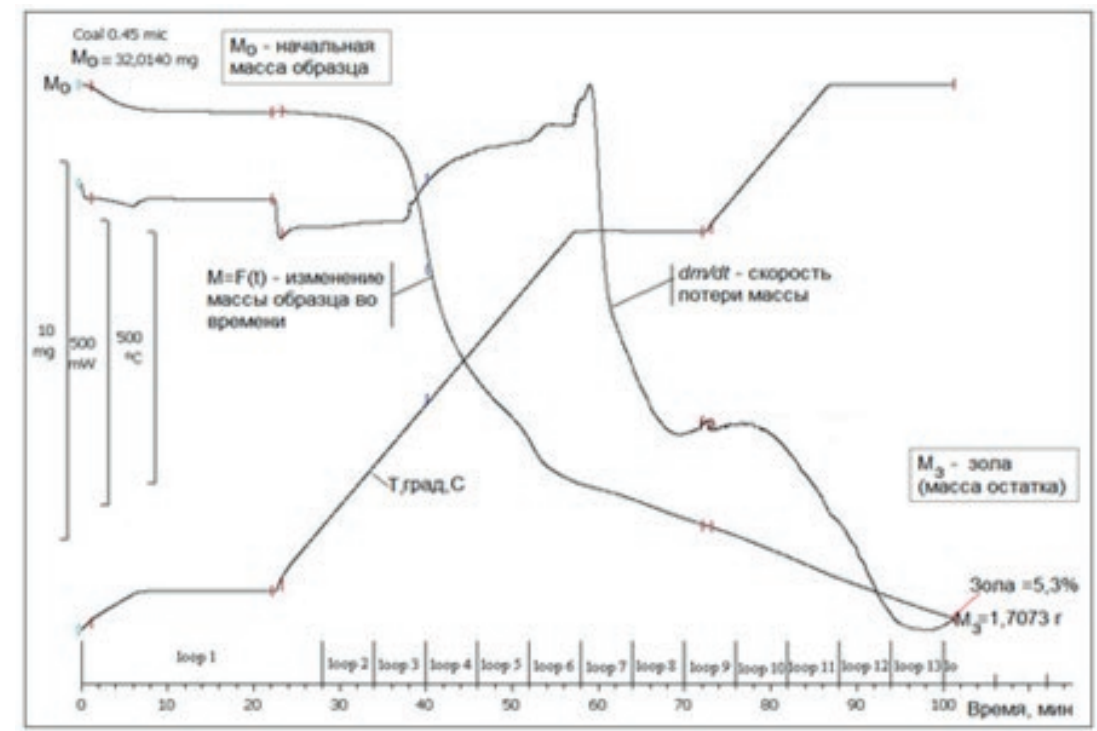

Рисунок 1. Термогравиметрические кривые при сложной функции изменения температуры (с квазистабильными интервалами и отбором проб газов) ${ }^{1}$

Figure 1. Thermogravimetric curves for a complex function of temperature change (with quasistable intervals and gas sampling) 
Полученные термогравиметрические кривые (рисунок 1) позволяют определить характерные точки процесса, судить о массе образца в начальном состоянии - $M_{0}$; массе золы или остатка - Мз, а также о степени термостабильности образца. По ДТГ кривым наиболее наглядно и достоверно получают данные по величине:

а) начальной температуры разложения $\left(T_{i},{ }^{\circ} \mathrm{C}\right)$ - температура, при которой суммарное изменение массы превышает чувствительность весов;

б) конечная температура - $\left(T_{f},{ }^{\circ} \mathrm{C}\right)$ при которой суммарное изменение массы достигает максимального значения, что соответствует завершению реакции;

в) интервал реакции, как разницу между величинами $T_{f}-T_{i}$;

г) по ГОСТ Р 53293-2009 [2] по ДТГ-кривым определяются экстраполированные точки начала и окончания стадии термодеструкции $\left(T_{i-9} T_{f-9}\right)$ - точки пересечения касательной из точки наибольшего наклона с экстраполированной базовой линией, а также температура максимальной скорости выхода летучих веществ $T_{\max }$.

В рамках настоящей публикации рассмотрено применение динамической термогравиметрии применительно к угольной пыли и данные по термической деструкции инертной пыли $\left(\mathrm{CaCO}_{3}\right)$ - как теоретическая основа методов контроля качества осланцевания или методов идентификации участия пыли во взрывах на этапах

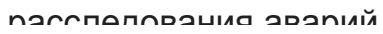

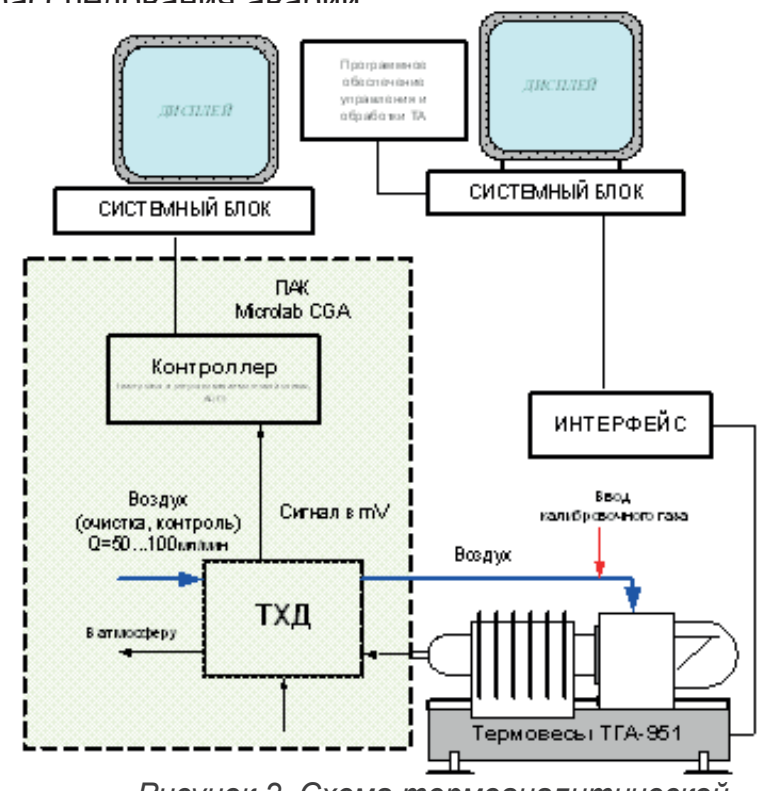

Рисунок 2 Схема термоаналитической системы при работе в совмещенном режиме «термовесы - анализ горючих газов» (ТХД термохимический детектор горючих газов) Figure 2 Diagram of the thermoanalytic system when working in the combined mode "thermowells - analysis of combustible gases" (TCDthermochemical detector of combustible gases)
1. Исследование процессов термодеструкции угля и интервала выхода горючих газов

Использование современных технических средств для термогравиметрического анализа предусмотрено ГОСТ Р 53293-2009 [2]. По данному стандарту проводится идентификация методами термического анализа различных материалов, веществ, включая угли различной стадии метаморфизма. Относительно медленный равномерный нагрев $\left(A=20^{\circ} \mathrm{C} /\right.$ мин) позволяет получать информацию, безвозвратно утрачиваемую при быстром нагревании угольной пыли: на первом этапе нагрева (до $100^{\circ} \mathrm{C}$ ) из образцов удаляется внешняя и гигроскопическая влага и по потере массы образца с высокой точностью определяется фрактическая влажность; определяется температура начала и окончания процесса выделения летучих веществ, интервал реакции.

В температурном диапазоне интервала реакции для угольного вещества происходит основной выход летучих веществ, выделившиеся газы для исследованных марок энергетических и коксующихся углей были протестированы на горючесть в совмещенном эксперименте «термовесы - анализ горючих газов» (ТГ-АГГ эксперименты). Схема совмещенной ТГ-АГГ системы приведена на рисунке 2.

Система газоснабжения для ТГ-АГГ экспериментов приведена на рисунке 3, включала основные составляющие: генератор воздуха; регулятор расхода и расходомер.

Термохимический детектор калибровался по газовым смесям с известными концентрациями и теплотой сгорания.

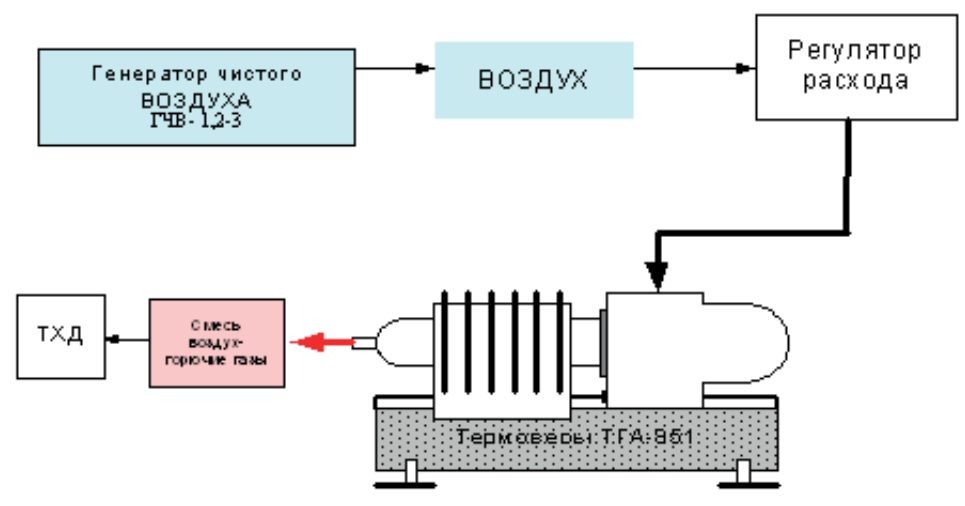

Рисунок 3 Газовая схема совмещенного ТГА-АГГ эксперимента

Figure 3 the Gas scheme of the combined TGA-AGG experiment 


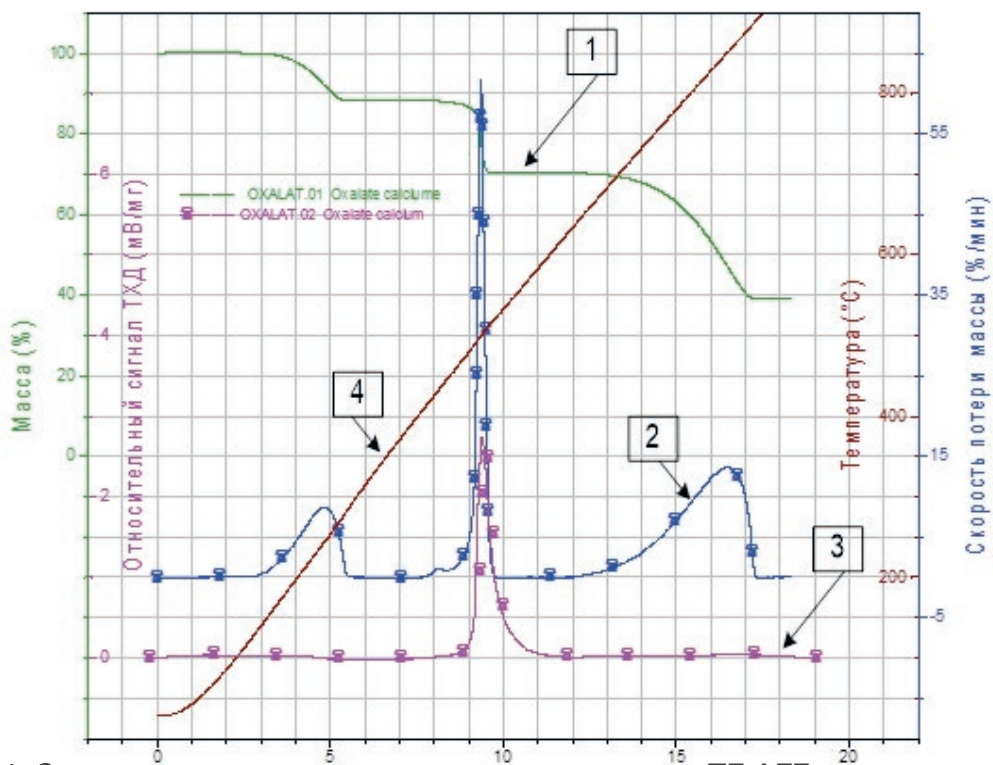

Рисунок 4 Совмещенные термоаналитические кривые ТГ-АГГ эксперимента: 1 - кривая потери массы (ТГ кривая); 2 - кривая скорости потери массы (ДТГ кривая); 3 - кривая выделения горючих газов; 4 температура

Figure 4 Combined thermoanalytic curves of the Tg-AGG experiment: 1-mass loss curve( TG curve); 2-mass loss rate curve (DT curve); 3-combustible gas release curve; 4-temperature

На рисунке 4 представлены результаты совмещенного термического анализа (термогравиметрические кривые и кривые выделения горючих газов) для эталонного твердого материала (оксалат кальция) и газовой смеси оксида углерода $(9,8 \%$ об.) в азоте (калибровочный образец).

Для угольной пыли (коксующийся уголь марки Ж) пик скорости потери массы образца Tmax и максимальный сигнал термохимического детектора горючих газов $\left(T_{\max }-T X Д\right)$ совпадают (рисунок 5). Также совпадают экстраполированные точки начала/окончания процесса и интервал реакции. Интервал реакции для кривых скорости потери массы и сигнала ТХД (рисунок 5) составил $330-645^{\circ} \mathrm{C}$, а наиболее интенсивная скорость потери массы и максимальный выход ТХД достигнуто при температуре около $490^{\circ} \mathrm{C}$. Это является экспериментальным подтверждением того, что основу выделяющихся из углей летучих веществ составляют горючие газы.

Фрагменты совмещенного ТГ-АГГ экспериментов для энергетической марки угля «Д» приведены на рисунках 6 и 7.

На рисунке 6 приведены результаты исследований для дисперсного состава пыли, соответствующему реальному пылеотложению в шахтах [9], а на рисунке 7 - для той же марки

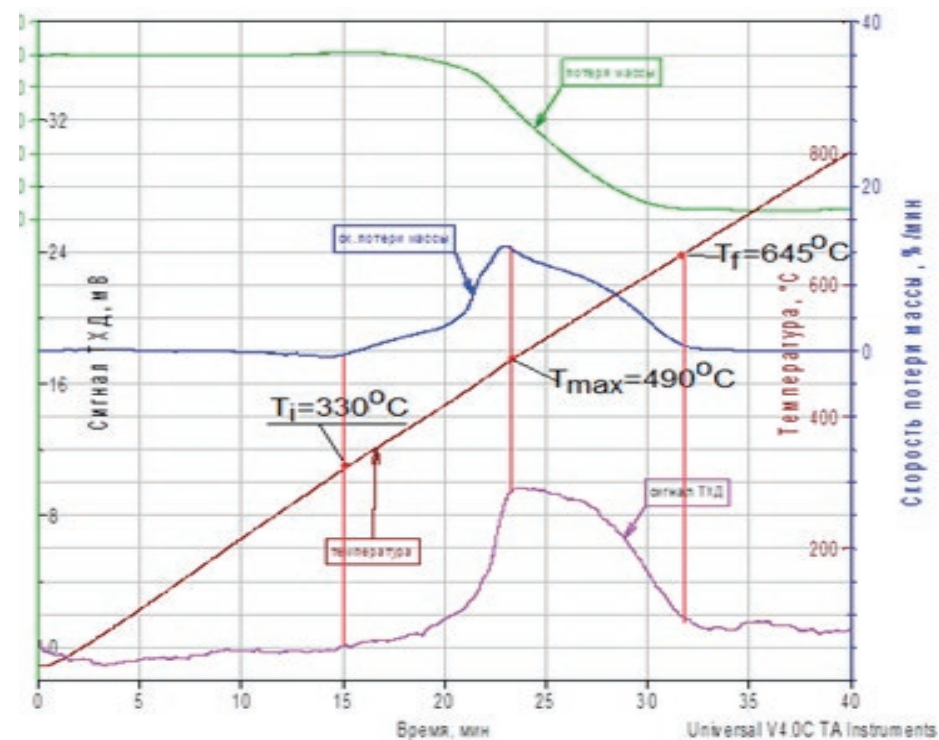

Рисунок 5 Результаты совмещенного ТГ-АГГ экспериментов для угля марки Ж Figure 5 Results of combined TG-AGG experiments for $W$ grade coal 


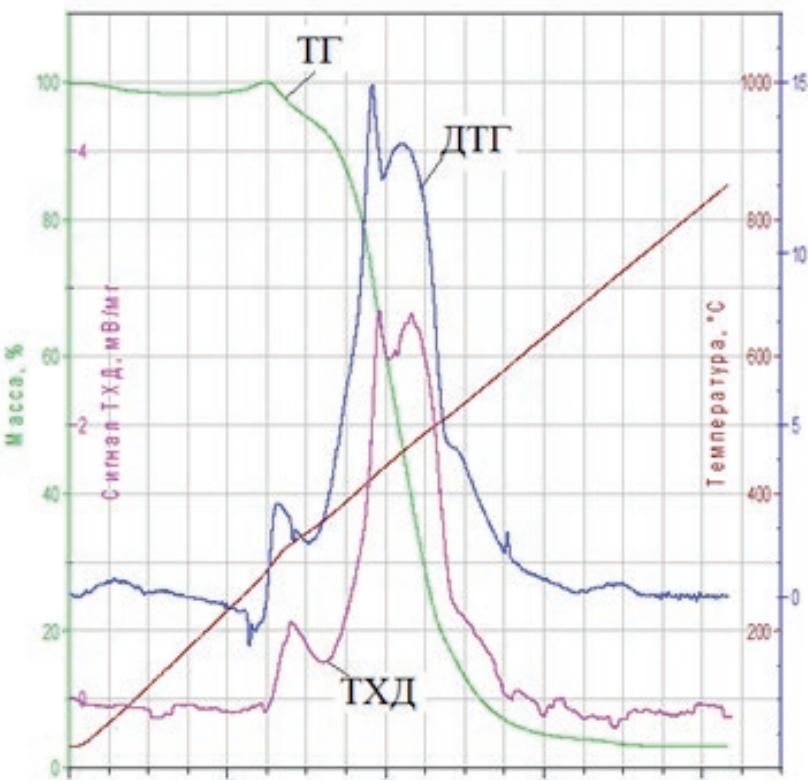

Рисунок 6 Кривые потери массы (ТГ), скорости потери массы (ДТГ) и сигнал выделения горючих газов (сигнал ТХД) образца "25 мкм" (уголь «Д»)

Figure 6 curves of mass loss (TG), speed of mass loss (DT) and signal of release of combustible gases (signal $T C D)$ of the sample "25 microns" (coal " D»)

угля и дисперсного состава по ГОСТ Р 556602013 [5]

В экспериментах на рисунках 6 и 7 (так же, как и для рисунка 5) отмечено практически полное совпадение максимума скорости потери массы образца Tmax с максимальным сигналом термохимического детектора горючих газов (Тmax-ТХД). Также совпадают экстраполированные точки начала/окончания процесса и интервал реакции. Интервал реакции для кривых скорости потери массы и сигнала ТХД (рисунок 6) составил $370-530^{\circ} \mathrm{C}$, а для рисунка 7 (более грубый размол) - $370-560^{\circ} \mathrm{C}$. Наиболее интенсивная скорость потери массы и, соответственно, пик максимального выходного сигнала ТХД достигнуто при температурах $480-501^{\circ} \mathrm{C}$ энергетического угля марки «Д».

Практические значение совмещенных ТГАГГ экспериментов состоит в выделении интервала выхода горючих газов, подтверждении факта горючести выделяющихся газов из угля для перспективных исследований смесей угольной и инертной пыли в различных концентрациях, требующих разделения летучих из углей и негорючих газов, выделяющихся из карбоната кальция.

2. Термический анализ инертной пыли (stone dust)

В угольном веществе изначально содержатся минеральные добавки (различные для пластовой или технологической зольности), которые в ходе нагревания в лаборатории, при пожаре или взрыве также выделяют летучие вещества, однако (в отличие от угольных) при термодеструкции неорганических веществ выделяются негорючие газы.

В ходе термического анализа рассмотрены два образца гидрофобной инертной (сланцевой) пыли, изготовленной по ГОСТ Р 51569-2000 (Пыль инертная):

- образец №1: - фабричного изготовления инертная пыль на основе известняка или карбоната кальция с гидрофобными добавками;

- образец №2 - инертная гидрофобная пыль, после просева на сите 25 мкм.

2.1 Методика проведения испытаний

Испытания образцов №1 и №2 проводились на метрологически аттестованном оборудовании - термовесах ТГА-951, входящих в термоаналитический комплекс «DuPont -9900».

При испытании образцов были выбраны следующие условия проведения термического анализа:

- скорость нагревания $-20^{\circ} \mathrm{C} / \mathrm{Mин;}$

-держатель образца - платиновая корзина с платиновым вкладышем;

- термопара образца - хромель-алюмель;

- атмосфера - воздух (расход газа - 50 мл/ мин);

- температурный диапазон нагревания от 30 до $950^{\circ} \mathrm{C}$;

- скорость съема информации (измерение

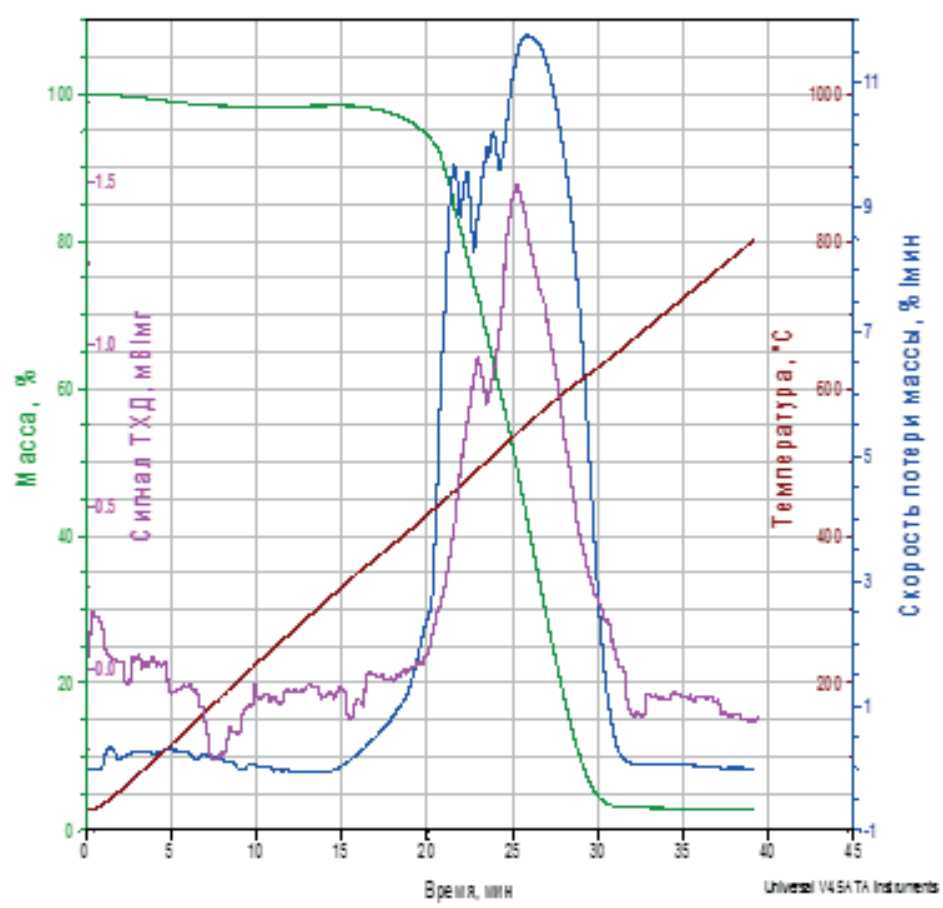

Рисунок 7- Кривые потери массы (ТГ), скорости потери массы (ДТГ) и сигнал выделения горючих газов (сигнал ТХД) образца "212 мкм"(уголь «Д») Figure 7-curves of mass loss (TG), speed of mass loss (DT) and signal of release of combustible gases (signal TCD) of the sample "212 microns"(coal " D») 


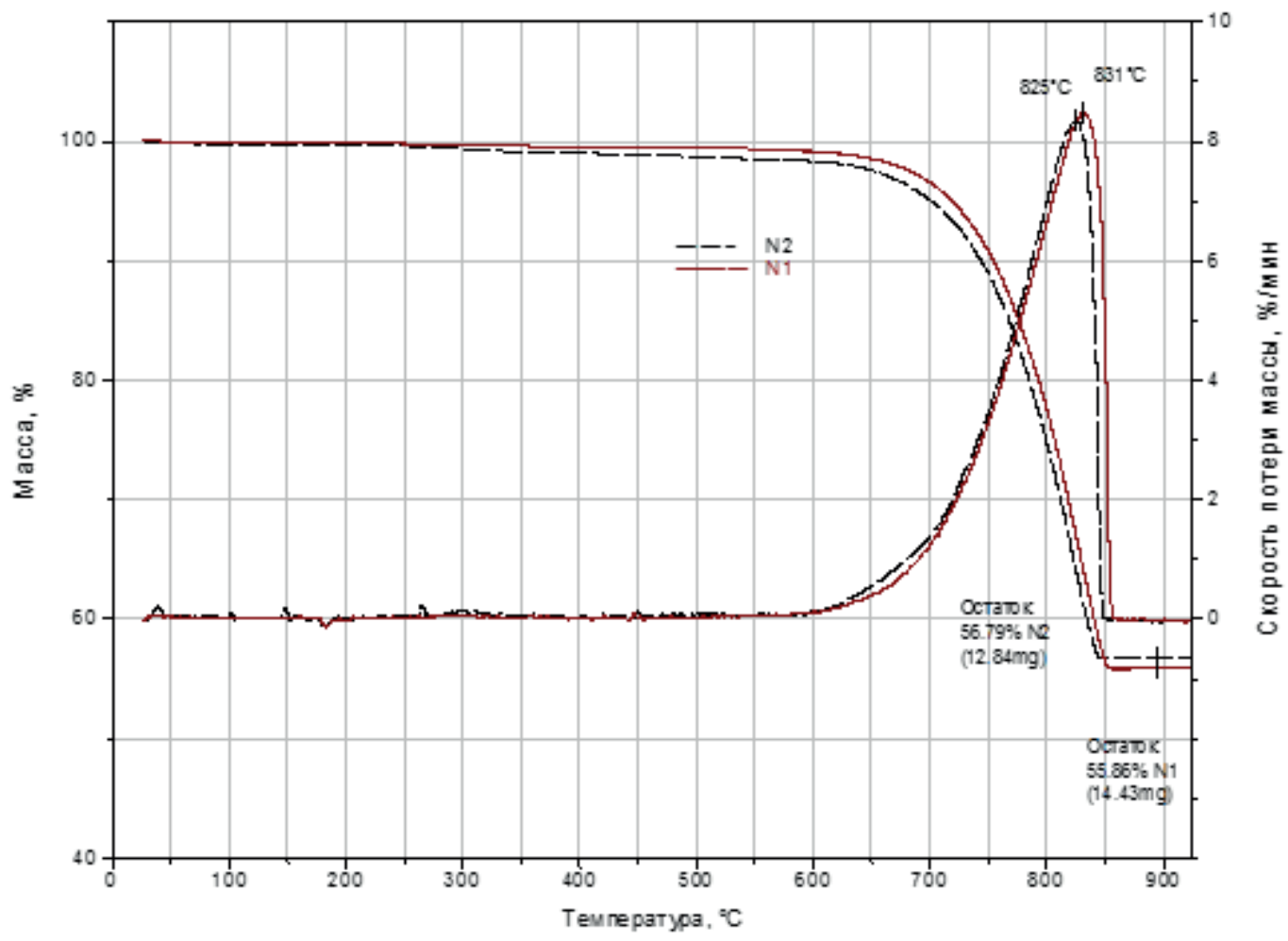

Рисунок 8 ТГ и ДТГ кривые сланцевой пыли для образцов №1 и №2

Figure 8 TG and DTG curves of oil shale dust for samples No. 1 and No. 2

массы испытуемого образца) - 30 точек/мин.

2.2 Результаты термодеструкции шахтной инертной пыли

В справочной литературе отмечено, что термическое разложение известняка происходит при температуре $500^{\circ} \mathrm{C}$ и выше. В ходе проведенных экспериментов установлены значения функций (1) и (2), представленные на рисунке 8, а также получены характерные точки ТГ процесса:

-характерная температура начала термодеструкции составляет $T_{i-}\left(\mathrm{CaCo}_{3}\right)=680{ }^{\circ} \mathrm{C}$, что значительно выше справочных данных;

- диапазон реакции $680-850^{\circ} \mathrm{C}$;

- максимальная скорость термодеструкции инертной пыли достигается при температуpe $825-831^{\circ} \mathrm{C}$, при этом среднее значение $T_{\text {ma }}$ $\left(\mathrm{CaCO}_{3}\right)=828^{\circ} \mathrm{C}$.

Судя по резко убывающему фронту ДТГкривых №1 и №2 (рисунок - 8) при достижении температур $\approx 828^{\circ} \mathrm{C}$ происходит достаточно быстрое (для условий нагрева - в течение 1 минуты) полное разрушение карбоната кальция на оксид кальция $\mathrm{CaO}$ и диоксид углерода :

$$
\mathrm{CaCO}_{3} \rightarrow \mathrm{CaO}+\mathrm{CO}_{2}
$$

Интервал реакции при термическом разложении $\mathrm{CaCO}_{3}$ существенно отличается от интервала термического разложения угольного вещества, что делает возможным последовательный анализ составляющих в осланцован- ной угольной пыли, то есть в смесях угольной и инертной пыли, применяемых в системах пылевзрывозащиты.

\section{ВЫВОДЫ}

Как показали проведенные исследования:

1) Температура термического разложения известняка (около $828^{\circ} \mathrm{C}$ ) существенно превышает интервал реакции выхода летучих веществ из угля $\left(330^{\circ} \mathrm{C}-645^{\circ} \mathrm{C}\right)$, что позволяет проводить последовательный анализ осланцованной угольной пыли по принципу «уголь-известняк».

2) Исходя из практического совпадения кривых №1 и №2 на рисунке 8, дисперсный состав инертной пыли практически не влияет на процесс её термической деструкции.

3) Теоретически, исходя из соотношения молярной массы карбоната кальция (известняка) и диоксида кальция, при завершении процесса термодеструкции $\mathrm{CaCO}_{3}$ ожидаемый выход летучих должен составить около 44\%. Экспериментально полученные данные в мусрельной печи и на термовесах ТГА-951 подтвердили теоретически ожидаемый результат: выход диоксида углерода из шахтной инертной пыли находится в пределах 43,2\% - 44,1\%. Поэтому в ходе термогравиметрических исследований инертная пыль (промышленно изготовленная по ГОСТ Р 51569-2000) может рассматриваться как $\mathrm{CaCO}_{3}$, гидрофобные добавки не вносят заметных изменений в вид термогравиметрических кривых. 


\section{СПИСОК ЛИТЕРАТУРЫ}

1. Уэндландт У. Термические методы анализа. - М.: Мир, 1978. - 526с.

2. ГОСТ Р 53293-2009. Пожарная опасность веществ и материалов. Материалы, вещества, и средства огнезащиты. Идентисикация методами термического анализа

3. ГОСТ 12.1.041-83.Пожаровзрывобезопасность горючих пылей. Общие требования.

4. ГОСТ 12.1.044-89. Пожаровзрывоопасность веществ и материалов. Номенклатура показателей и методы их определения.

5. Национальный стандарт РФ ГОСТ Р 55660-2013 Топливо твердое минеральное. Определение выхода летучих веществ. - М.: ФГУП «Стандартинформ».-2014.-17 с.

6. Романченко С.Б., Шентяпин Д.С., Чистяков А.В., Буторин С.Н. Экспериментальные исследования показателей взрывчатости угольной пыли. Пожарная безопасность -2016. №3.-С.156-162.

7. Романченко С.Б. Экспериментальные и теоретические исследования взрывоопасных рудничных аэрозолей/ Романченко С.Б., Гендлер С.Г., Тимченко А.Н., Костеренко В.Н.// В сб. ГИАБ, специальный выпуск №5-1, 2017. с181-190

8. Романченко С.Б., Девликанов М.О. Исследование динамики выхода летучих веществ из угольной пыли методами термогравиметрического анализа.// Вестник научного центра по безопасности работ в угольной промышленности. - 2019. №4. С.23-30.

9. Романченко С.Б., Руденко Ю.Ф., Костеренко В.Н. Пылевая динамика в угольных шахтах.-М.:Горное дело, $2011 .-$ 256c.

10. Gomes da Silva G. A Thermogravimetric Analysis of the Combustion of a Brazilian mineral Coal/ Quim. Nova, Bып. 31, № 1, c. 98-103, 2008.

11. Davini P., Ghetti P., Bonfanti, L.; De Michele, G.; Fuel 1996, 75, 1088.

\section{REFERENCES}

1. Wendlandt U. Thermal methods of analysis. - M.: Mir, 1978. - 526s.

2. GOST R 53293-2009. Fire hazard of substances and materials. Materials, substances, and means of fire protection. Identification by thermal analysis methods.

3. GOST 12.1.041-83.Fire and explosion safety of combustible dusts. General requirements.

4. GOST 12.1.044-89. Fire and explosion hazard of substances and materials. Nomenclature of indicators and methods for determining them.

5. National standard of the Russian Federation GOST R 55660-2013 solid mineral fuel. Determination of the yield of volatile substances. - Moscow: FSUE "standardinform".-2014. -17 p.

6. Romanchenko S. B., Chincapin D. S., Chistyakov, A.V., Butorin S. N. Experimental researches of parameters of the explosiveness of coal dust. Fire safety -2016. no. 3. - P. 156-162.

7. Romanchenko S. B. Experimental and theoretical studies of explosive mine aerosols/ Romanchenko S. B., Gendler S. G., Timchenko A. N., Kosterenko V. N./ / in SB. GIAB, special issue \# 5-1, 2017. c181-190

8. Romanchenko S. B., Devlikanov M. O. Investigation of the dynamics of volatiles output from coal dust by thermogravimetric analysis methods.// Bulletin of the scientific center for work safety in the coal industry. - 2019. no. 4. P. 23-30.

9. Romanchenko S. B., Rudenko Yu. F., Kosterenko V. N. Dust dynamics in coal mines. - Moscow: Mining, 2011. - 256s.

10. Gomes da Silva G. A Thermogravimetric Analysis of the Combustion of a Brazilian mineral Coal/ Quim. Nova, Issue 31, no. 1, c. 98-103, 2008.

11. Davini P., Ghetti P., Bonfanti, L.; De Michele, G.; Fuel 1996, 75, 1088.

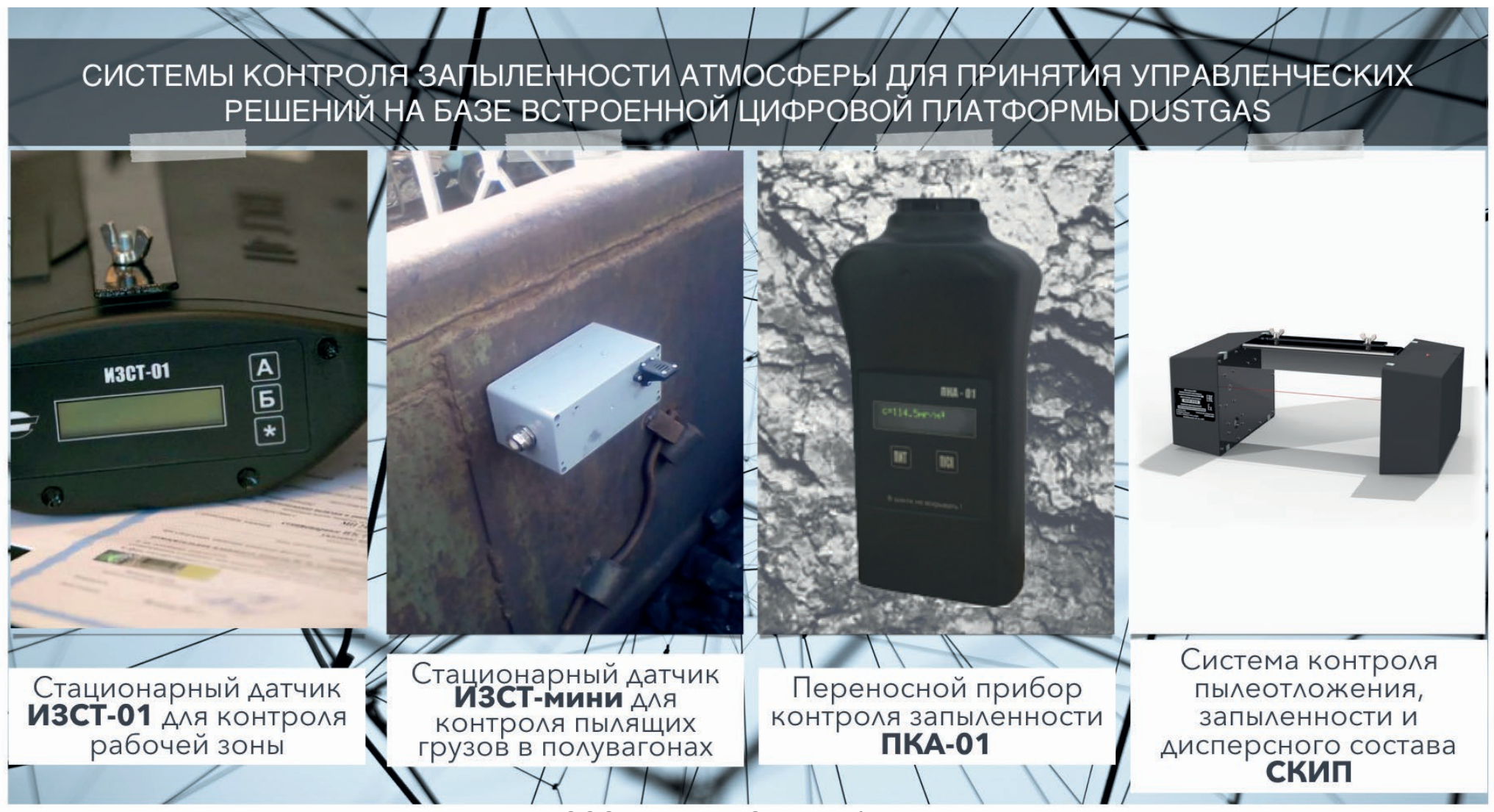

ООО "Горный-ЦОТ" indsafe.ru 


\section{І. ПРОМЫШЛЕННАЯ БЕЗОПАСНОСТЬ И ГЕОМЕХАНИКА I. INDUSTRIAL SAFETY AND GEOMECHANICS}

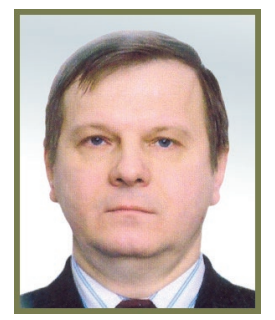

С.Б. Романченко //

S. B. Romanchenko romanchenkosb@mail.ru

д-р техн. наук, доцент, ведущий научный сотрудник ФГБУ ВНИИПО МЧС России, Россия, 143903, Московская область, г. Балашиха, мкр. ВНИИПО, д. 12 doctor of technical sciences, assistant professor, leading researcher of FGBU VNIIPO MChS of Russia, microdistrict 12, VNIIPO, Balashikha, Moscow Region, 143903, Russia

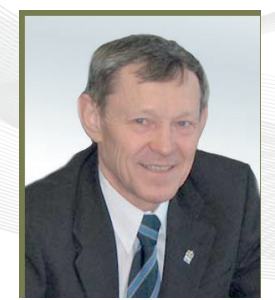

В.В. Соболев / V.V. Sobolev sobolev567@gmail.com

доктор техн. наук, заместитель генерального директора АО "НЦ ВостНИИ", Россия, 650002, г. Кемерово, ул. Институтская, 3

Doctor of technical sciences, deputy general director of JSC "ScC VostNII", 3, Institutskaia St., Kemerovo, 650002, Russia

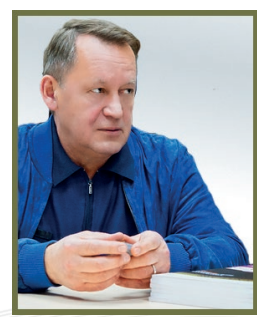

А. А. Трубицын //

A.A. Trubitsyn

atrubitsyn@rambler.ru

д-р техн. наук,, профессор, консультант по научной работе НАО "НЦ ПБ", "Горный ЦОТ", Россия, 650002, г. Кемерово, Сосновый бульвар, 1

doctor of technical sciences, professor, Scientific Advisor, NAO "Scientific Center of Industrial Safety", 1, Sosnoviy bulvar, Kemerovo, 6500002, Russia

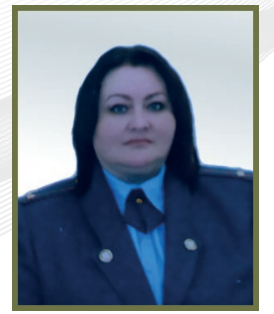

В.В. Вдовина // V.V. Vdovina

старший научный сотрудник ФГБУ ВНИИПО МЧС России.

143903, Московская область, г. Балашиха, мкр. ВНИИПО, д.12 senior researcher FGBU VNIIPO MChS of Russia, microdistrict 12, VNIIPO, Balashikha, Moscow Region, 143903, Russia

УДК 622.81

\section{ТЕОРЕТИЧЕСКИЕ АСПЕКТЫ ОПРЕДЕЛЕНИЯ ПЛОТНОСТИ УГОЛЬНОЙ ПЫЛИ И СЫПУЧИХ МАТЕРИАЛОВ THEORETICAL ASPECTS OF DETERMINING THE DENSITY OF COAL DUST AND BULK MATERIALS}

В статье рассмотрены проблемные вопросы определения плотности угольной пыли - одного из основных показателей, определяющих процессы её витания и распространения по сети горных выработок. Исследованы причины резкого (200-300\%) изменения насыпной плотности угольной пыли в ходе последовательного увеличения раздробленности частиц. Математически показано, что объем пор в сыпучем материале не зависит (или слабо зависит) от степени раздробленности сыпучих. Одновременно с этим исследованы фракторы изменения плотности пылевых частиц за счет образования окислительных поверхностных пленок и влияние на плотность витающей пыли её пористости. Рассмотрено влияние процессов самопроизвольного расширения пор и самодиспергации частиц. Проведен последовательный анализ причин, вызывающих резкие отклонения в плотности угольной пыли одного и того же фризического состава при изменении её дисперсности.

The article discusses the problematic issues of determining the density of coal dust - one of the main indicators that determine the processes of its soaring and distribution over the network of mine workings. The causes of a sharp (200-300\%) change in the bulk density of coal dust during a sequential increase in particle fragmentation are investigated. It is mathematically shown that the pore volume in bulk material does not depend (or weakly depends) on the degree of bulk fragmentation. At the same time, the factors of changes in the density of dust particles due to the formation of oxidative surface films and the influence of porosity on the density of the floating dust were studied. The influence of pores' spontaneous expansion processes and self-dispersion of particles is considered. A sequential analysis of sharp deviation causes in the density of coal dust of the same physical composition with a change in its dispersion was carried out.

Ключевые слова: УГОЛЬНЫЙ АЭРОЗОЛЬ, ТВЕРДАЯ ДИСПЕРСНАЯ ФАЗА, ДИСПЕРСНЫЙ СОСТАВ, ЭКВИВАЛЕНТНЫЙ ДИАМЕТР, МИКРОСКОПИЧЕСКИЕ ИССЛЕДОВАНИЯ, СКАНИРУЮЩАЯ МИКРОСКОПИЯ, СТРУКТУРА ЧАСТИЦ, ПЛОТНОСТЬ ПЫЛИ, НАСЫПНАЯ ПЛОТНОСТЬ, ИСТИННАЯ ПЛОТНОСТЬ, ДИСПЕРГАЦИЯ ЧАСТИЦ 
Key words: COAL AEROSOL, SOLID DISPERSED PHASE, DISPERSED COMPOSITION, EQUIVALENT DIAMETER, MICROSCOPIC STUDIES, SCANNING MICROSCOPY, PARTICLE STRUCTURE, DUST DENSITY, BULK DENSITY, TRUE DENSITY, PARTICLE DISPERSION

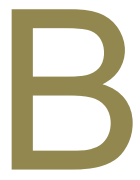

\section{ВЕДЕНИЕ}

Плотность твердой дисперсной фазы аэрозолей является одним из основных параметров, определяющим процессы витания и осаждения частиц. При кажущейся простоте измерения плотности (как отношения массы к объему) для микрочастиц неосуществимо непосредственное взвешивание, а наличие большого объема трещин и пор (хорошо различимых при микроскопическом анализе, начиная с увеличения x700 $\div$ x1000) делает неопределенным их фрактический объем $[3,7,8]$. По принципу «Melius est semel videre... ${ }^{1}$ » понятна сложность определения объема частиц пыли (рисунок 1). Так уже для частиц максимальных размеров из диапазона витания (Ø74 мкм) форма частиц весьма сложна, структура частиц имеет многочисленные трещины 0,7-2 мкм, разломы и поры до 23 мкм в диаметре. Микроскопические исследования на сканирующих микроскопах высокого разрешения (до х50 000) подтвердили подобную структуру для торокальных и респерабельных фракций пыли вплоть до 1 мкм [3,7,10].

Для экспериментального определения величины плотности пылевых частиц делаются попытки использовать традиционный подход, используемый на уровне макрообъектов (сыпучих строительных материалов и т.д.) - экспериментального определения насыпной плотности частиц с последующим учетом объема пустот, образующимися в мерной емкости между частицами [1]. Однако проведенные исследования насыпной плотности для угольных микрочастиц (пылей) не дали однозначных результатов: насыпная плотность для частиц из одной и той же пробы угля резко различается при изменении дисперсного состава пыли.

Эксперименты, выполненные в ходе исследований $[3,7,8]$, согласуются с выводами в классических работах из области механики аэрозолей $[2,4]$. Их совместное рассмотрение усиливает гипотезу о влиянии степени раздробленности материала на насыпную и, соответственно, фрактическую плотности пыли. Складывается как бы парадоксальная ситуация: одна и та же проба пыли или пыль одного и того же пласта имеют насыпные плотности, отличающиеся в несколько раз или на несколько сот процентов при изменении дисперсного состава частиц. В рамках

$1 \quad$ Melius est semel videre, quam audire centies (латынь) - лучше один раз увидеть, чем сто раз услышать. данной публикации проведено исследование причин резкого изменения плотности частиц при различной диспергации материалов.

\section{1. Методика определения плотности} пылей, как разновидности сыпучих материалов.

В общем случае для сыпучего материала [1, 2, 3] различают насыпную (объемную) плотность (ОПСМ) и плотность частиц сыпучего материала (рисунок 2). Объемная плотность ОПСМ - масса СМ, свободно насыпанного вещества в единицу объема. В объем пыли в данном случае входят непосредственно частицы угля (породы), внутренние и поверхностные поры частиц непосредственно в частицах, а также пространство между частицами - внешние по отношению к частицам поры.

В ходе исследований для угольной пыли применим вариант ОПСМ плотности с вибрационным уплотнением, не разрушающим частицы из хрупкого угольного вещества.

Методика исследований для каждой фиксированной пробы угля включает следующие этапы :

- размол (рисунок 3-а);

- для одной марки пыли подготавливается не менее 5 проб, отличающихся дисперсным составом при помощи рассева на сите с размером ячеек 220-300 мкм; 100 мкм; 74 мкм; 45 мкм; 25 мкм (рисунок 3-б). Указанный состав сит обобщен на основе требований ГОСТов из области борьбы с пылью и пылевзрывоопасности. Данный состав может быть дополнен другими размерами сит, при этом необходимо учитывать, что минимальный размер ячеек сита для рассева составляет 20 мкм. Лабораторные сита меньшего размера доступны только для микрорассева из-за крайне низкого живого сечения сита, делающего практически невозможным получение объема пыли $1 \mathrm{~cm}^{3}$ и более;

- засыпка, утруска и взвешивание определенного объема пыли. Как правило, ёмкость для засыпки составляет 2-5 см³, применяется ёмкость из прозрачного материала для контроля уровня заполнения. При кратковременной вибрации пыль в ёмкости за 1-2 секунды уменьшается в видимом объёме на $12-16 \%$ и при дальнейшей вибрации её видимый уровень не изменяется. Проводится досыпка пыли до требуемого объема (например - до $5 \mathrm{~cm}^{3}$ ) и прово- 


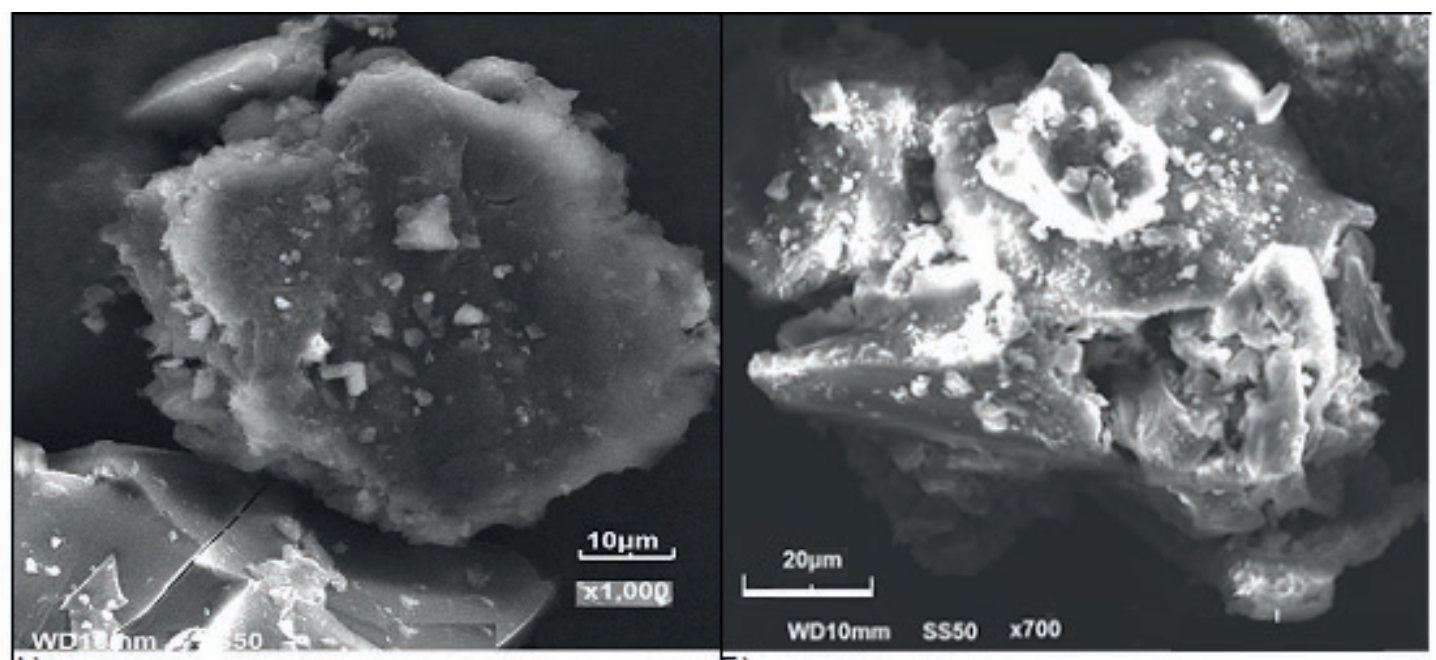

A)

5)

Рисунок 1 Характерные микроскопические изображения угольных частиц Figure 1 - Typical microscopic images of coal particles

дится измерение массы на аналитических весах с точностью до $10^{-4}$ г. Результат взвешивания делится на объем мерной емкости (в рассмотренном примере - деление на $5 \mathrm{~cm}^{3}$ ), что позволяет определить насыпную плотность для исследованной пробы с фиксированным максимальным размером частиц, соответствующих размеру ячеек сита пыли;

- операции повторяются для других марок угля, всего проведено исследование пыли угля 56 шахтопластов, предоставленных подразделениями МЧС (39 - Кузбасс; 9 - Воркута, 8 Восточный Донбасс). Типовые результаты измерений для пыли энергетических и коксующихся углей приведены в таблице 1.

В дополнении к данным (таблица 1) необходимо отметить, что минимальная насыпная плотность 0,2378 г/см³ была зафиксирована для пыли шахты «Барбара» (Силезия, Польша) ${ }^{2}$, подготовленной методом рассева через сито 20 мкм. Насыпная плотность данной пыли составила $18,3 \%$ от средней плотности угля (более чем в 5 раз ниже !), при этом визуально пыль по цвету и блеску полностью соответствовала образующей её углю марки «К». Видимые поры между частицами при такой степени диспергации полностью отсутствуют и пылевая масса 20-микронной пыли визуально приближена к нераздробленным угольным фрагментам. Ожидалось, что насыпная плотность таких пылей (2025 мкм) должна приближаться к плотности угля и разница между визуально-ожидаемым и фактическим значением превысила 500\%.

В целом исходя из рисунка 1, для определения плотности частиц необходимо учитывать объем поверхностных пленок, скрытых полостей

На момент проведения работ в научных центрах РФ возможность рассева на 20 мкм отсутствовала, пыль из КД «Барбара» была получена в рамках совместных проектов по программам EUREKA (Брюссель, Бельгия). и открытых пор (различимы при микроскопическом анализе).

Представленная по классификации на рисунке 2 истинная плотность частиц, определяющая процесс витания («плотность витания»), не будет равна плотности угля. С одной стороны микропоры заполнены удерживаемым газом и могут рассматриваться как пустоты в частице, с другой стороны внешний поток не проникает беспрепятственно в поры, так как на микроуровне сказывается вязкость воздуха и частица представляется как бы единым объемом, на который воздействуют аэродинамические силы: сила лобового давления потока воздуха $F_{\mu . \partial}$, сила продольного аэродинамического сопротивления $R_{x}$, подъемная аэродинамическая сила $F_{a . d}$, сила сопротивления осаждению $R_{y}$ (вертикальная составляющая силы аэродинамического сопротивления), а также условная сила воздействия турбулентной диффузии.

Плотность витания будет существенно

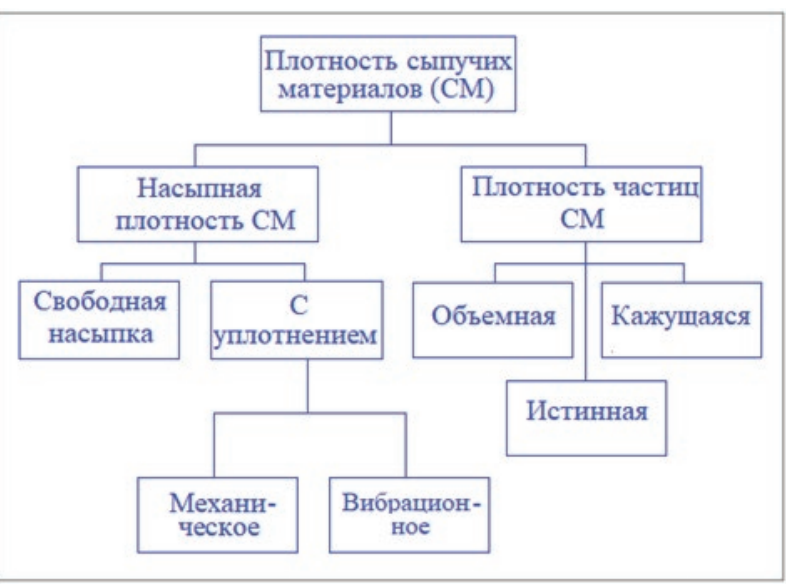

Рисунок 2 Дифрференциация плотности сыпучих веществ [1]

Figure 2 - Differentiation of bulk solids density [1] 

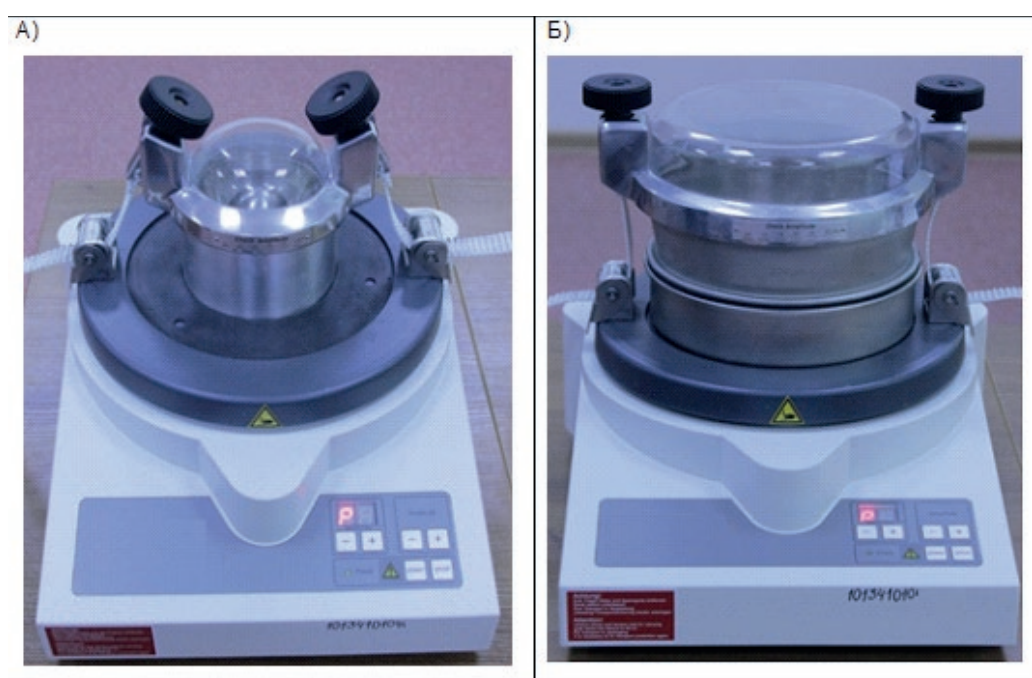

Рисунок 3 Подготовка проб пыли на виброгрохоте: а) - размол с шаровой приставкой; б) - односитовый рассев "сито-поддон»

Figure 3 - Preparation of dust samples on a vibrating screen: a) - grinding with a ball attachment; b) - single-sieve sieving "sieve-pallet"

уменьшаться при росте числа микропор или при увеличении их размеров.

Одновременно с порами в мелких угольных частицах при микроскопическом анализе явно различимы поверхностные окислительные пленки, детально рассмотренные авторами в работе [3] . Электронно-сканирующая микроскопия высокого разрешения (х25000-х50000) позволила определить их толщину в 120-150 нм (0,12-0,15 мкм). При этом объем пленочного покрытия $\left(V_{p}\right)$, как доля в общем объеме частицы $(V)$, составляет от 0,4\% (для частицы 100 мкм) до $4 \%$ у 10-микронных частиц и до $39 \%$ для частиц

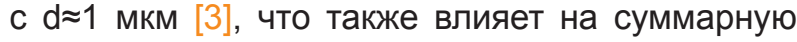
плотность частицы, поскольку плотность окис- лов существенно ниже плотности неокисленного материала. Вместе с этим необходимо отметить, что объем поверхностных пленок имеет значение только для частиц с эквивалентными диаметрами менее 10 мкм, поэтому резкое снижение плотности пыли в диапазоне от 300 мкм до 25 мкм определяется фракторами, отличными от пленочных покрытий.

В качестве возможных причин эффректа, приведенного в таблице 1, необходимо рассмотреть 3 основных фрактора, которые фрормируют экспериментально определяемую насыпную и истинную плотность пыли:

- возможность увеличения свободного пространства между частицами или внешних

Таблица 1 Насыпная плотность угольной пыли различного дисперсного состава Table 1 - The bulk density of coal dust of various disperse composition

\begin{tabular}{|c|c|c|c|c|c|}
\hline \multirow{2}{*}{ Шахта, марка угля } & \multicolumn{5}{|c|}{ 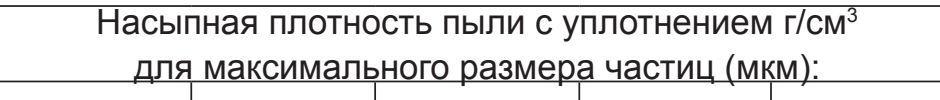 } \\
\hline & 220 & 100 & 74 & 45 & 25 \\
\hline Им. С.М.Кирова; Поленовский, Г & 0,7276 & 0,6833 & 0,6320 & 0,4545 & 0,3284 \\
\hline Талдинская Западная-1, 52 , Г & 0,7178 & 0,6700 & 0,6272 & 0,4472 & 0,3382 \\
\hline Алардинская, 6, КС & 0,7293 & 0,6724 & 0,5538 & 0,4438 & 0,3603 \\
\hline Распадская, 10, ГЖ & 0,7312 & 0,6619 & 0,5487 & 0,4612 & 0,3418 \\
\hline Воркутинская, Тройной, К & 0,7411 & 0,6037 & 0,5996 & 0,4903 & 0,3363 \\
\hline $\begin{array}{l}\text { Среднее значение (обработка): } \\
\text { г/см³ / \% к плотности угля }\end{array}$ & $\begin{array}{c}0,7454 / \\
59,4 \%\end{array}$ & $\begin{array}{c}0,6273 \\
/ \\
48,3 \%\end{array}$ & $\begin{array}{c}0,5643 / \\
43, \% 4\end{array}$ & $\begin{array}{c}0,4684 / \\
36,0 \%\end{array}$ & $\begin{array}{c}0,3488 / \\
26,8 \%\end{array}$ \\
\hline
\end{tabular}


пор при увеличении дисперсности пыли;

- рост числа внутренних пор непосредственно в угольных частицах при уменьшении их размеров;

- динамическими самопроизвольными процессами в угольных частицах, приводящих к расширению внутренних пор и разрушению частиц на мелкие фррагменты (эффект самопроизвольного разрушения угольной пыли во времени или эффект самодиспергации частиц).

2. Модель заполнения объема пылевыми частицами - исследование фактора внешних пустот в величине насыпной плотности пыли

При определении насыпной плотности пыль размещается в мерную емкость - куб. Не нарушая общности рассуждений, рассмотрим случай, когда частицы имеют форму шара - то есть тела, имеющего абсолютно равные размеры во всех трех измерениях. При этом известно, что большая часть угольных частиц $[3,4,7]$ имеет изометрическую фрорму, то есть являются телами с сопоставимыми (близкими по величине) значениями размеров в 3-х измерениях.

Степень влияния внешних пустот на величину насыпной плотности пыли может быть продемонстрирована на примере заполнения стандартного объема (куб с ребром равным 1) частицами - шарами с убывающим диаметром (рисунок 4). Первоначально куб имеет ребро, равное 1 и шар максимального размера, помещающийся в куб, имеет диаметр также равный 1. При этом для модели не имеет значения в каких единицах рассматривается размер началь- ного куба: в метрах, сантиметрах или микронах (для наглядности и близости к рассматриваемой проблематике - условно размер ребра куба принят 1 мм или 10-3 м, далее обозначаемый как 1). При последовательном уменьшении диаметра шаров в 2 раза процесс заполнения куба показан в фрагментах 1-3 рисунка 4.

Если обозначить через $n$ кратность уменьшения шара вдвое, то при уменьшении первоначального диаметра частицы $d$ в $\mathrm{n}$ раз число шаров возрастает в $2^{3 n}$ раз. Первоначально $(n=0)$ в кубе поместится один шар с диаметром, равным ребру куба (левый фррагмент рисунка 4). Для $n=1$ (однократное уменьшение диаметра) $d=1 / 2$, а число шаров, помещенных в тот же куб вырастет до 8 (средний фрагмент рисунка 4). При $(n=2)$ уменьшение диаметра происходит в 4 раза $(d=1 / 4)$, число шаров в кубе вырастет до 64 и так далее.

Объем внешних пор или пустот между шарами для насыпного материала (шаров) равен разности между объемом куба (в рассмотренном примере 1 мм³ $^{3}$ и объемом всех шаров. Для приведенных вариантов на рисунке 4 слева направо объем внешних по отношению частиц пор или пустот обозначен как $V_{p 1}, V_{p 2}, V_{p 3}$.

Как показывают элементарные математические преобразования, визуально резко отличающиеся пустоты $V_{p 1}, V_{p 2}, V_{p 3}$ по величине совпадают до бесконечной дроби: при уменьшении первоначального диаметра частицы $d$ в $n$ раз из объема куба вычитается суммарный объем частиц, число которых возрастает в $2^{3 n}$ раз при одновременном уменьшении объема каж-
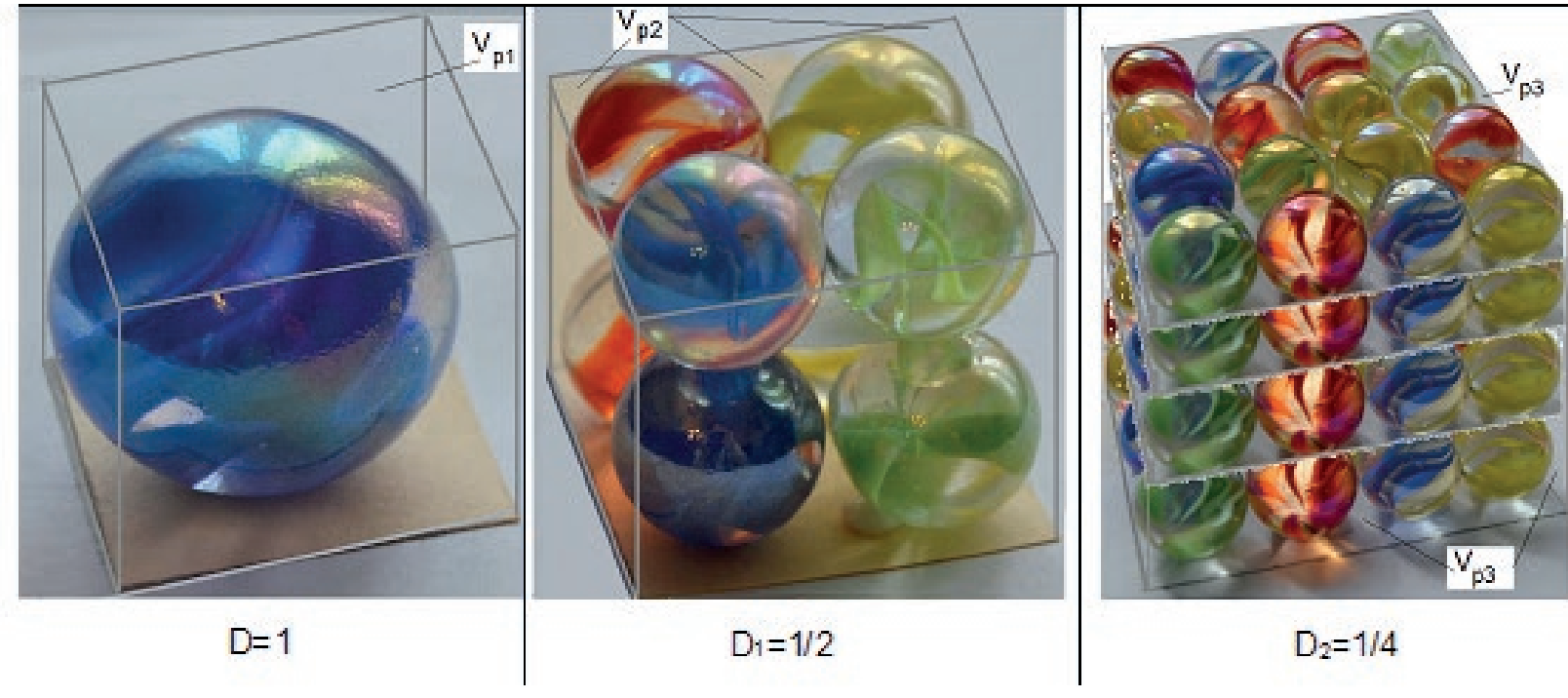

Рисунок 4 Заполнение куба фиксированного объема частицами уменьшающегося размера

Figure 4 - Filling a cube of a fixed volume with particles of decreasing size 


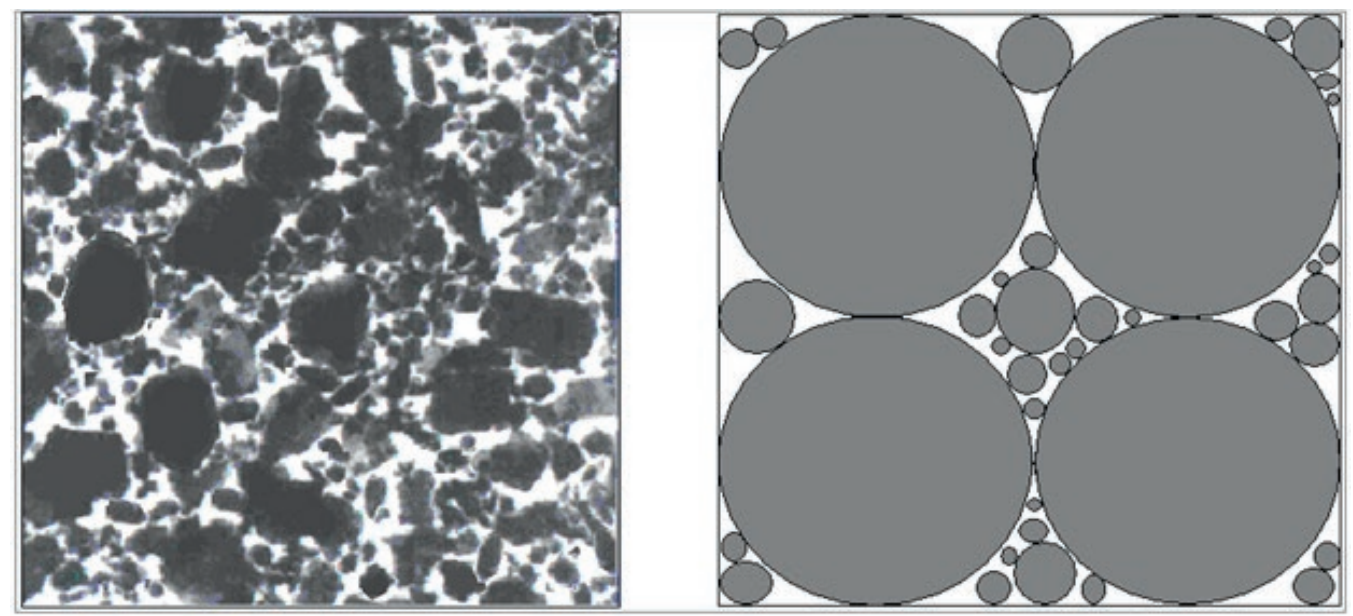

Рисунок 5 Заполнение стандартного объема полидисперсной пылью

Figure 5 - Filling the standard volume with polydisperse dust

дой частицы в $2^{3 n}$ раз :

$$
\begin{aligned}
V_{p}=V_{p 1} & =V_{p 2}=V_{p 3}=d^{3} \cdot\left(1-2^{3 n} \cdot \frac{\pi}{6} \cdot \frac{1}{2^{3 n}}\right)= \\
& =d^{3} \cdot\left(1-\frac{\pi}{6}\right) \approx 0,476417 \cdot d^{3}
\end{aligned}
$$

Согласно (1), суммарный объем пор $V_{p}$, образуемых при заполнении единицы объема (куба) шарообразными монодисперсными частицами, является константой, поры составляют около 47,6 \% от объема мерной емкости (куба) и не зависят от степени изменения диаметра насыпаемых частиц. Поэтому насыпная плотность частиц (без измерения их внутренней структуры в ходе дробления) не должна зависеть от их диаметра.

Согласно уравнению (1), насыпная плотность угольной пыли $\left(\rho_{\text {плли }}\right)$ должна быть около $52,4 \%$ от плотности угля $\left(\rho_{\text {угля }}\right)$ при условии, что пустоты составляют около $47,6 \%$, а частицы имеют плотность, равную плотности неразрушенного угля или угля крупных фракций

$$
\rho_{\text {пыли }}=0,524 \cdot \rho_{\text {углл }} \approx 0,6799 \square \mathrm{r} / \mathrm{cm}^{3}
$$

При переходе от монодисперсной пыли (рисунок 4) к полидисперсной пыли (рисунок 5), степень заполнения фиксированного объема существенно увеличится.

Как видно из рисунка 5 степень заполнения пустот по сравнению с рисунком 4 возрастает, доля пустот становится меньше 47,6 \% от общего объема и, соответственно, насыпная плотность частиц пыли должна быть выше, чем определено зависимостью (2), а именно:

$$
\rho_{\text {пыли }}>0,524 \cdot \rho_{\text {угля }}>0,6799 \square \mathrm{r} / \mathrm{cm}^{3}
$$

- из-за заполнения пустот мелкими частицами.

Как видно из фрагментов экспериментальных замеров зависимости (3) удовлетворяют только фракции угольной пыли с максимальным размером частиц 220 мкм и более. Частицы, про- сеянные через сито 100 мкм также в значительной степени близки к выполнению условий (3). Однако все витающие фракции пыли (74 мкм и менее) имеют насыпную плотность значительно меньше 0,6799|г/см³ тонное убывание данной величины пропорционально уменьшению диаметра частиц.

В зарубежной литературе и документации по системам обеспыливания насыпная плотность угольной пыли принимается на уровне 0,65 г/см ${ }^{3}$ что хорошо согласуется с выводами по уравнению (3) и частично с данными таблицы 1 для пыли с размерами частиц 100 мкм и выше. Однако такая величина насыпной плотности не учитывает экспериментальные данные по составу пылеотложения в высокопроизводительных очистных забоях [7]. В шахтах (согласно детальным исследованиям [7,8]) основу пылеотложения составляют частицы 20-32 мкм, для которых насыпная плотность в 2 и более раз ниже (таблица 1).

3. Внутренняя пористость угольных частиц, как фактор изменения плотности

Как следует из теоретических и экспериментальных данных, приведенных в первом и втором разделах данной публикации, уменьшение насыпной плотности угольной пыли при переходе от 200-микронных к 20-микронным частицам не может быть объяснено, как наличием окислительных пленок (этот фактор играет заметную роль в другом диапазоне размеров частиц - от 10 мкм и менее), так и фактором внешних пустот, которые исходя из (1) не изменяются при уменьшении диаметра частиц.

В этом случае единственным объяснением уменьшения насыпной плотности пыли с ожидаемых 0,65-0,68 г/см³ до минимально отмеченных

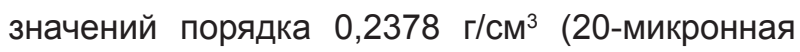
пыль) остается только гипотеза об существен- 


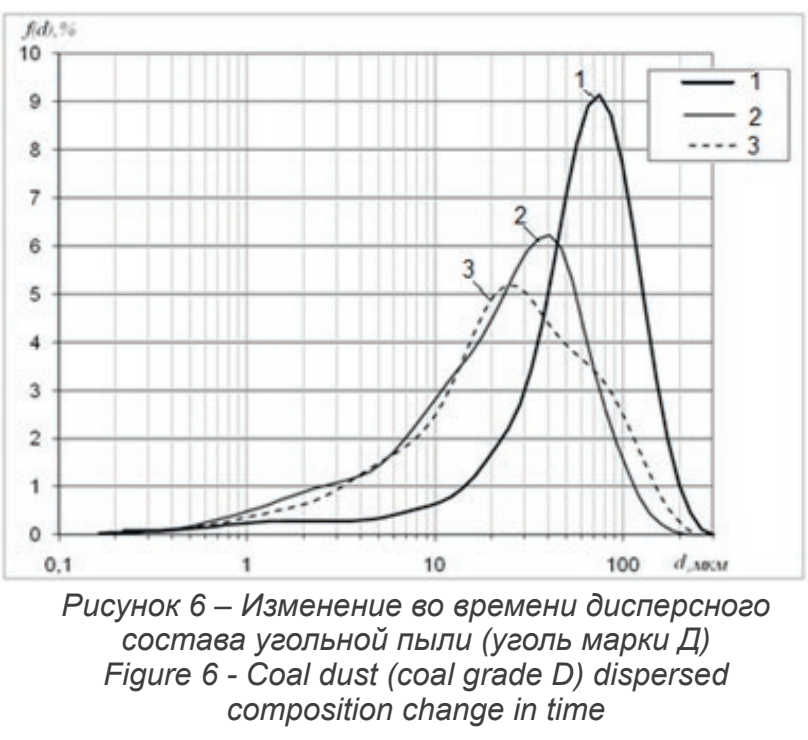

ном уменьшении плотности непосредственно частиц в процессе их дробления. В ходе дробления угольного вещества происходит рост трещин и внутренних пор пропорционально уменьшению размеров частиц. Наиболее явно данный эффект наблюдается при микроскопическом анализе для частиц 45 мкм и менее. Поскольку уголь является органическим веществом крайне сложным по химическому составу, его физические свойства также резко отличаются как от металлов, так и от кристаллов (алмаз, гранитные крепкие породы). Для кристаллов и твердых пород прочностные свойства мелких фракций возрастают, например, огранка крупных алмазов осуществляется за счет алмазной крошки. Исходя из факта резкого падения насыпной и, следовательно, фрактической плотности частиц для угля происходит отличный от алмазов процесс: мелкие фрракции (45-10 мкм) имеют повышенную трещиноватость по отношению к частицам размерами более 45 мкм, объем внутренних трещин обратно пропорционален диаметру частиц.

Указанная выше гипотеза подтверждается электронно-микроскопическими наблюдениями визуально, однако визуально возможно рассмотреть только ограниченное число частиц от нескольких десятков до нескольких сотен. При этом число частиц, содержащихся в ограниченном объеме выработки, измеряется величинами порядка $10^{10 \div 10^{15}}$ единиц. Только условное

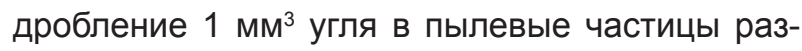
мерами 1 мкм дает 10+9 объектов. Для исследований таких объемов частиц применен лазерный анализ дисперсного состава пыли как непосредственно после её образования, так и с течением времени (для того же образца) $[7,9]$.

На основании лазерных исследований открыто новое явление для рудничных аэрозолей

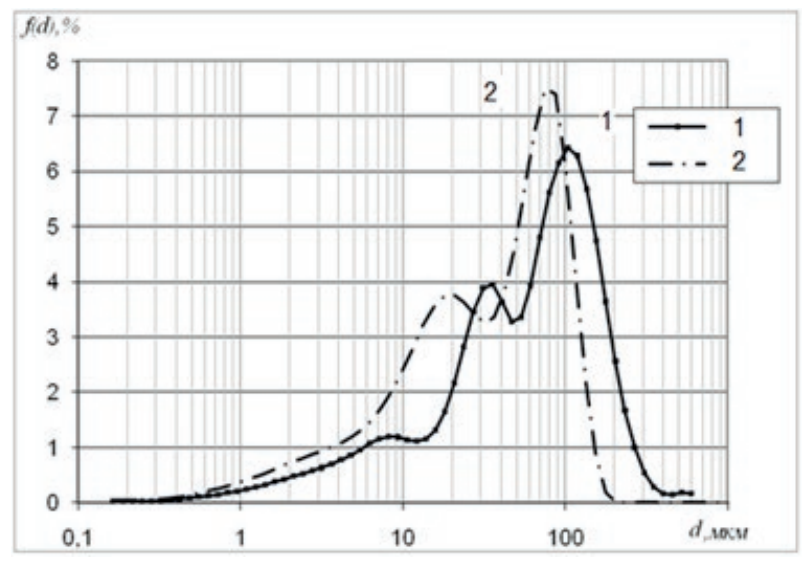

Рисунок 7 - Изменение во времени дисперсного состава угольной пыли (полимодальная пыль, уголь марки Ж)

Figure 7 - coal dust (multimodal dust, grade G coal) dispersed composition change in time

с твердой дисперсной фазой: в процессе дробления твердого вещества в частицах образуется значительное число трещин и пор, а протекающие фризико-химические процессы приводят к расширению пор вплоть до разрушения пылевых частиц (эфффект саморазрушения или самодиспергации углепородных частиц). Данный эффект подтверждает пористую структуру всех угольных частиц, возрастающую с уменьшением их размеров. На рисунках 6 и 7 представлены типовые результаты для проб пыли угля марок Д, Ж. Для проб проводился первоначальный анализ дисперсного состава. Повторный лазерный анализ тех же проб, выполненный через 3 месяца (средний срок отработки столба высокопроизводительным забоем). На рисунках 6 и 7 диффреренциальные кривые дисперсного состава пронумерованы по мере их получения с течением времени (1; 2; 3 и т.д. )

Как видно из рисунков 6 и 7, с течением времени происходит существенный рост доли тонких фрракций пыли в пробах; до 30\% наиболее грубых фракций пыли распадались на более мелкие фррагменты и в повторных пробах не фиксировались; происходило уменьшение моды эквивалентного диаметра мономодальной пыли (рисунок 6) или всех модальных значений (максимумов) в полимодальной пыли (рисунок 7).

\section{ВЫводы}

1. Фактическая плотность угольных частиц, определяющая характер их витания и осаждения существенно зависит не только от марки угля и стадии метаморфизма, но и от дисперсного состава пыли.

2. Экспериментально установлена зависимость плотности угольной пыли (насыпная с уплотнением) от величины эквивалентного диа- 
метра частиц: плотность аэрозольных частиц существенно убывает по нормально-логарифмической зависимости от модального диаметра пыли. При уменьшении эквивалентного диаметра взрывоопасных частиц от 200 до 20 мкм плотность уменьшается в 3,2 раза.

\section{3. На основании лазерных исследований}

выявлен эфрфект саморазрушения или самодиспергации угольных пылевых частиц во времени, что экспериментально подтверждает повышенную пористость микрочастиц угля применительно к практически приемлемой численности

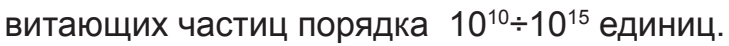

\section{СПИСОК ЛИТЕРАТУРЬ}

1. Мордасов Д.М., Мордасов М.М. Технические измерения плотности сыпучих материалов: учеб. пособие. Тамбов: Изд-во Там. гос. техн. ун-та, 2004. 80 с.

2. Уайтлоу-Грей Р., Паттерсон Х. Дым. Исследования в области аэродисперсных систем. М.: ОНТИ Госхимиздат, 1934. -184 c.

3. Романченко С.Б., Трубицин А.А., Кубрин С.С. Проблемы определения фрактической плотности угольных частиц в процессах витания и седиментации // Вестник научного центра по безопасности работ в угольной промышленности. - 2020. №1. С.6-14.

4. Фукс Н. А., Механика аэрозолей.- М.: Издательство Академии наук СССР, 1955.- 352 с.

5. Кудряшов В.В. О законе распределения частиц по крупности продуктов разрушения угля в области малых размеров частиц // Аэрология: сб. науч. тр. по материалам симпозиума «Неделя горняка-2007». Отдельный выпуск Горного информационно-аналитического бюллетеня. М.: Мир горной книги, 2007. № ОВ12. С. 180-187.

6. Райст П. Аэрозоли. Введение в теорию. М.: Мир, 1987. 280 с.

7. Романченко С.Б., Руденко Ю.Ф., Костеренко В.Н. Пылевая динамика в угольных шахтах.- М.: Горное дело, 2011.-256 c.

8. Романченко С.Б. Комплексные исследования фрракционного состава угольной пыли. //Горный информационноаналитический бюллетень. Отдельный выпуск - М.: «Горная книга».-2010.-№ОВ1. С.129-142.

9. Романченко С.Б. Самодиспергация угольной пыли - принципиально новый эффект, выявленный методом лазерных исследований. //Горный информационно-аналитический бюллетень. Mining informational and analytical bulletin.- М.: «Мир горной книги». - 2011. №7.- С.378-385.

10. Романченко С.Б., Трубицин А.А. Микроскопический метод анализа степени участия угольной пыли во взрывах // Вестник научного центра по безопасности работ в угольной промышленности. - 2019. №3. C.6-14.

\section{REFERENCES}

1. Mordasov, D.M., \& Mordasov, M.M. (2004). Tekhnicheskiye izmereniya plotnosti sypuchikh materialov: ucheb. posobiye [Technical measurements of the of bulk material density:textbook]. Tambov: Tambov State Technical University [in Russian].

2. Whitelow-Grey, P., \& Patterson, H. (1934). Dym. Issledovaniya v oblasti aerodispersnykh system [Smoke. Research in the field of aerodispersion systems].Moscow:ONTI Goskhimizdat [in Russian].

3. Romanchenko, S.B., Trubitsin, A.A., \& Kubrin, S.S. (2020). Problemy opredeleniya fakticheskoy plotnosti ugol'nykh chastits v protsessakh vitaniya i sedimentatsii [Problems of determining the actual density of coal particles in the processes of soaring and sedimentation]. Vestnik nauchnogo tsentra po bezopasnosti rabot $v$ ugolnoi promyshlennosti - Herald of Safety in Mining Industry Scientific Center, 1, 6-14 [in Russian].

4. Fuks, N.A. (1955). Mekhanika aerozoley [Aerosol mechanics]. Moscow: Publishing House of the USSR Academy of Sciences [in Russian].

5. Kudriashev, V.V. (2007). O zakone raspredeleniya chastits po krupnosti produktov razrusheniya uglya v oblasti malykh razmerov chastits [On the law of particle distribution by size of coal destruction products in the region of small particle sizes]. Aerology: collection of scientific. proceedings based on the materials of the Miner's Week 2007 symposium. A separate issue of the Mining News and Analysis Bulletin, OV 12, 180-187 Moscow: Mir gornoi knigi [in Russian].

6. Raist, P. (1987). Aerozoli. Vvedeniye v teoriyu. [Aerosols. Introduction to the theory]. Moscow: Mir [in Russian].

7. Romanchenko, S.B., Rudenko, Yu.F, \& Kosterenko, V.N. (2011) Pylevaya dinamika v ugol'nykh shakhtakh [Dust dynamics in coal mines]. Moscow: Gornoie delo [in Russian].

8. Romanchenko, S.B. (2010). Kompleksnyye issledovaniya fraktsionnogo sostava ugol'noy pyli [Comprehensive studies of coal dust fractional composition]. Mining news and analytical bulletin. Separate issue, OV 1, 129-142 Moscow: Gornaia kniga [in Russian].

9. Romanchenko, S.B. (2011). Samodispergatsiya ugol'noy pyli - printsipial'no novyy effekt, vyyavlennyy metodom lazernykh issledovaniy [Coal dust self-dispersion is a fundamentally new effect revealed by laser research]. Mining news and analytical bulletin. Separate issue, 7, 378-385 Moscow: Gornaia kniga [in Russian].

10. Romanchenko, S.B., \& Trubitsin, A.A. (2019). Mikroskopicheskiy metod analiza stepeni uchastiya ugol'noy pyli vo vzryvakh [Microscopic method for analyzing the coal dust participation degree in explosions]. Vestnik nauchnogo tsentra po bezopasnosti rabot v ugolnoi promyshlennosti - Herald of Safety in Mining Industry Scientific Center, 3, 6-14 [in Russian]. 


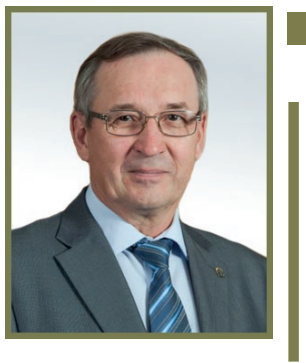

A.B ШадРИн // A. V. SHAdRiN avsh-357@mail.ru

д-р техн. наук, главный научный сотрудник лаборатории геофизических исследований горного массива

Института угля ФГБНУ ФИЦ УУХ СО РАН, г. Кемерово

doctor of technical sciences, chief researcher, laboratory of geophysical research of the rock massif, Institute of Coal FGBNU FIC UUKh SB RAS

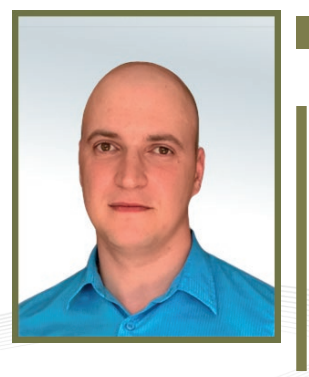

А.C. Телегуз // A.S. Teleguz alexanderteleguz@rambler.ru

младший научный сотрудник лаборатории геофизических исследований горного массива Института угля ФГБНУ ФИЦ УУХ СО $\mathrm{PAH}$, г. Кемерово

junior researcher, laboratory of geophysical research of the rock massif, Institute of Coal FGBNU FIC UUKh SB RAS, Kemerovo

УДК 622.831.322

\section{СТРУКТУРА ПОДСИСТЕМЫ ПРОГНОЗА ВЫБРОСООПАСНОСТИ МНОГОФУНКЦИОНАЛЬНОЙ СИСТЕМЫ БЕЗОПАСНОСТИ УГОЛЬНОЙ ШАХТЫ COAL MINE MULTIFUNCTIONAL SAFETY OUTBURST HAZARD FORECAST SUBSYSTEM STRUCTURE}

В работе дан анализ существующих подсистем прогноза внезапных выбросов угля и газа. Приведено обоснование структуры подсистемы прогноза выбросоопасности как части многофрункциональной системы безопасности (МФСБ) шахты, позволяющей контролировать основные фракторы опасности проявления динамических явлений, иметь научно обоснованную методику оперативного определения критерия опасности в конкретных горно-геологических условиях и использовать данные других подсистем МФСБ шахты. Подсистема основана на одновременном контроле геосризическими методами основных фракторов выбросоопасности: горного давления - спектрально-акустическим методом, внутрипластового давления газа - по концентрации метана в атмосфрере выработки аппаратурой аэрогазового контроля. Третий основной фрактор - прочность угля - периодически измеряется прочностномером. Подсистема состоит из функциональной и обеспечивающей частей. Назначение функциональной части - обосновать аналитически и экспериментально алгоритм непрерывного прогноза внезапных выбросов угля и газа для конкретного забоя. Этот алгоритм включает определение текущего и критического значений выбросоопасности, их сравнение, на этой основе определение степени опасности и, если опасно, активизируются действия по ее устранению. Назначение обеспечивающей части - создать условия для реализации ее функциональной части. Для этого она предусматривает создание специализированного подразделения, имеющего специальное оборудование для контроля основных фракторов выбросоопасности, включающее средства вычислительной техники со своим программным обеспечением, имеющее правовое обеспечение и информационную поддержку со стороны научных организаций и производственных компаний, поставивших методики прогноза выбросоопасности и оборудование. Кратко приведено основное содержание следующих видов обеспечения: технического, программного, организационного, нормативно-правового, методического, инфрормационного.

The paper analyzes the existing subsystems for forecasting sudden outbursts of coal and gas. The rationale for the structure of the outburst prediction subsystem as part of the mine's multifunctional safety system (MFSS) is given, which makes it possible to control the main hazards of the manifestation of dynamic phenomena, have a scientifically based methodology for quickly determining the hazard criterion in specific geological conditions and use data from other MFSS mine subsystems. The subsystem is based on the simultaneous monitoring by geophysical methods of the main outburst factors: rock pressure - by the spectral-acoustic method, gas insitu pressure - by methane concentration in the working atmosphere with air-gas control equipment. The third main factor - the strength of coal - is periodically measured with a strength meter. The subsystem consists of a functional and supporting part. The purpose of the functional part is to substantiate analytically and experimentally an algorithm for the continuous forecast of sudden coal and gas outbursts for a specific mine. This algorithm includes determining the current and critical values of the outburst hazard, comparing them, on this basis, determining the degree of danger and, if dangerous, activating actions to eliminate it. The purpose of the supporting part is to create conditions for the implementation of its functional part. For this aim, it provides for the creation of a specialized unit that has special equipment to control the main factors of outburst 
hazard, including computer equipment with its software, has legal support and information support from scientific organizations and production companies that supplied outburst forecast methods and the equipment. The main content of the following types of support is briefly described: technical, software, organizational, regulatory, methodological, and informational.

КлючевЫе слова: УГОЛЬНЫЙПЛАСТ, ФАКТОРЫВЫБРОСООПАСНОСТИ, МНОГОФУНКЦИОНАЛЬНАЯ СИСТЕМА БЕЗОПАСНОСТИШАХТЫ, СТРУКТУРАПОДСИСТЕМЫПРОГНОЗА ВЫБРОСООПАСНОСТИ, ФУНКЦИОНАЛЬНАЯ И ОБЕСПЕЧИВАЮЩАЯ ЧАСТИ ПОДСИСТЕМЫ.

Keywords: COAL SEAM, OUTBURST HAZARD FACTORS, MULTIFUNCTIONAL MINE SAFETY SYSTEM, STRUCTURE OF OUTBURST FORECAST SUBSYSTEM, FUNCTIONAL AND SUPPORTING PARTS OF THE SUBSYSTEM.

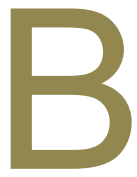

ведение. Современные многофункциональные системы безопасности (МФСБ) на угольных шахтах, разрабатывающих угрожаемые и опасные по проявлению динамических явлений (ДЯ) пласты, должны включать в свой состав подсистему непрерывного прогноза внезапных выбросов угля и газа и сходных с ними явлений в процессе ведения горных работ. В дальнейшем будем называть ее подсистема прогноза выбросоопасности (ПСПВ). Такие подсистемы должны отвечать двум основным требованиям: контролировать основные фракторы опасности проявления ДЯ и иметь научно обоснованную методику оперативного определения критерия опасности в конкретных горно-геологических условиях. Существующие в настоящее время подсистемы, как свидетельствует практика и сведения из литературных источников, этим требованиям в полной мере не удовлетворяют из-за недостаточного научного обоснования связи контролируемых величин с параметрами массива, определяющими его выбросоопасность [1-7].

Так, например, метод акустической эмиссии (АЭ), применяемый для прогноза внезапных выбросов угля и газа и горных ударов, строится, в основном, на экспериментальном факте, заключающемся в том, что в образцах твердого тела, нагруженных примерно на $70 \%$ от предела прочности на сжатие, начинают развиваться трещины. Однако горные работы связаны с разрушением угольного пласта, поэтому трещины в нем просто обязаны образовываться и расти. При этом их рост не всегда заканчивается ДЯ.

В этих условиях признаками угрозы выброса пытаются определить либо аномальный рост активности АЭ, либо аномальное увеличение энергии импульса АЭ, либо особенности спектрального состава импульсов АЭ. Причем критерий выбросоопасности пытаются установить по результатам статистической обработки импульсов АЭ, зарегистрированных перед ДЯ на конкретных шахтах. Достоверность такого прогноза часто оказывается недостаточной. Поэто- му прогноз, сделанный данным методом, чаще всего является лишь необходимым, но недостаточным условием для развязывания внезапного выброса.

Другим недостатком существующих ПСПВ является их слабая связь с другими подсистемами МФСБ шахт. А именно, известно, что внезапные выбросы происходят в зонах угольных пластов, которые характеризуются высокой газоносностью и наличием пачек слабого перемятого угля. Вместе с тем на шахтах имеются подсистемы газового контроля и контроля либо напряжений, действующих на крепь, либо деформаций бортов выработок, несущих информацию о газовыделении и напряженном состоянии краевой части пласта. Однако эти сведения в существующих методах прогноза внезапных выбросов не используются. Отсюда появилась идея встраивания ПСПВ в МФСБ шахты с тем, чтобы использовать данные других подсистем шахты для повышения достоверности прогноза внезапных выбросов.

Цель настоящей работы: обосновать структуру ПСПВ МФСБ угольной шахты, позволяющей контролировать основные фракторы опасности проявления ДЯ, иметь научно обоснованную методику оперативного определения критерия опасности в конкретных горно-геологических условиях и использовать данные других подсистем МФСБ.

Анализ существующих подсистем прогноза выбросоопасности угольных пластов

Чтобы удовлетворить указанным выше требованиям ПСПВ должна, во-первых, основываться на геофизических методах контроля основных фракторов выбросоопасности массива горных пород, т.к. только геофизические методы позволяют осуществлять неразрушающий (без бурения контрольных скважин и отбора проб) контроль. Во-вторых, контролируемые геофизическими методами величины должны быть функционально связаны с основными параметрами массива горных пород, определяющими опасность проявления ДЯ. В-третьих, такая подси- 
стема должна быть компьютеризирована, чтобы иметь возможность обрабатывать большие массивы информации в режиме онлайн.

Многофуннциональная система безопасности угольной шахты - это взаимосвязанный комплекс технических, технологических, инженерных и информационных систем, производственных мероприятий и персонала, которые реализуют проектные решения и обеспечивают снижение уровня риска [1].

Объектами контроля и управления, оценки и прогноза МФСБ служат аэрологическое и геомеханическое состояние массива горных пород, технологическое оборудование, системы и средства, обеспечивающие безопасность труда и контроль других процессов жизненного цикла шахты, и ее персонал.

Состав МФСБ определяется при проектировании и модернизируется в ходе эксплуатации. В ее состав по проекту, согласованному и утвержденному в установленном порядке, должны входить, по мнению ряда исследователей, электрические, электронные и программируемые системы [2-10], обеспечивающие: мониторинг и предупреждение условий возникновения опасности геодинамического, аэрологического и техногенного характера; оперативный контроль соответствия технологических процессов заданным параметрам; применение систем противоаварийной защиты людей, оборудования и сооружений [5].

Одним из вариантов повышения промышленной безопасности угольных шахт и снижения риска возникновения опасных для персонала аварий и инцидентов является разработка и строительство роботизированных угольных шахт, обеспечивающих отсутствие человека в опасных зонах [11, 12]. Дистанционное управление роботизированными техническими средствами при проведении выработок, выемке угля, транспорте горной массы до магистральных выработок должно быть возложено в этом случае на специализированные вычислительные комплексы, в том числе осуществляющие управление системами безопасности, входящими в МФСБ.

Однако полное замещение человека в шахтах пока не предполагается, поэтому контроль опасности проявления ДЯ осуществляют с помощью преимущественно стационарных систем текущего прогноза горных ударов и внезапных выбросов $[13,14]$. Эти системы в настоящее время слабо интегрированы с МФСБ шахт и не используют их информацию для решения своих задач.
Сегодня на шахтах России и за рубежом (Украина, Казахстан, Китай, Австралия, Польша, ЮАР и др.) применяются несколько инструментальных и автоматизированных методов текущего прогноза ДЯ, в том числе внезапных выбросов угля и газа, которые отличаются физической основой способов контроля массива горных пород, а, следовательно, точностью и продолжительностью $[4,5,15,16]$.

Достоверность способа прогноза тем выше, чем точнее учитываются основные влияющие на выбросоопасность факторы. Анализ известных моделей развития внезапных выбросов свидетельствует о том, что основными факторами выбросоопасности пластов с влажностью менее 5-6\% являются горное давление, газоносность и давление свободного газа в трещинах и порах угля, а также его структура и прочность [17-20]. Если же влажность угля превышает 6\%, то выбросы никогда не происходят, т.к. жидкость блокирует газ в микропорах, а уголь становится настолько пластичным, что зона повышенного горного давления плавно отодвигается достаточно далеко в глубину массива, чтобы мог развязаться выброс [21].

На контроле влияния горного давления на состояние призабойного пространства очистных выработок основана система прогноза динамических явлений фрирмы Марко. В ней прогноз вероятности горных ударов осуществляется путем анализа ползучести пород в окрестности очистного забоя. Программа анализа конвергенции в лаве с помощью системы электрогидравлического управления Марко «Цифровая шахта» позволяет контролировать стадии ползучести и неустойчивость массива посредством непрерывных измерений давления в стойках крепи и их последующем анализе. Момент ускорения ползучести свидетельствует о переходе в неустойчивое состояние. Необходимым критерием ДЯ является одновременный переход в неустойчивость, фриксируемый в нескольких соседних секциях крепи [22]. Для повышения достоверности прогноза контроль ползучести дополнен мониторингом АЭ [23].

Метод АЭ изначально был основан на анализе активности АЭ (числа импульсов АЭ в единицу времени, например, в 15-и минутный интервал) и в случае аномального превышения ее значения, принятого за неопасное, выносилось решение о вхождении в опасную зону [24]. Поскольку развитие трещин происходит под действием всех основных влияющих на выбросоопасность факторов, метод можно назвать всеобъемлюще контролирующим. Однако 
аномальный рост активности АЭ может сопровождаться как усугублением выбросоопасной ситуации, так и ее снижением вследствие разгрузки краевой части пласта в результате произошедшего развития трещин. А существующие критерии выбросоопасности методом АЭ эту неоднозначность ситуации дифференцировать не могут. Кроме того, наряду с эффректом увеличения активности АЭ перед газодинамическим явлением рядом исследователей установлен экспериментальный фракт ее затухания [25, 26]. Это послужило основанием для специалистов из Японии применить этот признак для начала работ по предотвращению ДЯ путем бурения разгрузочных скважин в зоне «затишья» до восстановления в обрабатываемой зоне прежнего уровня активности АЭ [27]. В настоящее время метод АЭ с определением координат источников АЭ широко применяется для мониторинга напряженного состояния горного массива на шахтах России и за рубежом [14, 28]. Но поскольку факт повышения активности АЭ оказался недостаточным для достоверного прогноза ДЯ, разрабатываются другие критерии опасности. К ним относится выявление в спектре сигнала АЭ высокочастотных или низкочастотных компонент [29] или определение энергии импульса АЭ [30], или использование комплекса параметров АЭ [31].

Несмотря на многочисленные попытки усовершенствовать метод прогноза ДЯ по параметрам АЭ, известные модификации этого метода не позволяют с достаточной достоверностью увязать количественные значения параметров АЭ с опасностью проявления ДЯ.

Помимо метода АЭ, в настоящее время применяются: газоаналитический метод - по концентрации метана в атмосфере выработки, замеряемой аппаратурой газового контроля (АГК); и спектрально-акустический - по отношению амплитуд высокочастотной и низкочастотной частей спектра шумов работающего горного оборудования [29].

Газоаналитический метод основан на наличии функциональной связи между внутрипластовым давлением газа, газоносностью и газопроницаемостью пласта, с одной стороны, и концентрацией метана в атмосфере выработки - с другой [32]. Одним из критериев выбросоопасности этим методом является такая концентрация метана, которая была зарегистрирована перед выбросом, когда-либо произошедшим на данном шахтопласте [33].

Такой критерий оказался очень недостоверным, что побудило его доработку путем учета не только концентрации метана, но и скорости нарастания и снижения концентрации метана соответственно при начале ведения горных работ по пласту и при их окончании, а также при проведении подготовительных выработок с помощью буровзрывных работ [34-36].

Несмотря на усовершенствования, данный метод контролирует преимущественно газовый фактор выбросоопасности. Поэтому для исключения аварий критерий берется с излишним «запасом надежности» прогноза, приводящим к неоправданным дорогостоящим противовыбросным мероприятиям.

Спектрально-акустический метод, как было установлено аналитически, контролирует преимущественно напряженное состояние $[37,38]$. Метод показал хорошие результаты на шахтах Донбасса, где на больших глубинах залегания угольных пластов при их малой мощности основным фактором потери устойчивости призабойного пространства является именно горное давление. В настоящее время системы, реализующие этот метод, установлены практически на всех шахтах АО «СУЭК-Кузбасс». Однако многочисленные исследования показали, что установленные экспериментально этим методом критерии выбросоопасности действительны только для тех конкретных горно-геологических условий и технологии ведения горных работ, в которых они получены [37, 38].

Поскольку в настоящее время нет однозначных количественных критериев выбросоопасности при контроле горного массива этим методом, в действующей «Инструкции по прогнозу динамических явлений в угольных шахтах...» предлагается пороговое значение показателя выбросоопасности первоначально определять по параметрам «шумов» работающего оборудования на участках проводимой горной выработки, для которой другими методами установлена категория «неопасно» [39]. Но если порог опасности установили на неопасном участке, то он таковым не является.

Такой порядок организации прогноза выбросоопасности данным методом обусловлен его недостаточным научным обоснованием, в частности, не учетом всего комплекса основных влияющих на выбросоопасность факторов и параметров горного массива.

Из выполненного анализа следует, что, хотя регистрируемые методом АЭ трещины происходят под действием всех основных факторов выбросоопасности, контролировать однозначно напряженное состояние массива по параметрам этого метода невозможно. Спектрально-акустический метод контролирует в каждый момент 
времени динамику изменения горного давления. Но он не учитывает газовый фактор выбросоопасности и прочность угля. Газоаналитический метод контролирует преимущественно газовый фактор, не позволяя учитывать влияние на выбросоопасность горного давления и прочности угля.

Таким образом, если одновременно использовать спектрально-акустический метод для контроля горного давления, газоаналитический - для контроля газового фактора выбросоопасности, и учесть прочность угля, то можно создать ПСПВ, учитывающую основные фракторы выбросоопасности. Для реализации такой ПСПВ предлагается следующая ее структура.

\section{Структура подсистема прогноза выбро- соопасности}

Типовая автоматизированная подсистема управления, входящая в МФСБ, а, следовательно, и подсистема ПСПВ включает в себя функциональную и обеспечивающую часть. На шахте одновременно могут быть реализованы несколько ПСПВ, каждая со своей функциональной и обеспечивающей частью. Рассмотрим подробнее назначение этих видов обеспечения.

\section{Функциональная часть ПСПВ}

Назначение функциональной части ПСПВ - обосновать аналитически и экспериментально алгоритм непрерывного прогноза внезапных выбросов угля и газа для конкретного забоя. Для функциональной части ПСПВ, основанной на использовании спектрально-акустического и газоаналитического методов контроля основных фракторов выбросоопасности, этот алгоритм должен включать в себя непрерывное выполнение следующих процедур по мере подвигания забоя выработки [40]:

1) Определение текущего значения показателя выбросоопасности, учитывающего основные фракторы выбросоопасности.

2) Определение критического значения показателя выбросоопасности для данного положения забоя выработки в каждый текущий момент времени.

3) Сравнение текущего и критического значений показателей выбросоопасности и на этой основе определение степени опасности.

4) При возникновении степени опасности «ОПАСНО» активизировать действия по оповещению и при необходимости мероприятия по обеспечению безопасности.

Для функциональной части ПСПВ, основанной на других методах контроля факторов выбросоопасности, например, методе АЭ и кон- троле давления на крепь реализуется свой алгоритм определения выбросоопасности.

Для реализации на практике ПСПВ МФСБ функциональная часть должна быть дополнена обеспечивающей частью.

\section{Обеспечивающая часть ПСПВ}

Назначение обеспечивающей части ПСПВ - создать условия для реализации ее функциональной части. Для этого она содержит следующие основные виды обеспечения: техническое, программное, организационное, нормативноправовое, методическое, информационное и др. [41].

Техническое обеспечение ПСПВ - это совокупность оборудования, расположенного в подземных горных выработках и наземных помещениях, а также каналов связи между ними. Для каждой фрунциональной части служит свое техническое обеспечение (ТО).

ТО для функциональной части, основанной на использовании спектрально-акустического и газоаналитического методов контроля основных фракторов выбросоопасности, включает следующее оборудование: распложенные в призабойном пространстве контролируемых горных выработок датчики для контроля акустического «шума» работающего горного оборудования и концентрации метана в атмосфере выработки у забоя; устройства первичной обработки сигналов датчиков; измеритель скорости воздуха в выработке; механический прочностномер; а также расположенные на поверхности шахты средства вычислительной техники и каналы связи между подземным и наземным оборудованием. Для каждой контролируемой выработки используются свои датчики и устройства первичной обработки их сигналов. Один прочностномер может использоваться для измерения прочности угля в нескольких забоях выработок. Эпизодически снимаемые с него показания вводятся вручную в наземный вычислительный комплекс, который является общим для всей ПСПВ шахты.

Таким образом, для данной функциональной части ПСПВ используется: оборудование для реализации спектрально-акустического контроля (САК) напряженного состояния призабойного пространства подготовительных и очистных выработок; часть оборудования системы аэрогазового контроля (АГК) атмосферы горных выработок вблизи контролируемых забоев; а также оборудование для контроля прочности угля. Сюда входит также наземный вычислительный комплекс для расчета текущего и критического значения показателя выбросоопасности на основе данных, снимаемых с датчиков аппаратуры 
САК и АГК, их сравнения и выработки управляющих сигналов при прогнозе «ОПАСНО». В ТО ПСПВ входит также оборудование для контроля работоспособности каналов связи, метрологического обеспечения и тестирования используемого оборудования САК и АГК.

Программное обеспечение ПСПВ - это совокупность программ для цифровой обработки сигналов, поступающих с датчиков в соответствии с алгоритмом, заложенным в ее функциональную часть. Для каждой функциональной части служит свое программное обеспечение (ПО).

ПО для функциональной части, основанной на использовании спектрально-акустического и газоаналитического методов контроля основных фракторов выбросоопасности, осуществляет выполнение следующих процедур: выбор коэфффициента усиления акустических сигналов «шума» работающего оборудования и электрических сигналов, несущих информацию о концентрации метана и скорости потока воздуха в атмосфере выработок; их оцифровку и запись в запоминающее устройство; ввод информации о прочности угля; обработку поступившей информации в соответствии с заданным алгоритмом; анализ полученных результатов; отображение и хранение результатов.

Для обеспечения допустимой погрешности в определении показателя выбросоопасности важно правильно выбрать основные параметры цифровой обработки входных сигналов: частоту дискретизации и длину экспериментальных выборок - блоков отсчетов, на которые разбивается оцифрованный измеряемый сигнал [42].

Частота дискретизации $f_{\partial}$ при оцифровывании аналогового сигнала в соответствии с теоремой отсчетов Котельникова должна быть не менее чем в два раза выше верхней частоты спектра обрабатываемого аналогового сигнала $f_{\text {в }}$ $[43,44]$ :

$$
f_{\partial} \geq 2 f_{\dot{s}} .
$$

Из чего следует, что чем выше частота дискретизации, тем более широкополосный сигнал сохранит свой спектр после восстановления оцифрованного сигнала. Однако при этом возрастает количество отсчетов, что требует увеличения памяти для их хранения.

Второй важный параметр - длина экспериментальных выборок $N$ - определяет разрешение по частоте $\Delta f$ в спектре восстановленного после быстрого преобразования Фурье (БПФ) оцифрованного сигнала в соответствии с выражением [44]:

$$
\Delta f=\frac{f_{0}}{N} .
$$

Из (2) видно, что чем длиннее эксперимен- тальные выборки, тем выше разрешение по частоте сигнала после БПФ, что снижает погрешность восстановления исходного сигнала после его цифровой обработки. Однако с увеличением длины выборки растет и число вычислений $M$ процедуры БПФ в соответствии с выражением [44]:

$$
M=(N / 2) \cdot \log _{2}(N) .
$$

Выбор этих параметров $f_{\partial}$ и $N$ определяется параметрами входного сигнала «шума» и помех, которые могут наводиться на токопроводящие линии, соединяющие датчики с устройствами обработки входного сигнала (спектральным составом, амплитудой).

При прогнозе выбросоопасности спектрально-акустическим методом входным полезным сигналом является акустический сигнал, генерируемый в контролируемую зону угольного пласта режущим органом работающего горного оборудования (исполнительного органа комбайна, буровой коронки, отбойного молотка). Частотный спектр этого сигнала лежит в пределах от нескольких герц до нескольких килогерц в зависимости от структуры горного массива, напряженного состояния пласта, расстояния между источником и приемником звука и ряда других параметров и может быть ограничен сверху и снизу рабочим диапазоном приемника акустических сигналов, например, электродинамического геофона. При его использовании диапазон регистрируемых частот составляет примерно от 10 Гц до 1,5 кГц.

Выполненные оценки показали [42, 45], что при расчете показателя выбросоопасности спектрально-акустическим методом в форме отношения высокочастотной и низкочастотной компонент спектра «шума» при отсутствии помех для обеспечения относительной погрешности менее $5 \%$ достаточно выбрать частоту дискретизации $f_{\partial}=4$ кГц и длину выборки $N=512$ отсчетов. При наложении на полезный сигнал помехи в виде белого шума амплитудой в 70 \% от амплитуды полезного сигнала длина выборки должна быть $N \geq 1024$ отсчета, при этом частота дискретизации свыше 4 кГц практически не влияет на относительную погрешность определения. При наложении на полезный сигнал узкополосных помех амплитудой, соизмеримой с амплитудой полезного сигнала, достижение относительной погрешности менее 5 \% обеспечивается в зависимости от частоты дискретизации в диапазоне $N \geq 1024-4096$ отсчетов.

Организационное обеспечение - это инфрраструктура, созданная для обеспечения успешной работы ПСПВ. 
Организационное обеспечение ПСПВ не менее важно, чем ТО и ПО. Для того чтобы ПСПВ нормально функционировала, необходимо организовать в составе участка аэрологической безопасности специальное подразделение, персонал которого знает сущность ДЯ; существующие методики их прогноза; категории прогнозируемой опасности и как на каждую из них реагировать; правила использования применяемого на данной шахте аппаратуры: установки датчиков, прокладки линий связи между подземным и наземным оборудованием, оценки уровня помех, регламентных работ.

Нормативно-правовое обеспечение - это совокупность следующих нормативных документов: положение о подразделении, выполняющем работы по прогнозу и предотвращению ДЯ; сертификаты, регламентирующие допуск оборудования и выполняемых на нем методов прогноза ДЯ в шахты; должностные инструкции персонала; рабочие методики и графики выполнения текущих, регламентных и ремонтных работ, обеспечивающих плановую работоспособность ПСПВ.

Методическое обеспечение - это плановые и по необходимости внеплановые консультации, семинары, вебинары и т.п. по выполнению работ на ПСПВ. Этот вид обеспечения выполняется на договорных условиях компаниями, осуществившими поставку ТО и ПО. Иногда компании, осуществляющие методическое обеспечение, имеют удаленный доступ к оборудованию ПСПВ.

Информационное обеспечение - это снабжение персонала ПСПВ дополнительной информацией, позволяющей учитывать изменения выбросоопасности, вызванные горно-геологическими и горнотехническими условиями. В состав этой информации входят сведения от маркшейдерско-геологической службы шахты о нарушениях, обводненных зонах, находящихся впереди контролируемых выработок, оставленных целиках на выше- или нижележащих пла- стах. К дополнительной информации относятся также сведения о внедрении новой техники из энергомеханического отдела. Это важно, так как более производительная техника усугубляет выбросоопасную ситуацию в забоях. В подразделение, реализующее ПСПВ, поступает также информация из отдела информационных технологий, который обслуживает базовое программное обеспечение средств вычислительной техники шахты.

\section{Выводы}

1. Оперативный и достоверный прогноз внезапных выбросов угля и газа возможен только при создании на шахте полноценной подсистемы прогноза выбросоопасности, содержащей функциональную и обеспечивающую часть, и увязанной с другими подсистемами МФСБ шахты.

2. Функциональная часть должна иметь аналитическое и экспериментальное обоснование алгоритма непрерывного прогноза внезапных выбросов угля и газа для конкретного забоя на основе контроля основных фракторов выбросоопасности.

3. Обеспечивающая часть предусматривает создание специализированного подразделения, имеющего специализированное оборудование для контроля основных фракторов выбросоопасности, включающее средства вычислительной техники со своим программным обеспечением, имеющее правовое обеспечение и информационную поддержку со стороны научных организаций и производственных компаний, поставивших методики прогноза выбросоопасности и оборудование.

4. Для повышения достоверности прогноза подсистемы прогноза выбросоопасности должны использовать информацию других подсистем МФСБ шахты.

\section{Источники финансирования.}

Исследование выполнено при фринансовой поддержке РФФИ и Кемеровской области в рамках научного проекта № 20-45-420014.

\section{СПИСОК ЛИТЕРАТУРЫ}

1. Матвеев В. В. Анализ требований к многофункциональной системе безопасности угольной шахты // Безопасность труда в промышленности. 2012, № 9. С. 62-66.

2. Бабенко А.Г. Опыт анализа основ построения многофункциональных систем безопасности угольных шахт // Безопасность труда в промышленности 2013, № 3. С 40 - 47.

3. Минеев С.П. Проведение выработок проходческими комбайнами по выбросоопасным пластам и породам / С.П. Минеев, А.А. Рубинский - Днепропетровск: Дніпро, 2006. - 384 с.

4. Лапин Э. С. Многофункциональные системы безопасности угольной шахты ООО «ИНГОРТЕХ»/ С.Э. Лапин, А.Г. Бабенко, А. Н. Кокорев // Наукоемкие технологии разработки и использования минеральных ресурсов: сб. науч. статей / Сиб. гос. ун-т; под общей ред. В.Н. Фрянова. - Новокузнецк, 2013. - С.217-224.

5. Правила безопасности в угольных шахтах: фредер. нормы и правила в обл. пром. безопасности. Утверждены приказом Федеральной службы по экологическому, технологическому и атомному надзору от 19.11.2013 г. №550. 
6. Фрянов В.Н., Павлова Л.Д. Экспериментально-численный метод прогноза геомеханических параметров технологии подземной угледобычи // Наукоемкие технологии разработки и использования минеральных ресурсов: сб. науч. статей / Сиб. гос. ун-т; под общей ред. В.Н. Фрянова. - Новокузнецк, 2015. - С. 5-13.

7. Лапин Э. С. «Микон-ГЕО» - система оперативного обнаружения и контроля состояния зон развития опасных геогазодинамических явлений при разработке месторождений полезных ископаемых подземным способом / Э. С. Лапин, В. Б. Писецкий, А. Г. Бабенко, Ю. В. Патрушев // Безопасность труда в промышленности. 2012. № $4-18-22.5$ c.

8. Положение об аэрогазовом контроле в угольных шахтах. Серия 05. Вып. 23. М.: ЗАО «НТЦ исследований проблем промышленной безопасности», 2012. 110 c.

9. Шестаков А.О. Перспективы использования геоинформационной системы в научно-исследовательской и производственной деятельности // Наукоемкие технологии разработки и использования минеральных ресурсов: сб. науч. статей / Сиб. гос. ун-т; под общей ред. В.Н. Фрянова. - Новокузнецк, 2014. - С.256-263.

10. Решетников В.В. многофункциональная система безопасности угледобывающего предприятия / В.В. Решетников, К.С. Давкаев, М.В. Корольков, М.В. Ляховец // Наукоемкие технологии разработки и использования минеральных ресурсов: науч. журнал / Сиб. гос. ун-т; под общей ред. В.Н. Фрянова. - Новокузнецк, 2018. - №4. - С. 336-339.

11. Фрянов В.Н. Перспективы применения роботизированной механогидравлической выемки газоносных угольных пластов на больших глубинах / В.Н. Фрянов, Л.Д. Павлова // Наукоемкие технологии разработки и использования минеральных ресурсов: науч. журнал / Сиб. гос. ун-т; под общей ред. В.Н. Фрянова. - Новокузнецк, 2016. - №2. - С. 19-27.

12. Фрянов В.Н. Теоретические подходы к проектированию роботизированных угольных шахт на основе современных технологий моделирования / В.Н. Фрянов, Л.Д. Павлова // Наукоемкие технологии разработки и использования минеральных ресурсов: науч. журнал / Сиб. гос. ун-т; под общей ред. В.Н. Фрянова. - Новокузнецк, 2017. - №3. - С. 15-21.

13. Методические указания по созданию систем контроля состояния горного массива и прогноза горных ударов как элементов многофункциональной системы безопасности угольных шахт / Д.В. Яковлев и др. - СПб.: ВНИМИ, - 2012. -83 c.

14. Беседина А.Н. Особенности сейсмического мониторинга слабых динамических событий в массиве горных пород / А.Н. Беседина, Н.В. Кабыченко, Г.Г. Кочарян // ФТПРПИ. 2013. - №5. - С. 20-36.

15. Егоров А.П. Обеспечение оперативного контроля безопасности ведения горных работ проведением локальных геофизических исследований и наблюдений на горных предприятиях Кузбасса / А.П. Егоров, В.А. Рыжов, Ю.П. Жвакин, Р.М. Сабиров, И.А. Кондаков // Наукоемкие технологии разработки и использования минеральных ресурсов: науч. журнал / Сиб. гос. ун-т; под общей ред. В.Н. Фрянова. - Новокузнецк, 2016. - №2. С.109-115.

16. Король В.И. Газодинамические явления в угольных шахтах: история и современное состояние проблемы // Материалы международной конференции «Форум горняков - 2007». - Днепропетровск: Национальный горный университет. 2007, с. 60-63.

17. Основы теории внезапных выбросов угля, породы и газа. - М.: Недра, 1978. - 164.

18. Pros. of international symposium-cum-workshop/ Management and control of high gas emission and outbursts in underground coal mines. - Australia, 1995. - 620 p.

19. C. Fan, S. Li, M. Luo, Mingkun, W. Du, Z. Yang. Coal and gas outburst dynamic system // International Journal of Mining Science and Technology, 2017, 27(1): pp. 49-55.

20. Geng Jiabo, Xu Jiang, Nie Wen, Peng Shoujian, Zhang Chaolin, Luo Xiaohang. Regression analysis of major parameters affecting the intensity of coal and gas outbursts in laboratory // International Journal of Mining Science and Technology Volume 27, Issue 2, 2017, Рp. 327-332.

21. Чернов О.И. Прогноз внезапных выбросов угля и газа / О.И. Чернов, В.Н. Пузырев. М.: «Недра», $1979 .-296$ с.

22. Ройтер М. Крах М., Майрхофер К., Кислинг У., Векслер Ю. Мониторинг динамических проявлений горного давления в системе управления марко «Цифровая шахта» // Наукоемкие технологии разработки и использования минеральных ресурсов: сб. науч. статей / Сиб. гос. ун-т; под общей ред. В.Н. Фрянова. - Новокузнецк, 2015. - C. 33-39.

23. Reuter M., Crash M., Kiessling W., Veksler Yu. Геомеханический мониторинг методом анализа конвергенции: прогноз вероятности горных ударов и участков их проявления в лавах // Наукоемкие технологии разработки и использования минеральных ресурсов: науч. журнал / Сиб. гос. ун-т; под общей ред. В.Н. Фрянова. - Новокузнецк, 2018. - №4. - С. 17-22.

24. Предупреждение газодинамических явлений в угольных шахтах: Сборник документов. Серия 05. Выпуск 2 / Колл. авт. - 4-е изд., испр. - М.: ЗАО «Научно-технический центр исследований проблем промышленной безопасности», 2011. - 304 с.

25. Brady B.T. Prediction of failures in mines - an overview. U.S. Dept. Of the Interior, Bu Mines RI 8285,1978.-16 p.

26. Brady B.T. Tilt precursors in rock before failure: a laboratory investigation. Bu Mines RI $8101<1975$. $-9 p$.

27. Watanabe Y., Nakajima J. The application of AE techniques as a forecasting method to the rock and gas outburst in coal mine. XIX International conference of research institutes in safety in mines. Katowice, Poland, 1981, p.564-573.

28. S. Arndt. Forecasting Seismicity, Stability and Stress in Underground Mining. Proc. of SIMULIA Community Conference. 2013. pp.807-820.

29. Мирер С.В. Спектрально-акустический прогноз выбросоопасности угольных пластов / С.В.Мирер, О.И. Хмара, А.В. Шадрин. Кемерово: Кузбассвузиздат, 1999. - 92 с.

30. Jing Li, Si-Yuan Gong, Jiang He, Wu Cai, Guang-An Zhu, Chang-Bin Wang, Tian Chen. Spatio-temporal assessments of rockburst hazard combining b values and seismic tomography // Acta Geophysica, 2017, Volume 65, Issue 1, pp. 77-88.

31. Яковлев Д.В. Закономерности развития и методика оперативной оценки техногенной сейсмической активности на горных предприятиях и в горнодобывающих регионах / Д.В. Яковлев, С.В Цирель., С.Н. Мулев // ФТПРПИ. - 2016. - №2. - С. 34-47.

32. Ходот В.В. Внезапные выбросы угля и газа. - М.: Гос. науч.-техн. изд-во лит-ры по горному делу, $1961 .-364$ с. 
33. Бабенко В.С. Сопоставление различных критериев выбросоопасности угольных пластов при проведении подготовительной выработки / В.С. Бабенко, Е.С. Ткаченко, Е.И. Зеленская // Уголь, №7. 1991. - С. 60-61.

34. Временная методика прогноза газодинамических явлений с использованием аппаратуры контроля метана при проведении подготовительных выработок. - Кемерово: ИУ СО РАН, 1992. - 12 с.

35. Методика прогноза газодинамических явлений с использованием аппаратуры контроля метана при проведении подготовительных выработок. - Кемерово: Ин-т угля СО РАН, 1994. - 48 с.

36. Индыло С.В. Разработка методики прогноза выбросоопасности и управления газодинамическим режимом призабойного пространства при проведении подготовительных выработок. Автореферат дисс. на соискание уч. степ. канд. тех. Наук. М., 2008. - 20 с.

37. Шадрин А.В. Основы автоматизированного непрерывного ГДЯ-мониторинга на угольных шахтах Кузбасса / А.В. Шадрин, В.А. Коноваленко // Вестник КузГТУ. - 2001. - №3.-С.28-31.

38. Захаров В.Н. Разработка методологии и обоснование критериев прогнозирования состояния горного массива сейсмоакустическими методами при подземной угледобыче. Автореферат дисс. на соискание уч. степ. докт. тех. Наук. М., 2003. - 38 с.

39. Инструкция по прогнозу динамических явлений и мониторингу массива горных пород при отработке угольных месторождений: фредер. нормы и правила в обл. пром. безопасности. - Сер. 05. - Вып. 49. - М.: ЗАО НТЦ ПБ, 2019. - 148 с.

40. Шадрин А.В. Функциональная часть подсистемы прогноза выбросоопасности многофункциональной системы безопасности угольной шахты // Безопасность труда в промышленности, 2020. №6. С. 72-78.

41. Бабенко А.Г. Теоретическое обоснование и методология повышения уровня охраны труда в угольных шахтах на основе риск-ориентированного подхода и многофункциональных систем безопасности. Дис. докт. техн. наук. - Екатеринбург: УГГУ, 2016. - 259 с.

42. Шадрин А.В. Оценка точности спектрально-акустического прогноза выбросоопасности в условиях узкополосных и широкополосных помех различной амплитуды / А.В. Шадрин, Ю.А. Бирева, А.М. Ермолаев, А.И. Фомин // Безопасность труда в промышленности, 2016. №7. С. 77-81.

43. Баскаков С.И. Радиотехнические цепи и сигналы. - М.: Высш. шк., 1988. - 448 с.

44. Смит Стивен. Цифровая обработка сигналов. Практическое руководство для инженеров и научных работников: пер. с англ. Лисовича А.Ю., Витязева С.В., Гусинского И.С. - М.: Додэка-XXI, 2012. - 720 с.

45. Диюк Ю.А. Исследование влияния акустических помех различного спектрального состава на показатель выбросоопасности спектрально-акустического метода / Ю.А. Диюк, А.В. Шадрин // Вестник Научного центра ВостНИИ по промышленной и экологической безопасности. 2019, №3. - C. 70-82. DOI: 10.25558/VOSTNII.2019.13.3.005.

\section{REFERENCES}

1. Matveev, V.V. (2012). Analiz trebovaniy k mnogofunktsional'noy sisteme bezopasnosti ugol'noy shakhty [Analysis of requirements for a multifunctional coal mine safety system]. Bezopasnost truda v promyshlennosti - Industrial Labor Safety, 9, 62-66 [in Russian].

2. Babenko, A.G. (2013). Opyt analiza osnov postroyeniya mnogofunktsional'nykh sistem bezopasnosti ugol'nykh shakht [Basics analysis experience of building multifunctional coal mine safety systems]. Bezopasnost truda v promyshlennosti - Industrial Labor Safety, 3, 40-47 [in Russian].

3. Mineev, S.P., \& Rubinsky, A.A. (2006). Provedeniye vyrabotok prokhodcheskimi kombaynami po vybrosoopasnym plastam i porodam [Mine working heading with the heading machines through outburst hazardous coal seams and rocks]. Dnepropetrovsk: Dnipro [in Russian].

4. Lapin, E.S., Lapin, S.E., Babenko, A.G., \& Kokorev, A.N. (2013). Mnogofunktsional'nyye sistemy bezopasnosti ugol'noy shakhty OOO «INGORTEKH» [Multifunctional safety systems of INGORTECH coal mine]. Naukoyemkiye tekhnologii razrabotki i ispol'zovaniya mineral'nykh resursov: sb. nauch. statey - High technology development and use of mineral resources: scientific articles' collection, Novokuznetsk: Siberian State University [in Russian].

5. Pravila bezopasnosti v ugol'nykh shakhtakh: feder. normy i pravila v obl. prom. bezopasnosti. Utverzhdeny prikazom Federal'noy sluzhby po ekologicheskomu, tekhnologicheskomu i atomnomu nadzoru ot 19.11.2013 g. №550 [Safety rules in coal mines: fed. rules and regulations in the industrial safety. Approved by order of the Federal Service for Ecological, Technological and Nuclear Supervision dated November 19, 2013 No. 550 [in Russian].

6. Frianov, V.N., \& Pavlova, L.D. (2015). Eksperimental'no-chislennyy metod prognoza geomekhanicheskikh parametrov tekhnologii podzemnoy ugledobychi [An experimental-numerical method for forecasting the geomechanical parameters of underground coal mining technology]. Naukoyemkiye tekhnologii razrabotki i ispol'zovaniya mineral'nykh resursov: sb. nauch. statey - High technology development and use of mineral resources: scientific articles' collection, Novokuznetsk: Siberian State University [in Russian].

7. Lapin, E.S., Pisetsky, V.B., Babenko, A.G., \& Patrushev, Yu.V. (2012). «Mikon-GEO» - sistema operativnogo obnaruzheniya i kontrolya sostoyaniya zon razvitiya opasnykh geogazodinamicheskikh yavleniy pri razrabotke mestorozhdeniy poleznykh iskopayemykh podzemnym sposobom ["Mikon-GEO" - a system for the operational detection and monitoring of dangerous geogasdynamic phenomena development zones at the underground mineral deposits' development]. Bezopasnost truda v promyshlennosti - Industrial Labor Safety, 4, 18-22 [in Russian].

8. Polozheniye ob aerogazovom kontrole v ugol'nykh shakhtakh. Seriya 05. Vyp. 23. (2012) [Regulation on airgas control in coal mines]. Series 05. Vol. 23. Moscow: ZAO «NTTS issledovaniy problem promyshlennoy bezopasnosti» [in Russian]

9. Shestakov, A.O. (2014). Perspektivy ispol'zovaniya geoinformatsionnoy sistemy v nauchno-issledovatel'skoy i proizvodstvennoy deyatel'nosti [Prospects for the use of a geoinformation system in research and production activities]. Naukoyemkiye tekhnologii razrabotki i ispol'zovaniya mineral'nykh resursov: sb. nauch. statey - High technology development and use of mineral resources: scientific articles' collection, Novokuznetsk: Siberian State University [in Russian]

10. Reshetnikov, V.V., Davkaev, K.S., Korolkov, M.V., \& Liakhovets, M.V. (2018). Mnogofunktsional'naya sistema bezopasnosti ugledobyvayushchego predpriyatiya [Coal mining enterprise multifunctional safety system]. Naukoyemkiye 
tekhnologii razrabotki i ispol'zovaniya mineral'nykh resursov: sb. nauch. statey - High technology development and use of mineral resources: scientific articles' collection, 4, 336-339. Novokuznetsk: Siberian State University [in Russian].

11. Frianov, V.N., \& Pavlova, L.D. (2016). Perspektivy primeneniya robotizirovannoy mekhanogidravlicheskoy vyyemki gazonosnykh ugol'nykh plastov na bol'shikh glubinakh [Prospects for the use of robotic mechanohydraulic extraction of gas-bearing coal seams at big depths]. Naukoyemkiye tekhnologii razrabotki i ispol'zovaniya mineral'nykh resursov: sb. nauch. statey - High technology development and use of mineral resources: scientific articles' collection, 2, 19-27. Novokuznetsk: Siberian State University [in Russian]

12. Frianov, V.N., \& Pavlova, L.D. (2017). Teoreticheskiye podkhody k proyektirovaniyu robotizirovannykh ugol'nykh shakht na osnove sovremennykh tekhnologiy modelirovaniya [Theoretical approaches to the design of robotic coal mines based on modern modeling technologies]. Naukoyemkiye tekhnologii razrabotki i ispol'zovaniya mineral'nykh resursov: sb. nauch. statey - High technology development and use of mineral resources: scientific articles' collection, 3, 15-21. Novokuznetsk: Siberian State University [in Russian].

13. Yakovlev, D.V. et al. (2012). Metodicheskiye ukazaniya po sozdaniyu sistem kontrolya sostoyaniya gornogo massiva i prognoza gornykh udarov kak elementov mnogofunktsional'noy sistemy bezopasnosti ugol'nykh shakht [Guidelines for the creation of systems for monitoring the state of the massif and forecasting rock shocks as elements of a multifunctional coal mine safety system]. St. Petersburg: VNIMI [in Russian].

14. Besedina, A.N., Kabychenko, N.V., \& Kochiarian, G.G. (2013). Osobennosti seysmicheskogo monitoringa slabykh dinamicheskikh sobytiy $v$ massive gornykh porod [Seismic monitoring features of weak dynamic events in a rock massif]. FTPRPI, 5, 20-36 [in Russian].

15. Yegorov, A.P., Ryzhov, V.A., Zhvakin, Yu.P., Sabirov, R.M., \& Kondakov, I.A. (2016). Obespecheniye operativnogo kontrolya bezopasnosti vedeniya gornykh rabot provedeniyem lokal'nykh geofizicheskikh issledovaniy i nablyudeniy na gornykh predpriyatiyakh Kuzbassa [Ensuring operational monitoring of mining safety by conducting local geophysical surveys and observations at mining enterprises of Kuzbass]. Naukoyemkiye tekhnologii razrabotki i ispol'zovaniya mineral'nykh resursov: sb. nauch. statey - High technology development and use of mineral resources: scientific articles' collection, 2, 109-115. Novokuznetsk: Siberian State University [in Russian].

16. Korol, V.I. (2007). Gazodinamicheskiye yavleniya v ugol'nykh shakhtakh: istoriya i sovremennoye sostoyaniye problem [Gas-dynamic phenomena in coal mines: history and current state of the problem]. Proceedings from: "Miners' Forum - 2007", Mezhdunarodnaya konferentsiia - International Conference. (pp. 60-63). Dnepropetrovsk: Natsionalny Gorny Universitet [in Russian].

17. Osnovy teorii vnezapnykh vybrosov uglya, porody i gaza [Theory fundamentals of sudden coal, rock and gas outbursts]. (1978). Moscow: Nedra [in Russian].

18. Pros. of international symposium-cum-workshop/ Management and control of high gas emission and outbursts in underground coal mines. - Australia, 1995 [in English].

19. C. Fan, S. Li, M. Luo, Mingkun, W. Du, Z. Yang. Coal and gas outburst dynamic system // International Journal of Mining Science and Technology, 2017, 27(1): pp. 49-55 [in English].

20. Geng Jiabo, Xu Jiang, Nie Wen, Peng Shoujian, Zhang Chaolin, Luo Xiaohang. Regression analysis of major parameters affecting the intensity of coal and gas outbursts in laboratory // International Journal of Mining Science and Technology Volume 27, Issue 2, 2017, Pp. 327-332 [in English].

21. Chernov, O.I., \& Puzyrev, V.N. (1979). Prognoz vnezapnykh vybrosov uglya i gaza [Sudden coal and gas outbursts forecast]. Moscow: Nedra [in Russian].

22. Reuter, M., Crash, M., Mairkhofer, K., Kiessling, W., \& Veksler, Yu. (2015). Monitoring dinamicheskikh proyavleniy gornogo davleniya v sisteme upravleniya marko «Tsifrovaya shakhta» [Monitoring of rock pressure dynamic manifestations in the marco "Digital mine" control system]. Naukoyemkiye tekhnologii razrabotki i ispol'zovaniya mineral'nykh resursov: sb. nauch. statey - High technology development and use of mineral resources: scientific articles' collection, 33-39. Novokuznetsk: Siberian State University [in Russian].

23. Reuter, M., Crash, M., Kiessling, W., \& Veksler, Yu. (2018). Geomekhanicheskiy monitoring metodom analiza konvergentsii: prognoz veroyatnosti gornykh udarov i uchastkov ikh proyavleniya v lavakh [Geomechanical monitoring using the convergence analysis method: forecasting the probability of rock shocks and areas of their manifestation in longwalls]. Naukoyemkiye tekhnologii razrabotki i ispol'zovaniya mineral'nykh resursov: sb. nauch. statey - High technology development and use of mineral resources: scientific articles' collection, 4, 17-22. Novokuznetsk: Siberian State University [in Russian].

24. Team of Authors (2011). Preduprezhdeniye gazodinamicheskikh yavleniy v ugol'nykh shakhtakh: Sbornik dokumentov. Seriya 05. Vypusk 2, 4-ye izd., ispr. [Prevention of gas-dynamic phenomena in coal mines: Collection of documents. Series 05. Issue 2, 4th edition, revised. - Moscow: ZAO Scientific and Technical Center for Research on Industrial Safety Problems [in Russian].

25. Brady B.T. (1978). Prediction of failures in mines - an overview. U.S. Dept. Of the Interior, Bu Mines RI 8285 [in English].

26. Brady B.T. (1975). Tilt precursors in rock before failure: a laboratory investigation. Bu Mines RI 8101 [in English].

27. Watanabe Y., \& Nakajima J. (1981). The application of AE techniques as a forecasting method to the rock and gas outburst in coal mine. XIX International conference of research institutes in safety in mines. Katowice, Poland,[in English).

28. Arndt, S. (2013). Forecasting Seismicity, Stability and Stress in Underground Mining. Proc. of SIMULIA Community Conference [in English].

29. Mirer, S.V., Khmara, O.I., \& Shadrin, A.V. (1999). Spektral'no-akusticheskiy prognoz vybrosoopasnosti ugol'nykh plastov [Spectral-acoustic forecast of coal seam outburst hazard]. Kemerovo: Kuzbassvuzizdat [in Russian].

30. Jing Li, Si-Yuan Gong, Jiang He, Wu Cai, Guang-An Zhu, Chang-Bin Wang, Tian Chen. Spatio-temporal assessments of rockburst hazard combining b values and seismic tomography // Acta Geophysica, 2017, Volume 65, Issue 1, pp. 77-88.[in English].

31. Yakovlev, D.V., Tsyrel, S.V., \& Mulev, S.N. (2016). Zakonomernosti razvitiya i metodika operativnoy otsenki tekhnogennoy seysmicheskoy aktivnosti na gornykh predpriyatiyakh i v gornodobyvayushchikh regionakh [Patterns of development and methodology for the rapid assessment of technogenic seismic activity at mining enterprises and in mining 
regions]. FTPRPI, 2, 34-47 [in Russian].

32. Khodot, V.V. (1961). Vnezapnyye vybrosy uglya i gaza [Sudden outbursts of coal and gas]. Moscow: Gosudarstvennoye nauchno-tekhnicheskoye izdatel'stvo literatury po gornomu delu [in Russian]

33. Babenko, V.S., Tkachenko, Ye.S., \& Zelenskaia, Ye.I. (1991). Sopostavleniye razlichnykh kriteriyev vybrosoopasnosti ugol'nykh plastov pri provedenii podgotovitel'noy vyrabotki [Comparison of outburst hazard various criteria of coal seams during development working heading]. Ugol - Coal, 7, 60-61 [in Russian]

34. Vremennaya metodika prognoza gazodinamicheskikh yavleniy $\mathrm{s}$ ispol'zovaniyem apparatury kontrolya metana pri provedenii podgotovitel'nykh vyrabotok [A temporary forecasting technique of gas-dynamic phenomena using methane control equipment during development working heading].Kemerovo: Institute of Coal SB RAS, 1992 [in Russian].

35. Metodika prognoza gazodinamicheskikh yavleniy s ispol'zovaniyem apparatury kontrolya metana pri provedenii podgotovitel'nykh vyrabotok [Methodology for gas-dynamic phenomena forecasting using methane control equipment during development working heading]. Kemerovo: Institute of Coal SB RAS, 1994 [in Russian].

36. Indylo, S.V. (2008). Razrabotka metodiki prognoza vybrosoopasnosti i upravleniya gazodinamicheskim rezhimom prizaboynogo prostranstva pri provedenii podgotovitel'nykh vyrabotok [Development of a methodology for forecasting outburst hazard and controlling the gas-dynamic regime of the face area during development working heading]. Extended abstract of candidate's thesis]. Moscow [in Russian]

37. Shadrin, A.V., \& Konovalenko, V.A. (2001). Osnovy avtomatizirovannogo nepreryvnogo GDYA-monitoringa na ugol'nykh shakhtakh Kuzbassa [The basics of automated continuous monitoring of rock dynamic phenomena in the coal mines of Kuzbass]. Vestnik KuzGTU - KuzGTU Herald, 3, 28-31 [in Russian]

38. Zakharov, V.N. (2003). Razrabotka metodologii i obosnovaniye kriteriyev prognozirovaniya sostoyaniya gornogo massiva seysmoakusticheskimi metodami pri podzemnoy ugledobyche [Development of a methodology and substantiation of criteria for forecasting the state of a rock mass using seismic-acoustic methods in underground coal mining] Extended abstract of doctor's thesis]. Moscow [in Russian].

39. Instruktsiya po prognozu dinamicheskikh yavleniy i monitoringu massiva gornykh porod pri otrabotke ugol'nykh mestorozhdeniy: feder. normy i pravila $v$ obl. prom. Bezopasnosti [Instructions for predicting dynamic phenomena and monitoring a rock massif during mining of coal deposits: federal norms and rules in the field of industrial safety]. Series 05. - Issue 49. - Moscow: ZAO NTC PB, 2019 [in Russian].

40. Shadrin, A.V. (2020). Funktsional'naya chast' podsistemy prognoza vybrosoopasnosti mnogofunktsional'noy sistemy bezopasnosti ugol'noy Shakhty [The functional part of the outburst forecast subsystem of the multifunctional coal mine safety system]. Bezopasnost truda v promyshlennosti - Industrial Labor Safety, 6, 72-78.

41. Babenko, A.G. (2016). Teoreticheskoye obosnovaniye i metodologiya povysheniya urovnya okhrany truda $v$ ugol'nykh shakhtakh na osnove risk-oriyentirovannogo podkhoda i mnogofunktsional'nykh sistem bezopasnosti [Theoretical grounding and methodology for improving labor protection in coal mines based on a risk-based approach and multifunctional safety systems].Doctor's thesis, Yekaterinburg [in Russian]

42. Shadrin, A.V., Bireva, Yu.A., Yermolaev, A.M., \& Fomin, A.I. (2016). Otsenka tochnosti spektral'no-akusticheskogo prognoza vybrosoopasnosti v usloviyakh uzkopolosnykh i shirokopolosnykh pomekh razlichnoy amplitudy [Outburst hazard spectral-acoustic forecast accuracy evaluation in the conditions of narrow-band and wide-band interference of various amplitudes]. Bezopasnost truda v promyshlennosti - Industrial Labor Safety, 7, 77-81 [in Russian].

43. Baskakov, S.I. (1988). Radiotekhnicheskiye tsepi i signaly [Radio circuits and signals].Moscow: Vysshaia Shkola [in Russian].

44. Smith Steven (2012). Tsifrovaya obrabotka signalov. Prakticheskoye rukovodstvo dlya inzhenerov i nauchnykh rabotnikov [Digital signal processing. A practical guide for engineers and scientists]. Moscow: Dodeka [in Russian).

45. Diiuk, Yu.A., \& Shadrin, A.V. (2019). Issledovaniye vliyaniya akusticheskikh pomekh razlichnogo spektral'nogo sostava na pokazatel' vybrosoopasnosti spektral'no-akusticheskogo metoda [Various spectral composition acoustic noise influence on the spectral-acoustic method outburst hazard indicator research]. Vestnik Nauchnogo tsentra VostNII po promyshlennoi i ekologicheskoi bezopasnosti - Herald of Industrial and Environmental Safety Scientific Center VostNII, 3, 70-82 [in Russian].

\section{СИСТЕМЫ ПНЕВМОГИАРООРОШЕНИЯ ААЯ БОРЬБЫ С ПЫАЬЮ}

\section{Система пымеподавления разработана ГК «ВостЭКО и Горный-ЦОТ»}

созАаёт водовоздушный туман Ао 3,5 мкм, который поглощает угольную, породную, рудную и др виды пыли и препятствует её Аальнейшему распространению

- Снижение расхода воды до 12 раз, рабочее давление 5 атм, расход воды от 0,5 ^/мин на 1 форсунку

- Может использоваться со спец добавкой для работы при отрицательных температурах

- Снижение запыленности на 80 \%

Установлена на Кемеровской ТЭЦ, пройдены испытания на карьере «Борок» и Ар промышленных объектах

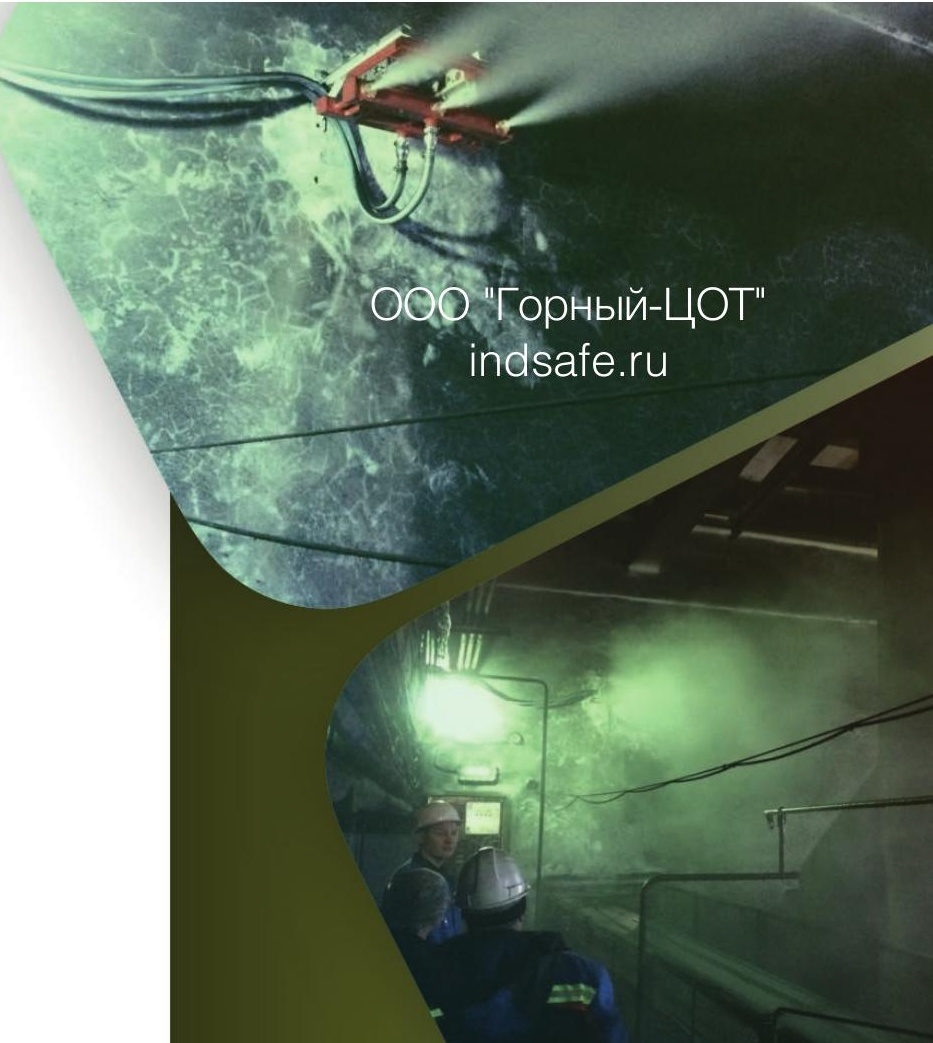




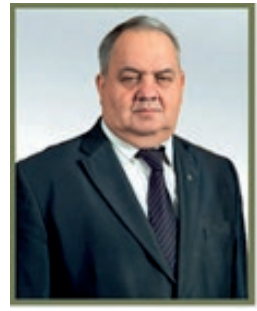

\title{
В. С. Зыков // V.S. Zykov
}

д-р техн наук, профессор,

заместитель генерального директора

по научной работе АО «НЦ ВостНИИ»,

Россия, 650002, г. Кемерово, ул.

Институтская, 3

doctor of technical sciences, deputy

general director for scientific work,

AO "ScC VostNII" Russia, 650002,

Kemerovo, Institutskaia St., 3

УДК 622.831

\section{ОБОСНОВАНИЕ ПОКАЗАТЕЛЯ СТЕПЕНИ ВЫБРОСООПАСНОСТИ ПРИЗАБОЙНОЙ ЧАСТИ УГОЛЬНОГО}

\author{
ПЛАСТА
}

\author{
COAL SEAM FACE AREA OUTBURST HAZARD DEGREE \\ FACTOR JUSTIFICATION
}

Изложены результаты теоретических исследований газодинамического состояния массива в подготовительной стадии и на стадии отторжения слоя угля между обнаженной плоскостью забоя или обнаженной поверхностью вблизи него и ближайшей системой заполненных свободным газом под высоким давлением трещин. Получено условие нарушения равновесного состояния потенциально выбросоопасного состояния угольного массива в начале развязывания внезапного выброса. Выполнена адаптация данного условия с целью использования его для оперативного контроля за выбросоопасностью угольного массива при проведении подготовительных выработок и ведении очистных работ на угольных пластах. Разработанный показатель выбросоопасности отличается от многих аналогов тем, что говорит о степени выбросоопасности. Экспериментальная проверка показателя свидетельствует о том, что он позволяет примерно в 2 раза повысить точность выявления выбросоопасных зон, не снижая при этом гарантии их своевременного установления.

The theoretical studies results of the massif gas-dynamic state at the preparatory stage and at the stage of the coal layer separation between the exposed face plane or the exposed surface near it and the nearest sys-tem of cracks filled with free gas under high pressure are presented. A condition is obtained for the disturbance of the equilibrium state of the potentially outburst-dangerous state of the coal massif at the beginning of the unleashing of a sudden outburst. An adaptation of this condition has been carried out with the aim of using it for operational control of the coal massif outburst hazard during preparatory workings and coal extraction operations on coal seams. The developed out-burst factor differs from many analogues in that it indicates the degree of outburst hazard. The factor experimental verification indicates that it allows approximately to increase 2 times the hazardous areas' detection accuracy, without compromising the guarantee of their timely detection. КлючевЫе слова: ПЛОСКОСТЬ ЗАБОЯ, ПОРИСТОСТЬ УГОЛЬНОГО МАССИВА, ТЕКТОНИЧЕСКИ НАРУШЕННЫЙ УГОЛЬ, ВЫБРОСООПАСНАЯ УГОЛЬНАЯ ПАЧКА, ИЗБЫТОЧНОЕ ДАВЛЕНИЕ ГАЗА В ПЛАСТЕ, НАЧАЛЬНАЯ СКОРОСТЬ ГАЗОВЫДЕЛЕНИЯ ИЗ КОНТРОЛЬНЫХ СКВАЖИН, КОНТУР ПИТАНИЯ СКВАЖИНЫ

Key words: FACE PLANE, COAL MASSIF POROSITY, TECTONICALLY DISTURBED COAL, OUTBURST HAZ-ARDOUS COAL BAND, EXCESSIVE GAS PRESSURE IN THE SEAM, INITIAL GAS EMISSION VELOCITY FROM CONTROL BOREHOLES, BOREHOLE FEEDIN CONTOUR

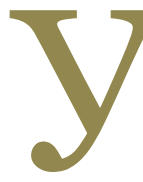

словие нарушения равновесного состояния потенциально выбросоопасного угольного массива вблизи плоскости обнажения в призабойной части выработки согласно [1] можно записать:

$$
\frac{F_{a}}{F_{\Pi}}=\frac{\sqrt[3]{m^{2}}\left(\frac{d p}{d x}\right)}{\tau \frac{\Pi}{S}} \geq 1
$$

где $F_{a}$ и $F_{n}$ - соответственно активная сила, стремящаяся отторгнуть слой угля между плоскостью обнажения в призабойной части массива и развитой системой квазипараллельных этой плоскости систем трещин на расстоянии $d x$ от обнажения, и пассивная сила сопротивления слоя угля отрыву; $m$ - пористость угольного массива в зоне влияния выработки; $d p / d x-$ градиент газового давления; П и $S$ - соответственно пери- 
метр и площадь обнаженного угольного массива в сечении выработки.

Это условие для конкретного сечения потенциально выбросоопасной пачки на расстоянии х от плоскости забоя выразится в виде:

$$
\frac{F_{a}}{F_{c}}=\frac{p_{x} S_{s} \sqrt[3]{m_{x}^{2}}}{\tau \prod_{\sigma} x} \geq 1
$$

где $p_{x}$ - избыточное давление газа на расстоянии $x$ от забоя; $m$ - пористость угольного массива на расстоянии $x$ от забоя; $S_{b}, P_{6}-$ соответственно площадь и периметр поперечного сечения потенциально выбросоопасной угольной пачки в месте подвигания забоя, м; $\tau$ - касательные напряжения по периметру $P_{6}$

Согласно [2] можно принять

$$
\tau=k+k v \operatorname{tg} \rho
$$

где $k$ - коэффициент сцепления угля; $k v-$ напряжения на кромке забоя; $p$-угол внутреннего трения угля.

Заменив в формуле (2) параметр $\tau$ выражением (3), получим:

$$
\frac{P_{x} S_{\varepsilon} \sqrt[3]{m_{x}^{2}}}{(k+k \operatorname{vtg} \rho) \Pi_{\varepsilon} x} \geq 1
$$

Параметром, связанным с давлением газа и пористостью массива, является начальная скорость газовыделения из контрольных скважин, пробуренных в исследуемый массив. Основываясь на законе Дарси [3,4] и пренебрегая давлением газа в скважине, ее можно выразить в виде:

$$
g_{\text {r.x }}=\frac{\pi k_{x} P_{k}^{2}}{\mu \ln \frac{r_{k}}{r_{c}}}
$$

где $g_{\mu . x}, k_{x}, P_{k}$ - соответственно объемный расход газа на единицу длины скважины, коэффицциент проницаемости пласта, избыточное давление газа в пласте на расстоянии х от забоя; $r_{k}-$ радиус контура питания скважины; $r$ - радиус скважины; $\mu$ - коэффициент динамической вязкости газа.

Н. Г. Вершининым доказано [5], что для начального газовыделения можно отношение $\frac{\pi}{\alpha \ln \frac{r_{k}}{r_{0}}}$ принять постоянной величиной $\eta=17$ $\mathrm{M}^{3} \mathrm{c} / \mathrm{k}^{r_{*}},{ }^{\prime}$ т. к. оно изменяется в небольших пределах.

С учетом того, что давление газа на контуре питания скважины $P_{k}$ в начальный момент времени равно $P_{x}$, можно записать следующее выражение:

$$
g_{H . x}=10 \eta k_{x} P^{2}
$$

В соответствии с [6]

$$
k_{x}=\frac{a_{x}^{3} \Gamma_{x}}{A} \mid
$$

где $a_{x}$ и $\Gamma_{x}$-соответственно величина раскрытия и густота трещин на расстоянии $x$ от обнажения массива; $A$ - постоянный коэффрициент. Подставив (7) в (8), получим:

$$
g_{\text {к.x }}=\frac{10}{A} \eta P_{x}^{2} a_{x}^{3} \Gamma_{x}
$$

Если рассматривать систему трещин, определяющую газовыделение в скважину, пробуренную в исследуемый массив, то для этой системы можно записать:

А далее следует:

$$
m_{x}=a_{x} \Gamma_{x}
$$

$$
g_{\text {r.x }}=\frac{10}{A} \eta P_{x}^{2} a_{x}^{2} m_{x}
$$

После преобразования выражения (10) можно получить $\varphi$ :

$$
0,32 \sqrt{\frac{A}{\eta}} \frac{\sqrt{g_{x \cdot x}}}{a_{x}}=P_{x} \sqrt{m_{x}}
$$

Обозначим правую часть выражения функцией $F\left(P_{x}, m_{x}\right)$, т. е.

$$
F\left(P_{x}, m_{x}\right)=P_{x} \sqrt{m_{x}}
$$

С другой стороны, составляющая активной силы внезапного выброса $F_{a}$, зависящая от $P_{x}$ и $m_{x}$ (обозначим эту составляющую функцией $\varphi\left(P_{x}, m_{x}\right)$, в соответствии с фрормулой (4) выразится как

$$
\varphi\left(P_{x}, m_{x}\right)=P_{x} \sqrt[3]{m_{x}^{2}}
$$

Функции $\varphi\left(P_{x}, m_{x}\right)$ и $F\left(P_{x}, m_{x}\right)$ от параметра $P_{x}$ зависят одинаково. Зависимости их от $m_{x}$ очень близки и, чтобы подтвердить это, построим графики обеих функций в пределах реальных значений параметра $m_{x}$. Чтобы определить область реальных значений $m_{x}$, необходимо задаться интервалами изменения параметров, определяющих его величину.

Согласно [7], в качестве таких параметров могут быть приняты коэффициент крепости угля, глубина проведения и сечение выработки по углю, скорость подвигания забоя и глубина заходки при отбойке угля.

Ниже приведены пределы изменения указанных параметров для шахт России при ведении горных работ на склонных к ГДЯ угольных пластах:

- средневзвешенный коэфффициент крепости угля $f=0,4-1,0$;

- глубина проведения выработки $H=150$ $800 \mathrm{M}$;

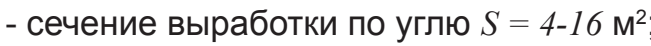

- скорость подвигания забоя выработки $V$ $=2-10 \mathrm{M} /$ сут;

- глубина заходки $l=0,5-2,0$ м.

Минимальная величина $m_{x}$ соответствует максимальным значениям прочности угля, скорости подвигания выработки и глубины заходки 
и максимальным значениям глубины проведения выработок и их сечений, максимальная - наоборот.

Влияние на $m_{x}$ скорости подвигания забоя выработки при соответствующей глубине заходки учитывается согласно руководства [7] временным параметром $t=15,1 / \mathrm{l} \mathrm{V}$.

C применением предложенного в [7] математического аппарата выполнены расчеты изменения $m_{x}$ в зависимости от указанных параметров. По результатам расчета получен интервал изменения $m_{x}$ от 0,00 до 0,20.

Для этого интервала построены графики изменения $\varphi\left(P_{x}, m_{x}\right)$ и $F\left(P_{x}, m_{x}\right)$ в зависимости от величины $m_{x}$ (рис. 1).

Давление газа при расчетах принято 2,9 МПа. Графики показывают почти синхронное изменение фрункций, что позволяет, сохраняя достаточно высокую точность описываемых преобразований, заменить в формуле (4) выражение $P_{x}^{3} \sqrt{ }\left(m_{x}^{2}\right)$ выражением $0,32 \sqrt{\frac{A}{\eta}} \sqrt{g_{\mu . x}}$, умноженным на некоторую постоянную величину $d$, т. е. выражение (4) примет вид:

$$
\frac{0,32 d \sqrt{\frac{A}{\eta}} \sqrt{g_{u . x}} S_{s}}{a_{x}(k+k v \operatorname{tg} \rho) \Pi_{6} x} \geq 1
$$

Величина раскрытия трещин $a_{x}$ зависит от тех же параметров, что и трещинная пористость $m_{x}$ и, кроме того, определяется густотой трещин $\Gamma_{x}$.

Эти зависимости исследованы с использованием руководства [7] в тех же пределах изменения параметров $f, H, S$ и $t$, как при расчете интервала изменения $m_{x}$. Вначале рассчитывались значения $m_{x}$, а затем, с учетом того, что $m_{x}=a_{x} \Gamma_{x}$, вычислялись значения $a_{x}$. При этом при расчете зависимости $a_{x}$ от какого-либо параметра остальные параметры принимались постоянными, равными средним $\left(f_{c p}=0,6 ; H_{c p}=475 \mathrm{~m} ; S_{c p}=10\right.$ $\mathrm{M}^{2} ; t_{c p}=7,92$ ч).

Поскольку контрольные скважины бурятся лишь по тектонически нарушенному углю, в котором густота трещин изменяется незначительно, ее величина принята постоянной, равной средней для нарушенных углей, по данным монографрии [8] $\left(\Gamma_{x}=1000\right.$ 1/м).

В результате были получены данные, представленные кривой 1 на рис. 2.

На этом же рисунке приведен график упрощенной зависимости вида

$$
a_{x}=\frac{a}{f^{2}}
$$

где $a$ - постоянный коэфрфициент ( $a=0,0033)$.
Графики 1 и 2 достаточно близки. Это дает основание записать зависимость (14) в виде:

$$
\frac{96,7 \sqrt{\frac{A}{\eta}} \sqrt{g_{н . x}} S_{s} \mathrm{f}^{2}}{(k+k v \operatorname{tg} \rho) \Pi_{s} x} \geq 1
$$

Путем проведенных преобразований в условии нарушения равновесного состояния массива составляющую активной силы внезапного выброса, зависящую от $P_{x}$ и $m_{x}$, можно выразить через начальную скорость газовыделения $g_{н . x}$ в контрольную скважину на расстоянии х от забоя, коэффрициент крепости угля по М. М. Протодьяконову и постоянное выражение $96,7 \sqrt{\frac{A}{\eta}}$.

Для упрощения при дальнейших рассуждениях примем:

$$
96,7 \sqrt{\frac{A}{\eta}}=c
$$

однако будем иметь в виду, что при этом сделано некоторое допущение, т. к. параметры $A$ и $\eta$ имеют небольшие колебания своих значений.

В начале рассмотрения условия развязывания внезапного выброса угля и газа было отмечено, что $P_{x}$ - это избыточное давление газа в угольном массиве, т. е. давление газа на стенки пор и трещин на расстоянии $x$ от забоя. Поэтому имеет смысл в качестве $g_{\text {н.x }}$ рассматривать то начальное газовыделение на расстоянии $x$ от забоя, которое характеризует это давление, а не в целом объем фильтруемого со стенок скважин газа. Ближайшему к обнажению интервалу контрольной скважины соответствует близкое к нулю давление газа в массиве, поэтому начальное газовыделение в этом интервале определяет объем фильтруемого свободно, почти без напора, газа. Из этих соображений в качестве $g_{\text {н.x }}$ целесообразно принимать разность максимального начального газовыделения по длине скважины и начального газовыделения в ближайшем к забою интервале $g_{\text {н.x }}$.

Такой вывод подтверждается описанными во многих научных трудах результатами исследований изменения начальной скорости газовыделения по длине контрольных скважин в зонах различной степени опасности по внезапным выбросам угля и газа [9-12 и др.]. Степень опасности зон тем выше, чем больше значение разности максимального начального газовыделения и газовыделения в ближайшем к забою интервале, как правило, минимальному по длине скважины. При этом обязательно необходимо использовать скорректированные по формуле, т. е. приведенные к диаметру бурового резца, значения начальной скорости газовыделения из контрольных скважин, которые определяются по формуле [13]: 


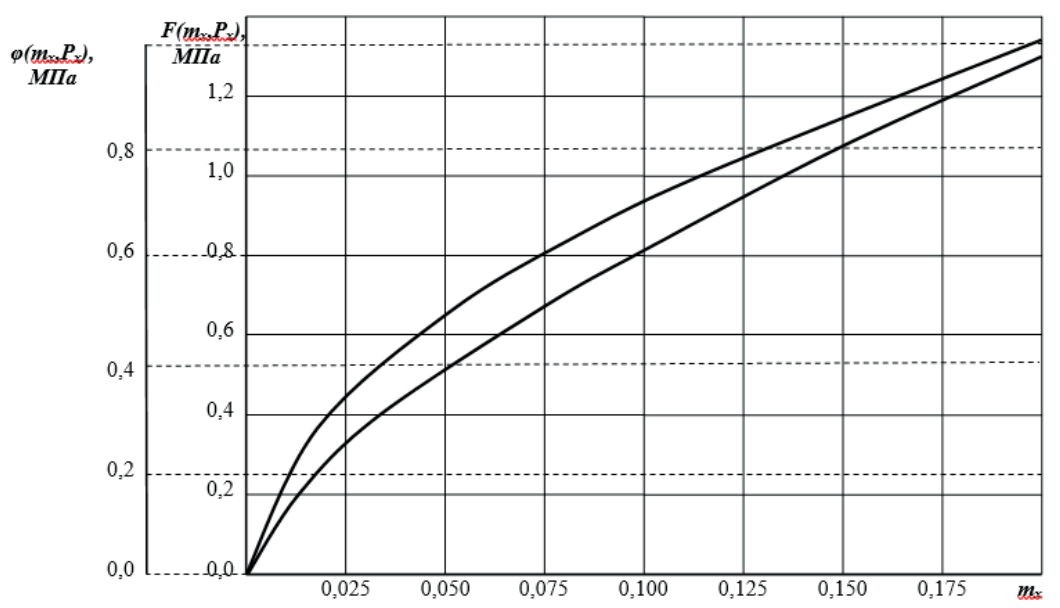

Рисунок 1. Графики зависимости $\varphi\left(P_{x}, m_{x}\right)$ и $F\left(P_{x}, m_{x}\right)$ om $m_{x}$ Figure 1. Graphs of the dependence $\varphi(P x, t x)$ and $F\left(P_{x}, t x\right)$ versus $t x$

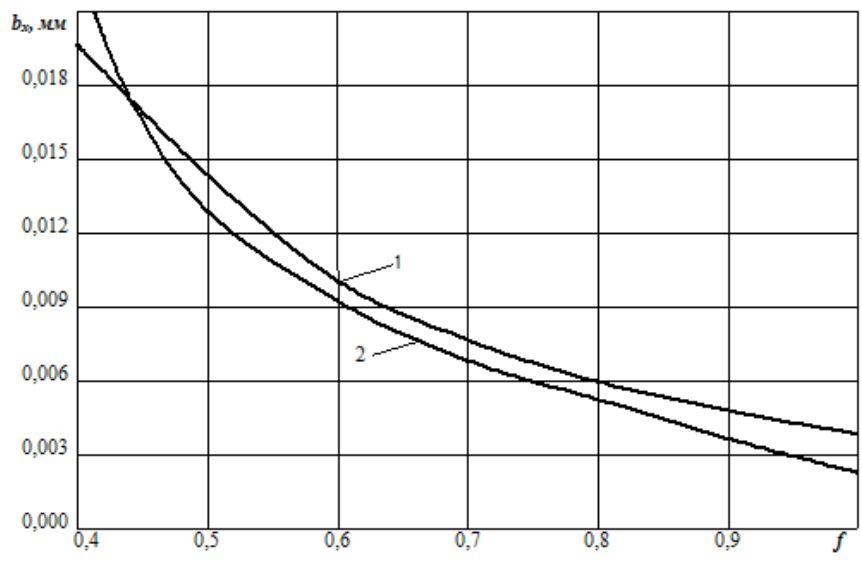

Рисунок 2. Графрики зависимости ах от f: 1 - рассчитанные по руководству [7]; 2 - определенные по формуле (13)

Figure 2. Graphs of the dependence of ax on $f: 1$ - calculated according to the guide-lines [7]; 2 - defined by the formula (13)

$$
g_{H . i}^{*}=g_{H . i} \sqrt{\frac{S_{n p}}{S_{i}}},
$$

где $g_{\text {н.i }}$-измеренное значение начальной скорости газовыделения из скважин в $i$-том интервале; $S_{i}$ и $S_{n p}$ - соответственно измеренное и проектное значения $S$ в том же интервале.

В результате получим:

$$
g_{H . x}=g_{H . \mathrm{max}}^{*}-g_{H .3}^{*} .
$$

Условие (16) сейчас можно записать:

$$
\frac{c \sqrt{g_{\text {н.sax }}^{*}-g_{H .3}^{*}} S_{B} f^{2}}{(k+k v \operatorname{tg} \rho) \Pi_{B} x} \geq 1 .
$$

Расстояние $x$ с учетом вышеизложенного будет представлять собой расстояние от забоя до середины интервала скважины, для которого установлено по результатам текущего прогноза $g_{\text {н.мах }}$. Обозначим его $l_{g^{*}}$.

Параметры $k, k v$ и $\operatorname{tg} \rho$, входящие в неравенство 19, могут быть рассчитаны в зависимо- сти от f с применением формул, представленных в руководстве [7]. На рис. 3 показан график 1, рассчитанный по этим формулам, а также график 2, построенный с помощью подобранной упрощенной зависимости

$$
\tau=b f^{3}
$$

где $b$ - постоянный коэффрициент $(b=34,11)$.

С учетом сходимости графиков 1 и 2 и предложенного значения х можно неравенство (19) представить в следующем виде:

$$
\frac{c \sqrt{g_{\text {н.мах }}^{*}-g_{\text {н.3 }}^{*}} S_{s}}{1_{\mathrm{g} *} b f \Pi_{в}} \geq 1
$$

С целью получения более удобного для практики вида выражение $\sqrt{g_{\text {н.мах }}^{*}-g_{\text {н.з }}^{*}}$ заменено на выражение $g_{\text {н.мах }}^{*}-g_{\text {н.3 }}^{*}$ С учетом тех обстоятельств, что это, во-первых, более удобно для практики, во-вторых, такая замена лишь увеличит резерв безопасности (т. к. увеличивается вес главного параметра в показателе) и, в тре- 


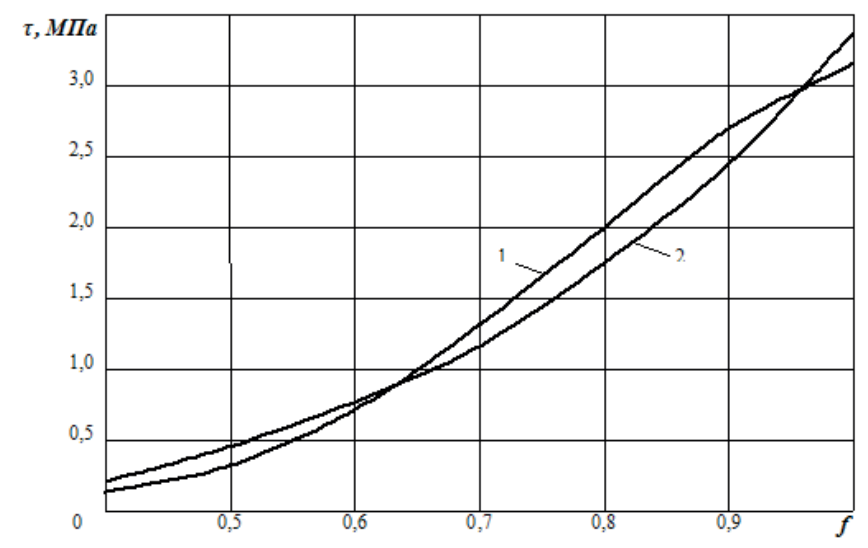

Рисунок 3. Графрики зависимости $\tau$ om f : 1 - рассчитанные по руководству [7]; 2 - определенные по фрормуле (20)

Figure 3. Graphs of the dependence $\tau$ versus $f: 1$ - calculated according to the guidelines [7]; 2 - defined by the formula (20)

тьих, она существенно не отразится на точности разграничения опасных и неопасных зон.

Окончательный вид показателя получился следующим:

$$
\frac{k\left(g_{\text {н.мax }}^{*}-g_{\text {н.3 }}^{*}\right) S_{B^{\prime}}}{1_{\mathrm{g}^{*}} f \Pi_{в}} \geq 1
$$

где $k$ - постоянный коэфффициент, равный $c / b$.

После получения данного показателя проведена его проверка в шахтных условиях в различных угольных районах России. Целью проверки являлось установление критического значения показателя, разделяющего прогнозируемые зоны на опасные и неопасные по внезапным выбросам угля и газа. С учетом вида условия (22) она была сведена к определению значения коэффициента $k$, в который должен был войти запас с учетом всех сделанных в процессе получения показателя допущений. С использованием теории вероятностей и методов математической статистики значение коэффрициента $k$ составило 1,25 мин/л.
В результате для практического использования получен показатель выбросоопасности зоны в окрестности забоя проводимой по угольному пласту подготовительной выработки

$$
B_{n}=\frac{1,25\left(g_{\text {н.мax }}^{*}-g_{\text {н.3 }}^{*}\right) S_{B}}{f \Pi_{B} 1_{\mathrm{g}^{*}}} \geq 1
$$

Используемые в показателе параметры могут быть достаточно оперативно определены. Его преимущество перед другими показателями заключается в том, что он получен не эмпирическим путем, а исходя из математического выражения условия развязывания внезапного выброса угля и газа.

Применение данного показателя позволило повысить примерно в 2,5 раза точность текущего прогноза выбрососопасности за счет сокращения числа фрактически не опасных зон, квалифицируемых по применявшемуся ранее показателю выбросоопасности $R$ [10] как опасные.

\section{СПИСОК ЛИТЕРАТУРЫ}

1. Мурашев В. И. Механизм развязывания внезапных выбросов угля и газа в горных выработках // Основы теории внезапных выбросов угля, породы и газа: Сб. науч. тр. - М.: Недра, 1978. - С. 141-162.

2. Руководство по определению безопасных технологических параметров проведения подготовительных выработок по выбросоопасным зонам угольных пластов / В. И. Мурашев, В. С. Черкасов, В. Л. Бульбенко, В. Г. Исаченко. - Кемерово, 1978 - 25 с. - (ВостНИИ).

3. Щербань А. Н., Цырульников А. С. Газопроницаемость угольных пластов. - Киев, 1958. - 110 с.

4. Ромм Е. С. Фильтрационные свойства трещиноватых горных пород. - М.: Недра, 1966. - 284 с.

5. Вершинин Н. Г. Исследование газовыделения из скважин для прогноза выбросоопасных и неопасных зон в угольных пластах Кузбасса при проведении подготовительных выработок: Автореф. дисс. ... канд. техн. наук. - Кемерово, 1974.

6. Губайловский А. Г. Исследование фрильтрационно-коллекторских характеристик угольных пластов Ленинского района Кузбасса. - В кн.: Вопросы аэрологии и бзопасности в угольных шахтах. Научные сообщения. Выпуск 143. М.: Наука, 1973. - 139 с.

7. Руководство по определению безопасных технологических параметров проведения подготовительных выработок по выбросоопасным зонам угольных пластов / В. И. Мурашев, В. С. Черкасов, В. Л. Бульбенко, В. Г. Исаченко. - Кемерово, 1978 - 25 с. - (ВостНИИ).

8. В. В. Ходот, М. Ф. Яновская, Ю. С. Премыслер и др. Физико-химия газодинамических явлений в шахтах. М.:Наука, 1973. - 139 с.

9. Чернов О. И., Пузырев В. Н. Прогноз внезапных выбросов угля и газа. - М.: Недра, 1979. - 296 с.

10. R. D. Lama. Safe gas content theshold value for safety against outbursts in the mining of the Bulli seam. International 
symposium - cum-workshop. - Australia. - 1995. - P. 175-191.

11. Зыков В.С., Лебедев А.В., Сурков А.В. Предупреждение газодинамических явлений при проведении выработок по угольным пластам. - Кемерово: КРО АГН, 1997. - 261 с.

12. Зыков В. С. Внезапные выбросы угля и газа и другие газодинамические явления в шахтах. - Кемерово: Институт угля и углехимии СО РАН, 2010. - 333 с.

13. Зыков В. С. Приведение газовыделения к диаметру шпура при прогнозе выбросоопасности // Уголь Украины. 1983. - № 6. - с. 22.

\section{REFERENCES}

1. Murashev, V.I. (1978). Mekhanizm razvyazyvaniya vnezapnykh vybrosov uglya i gaza v gornykh vyrabotkakh. Osnovy teorii vnezapnykh vybrosov uglya, porody i gaza: Sbornik nauchnykh trudov [Coal and gas sudden outburst unleashing mechanism in mining. Coal, rock and gas sudden outburst theory fundamentals: collection of scientific papers]. Moscow: Nedra [in Russian].

2. Murashev, V.I., Cherkasov, V.S., Bulbenko, V.L., \& Isachenko, V.G. (1978). Rukovodstvo po opredeleniyu bezopasnykh tekhnologicheskikh parametrov provedeniya podgotovitel'nykh vyrabotok po vybrosoopasnym zonam ugol'nykh plastov [Guidelines for the safe technological parameters determination for working heading through outburst hazardous zones of coal seams]. Kemerovo: VostNII [in Russian].

3. Shcherban, A.N., \& Tsyrulnikov, A.S. (1958). Gazopronitsayemost' ugol'nykh plastov [Gas permeability of coal seams]. Kiev [in Russian].

4. Romm, Ye.S. (1966). Fil'tratsionnyye svoystva treshchinovatykh gornykh porod [Filtration properties of jointed rocks]. Moscow: Nedra [in Russian].

5. Vershinin, N.G. (1974). Issledovaniye gazovydeleniya iz skvazhin dlya prognoza vybrosoopasnykh i neopas-nykh zon v ugol'nykh plastakh Kuzbassa pri provedenii podgotovitel'nykh vyrabotok [The study of gas emission from boreholes to predict the outburst hazardous and non-hazardous zones in the coal seams of the Kuzbass during preparatory workings' heading]. Extended abstract of candidate's thesis. Kemerovo [in Russian].

6. Gubailovsky, A.G. (1973). Issledovaniye fil'tratsionno-kollektorskikh kharakteristik ugol'nykh plastov Leninskogo rayona Kuzbassa [The study of filtration and reservoir characteristics of coal seams of the Kuzbass Leninsky district]. Voprosy aerologii i bezopasnosti v ugol'nykh shakhtakh. Nauchnyye soobshcheniya - Issues of aerology and safety in coal mines. Scientific Reports, Issue 143. Moscow: Nauka [in Russian].

7. Murashev, V.I., Cherkasov, V.S., Bulbenko, V.L., \& Isachenko, V.G. (1978). Rukovod-stvo po opredeleniyu bezopasnykh tekhnolog-icheskikh parametrov provedeniya podgo-tovitel'nykh vyrabotok po vybrosoopasnym zonam ugol'nykh plastov [Guidelines for the safe technological parameters determination for working heading through outburst hazardous zones of coal seams]. Kemerovo: VostNII [in Russian].

8. Khodot, V.V., Yanovskaia, M.F., Premysler, Yu.S., et.al (1973). Fiziko-khimiya gazodinamicheskikh yavleniy v shakhtakh [Physical chemistry of gas-dynamic phenomena in mines]. Moscow: Nauka [in Russian].

9. Chernov, O.I., \& Puzyrev, V.N. (1979). Prognoz vnezapnykh vybrosov uglya i gaza [Forecast of sudden coal and gas outburst]. Moscow: Nedra

10. 10. Lama, R. D. (1995). Safe gas content theshold value for safety against outbursts in the mining of the Bulli seam. International symposium - cum-workshop. - Australia. P. 175-191 [in English].

11. Zykov, V.S., Lebedev, A.V., \& Surkov, A.V. (1997). Preduprezhdeniye gazodinamicheskikh yavleniy pri provedenii vyrabotok po ugol'nym plastam [The prevention of gas-dynamic phenomena when heading workings through coal seams]. Kemerovo: KRO AGN [in Russian].

12. Zykov, V.S. (1983). Privedeniye gazovydeleniya k diametru shpura pri prognoze vybrosoopasnosti [The dependence of gas emission on the diameter of the borehole in the outburst hazard forecast]. Ugol Ukrainy - Coal of Ukraine, 6 , p. 22 [in Russian].

13. Zykov, V.S. (2010). Vnezapnyye vybrosy uglya i gaza i drugiye gazodinamicheskiye yavleniya v shakhtakh [Sudden outbursts of coal and gas and other gas-dynamic phenomena in mines]. Kemerovo: Institute of Coal Coal Chemistry, SB RAS [in Russian]. 


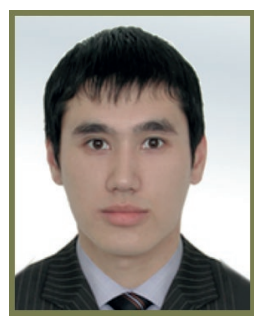

\section{К.X. Ли// K.Kh. Li}

научный сотрудник лаборатории борьбы с газодинамическими проявлениями АО «НЦ ВостНИИ», 650002, г. Кемерово, ул. Институтская, 3

scientific researcher of gas-dinamic manifestation suppression laboratory, AO "ScC VostNII", 650002, Kemerovo, Institutskaia St., 3

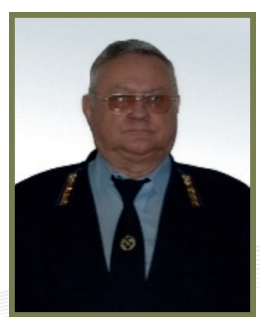

В. В. Иванов// V.V. Ivanov

v.ivanov@nc.vostnii.ru

доктор техн. наук, профессор,

ведущий научный сотрудник $\mathrm{AO}$ «НЦ ВостНИИ», 650002, г. Кемерово, ул. Институтская, 3

leading researcher of AO "ScC VostNII", doctor of technical sciences, professor, 650002, Kemerovo, Institutskaia St., 3

Удк 622.831

\section{КИНЕТИЧЕСКИЕ ПРЕДСТАВЛЕНИЯ О РАЗРУШЕНИИ ГОРНЫХ ПО-}

Рассматривается кинетическая концепция подготовки горных ударов и предлагается кинетическая модель накопления трещин. Показано, что в основе разрушения структурных блоков горных пород любого иерархического уровня лежит случайный процесс накопления повреждений (трещин) меньщего размера, причем на этот процесс оказывает влияние множество различных горно-геологических и горно-технических фракторов. Процесс накопления трещин в естественных условиях является квазистационарным случайным процессом, при этом периоды стационарности описываются пуассоновским распределением. На стадии нестационарности происходит локальное повышение уровня действующих напряжений и лавинное нарастание числа трещин, причём интенсивность пуассоновского потока становится возрастающей функцией времени. Интенсивность случайного потока трещин предлагается определять с помощью скорректированного кинетического уравнения прочности С.Н. Журкова. Критическое число накопленных трещин, которое непосредственно предшествует катастрофрическому разрушению предлагается оценивать на основе концентрационного критерия Журкова С.Н. - Петрова В.А. Кинетический подход к описанию разрушения горных пород позволяет спрогнозировать дату крупномасштабного разрушения. Приводится пример прогноза горного удара из каталога горных ударов Таштагольского рудника на основе регистрации акустических предвестников горного удара. Таким образом, предлагаемая кинетическая модель подготовки горных ударов показывает свою работоспособность и может быть использована при описании кинетики подготовки горных ударов.

The kinetic concept of preparing rock impacts is considered and a kinetic model of crack accumulation is proposed. It is shown that the destruction of structural blocks of rocks of any hierarchical level is based on a random process of accumulation of damages (cracks) of a smaller size, and this process is influenced by many different mining and geological and mining and technical factors. The process of crack accumulation under natural conditions is a quasi-stationary random process, and the periods of stationarity are described by the Poisson distribution. At the non-stationary stage, there is a local increase in the level of active stresses and an avalanche increase in the number of cracks, and the intensity of the Poisson flow becomes an increasing function of time. The intensity of the random crack flow is proposed to be determined using the corrected kinetic strength equation of S. N. Zhurkov. The critical number of accumulated cracks that immediately precedes a catastrophic failure is proposed to be estimated based on the concentration criterion of Zhurkov S. N.-Petrov $V$. A. The kinetic approach to describing the destruction of rocks allows us to predict the date of large-scale destruction. The example of the forecast of the mining the impact of mining strikes catalogue of Tashtagol mine based on the acoustic precursors of rock burst. Thus, the proposed kinetic model of mountain shock preparation shows its efficiency and can be used in describing the kinetics of mountain shock preparation.

КЛючевЫе сЛОва: ГОРНЫЙ УДАР, ПОДГОТОВКА, ПРОГНОЗ, КИНЕТИЧЕСКАЯ ТЕОРИЯ, ТРЕЩИНЫ, НАКОПЛЕНИЕ

Key words: ROCK BUMP, PREPARATION, FORECAST, KINETIC THEORY, CRACKS, ACCUMULATION

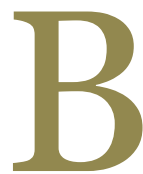

основе разрушения структурных блоков горных пород любого иерархического уровня лежит случайный процесс накопления повреждений меньшего разме- ра [1]. На этот процесс оказывает влияние множество различных горно-геологических и горно-технических фракторов. Процесс накопления трещин в естественных условиях является квазистацио- 
нарным случайным процессом, при этом периоды стационарности описываются пуассоновским распределением. На стадии нестационарности происходит локальное повышение уровня действующих напряжений и лавинное нарастание числа трещин, причём интенсивность пуассоновского потока становится возрастающей функцией времени.

Интенсивность случайного потока трещин оценивается с помощью скорректированного кинетического уравнения прочности С.Н. Журкова [1,2].

Разрушение блока заданных размеров происходит при выполнении концентрационного критерия разрушения [3].

На всех стадиях вследствие накопления трещин разрушение горных пород сопровождается акустической эмиссией (АЭ) и электромагнитным излучением (ЭМИ) в очень широком диапазоне частот. Электромагнитные и акустические предвестники используются для прогноза разрушения участков массива горных пород. Кинетический подход к описанию разрушения горных пород позволяет спрогнозировать дату крупномасштабного разрушения [4].

Прогноз удароопасности на основе кинетических представлений о подготовке горных ударов осуществляется следующим образом. Удароопасные участки массива выделяются на ранних стадиях по величине потенциала квазистационарного электрического поля, повышенному уровню электромагнитного излучения, аномально высоким значениям частоты счёта импульсов ЭМИ и т.п. Породы на удароопасных участках обладают обычно повышенной хрупкостью и другими специфическими свойствами.

На удароопасном участке массива выбирается пространственное окно с размерами, примерно на порядок превышающими размер готовящегося очага разрушения. Связь энергии прогнозируемого события (в джоулях) с размерами очага (в метрах) можно определить по эмпирической формуле К. Касахары [5] .

Поскольку отношение энергий двух соседних иерархических уровней разрушения составляет примерно четыре порядка, по выбранной энергии $W$ прогнозируемого события можно определить энергию предвестников и размер трещин, кинетику которых необходимо отслеживать в процессе мониторинга участка массива. Например, прогноз события с энергией $10^{5}$ Дж осуществляют по кинетической кривой накопления событий с энергией $10^{1}$ Дж, что соответствует размеру образующихся трещин $L_{0} \approx 0,9$ м.

Для удобства использования данных представлений в табл. 1 приведены иерархические уровни разрушения и соответствующая им выделяемая сейсмическая (сейсмоакустическая) энергия.

В работе [1] показано, что кинетический подход к разрушению горных пород позволяет оценить текущую дату горного удара по непосредственным наблюдениям за процессом трещинообразования в выбранном структурном блоке массива горных пород.

Проверка сфрормулированных принципов прогноза разрушения горных пород в реальных условиях была проведена на основе обработки наблюдений, зарегистрированных сейсмостанцией Таштагол.

На рис.1 приведены результаты ретроспективного прогноза горного удара с энергией $W=10^{7}$ Дж по предвестникам с энергией $W=10^{3}$ Дж.

Таким образом, приведённые данные свидетельствуют об удовлетворительной точности прогноза горных ударов по сейсмическим предвестникам и правильности предложенной

Таблица 1 Иерархия структур в массиве горных пород Table 1 Structure hierarchy in a rock massif

\begin{tabular}{|c|c|}
\hline $\begin{array}{c}\text { Размер трещины (линейный размер очага } \\
\text { разрушения или очага горного удара), L, M }\end{array}$ & $\begin{array}{c}\text { Сейсмическая энергия, выделяемая при разрушении } \\
\text { горных пород,W, Дж }\end{array}$ \\
\hline 0,04 & $10^{-3}$ \\
\hline 0,86 & 10 \\
\hline 1,82 & $10^{2}$ \\
\hline 3,89 & $10^{3}$ \\
\hline 8,31 & $10^{4}$ \\
\hline 18,6 & $10^{5}$ \\
\hline 39,8 & $10^{6}$ \\
\hline 85,3 & $10^{7}$ \\
\hline 183,6 & $10^{8}$ \\
\hline 397,8 & $10^{9}$ \\
\hline
\end{tabular}




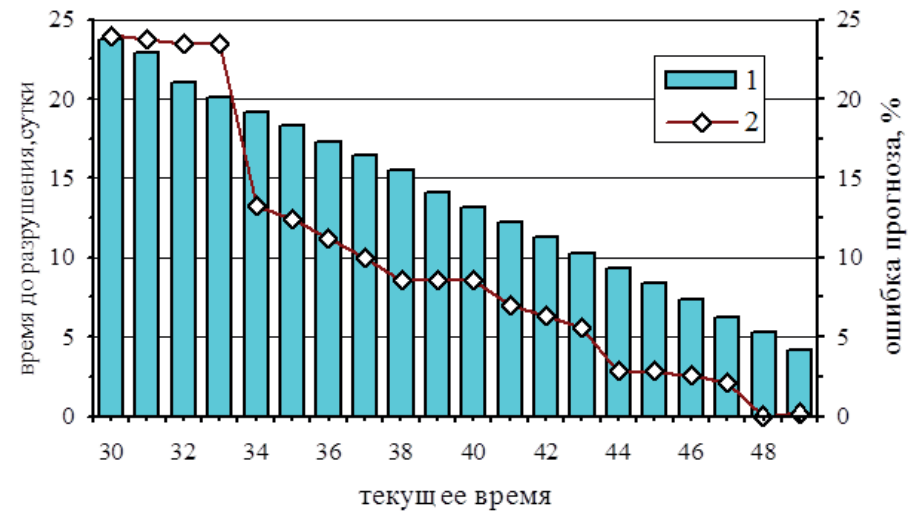

Рисунок 1. Прогноз горного удара $c$ энергией $W=3,5 \cdot 10^{7}$, Дж. (1-прогнозируемое время до горного удара, 2-ошибка прогноза)

Figure 1. Forecast of a rock bump with energy $W=3.5 \cdot 07$, J. (1-forecasted time before a rock bump, 2-forecast error)

кинетической модели подготовки горных ударов. По мере накопления информации прогноз становится всё более точным вследствие приближения теоретической кривой накопления событий к экспериментальной.

Решение задачи прогноза горных ударов требует точного определения координат предвестников в массиве. До середины девяностых годов прошлого века эту задачу на Таштагольском руднике решала система сейсмоакустического контроля, которая включала в себя стационарную сейсмостанцию на земной поверхности, датчики акустической эмиссии, размещаемые под землей в массиве горных пород рудника, а также проводную систему связи подземных павильонов с сейсмостанцией.

В настоящее время эта система не работает.

Таким образом, предлагаемая кинетическая модель подготовки горных ударов показывает свою работоспособность и может быть использована при описании кинетики подготовки горных ударов.

\section{СПИСОК ЛИТЕРАТУРЫ}

1. Иванов, В.В. Физические основы электромагнитных процессов при фрормировании очага разрушения в массиве горных пород.[Текст]: дис. докт. техн. наук: 05.15.11: защищена 02.07.94: утв. 15.09.94 / В. В. Иванов. - Кемерово, 1994. -366 с.

2. Журков, С.Н. Кинетическая концепция прочности твёрдых тел // Вестн. АН СССР.- 1968.- №3.- С. 3-17.

3. Концентрационный порог разрушения и прогноз горных ударов / А.Ю. Гор, В.С.Куксенко, Н.Г. Томилин, Д.И. Фролов // ФТПРПИ.- 1989.- №3.- С. 54-60.

4. Журков, С. Н. Физические основы прогнозирования механического разрушения [Текст] / С. Н. Журков, В. С. Куксенко, В. А. Петров // ДАН СССР 1981, т. 259, № 6, - с. 1350 - 1353.

5. Касахара К. Механика землетрясений.- М.:Мир,1985.- 264с.

\section{REFERENCES}

1. Ivanov, V.V. (1994). Fizicheskiye osnovy elektromagnitnykh protsessov pri formirovanii ochaga razrusheniya $v$ massive gornykh porod [The physical basis of electromagnetic processes in the formation of destruction center in a rock mass].Doctor's thesis. Kemerovo [in Russian].

2. Zhurkov, S.N. (1968). Kineticheskaya kontseptsiya prochnosti tvordykh tel [Kinetic concept of solids strength]. Vestnik AN SSSR - Bulletin of the USSR Academy of Sciences6 3, 3-17 [in Russian].

3. Gor, A.Yu., Kuksenko, V.S., Tomilin, N.G., \& Frolov, D.I. (1989). Kontsentratsionnyy porog razrusheniya i prognoz gornykh udarov [Destruction concentration threshold and rock bump forecast]. FTPRPI, 3, 54-60 [in Russian].

4. Zhurkov, S.N., Kuksenko, V.S. \& Petrov, V.A. (1981). Fizicheskiye osnovy prognozirovaniya mekhanicheskogo razrusheniya [Physical basis for mechanical destruction forecast]. DAN USSR, volume 259, 6, 1350-1353 [in Russian].

5. Kasakhara, K. (1985). Mekhanika zemletriasenii [Earthquake mechanics]. Moscow: Mir [in Russian]. 


\title{
ІІ. ПОЖАРНАЯ И ПРОМЫШЛЕННАЯ БЕЗОПАСНОСТЬ II. FIRE AND INDUSTRIAL SAFETY
}

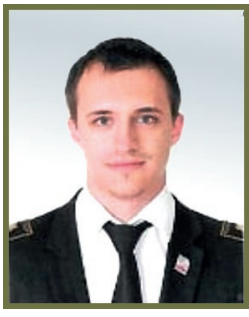

\author{
К. А. Кольвах// К. A. Kolvakh \\ kupijersey@yandex.ru \\ аспирант кафедры Безопасности \\ производств, ФГБОУ ВО "Санкт- \\ Петербургский горный университет”, \\ 199106, Санкт-Петербург, Васильевский \\ остров, 21 линия, д. 2. \\ post-graduate student of Department of \\ Industrial safety, \\ Saint-Petersburg Mining University \\ (199106, Saint-Petersburg, Vasilievsky \\ island, 21 line, h. 2
}

УДК 331.438

\section{ОБОСНОВАНИЕ КЛЮЧЕВОГО СТАТИСТИЧЕСКОГО ПОКАЗАТЕЛЯ ПРИМЕНИТЕЛЬНО К ОЦЕНКЕ ИНДИВИДУАЛЬНОГО РИСКА РАБОТНИКОВ УГОЛЬНЫХ ШАХТ ВСЛЕДСТВИЕ ОБРУШЕНИЯ ГОРНЫХ ПОРОД SUBSTANTIATION OF A KEY STATISTICAL INDICATOR FOR ASSESSING THE INDIVIDUAL RISK OF COAL MINE WORKERS DUE TO ROCK COLLAPSE}

Обрушения горных пород являются второй по распространенности причиной случаев смертельного травмирования работников угольных шахт. Несмотря на то что в данный момент наметилась тенденция к снижению числа случаев смертельного травмирования, обусловленных данным фактором, их количество все еще остается недопустимо высоким. Регламентируется оснащение горных выработок системами, которые обеспечивают безопасное ведение горных работ. Данные системы объединяются в рамках многоффункциональных систем безопасности (МФСБ). На предотвращение риска смертельного травмирования в результате обрушения горных работ направлена система геофизических наблюдений, являющаяся одной из составляющих МФСБ.

Вданной статьепроведенанализслучаев смертельного травмирования, обусловленныхобрушениями горных пород, приведены статистические данные за двенадиать лет. Рассматривается возможность применения системы геофризических наблюдений «Микон-ГЕО» в целях оценки вероятности обрушения горных пород и, как следствие, для оценки величины индивидуального риска смертельного травмирования работников угольных шахт. В качестве ключевого статистического показателя предлагается использовать интегрированный критерий, определяемый при помощи системы данного типа. На его основе разработана математическая модель, позволяющая определить вероятность обрушений. Далее полученный результат используется для определения величины индивидуального риска.

Rock collapses are the second most common cause of fatal injuries to coal mine workers. Despite the fact that there is currently a downward trend in the number of fatal injuries caused by this factor, their number is still unacceptably high. It regulates the equipment of mine workings with systems that ensure safe mining operations. These systems are combined in the framework of multifunctional security systems (IFSS). The system of geophysical observations, which is one of the components of the IFSB, is aimed at preventing the risk of fatal injury as a result of mining collapses.

This article analyzes cases of fatal injuries caused by rock collapses and provides statistics for twelve years. The article considers the possibility of using the system of geophysical observations "Mikon-GEO" in order to assess the probability of rock collapse and, as a result, to assess the magnitude of the individual risk of fatal injury to coal mine workers. As a key statistical indicator, it is proposed to use an integrated criterion determined using this type of system. Based on it, a mathematical model has been developed to determine the probability of collapses. Further, the result obtained is used to determine the amount of individual risk. 
КЛючевЫе СЛОВа: ОБРУШЕНИЯ ГОРНЫХ ПОРОД, ИНДИВИДУАЛЬНЫЙ РИСК, УГОЛЬНЫЕ ШАХТЫ, СИСТЕМА ГЕОФИЗИЧЕСКИХ НАБЛЮДЕНИЙ, ОЦЕНКА РИСКА, КЛЮЧЕВОЙ СТАТИСТИЧЕСКИЙ ПОКАЗАТЕЛЬ.

KEYWORDS: ROCK COLLAPSES, INDIVIDUAL RISK, COAL MINES, A SYSTEM OF GEOPHYSICAL OBSERVATIONS, RISK ASSESSMENT, A KEY STATISTICAL INDICATOR.

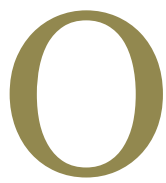

брушения горных пород являются причиной более $17 \%$ случаев смертельного травмирования работников угольных шахт от всех травмирующих факторов, являясь второй по распространенности причиной смертельных несчастных случаев. За период с 2006 по 2018 гг. на угольных шахтах было выявлено 106 смертельных несчастных случаев, обусловленных данным фрактором [1].

Около 65\% смертельных несчастных случаев вследствие обрушения горных пород на угольных шахтах приходятся на очистные забои, а порядка $35 \%$ случаев смертельного травмирования происходят в забоях вспомогательных горных выработок. 30\% смертельных несчастных случаев, приходящихся на очистные забои, происходят на концевых участках. При этом на травматизм в значительной степени влияют горно-геологические условия [2,3].

Согласно методике, описанной в Приказе Ростехнадзора №339, вероятность наступления опасного события, обусловленного геодинамическими причинами, в том числе и обрушения горных пород, определяется по выходу буровой мелочи (л/м) [4]. Среди всех систем геофизических наблюдений, входящих в МФСБ, осуществлять перевод получаемых величин в нормативные, возможно только при помощи системы «Микон-ГЕО».

Данная система производит измерение градиента горного давления и величины сейсмической энергии. На основе существующей статистической взаимосвязи данные величины переводятся в интегрированный критерий, с установленной размерностью л/м [5].

Система, проводящая регистрацию сейсмических волн, включает произвольное размещение трехкомпонентных (3C) геофонов в забое и стенках горной выработки. Положение источника в таком случае подразумевает произвольное расположение. Система оперативной обработки результатов позволяет получить величину интегрированного критерия, включающего величину градиента горного давления и величину сейсмической энергии, выраженного в литрах выхода буровой мелочи [6].

Необходимо отметить, что данная система ни в чем не уступает зарубежным аналогам, а принцип интегрирования независимых сейсми- ческих параметров выгодно отличается от них. Получаемое значение величины интегрированного критерия, выраженное в литрах выхода буровой мелочи, подлежит сравнению с пороговым значением, определяемым по номограммам $[7,8]$.

Методика исследования. Математическая модель, включающая значения величин интегрированного критерия и позволюящая определить вероятность обрушения горных пород, построена на основе критерия максимального правдоподобия. Данный критерий достаточно прост в вычислениях и позволяет оценивать достоверность решений $[9,10]$.

Математическая модель оценки риска обрушения горных пород на основе критерия максимального правдоподобия имеет вид (Ур. 1):

$$
R=\left\{\begin{array}{c}
R_{\text {доп }}, \text { если } L(P) \geq 1 \\
R_{\text {недоп }}, \text { если } L(P)<1
\end{array}\right.
$$

где $R_{\text {доп }}$ - допустимый риск, $R_{\text {недоп }}-$ недопустимый риск, $L(P)$ - отношение правдоподобия значений интегрированного критерия выше и ниже порогового [11].

Коэффициент правдоподобия значений интегрированного критерия $\left(L_{i}\right)$ вычисляется по следующей формуле (Ур. 2):

$$
L_{i}=\frac{N_{\text {доп }} / N_{\text {общ }}}{N_{\text {недоп }} / N_{\text {общ }}}
$$

где $N_{\text {доп }}$ - число величин интегрированного критерия ниже порогового значения за интервал измерений, получаемых от МФСБ; $N_{\text {недоп }}-$ число величин интегрированного критерия выше порогового значения за интервал измерений, получаемых от МФСБ; $N_{\text {общ }}$ - общее число значений за интервал измерений, полученных от МФСБ. 3):

Плотность распределения для $R_{\text {недоп }}$ (Ур.

$$
f_{i}^{\text {недоп }}=\frac{q_{i}}{\sum q_{i}}
$$

где $q_{i}$ - количество превышений пороговой величины интегрированного критерия за интервал измерений, полученных от МФСБ; $\sum q_{i}-$ количество значений величин интегрированного критерия за интервал усреднения, полученных от МФСБ.

Аналогично для $R_{\text {доп }}$ (Ур. 4):

$$
f_{i}^{\text {доп }}=\frac{z_{i}}{\sum z_{i}}
$$

где $z$ - количество значений интегрированного критерия, не превышающих пороговое за интер- 
вал измерения, полученных от МФСБ; $\sum z_{i}-$ количество значений величин интегрированного критерия за интервал усреднения, полученных от МФСБ.

Вероятность принятия решения $R=R_{\text {недоп' }}$

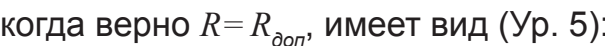

$$
\beta=\int_{0}^{1} f\left(L \mid R_{\text {доп }}\right) d L=\sum_{i=1}^{n} f_{i}^{\text {доп. } L_{i}}
$$

Соответственно, вероятность обрушения горных пород будет вычисляться по следующей формуле (Ур. 6):

$$
R_{\text {недоп }}=1-\beta
$$

Оценка величины индивидуального риска смертельного травмирования работников угольных шахт определяется с учетом вероятности обрушения горных пород. Данная оценка производится на основе теоремы Байеса:

$$
R_{\text {инд }}=\frac{A R_{\text {недоп }}}{B}
$$

где $A$ - доля работников, получивших смертельную травму, в результате обрушения горных пород (от общего числа работников, находившихся на участке ведения работ);

$R_{\text {недоп }}$ - вероятность обрушения горных пород;

$B$ - доля случаев смертельного травмирования работников на угольных шахтах, обусловленная обрушениями горных пород;

$R_{\text {инд }}$ - вероятность того, что работник получит смертельную травму в случае обрушения горных пород.

Доля работников, получивших смертельную травму в результате обрушения вычисляют как отношение случаев смертельного травмирования к общему числу работников, занятых на участках ведения горных работ [12].

Доля случаев смертельного травмирования работников на угольных шахтах, обуслов- ленная именно обрушениями, вычисляется как отношение числа случаев смертельного травмирования в результате обрушения горных пород к общему числу смертельных несчастных случаев на угольных шахтах [13].

Подробнее данная методика описана в [14].

При определении уровня риска смертельного травмирования целесообразнее проводить сравнение получаемого по результатам вычислений значения с величиной 2,5·10-4. Данная величина представляет собой среднюю величину индивидуального риска в профессиональной сорере деятельности [15].

Заключение. Общая тенденция к снижению числа смертельных несчастных случаев в результате обрушения горных пород нарушается крупными инцидентами, в результате которых гибнут работники угольных шахт. Это свидетельствует о том, что существует необходимость более эффрективного мониторинга состояния массива горных пород. Как указывалось выше, система типа «Микон-ГЕО» является наиболее актуальной применительно к оценке индивидуального риска вследствие соответствия получаемых значений нормативным единицам измерения.

Актуальность математической модели состоит в том, что в ней используются получаемые от МФСБ данные, а также используется статистическая информация за значительный временной отрезок. Необходимой задачей является проведение апробации данной модели в реальных производственных условиях, а также установление зависимости между ключевым статистическим показателем и величиной риска.

\section{СПИСОК ЛИТЕРАТУРЫ}

1. Доклад Ростехнадзора "Состояние промышленной безопасности на опасных производственных объектах угольной промышленности" [Электронный ресурc] // URL: https://www.nadzor-info.ru/media/blog/51260/ (дата обращения 07.03.2019)

2. Статистический сборник ТЭК России - 2016: Выпуск июнь 2017 [Электронный ресурс] / Аналитический центр при Правительстве Российской Федерации. - URL: http://ac.gov.ru/files/publication/a/13691.pdf

3. Твердов, А.А. Тенденции повышения безопасности на угольных шахтах с особо опасными горно-геологическими условиями / А.А. Твердов, С.Б. Никишичев, А.Б. Яновский, А.И. Скрыль // Уголь. - 2017. - № 3. - 4-9.

4. Приказ Ростехнадзора от 15.08.2016 №339 «Об утверждении Федеральных норм и правил в области промышленной безопасности «Инструкция по прогнозу динамических явлений и мониторингу массива горных пород при отработке угольных месторождений» (Зарегистрировано в Минюсте России 07.11.2016 №44251».

5. Рудаков М.Л., Кольвах К.А. О возможности использования критерия максимального правдоподобия в целях оценки профрессионального риска, обусловленного обрушениями горных пород при подземной добыче угля // Безопасность жизнедеятельности. - 2019. - № 8. - С. 10-13.

6. Лапин, Э. С. «Микон-ГЕО» - система оперативного обнаружения и контроля состояния зон развития опасных геогазодинамических явлений при разработке месторождений полезных ископаемых подземным способом /Э. С. Лапин, В. Б. Писецкий, А. Г. Бабенко, Ю. В. Патрушев // Безопасность труда в промышленности. 2012 №4 $18-22.5 \mathrm{C}$.

7. Бабенко, А.Г. Теоретическое обоснование и методология повышения уровня охраны труда в угольных шахтах но основе риск-ориентированного подхода и многофункциональных систем безопасности: Дис. ... докт. техн. наук: 05.26.01 / Бабенко Александр Григорьевич. - СПб., 2018. - 259 с.

8. Пугачев, Е. В. Особенности эксплуатации многофункциональных систем безопасности на угольных предприятиях Кузбасса / Е. В. Пугачев, В.В.Бих, А. А. Журавлев // Наукоемкие технологии и разработки использования минеральных ресурсов:- 201- 203 с.

9. Мясников, С.В. Метод комплексной оценки и прогноза профессионального риска травмирования персонала 
угольных шахт при взрывах метана и пыли / С.В. Мясников, Г.И. Коршунов, Е.И. Кабанов // Безопасность труда в промышленности. - 2018. - № 5. - С. 60-65.

10. Попов, А.Н. Риск-ориентированный подход в промышленной безопасности / А.Н. Попов, Н.С. Ивашова, А.А. Деулин и др. // Промышленная и экологическая безопасность, охрана труда. - 2015. - № 2 (99). - С. 20-22.

11. Гражданкин, А.И. Анализ опасностей и оценка риска крупных аварий в нефтегазовой и угольной промышленности: Дис. ... докт. техн. наук: 05.26.03 / Гражданкин Александр Иванович. - М., 2016. - 340 с.

12. Кабанов Е.И. Разработка методики оценки рисков аварий на угольных шахтах с учетом конкретных горно-геологических условий / Г.И. Коршунов, О.И. Казанин, М.Л. Рудаков, А.О. Недосекин, Е.И. Кабанов // Горный информационно-аналитический бюллетень. - 2017. - № 4. - С. 374-383.

13. Ежегодные отчеты о деятельности Федеральной службы по экологическому, технологическому и атомному надзору [Электронный ресурс] / Федеральная служба по экологическому, технологическому и атомному надзору. - URL: http://www.gosnadzor.ru/public/annual reports/.

14. Кольвах К.А. Применение теоремы Байеса для оценки величины индивидуального риска, обусловленного обрушениями горных пород, на угольных шахтах. // Вестник научного центра по безопасности работ в угольной промышленности, 2020, №1. - С. 77-80.

15. Кабанов, Е.И. Использование модели нечеткого вывода при организации менеджмента профессиональных рисков на угольных шахтах / Е.И. Кабанов // Вестник современных исследований. - 2018. - № 6-1(21). - С. 400-402.

\section{REFERENCES}

1. Doklad Rostekhnadzora "Sostoyaniye promyshlennoy bezopasnosti na opasnykh proizvodstvennykh ob"yektakh ugol'noy promyshlennosti" [Report of Rostekhnadzor "Industrial safety condition at hazardous production facilities of the coal industry"]. Retrieved from: https://www.nadzor-info.ru/media/blog/51260/ [in Russian]

2. Statisticheskiy sbornik TEK Rossii - 2016: Vypusk iyun' 2017. Analiticheskiy tsentr pri Pravitel'stve Rossiyskoy Federatsii. [Statistical Digest of the Fuel and Energy Complex of Russia - 2016: Issue June 2017. Analytical Center under the Government of the Russian Federation]. Retrieved from: http://ac.gov.ru/files/publication/a/13691.pdf [in Russian].

3. Tverdov, A.A., Nikishichev, S.B., Yanovsky, A.B. \& Skrul, A.I. (2017). Tendentsii povysheniya bezopasnosti na ugol'nykh shakhtakh s osobo opasnymi gorno-geologicheskimi usloviyami [Safety trends in coal mines with particularly hazardous mining and geological conditions]. Ugol - Coal, 3, 4-9 [in Russian].

4. Prikaz Rostekhnadzora ot 15.08.2016 №339 «Ob utverzhdenii Federal'nykh norm i pravil v oblasti promyshlennoy bezopasnosti «Instruktsiya po prognozu dinamicheskikh yavleniy i monitoringu massiva gornykh porod pri otrabotke ugol'nykh mestorozhdeniy» (Zaregistrirovano v Minyuste Rossii 07.11.2016 №44251) [4. Order of Rostekhnadzor of August 15, 2016 No. 339 "On approval of Federal norms and rules in the field of industrial safety" Instruction for predicting dynamic phenomena and monitoring the rock massif during mining of coal deposits "(Registered in the Ministry of Justice of Russia on November 7, 2016 No. 44251). [in Russian].

5. Rudakov, M.L., \& Kolvakh, K.A. (2019). O vozmozhnosti ispol'zovaniya kriteriya maksimal'nogo pravdopodobiya v tselyakh otsenki professional'nogo riska, obuslovlennogo obrusheniyami gornykh porod pri podzemnoy dobyche uglya [On the possibility of using the maximum likelihood criterion in order to assess occupational risk due to rock collapse during underground coal mining]. Bezopasnost' zhiznedeyatel'nosti.- Life Safety, 8, 10-13 [in Russian].

6. Lapin, E.S., Pisetsky, V.B., Babenko, A.G., \& Patrushev, Yu.V. (2012). «Mikon-GEO» - sistema operativnogo obnaruzheniya i kontrolya sostoyaniya zon razvitiya opasnykh geogazodinamicheskikh yavleniy pri razrabotke mestorozhdeniy poleznykh iskopayemykh podzemnym sposobom ["Mikon-GEO" - a system for the operational detection and monitoring of dangerous geogasdynamic phenomena development zones at underground mineral deposits' development]. Bezopasnost truda v promyshlennosti - Industrial Labor Safety, 4, 18-22 [in Russian].

7. Babenko, A.G. (2018). Teoreticheskoye obosnovaniye i metodologiya povysheniya urovnya okhrany truda $v$ ugol'nykh shakhtakh no osnove risk-oriyentirovannogo podkhoda i mnogofunktsional'nykh sistem bezopasnosti [Theoretical background and methodology for increasing labor protection in coal mines based on a risk-based approach and multifunctional safety systems]. Doctor's thesis. St Petersburg [in Russian].

8. Pugachev, Ye.V., Bikh, V.V., \& Zhuravlev, A.A. ( ). Osobennosti ekspluatatsii mnogofunktsional'nykh sistem bezopasnosti na ugol'nykh predpriyatiyakh Kuzbassa [Multifunctional security systems' operation features at the coal enterprises of Kuzbass]. Naukoyemkiye tekhnologii i razrabotki ispol'zovaniya mineral'nykh resursov - High technology and mineral resources use development - 201-203 [in Russian].

9. Miasnikov, S.V., Korshunov, G.I., \& Kabanov, Ye.I. (2018). Metod kompleksnoy otsenki i prognoza professional'nogo riska travmirovaniya personala ugol'nykh shakht pri vzryvakh metana i pyli [A method for the comprehensive assessment and forecast of injury occupational risk to coal mine personnel in methane and dust explosions]. Bezopasnost truda v promyshlennosti - Industrial Labor Safety, 5, 60-65 [in Russian].

10. Popov, A.N., Ivasheva, N.S., Deulin, A.A. et al. (2015). Risk-oriyentirovannyy podkhod v promyshlennoy bezopasnosti [Risk-oriented approach in industrial safety]. Promyshlennaya i ekologicheskaya bezopasnost', okhrana truda - Industrial and environmental safety, labor protection, 2(99), 20-22 [in Russian].

11. Grazhdankin, A.I. (2016). Analiz opasnostey i otsenka riska krupnykh avariy v neftegazovoy i ugol'noy promyshlennosti [Hazard analysis and risk assessment of major accidents in the oil and gas and coal industries]. Doctor's thesis. Moscow [in Russian].

12. Kabanov, Ye.I., Korshunov, G.I., Kazanin, O.I., Rudakov, M.L., \& Nedosekin, A.O. (2017). Razrabotka metodiki otsenki riskov avariy na ugol'nykh shakhtakh s uchetom konkretnykh gorno-geologicheskikh usloviy [Development of a methodology for assessing the risks of accidents in coal mines, taking into account specific mining and geological conditions]. Gorny informatsionno-analiticheskii biulleten - Mining Informational Analytical Bulletin, 4, $374-383$ [in Russian].

13. Yezhegodnyye otchety o deyatel'nosti Federal'noy sluzhby po ekologicheskomu, tekhnologicheskomu i atomnomu nadzoru [Elektronnyy resurs] / Federal'naya sluzhba po ekologicheskomu, tekhnologicheskomu i atomnomu nadzoru [Annual reports on the activities of the Federal Service for Ecological, Technological and Nuclear Supervision. Federal Service for Ecological, Technological and Nuclear Supervision. Retrieved from: http://www.gosnadzor.ru/public/annual_reports/ [in Russian].

14. Kolvākh, K.A. (2020). Primeneniye teoremy Bayyesa dlya otsenki velichiny individual'nogo riska, obuslovlennogo obrusheniyami gornykh porod, na ugol'nykh shakhtakh [Application of Bayes theorem for estimating the value of individual risk caused by rock collapse in coal mines]. Vestnik nauchnogo tsentra po bezopasnosti rabot $v$ ugolnoi promyshlennosti - Herald of Safety in Mining Industry Scientific Center, 1, 77-80 [in Russian].

15. Kabanov, Ye.I. (2018). Ispol'zovaniye modeli nechetkogo vyvoda pri organizatsii menedzhmenta professional'nykh riskov na ugol'nykh shakhtakh [Using the fuzzy inference model for organizing occupational risk management in coal mines]. Vestnik Sovremennykh Issledovanii - Herald of Modern Researches, 6-1(21), 400-402 [in Russian]. 


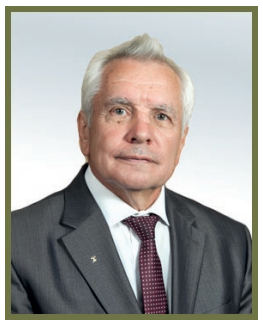

А. И. Фомин // A. I. Fomin ncvostnii@yandex.ru

д-р техн. наук, ведущий научный сотрудник отдела АО "НЦ ВостНИИ", Россия, 650002 , г. Кемерово, ул. Институтская, 3 doctor of technical sciences, department leading scientific researcher, JSC «ScC VostNII», 3, Institutskaya Str., Kemerovo, 650002, Russia

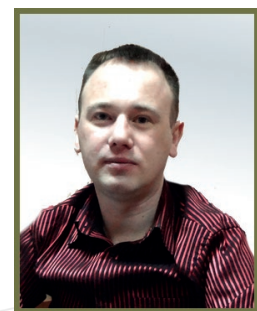

Д.А. Бесперстов//

D.A. Besperstov gpnbesperstov@yandex.ru

кандидат техн. наук, доцент кафедры «Безопасность жизнедеятельности», ФГБОУ ВПО «КемГУ», г. Кемерово. Россия, 650056 г. Кемерово, Бульвар Строителей, д. 47.

candidate of technical sciences, associate professor of "Life Safety" chair, FGBOU VPO "KemGU", Kemerovo. Russia, 650056 Kemerovo, Stroitelei Boulevard, d. 47.

УДК 622.82;85;87;614.849

\section{PROBLEMS AND WAYS OF THEIR SOLUTION ARISING WHEN OP- ERATING AND MAINTAINING COAL ENTERPRISES AND SLUDGE PITS}

В статье приведены проблемы, возникающие при проектировании, строительстве, эксплуатации и консервации уәледобывающих и углеперерабатывающих предприятий. Изложена проблема $c$ учетом их эксплуатации не один десяток лет и соответствующих законодательных изменений, являющихся неотъемлемой частью при длительном периоде времени. Обоснована необходимость снятия избыточных административных барьеров для добросовестных собственников. При разработке угольных месторождений приведена необходимость выработки адресных мер по обеспечению безопасности населения, в том числе экологической, в районах размещения угольных предприятий. Для разработки мер по безопасности на угольных предприятиях требуется прогнозирование рисков возникновения негативных ситуаций природного и техногенного характера. Необходимо, также, учитывать сложность технологических процессов, которые обеспечены системами безопасности. При фоормировании данных систем собственник объекта руководствуется социально - экономическим обоснованием, рентабельностью своего производства. С учетом того, что недра в Российской Федерации принадлежат государству, по завершению проведения горных работ вверенную территорию необходимо привести в безопасное состояние. The article describes the problems encountered in the design, construction, operation and conservation of coal mining and coal processing enterprises. The problem is described taking into account their operation for more than a dozen years and the corresponding legislative changes, which are an integral part for a long period of time. The necessity of removing excessive administrative barriers for bona fide owners is substantiated. When developing coal deposits, the necessity of developing targeted measures to ensure the population safety, environmental including, in the areas where coal enterprises are located, is given. To develop safety measures at coal mines, forecasting negative situation occurrence risks of natural and anthropogenic origin is required. It is also necessary to take into account the complexity of the technological processes that are provided by safety systems. In the formation of these systems, the owner of the object is guided by socioeconomic substantiation, the profitability of its production. As the subsoil in the Russian Federation belongs to the state, upon completion of mining operations, the entrusted territory must be brought into a safe state.

КлючевЫе слова: УГОЛЬНЫЕ ПРЕДПРИЯТИЯ, ШЛАМООТСТОЙНИКИ, СОЦИАЛЬНАЯ И ЭКОЛОГИЧЕСКАЯ БЕЗОПАСНОСТЬ, НЕДРА, АДМИНИСТРАТИВНЫЕ И НОРМАТИВНЫЕ БАРЬЕРЫ, РАЗВИТИЕ ПРЕДПРИНИМАТЕЛЬСТВА, ГОСУДАРСТВЕННОЕ РЕГУЛИРОВАНИЕ, ПРОМЫШЛЕННАЯ БЕЗОПАСНОСТЬ.

Key words: COAL ENTERPRISES, SLUDGE PITS, SOCIAL AND ENVIRONMENTAL SAFETY, SUBSOIL, ADMINISTRATIVE AND NORMATIVE BARRIERS, ENTREPRENEURSHIP DEVELOPMENT, STATE REGULATION, INDUSTRIAL SAFETY. 
$\mathrm{B}$ настоящее время человечество пытается перейти на возобновляемые виды энергии, рентабельность которой остается достаточно низкой, чтобы заменить такие виды топлива как лес, газ, нефть, уголь. Несмотря на значительный экологический ущерб от исчерпаемых видов топлива, вопрос открыт и по социальным потерям при их добыче.

Особое внимание хотелось бы уделить угольным предприятиям. Значительную угрозу представляют предприятия угольной промышленности, ведущие добычу угля открытым способом и обогатительные фабрики. Их деятельность сопровождается миллионами квадратных километров задействованной поверхности, то есть тех земельных участков, на которых впоследствии не представляется возможным проведение сельскохозяйственных работ, строительство зданий и сооружений различного типа, в том числе и жилья. Обогатительные фабрики в процессе улучшения качества угля выбрасывают в атмоссреру и на поверхность значительное количество шлама, представляющего опасность как для человека, так и для окружающей среды.

Социальный же ущерб в основном возникает при подземной добыче угля, когда из-за износа оборудования, неверных геологических расчетов или элементарной халатности, некомпетентных действий работников происходят трагические ситуации, связанные с гибелью шахтеров [1, 2].

В рамках рассматриваемой проблемы к более актуальным негативным последствиям можно отнести ненадлежащее содержание и консервацию шламоотстойников. Данная проблема усугубляется тем, что она может возникнуть через несколько десятков лет, после прекращения работы предприятия, в результате подземного самовозгорания угольных отходов. Столь значительный промежуток времени касается изменений социально-экономической и политической ситуации в стране. Так угольные предприятия, существующие и прекратившие свою деятельность при СССР несут потенциальную опасность в виде горения шламоотстойников и в настоящее время. Для решения данной проблемы необходимо разобрать адресный порядок проектирования, эксплуатации и консервации шламоотстойников и сооружений хвостового хозяйства.

Порядок создания, эксплуатации и консервации шламоотстойников

Шламоотстойники в процессе своего существования, как и все объекты угольных предприятий, переживают ряд жизненных циклов, таких как проектирование, строительство, эксплуатация, консервация. От каждого предыдущего этапа зависит последующий. Так, при нарушении норм проектирование невозможно надлежащее качественное строительство, а от несоответствующего строительства, эксплуатация будет затруднительна.

С учетом данного рассмотрим более подробно порядок создания, эксплуатации и закрытия мест хранения отходов обогащения угля [3]. На всех этапах, работы осуществляются организациями, имеющими соответствующие лицензии.

Требования ужесточаются тем, что шламоотстойники угольной промышленности представляют собой гидротехнические сооружения, которые находятся на контроле у органов надзора за исполнением требований в области промышленной безопасности $[4,5]$.

При проектировании шламоотстойников особое внимание необходимо уделять площадкам их для размещения. Они должны не только непосредственно не ухудшать населению условия проживания в местах размещения сооружений, но и обеспечивать экологическую безопасность. Необходимо учитывать проезды, системы оповещения людей, которые могут попасть в волну гидротехнического сооружения при его прорыве [6], чистоту воздуха, для недопущения размножения насекомых и развития запахов.

Как правило, рассматриваемые хозяйства проектируются с учетом современных научно обоснованных технологий. Данное необходимо для надлежащей реализации проекта с учетом последующей эксплуатации сооружения не один десяток лет. На проектирование, строительство и эксплуатацию данных хозяйств необходимо соответствующее разрешение (лицензия). Все этапы сопровождаются под контролем Федеральной службы по экологическому, технологическому и атомному надзору.

\section{Классификация шламоотстойников}

Шламоотстойники или шламохранилища классифицируются в зависимости от характера их создания. Классификация приведена на схеme 1.

Вышеприведенное разнообразие шламохранилищ свидетельствует о необходимости индивидуального подхода к их проектированию, эксплуатации и консервации. Так как все они открытого типа требуется соблюдение на них требований пожарной и экологической безопасности с учетом розы ветров, нахождения жилого фонда и запасов питьевой воды, перспективы застройки населенных пунктов, гидрологических 


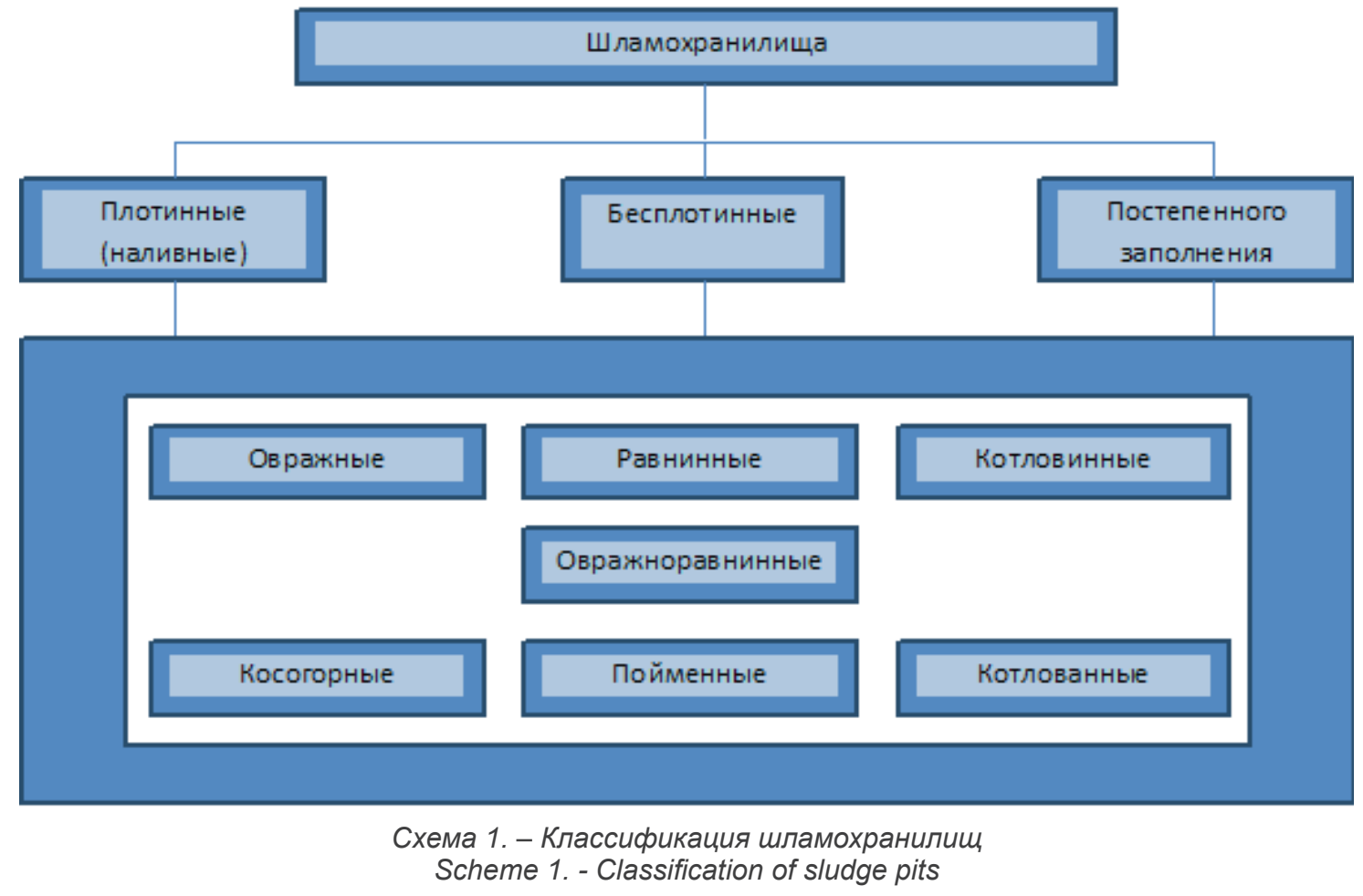

и климатических особенностей местности.

Передача государством земли для угледобычи и углепереработки

В соответствии с Федеральным законодательством Российской Федерации недра, в том числе подземные и ископаемые принадлежат государству [7]. Государство предоставляет возможность организациям пользоваться участками для добычи полезных ископаемых. В свою очередь на данный вид деятельности у организации должна быть соответствующая лицензия. Для получения участка (горного отвода) необходимо проведение государственной экспертизы, положительное заключение которой позволяет сделать выводы о возможности использования недр.

При необходимости охраны окружающей среды использование недр может быть ограничено.

Как правило, пользователями недр являются предприниматели, зарегистрированные в установленном порядке государством [8].

Участки для разработок месторождений полезных ископаемых (угля) предоставляются на значительное количество лет. Так только на геологические изучения отведено до 5 лет. Законодательством предусмотрено и продление сроков пользования недрами.

В свою очередь, государственные и муниципальные земельные участки предоставляются для добычи и переработки угля в порядке установленном законодательством РФ [9].
Законодательство устанавливает достаточно «жесткие» требования по передаче государственных земель предприятиям (компаниям) по добыче и переработке угля. С одной стороны, данное позволит убрать с рынка недобросовестных предпринимателей, заинтересованных исключительно в собственной прибыли, независимо от возможных негативных рисков социального и экологического характера. С другой стороны, данный бюрократический порядок препятствует на пути развития добросовестного предпринимательства, заинтересованного не только в своей прибыли, но и дающего рабочие места для населения, отчисляющего необходимые налоги, выполняющего весь комплекс мер по обеспечению безопасности, как персонала, так и окружающей среды.

Передача угольным предприятием земельного участка государству после завершения работ

Не менее важный этап жизненного цикла угледобывающего и углеперерабатывающего предприятия это, его ликвидация и консервация с последующей передачи земель государству [7].

При ненадлежащем выполнении комплекса работ собственник объекта несет ответственность в соответствии с законодательством Российской Федерации [10, 11]. Однако, имеют место недобросовестные организации, которые, в целях экономии денежных средств, необходимых для прекращения работ по недропользованию, проводят ряд мероприятий по банкротству 
и не приводят в надлежащее состояние вверенные участки недропользования.

Данное крайне отрицательно складывается на экологическом состоянии заброшенных объектов, ведь незаконсервированные угольные предприятия из-за неконтролируемых процессов самовозгорания несут потенциальную угрозу близ проживающему населению и экологии региона [12].

Проблемы, возникающие на жизненном цикле угольного предприятия

Как мы видим, на каждом жизненном цикле угольного предприятия, в том числе эксплуатирующего шламоотстойники имеются соответствующие проблемы.

Проблемы предоставляют собой зачастую, излишние административные барьеры, стоящие перед предпринимателями. Органам государственного надзора, контролирующих надлежащее проведение работ по угледобыче и углепереработке, не представляется возможным определить недобросовестных собственников, выполняющих исчерпывающие требования по обеспечению безопасности производства и окружающей среды.

Также, проблемы сопровождаются сложностью технологических процессов, характерных для угольного предприятия, а также значительными фринансовыми затратами на реализацию функционирования.

\section{Предложения по реализации дополни-}

тельных мероприятий, в части решения нормативно - правовых проблем

Для решения данных проблем необходимо не усиливать влияние государства на процесс добычи и переработки угольных предприятий. Требуется отслеживать историю угольной компании (предприятия), не создана ли она на краткосрочное время, возможно ли покрыть уставным капиталом или страховкой предположительных убытков предприятия. Объектом и государством должны быть спрогнозированы все риски, возникновение которых возможно при открытии, эксплуатации и консервации угольных предприятий.

\section{Заключение}

В заключении хотелось бы отметить, что при решении проблем, возникающих при эксплуатации и консервации угольных предприятий, в том числе шламоотстойников, необходима разработка и реализация адресных мероприятий, направленных на снижение экологических, социальных и материальных потерь, возникновение которых возможно в результате негативной обстановки (аварии, взрыва, загорания или пожара, экологической катастрофы, чрезвычайной ситуации).

Вместе с тем мероприятия не должны содержать излишних нормативных и административных барьеров, так как данное отрицательно может повлиять на угольную отрасль Российской Федерации.

\section{СПИСОК ЛИТЕРАТУРЫ}

1. Авария на шахте «Распадская» 8-9 мая 2010 года [Электронный ресурc]: URL: https://miningwiki.ru/wiki

2. С метаном наедине. Крупнейшие аварии на угольных шахтах России [Электронный ресурc]: URL: https://lenta. ru/articles/2016/03/01/mining/

3. Уголь. Обогащение. Термины и определения [Электронный ресурс]: ГОСТ 17321-2015 URL: http://docs.cntd.ru/ document/1200132463 (дата обращения: 09.01.2020).

4. О промышленной безопасности опасных производственных объектов [Электронный ресурс]: Федеральный закон от 21.07.1997 № 116-Ф3 (ред. от 29.07.2018). URL: http://www.consultant.ru/document/cons_doc_LAW_15234/ (дата обращения: 09.01.2020).

5. О безопасности гидротехнических сооружений [Электронный ресурс]: Федеральный закон от 21.07.1997 № 117-Ф3 (ред. от 29.07.2018). URL: http://www.consultant.ru/document/cons_doc_LAW_15265/ (дата обращения: 09.01.2020).

6. О создании локальных систем оповещения в районах размещения потенциально опасных объектов [Электронный ресурс]: Постановление Правительства РФ от 01.03.1993 № 178 URL: http://www.consultant.ru/document/ cons_doc_LAW_86328/ (дата обращения: 09.01.2020).

7. О недрах [Электронный ресурс]: Федеральный закон от 21.02.1992 № 2395-1 (ред. от 27.12.2019). URL: http:// www.consultant.ru/document/cons_doc_LAW_343/ (дата обращения: 09.01.2020).

8. О развитии малого и среднего предпринимательства в Российской Федерации [Электронный ресурс]: Федеральный закон от 24.07.2007 № 209-Ф3 (ред. от 27.12.2019). URL: http://www.consultant.ru/document/cons_doc_ LAW 52144/ (дата обращения: 09.01.2020).

9. Земельный кодекс Российской Федерации [Электронный ресурс]: Федеральный закон от 25.10.2001 № 136 Ф3 (ред. от 27.12.2019). URL: http://www.consultant.ru/document/cons_doc_LAW_33773/ (дата обращения: 09.01.2020).

10. Кодекс Российской Федерации об административных правонарушениях [Электронный ресурс]: Федеральный закон от 30.12.2001 № 195-Ф3 (ред. от 27.12.2019). URL: http://www.consultant.ru/document/cons_doc_ LAW_34661/ (дата обращения: 09.01.2020).

11. Уголовный кодекс Российской Федерации [Электронный ресурс]: Федеральный закон от 13.06.1996 № 63Ф3 (ред. от 27.12.2019). URL: http://www.consultant.ru/document/cons_doc_LAW_10699/ (дата обращения: 09.01.2020). 
12. В Кузбассе двое детей упали в горящую яму со шлаком, один мальчик погиб [Электронный pecypc]: URL: https:// www.city-n.ru/view/396001.html

\section{REFERENCES}

1. Avaria na shakhte «Raspadskaya» 8-9 maia 2010 goda [The accident at the mine "Raspadskaya" May 8-9, 2010] Retrieved from: https://miningwiki.ru/wiki [in Russian].

2. S metanom naiedine. Krupneishie avarii na ugolnykh shakhtakh Rossii [With methane alone. The largest accidents at coal mines in Russia]. Retrieved from: https://lenta.ru/articles/2016/03/01/mining/ [in Russian].

3. Ugol. Obogashchenie. Terminy i opredelenia. GOST 17321-2015 [Coal. Preparation. Terms and definitions. GOST 17321-2015]. Retrieved from: http://docs.cntd.ru/document/1200132463 [in Russian].

4. O promyshlennoi bezopasnosti opasnykh proizvodstvennykh obiektov. Federalny zakon ot 21.07.1997 № 116-FZ (red. ot 29.07.2018) [On the industrial safety of hazardous production facilities. Federal law of July 21, 1997 No. $116-$ FZ (as amended on July 29, 2018). Retrieved from: http://www.consultant.ru/document/cons_doc_LAW_15234/ [in Russian].

5. O bezopasnosti gidrotekhnicheskikh sooruzheni. Federalny zakon ot 21.07.1997 № 117-FZ (red. ot 29.07.2018) [On the safety of hydrotechnical constructions. Federal law of July 21, 1997 No. 117-FZ (as amended on July 29, 2018)] Retrieved from: http://www.consultant.ru/document/cons_doc_LAW_15265/ [in Russian].

6. O sozdanii lokalnykh sistem opoveshchenia v raonakh razmeshchenia potentsialno opasnykh obiektov. Postanovlenie Pravitelstva RF ot 01.03.1993 № 178 [On the creation of local warning systems in areas where potentially dangerous facilities are located. Decree of the Government of the Russian Federation of March 01, 1993 No. 178]. Retrieved from: http://www.consultant.ru/document/cons_doc_LAW_86328/ [in Russian].

7. O nedrakh. Federalny zakon ot 21.02.1992 № 2395-1 (red. of 27.12.2019) [On subsoils. Federal law of 21.02.1992 No. 2395-1 (as amended on December 27, 2019)]. Retrieved from: http://www.consultant.ru/document/cons doc LAW_343/ [in Russian].

8. O ražvitii malogo i srednego predprinimatelstva v Rossiiskoi Federatsii. Federalny zakon ot 24.07.2007 № 209-FZ (red. ot 27.12.2019) [On the development of small and medium-sized enterprises in the Russian Federation. Federal law of July 24, 2007 No. 209-FZ (as amended on December 27, 2019)]. Retrieved from: http://www.consultant.ru/ document/cons_doc_LAW_52144/[in Russian].

9. Zemelny kodeks Rossiiskoi Federatsii. Federalny zakon ot 25.10.2001 № 136-FZ (red. ot 27.12.2019) [Land Code of the Russian Federation. Federal Law of October 25, 2001 No. 136-FZ (as amended on December 27, 2019)] Retrieved from: http://www.consultant.ru/document/cons doc LAW 33773/ [in Russian].

10. Kodeks Rossiiskoi Federatsii ob administrativnykh pravonarusheniiakh. Federalny zakon ot 30.12.2001 № 195-FZ (red. ot 27.12.2019) [Code of the Russian Federation on Administrative Offenses. Federal law dated December 30, 2001 No. 195-FZ (as amended on December 27, 2019)]. Retrieved from: http://www.consultant.ru/document/cons doc LAW 34661/ [in Russian].

11. Ugolovnyy kodeks Rossiskoi Federatsii. Federalny zakon ot 13.06.1996 № 63-FZ (red. ot 27.12.2019) [Criminal Code of the Russian Federation. Federal Law of June 13, 1996 No. 63-FZ (as amended on December 27, 2019)]. Retrieved from: http://www.consultant.ru/document/cons_doc_LAW_10699/ [in Russian].

12. V Kuzbasse dvoie detei upali v goriashchuiu iamu so shlak̄om, odin malchik pogib [In Kuzbass, two children fell into a burning hole with sludge, one boy died]. Retrieved from: https://www.city-n.ru/view/396001.html [in Russian].
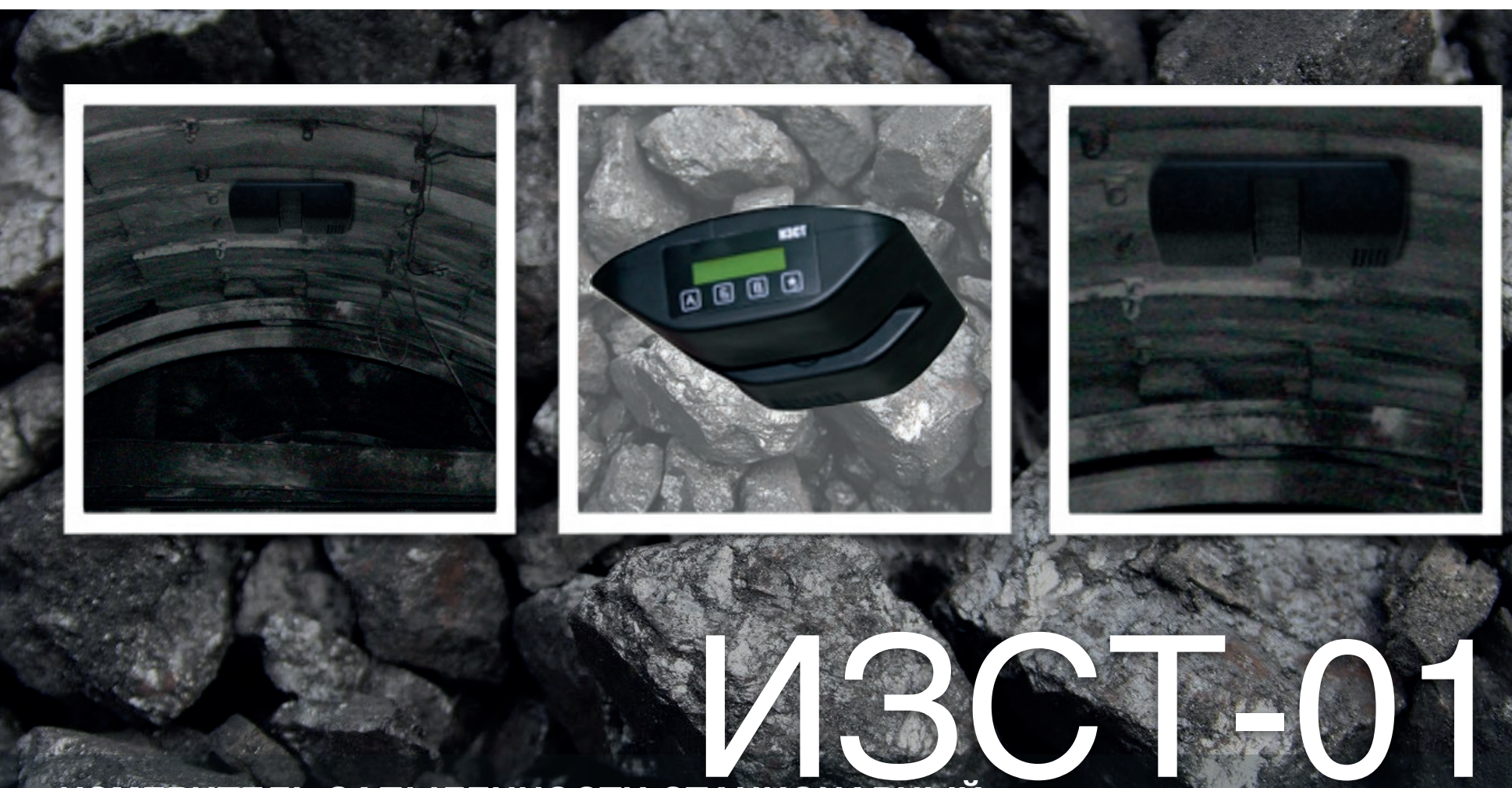

ИЗМЕРИТЕЛЬ ЗАПЫЛЕННОСТИ СТАЦИОНАРНБЙ

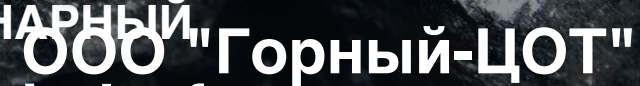
indsafe.ru 


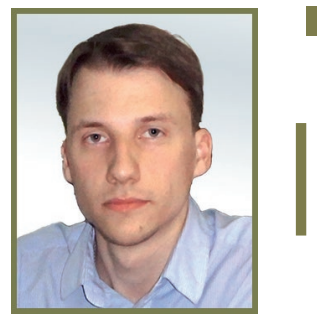

И.М. Анисимов//

I.M. Anisimov

i.m.anisimov25@gmail.com

кандидат технических наук, г. Кемерово candidate of technical sciences, Kemerovo

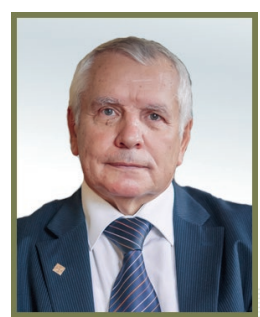

А. И. Фомин // A. I. Fomin ncvostnii@yandex.ru

д-р техн. наук, ведущий научный сотрудник отдела АО "НЦ ВостНИИ", Россия, 650002 , г. Кемерово, ул. Институтская, 3 doctor of technical sciences, department leading scientific researcher, JSC «ScC VostNII», 3, Institutskaya Str., Kemerovo, 650002, Russia

УДК 622.33;614.8.069

\section{АНАЛИЗ ПОТЕРЫ ПРИ ПОЛУЧЕНИИ РАБОТНИКОМ ТРАВМЫ ANALYSIS OF LOSSES IN CASE WHEN AN EMPLOYEE HAS INJURY}

В статье изложены основные риски производственной деятельности на предприятиях по добыче угля подземным способом, связанные с возникновением аварийных ситуаций, несчастных случаев п профессиональных заболеваний. Проведен анализ негативных событий при получении работником угольной шахты производственной травмы. Исследованы, проанализированы и отображены потери угледобывающего предприятия в случае причинения вреда здоровью работника. Разобран механизм расчета тарифа для страховых взносов в фонд социального страхования, а также возможности получения скидки по данным выплатам. The article outlines the main risks of production activities at coal mining enterprises by underground method associated with the occurrence of emergency situations, accidents and occupational diseases. The analysis of negative events when an employee of a coal mine received an industrial injury was carried out. There were investigated, analyzed and reflected the losses of the coal-mining enterprise in the event of damage to the health of the employee. The mechanism of calculating the tariff for insurance contributions to the social insurance fund was worked out, and the possibility of receiving a discount on these payments was analyzed. КлючевЫе слова: УГОЛЬНАЯ ОТРАСЛЬ, ДОБЫЧА УГЛЯ ПОДЗЕМНЫМ СПОСОБОМ, НЕСЧАСТНЫЕ СЛУЧАИ, ФИНАНСОВЫЕ ПОТЕРИ ОТ НЕСЧАСТНОГО СЛУЧАЯ, СКИДКИ К СТРАХОВОМУ ТАРИФУ Key words: COAL INDUSTRY, COAL MINING BY UNDERGROUND METH-OD, ACCIDENTS, FINANCIAL LOSSES FROM AN ACCIDENT, DISCOUNTS TO INSURANCE TARIFF.

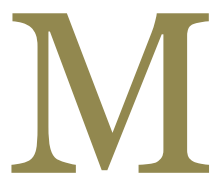

ероприятия, направленные на снижение уровня профессиональных заболеваний и травматизма требуют значительных материальных вложений. При этом, каждая вложенная единица средств так или иначе влияет на общий уровень условий труда, безопасность ведения горных работ. Это видно даже исходя из определения «охраны труда» - система сохранения жизни и здоровья работников в процессе трудовой деятельности, включающая в себя правовые, социально-экономические, организационно-технические, санитарно-гигиенические, лечебнопрофилактические, реабилитационные и иные мероприятия. Соответственно направлений для инвестирования и развития уровня безопасности на предприятии всегда остается множество, и выбрать наиболее перспективное и максимально эффективное иногда не представляется возможным.

В данной ситуации необходим индивидуальный подход с точки зрения снижения уровня риска возникновения неблагоприятных последствий. В случае фрормирования данных мероприятий, их расчету и оценки эфрфективности, возникает вопрос о перспективности данных вложений. Общепризнанное понятие того что жизнь человека не имеет цены - неоспоримо. В свою очередь, крупные проекты направленные на сохранение жизни и здоровья работника необходимо обосновывать с экономической точки зрения. Ввиду того, что состояние условий труда и безопасности на предприятии влияет на множество фракторов, как производственных, социально-экономических, так и репутационных, задача оценки потерь в случае получения травмы или установления профессионального заболевания является комплексной.

Для проведения анализа необходимо отталкиваться непосредственно от фракта наступления негативного воздействия. В случае с производственной травмой, самым первым негативным последствием будет исключение работника из трудовой деятельности. Потери могут быть следующего характера:

1. Невыполнение работником своих обязанностей до конца рабочей смены или до возложения обязанностей на иного работника; 
2. Нарушение технологических процессов, порча сырья или готового продукта;

3. Остановка производственной деятельности на период работы комиссии по расследованию; 4. Отвлечение работников от основной производственной деятельности (оказывающих первую помощь, помогающих транспортировке пострадавшего, обеспечивающих работу комиссии по расследованию);

5. Обучение и стажировка нового работника на период замещения или на постоянной основе;

6. Оплата экспертиз (судебно-медицинской и иных в случае необходимости).

При этом, необходимо отметить что в соответствии с действующим законодательством, на основании Федерального закона № 125 от 24.07.1998 «Об обязательном социальном страховании от несчастных случаев на производстве и профессиональных заболеваний» [1] работник получивший травму или профессиональное заболевание имеет право на выплаты из фонда социального страхования, которые направлены на лечение и реабилитацию работника, а также на возмещение ущерба соизмеримому причинённому вреду здоровья.

Bce вышеуказанные выплаты выполняемые ФСС обеспечиваются средствами работодателя, посредствам взносов в соответствии с расчетным коэфффициентом. Одним из ключевых показателей для данных расчетом, является уровень профрессионального риска, устанавливаемым на основании приказа Минтруда России № 851 от 30.12.2016 «Об утверждении Классификации видов экономической деятельности по классам профессионального риска» [2]. Всего существуют 32 класса профессионального риска, при этом, в самый высокий класс риска входят виды экономической деятельности, связанные с добычей угля подземным способом.

Соответственно, при классе професссионального риска равном 32, в соответствии с Федеральным законом № 179 от 22.12.2005 «О страховых тарифрах на обязательное социальное страхование от несчастных случаев на производстве и профессиональных заболеваний на 2006 год» [3], который применяется в 2020 году, страховой тариф составляет 8,5\%. При средней заработной плате в сфере добычи угля, согласно данных Кемеровостата, в 61 тыс. руб. ежемесячно работодатель отчисляет сумму равную 5 185 рублей на каждого работника. При предполагаемой численности угольного предприятия в 800 человек, оно за 1 год своей деятельности направляет средства в фонд социального страхования, в размере 50 млн. руб.
Данная цифра является базовой, но в соответствии с методикой расчета утвержденной приказом Минтруда России № 39 от 01.08.2012 «Об утверждении Методики расчета скидок и надбавок к страховым тарифрам на обязательное социальное страхование от несчастных случаев на производстве и профрессиональных заболеваний» [4] размер страхового взноса может изменятся, но не более чем на $40 \%$ от базового.

Соответственно, организовав грамотно работу в части обеспечения безопасных условий труда и минерализации рисков возникновения профессиональных заболеваний и травматизма, есть шанс достичь экономии в $40 \%$.

Но, в первую очередь, наличие данной скидки зависит от отсутствия смертельных несчастных случаев на предшествующий год. При наличии смертельного несчастного случая, начисление скидки не производится.

Размер скидки рассчитывается по следующей фрормуле 1:

$$
\mathrm{C}=\left\{\left(1-\left(\frac{a_{\mathrm{CTP}}}{a_{\mathrm{B} 3 \mathrm{~A}}}+\frac{b_{\mathrm{CTP}}}{b_{\mathrm{B} 3 \mathrm{~A}}}+\frac{c_{\mathrm{CTP}}}{c_{\mathrm{B} 3 \mathrm{H}}}\right) / 3\right)\right\} \times q 1 \times q 2 \times 100
$$

где $C$ - размер скидки в \%; $a, b, c$ - показатели рассчитываемые как для каждого страхователя (стр), так и по виду экономической деятельности (вэд); $q 1$ - коэффрициент проведения специальной оценки условий труда; $q 2$ - коэффрициент проведения медицинских осмотров.

$$
q 1=(q 11-q 13) / q 12
$$

где $q 11$ - количество рабочих мест, в отношении которых проведена специальная оценка условий труда на 1 января текущего календарного года; q13 - количество рабочих мест, условия труда на которых отнесены к вредным или опасным условиям труда; $q 12$ - общее количество рабочих мест.

Соответственно, при условии своевременного проведения специальной оценки условий труда и $60 \%$ рабочих мест отнесены к вредным условиям труда, коэфрфициент q1 расчитывается: $q 1=\frac{800-680}{800}=0,4$.

Из этого следует, что при условии соблюдения порядка проведения специальной оценки условий труда, q1 является показателем процента рабочих мест не отнесенным к вредным. Что в рассматриваемом случае соответствует 40\%. Данный коэфрфициент объективно не поддается значительному воздействию на угольных предприятиях. Использование современных технологий ведения горных работ на угледобывающих шахтах предприятия снижают вредное воздействие на работников, но не обеспечивают допустимые уровни согласно санитарных норм 
и правил.

$$
q 2=q 21-q 22
$$

где $q 21$ - число работников, прошедших обязательные предварительные и периодические медицинские осмотры в соответствии с действующими нормативно-правовыми актами на 1 января текущего календарного года; q22 - число всех работников, подлежащих осмотрам. Значение данного коэффициента при условиях соблюдения требований действующего законодательство можно принять $q 2=1$.

Далее необходимо уделить внимание коэффрициентам $a, b, c$ с индексами «стр» и «вэд» соответственно. Индекс «стр» рассчитывается относительно непосредственно страхователя. Иднекс «вэд» расчитывается по виду экономической деятельности.

$$
a_{\mathrm{cTp}}=\frac{O}{V}
$$

где $O$ - сумма обеспечения по страхованию за три года; $V$ - сумма начисленных страховых взносов за три года. Значение $O$ может значительно отличаться в различных организациях, при этом имеется незначительный шанс что данное значение будет приравнено к 0. Но, чем больше данная сумма будет приближаться к значению $\mathrm{V}$, тем меньше вероятности получения скидки. В случае если $О$ окажется больше значения $\mathrm{V}$, возрастает риск не только неполучения скидки, но и надбавки по страховому тарифу. Но окончательное заключение по коэффициенту $\alpha$ можно будет сделать, только после соотнесения значений страхователя и по виду экономической деятельности. В соответствии с постановлением ФСС РФ от 23.05.2019 N 64 "Об утверждении значений основных показателей по видам экономической деятельности на 2020 год" [5] значения коэфффициентов $a_{\text {вэд } ; ~} ;$ вэд ; $c_{\text {вэд }}$ в 2020 году для организаций занимающихся добычей угля подземным способом равны 0,07; 20,50; 131,14 соответственно.

Для текущего анализа необходимо принять средние показатели. Соответственно значение $\frac{a_{\text {लтр }}}{a_{\text {взд }}}=1$.

$$
b_{\text {стр }}=\frac{K}{N} \cdot 1000
$$

где $K$ - количество случаев, признанных страховыми за три года, предшествующих текущему; $N$ - среднесписочная численность работающих за три года, предшествующих текущему. Данный показатель по сути является общепризнанным коэффрициентом частоты травматизма, на период в 3 года. Отраслевой показатель достаточно высок и составляет $b_{\text {вэд }}=20,50$. Это порядка 5 несчастных случаев за год в среднем по отрасли. Для примера возьмем показатель в 4 несчастных случая за год. Соответственно $b_{\text {стр }}=15$ и соотношение $\frac{b_{\text {लтр }}}{b_{\text {вэд }}}=0,73$.

$$
c_{\text {стр }}=\frac{T}{S}
$$

где $T$ - число дней временной нетрудоспособности в связи с несчастными случаями, признанными страховыми, за три года, предшествующих текущему; $S$ - количество несчастных случаев, признанных страховыми, исключая случаи со смертельным исходом, за три года, предшествующих текущему. Показатель с является более известным коэффициентом частоты травматизма, который выражает число дней нетрудоспособности, приходящихся на 1 травму. В данном случаев, за период в 3 года.

Соответственно коэффициент частоты травматизма в данной отрасли составляет 131,14. Фактический это означает что в среднем, на 1 травму приходится 131 день нетрудоспособности, что более 4 месяцев. Отсутствие смертельных случаев исключает положительную динамику коэффрициента при их фрактическом избыточном количестве. Но, также не учитывает негативный характер смертельных несчастных случаев при расчете скидок. Значение коэффициента в исследуемом примере необходимо рассчитать, установив, что средняя продолжительность больничного на $20 \%$ меньше общеотраслевого.

Соответственно $c_{\text {стр }}=104,912$ и далее $\frac{c_{\mathrm{crp}}}{c_{\mathrm{B} 3 \mathrm{I}}}=0,8$

Применяя вышеуказанные показатели для примерного расчета скидки по страховому тарифpy.

$$
\begin{gathered}
C=\{(1-(1+0,73+0,8) / 3)\} \times 0,4 \times 1 \times 100= \\
=\{(1-2,53 / 3)\} \times 0,4 \times 1 \times 100 \\
=\{(1-0,843)\} \times 0,4 \times 1 \times 100=6,28
\end{gathered}
$$

Соответственно, с учетом округления скидка в расчетном случае будет составлять $6 \%$. Вернувшись к годовому объему средств необходимых к перечислению в фонд социального страхования угольному предприятию, осуществляющему подземную добычу, размер скидки за год, в денежном выражении составит 3 млн. руб. в год. Данная цифра рассчитана к условиям, близким к общеотраслевым.

Далее нельзя не рассмотреть идеальный вариант развития событий и предположить, что даже в условиях воздействия вредных производственных фракторов присущих угольным 
шахтам и их значений превышающих предельно допустимые концентрации и уровни удалось избежать несчастных случаев за отчетный период. Скидка будет составлять следующее значение.

$$
\begin{gathered}
C=\{(1-(1+0+0) / 3)\} \times 0,4 \times 1 \times 100= \\
=\{(1-1 / 3)\} \times 0,4 \times 1 \times 100 \\
=\{(1-0,333)\} \times 0,4 \times 1 \times 100=26,68
\end{gathered}
$$

Соответственно скидка будет иметь значение $26 \%$. И в денежном выражении будет составлять 13 млн. руб. ежегодно. Данное значение может быть идеальным и целевым для угольных шахт, но не является недостижимым.

Не стоит забывать, что в случае превышение показателей $a, b, c$, на предприятии в сравнении с показателями в данном виде экономической деятельности, а также наличия группового несчастного случая со смертельным исходом скидка не только не может быть установлена, но и рассчитывается коэффициент увеличивающий выплаты. Но, даже в случае хороших показателей $a, b, c$, скидка также может быть не установлена если в предшествующем году произошел несчастных случай со смертельным исходом.

Не смотря на высокие базовые страховые тарифы для угольных шахт, при должной организации профилактической работы, исключающей высокий уровень травматизма, даже в условиях выполнения работ на горных участках, в подземных выработках далёких от нормальных, в опасных и вредных условиях труда, имеется возможность снижения уровня страховых взносов как минимум на 25\%. Соответственно, расходы связанные с травмированием работников на угледобывающем предприятии исчисляются десятками миллионов рублей и закладываются в различных областях деятельности компании.

\section{СПИСОК ЛИТЕРАТУРЫ}

1. Федеральный закон об обязательном социальном страховании от несчастных случаев на производстве и профессиональных заболеваний / Федерального закона от 24.07.1998 №125 // Доступ из справочно-правовой системы «КонсультантПлюс».

2. Приказ об утверждении Классификации видов экономической деятельности по классам профессионального риска / Приказ Минтруда России от 30.12.2016 №851 // Доступ из справочно-правовой системы «КонсультантПлюс».

3. Федеральный закон о страховых тарифах на обязательное социальное страхование от несчастных случаев на производстве и профессиональных заболеваний на 2006 год / Федеральным законом от 22.12.2005 №179 // Доступ из справочно-правовой системы «КонсультантПлюс».

4. Приказ об утверждении Методики расчета скидок и надбавок к страховым тарифам на обязательное социальное страхование от несчастных случаев на производстве и профессиональных заболеваний / Приказ Минтруда России от 01.08.2012 №39 // Доступ из справочно-правовой системы «КонсультантПлюс».

5. Постановление об утверждении значений основных показателей по видам экономической деятельности на 2020 год / Постановлением ФСС РФ от 23.05.2019 N 64 // Доступ из справочно-правовой системы «КонсультантПлюс».

\section{REFERENCES}

1. Federal'nyy zakon ob obyazatel'nom sotsial'nom strakhovanii ot neschastnykh sluchayev na proizvodstve i professional'nykh zabolevaniy ot 24.07.1998 №125 [Federal Law on Compulsory Social Insurance against Industrial Accidents and Occupational Diseases of July 24, 1998, No. 125. Retrieved from the ConsultantPlus reference legal system [in Russian].

2. Prikaz ob utverzhdenii Klassifikatsii vidov ekonomicheskoy deyatel'nosti po klassam professional'nogo riska / Prikaz Mintruda Rossii ot 30.12.2016 №851 [Order on approval of the Classification of Economic Activities by Occupational Risk Classes / Order of the Ministry of Labor of Russia dated December 30, 2016 No. 851]. Retrieved from the ConsultantPlus reference legal system. [in Russian].

3. Federal'nyy zakon o strakhovykh tarifakh na obyazatel'noye sotsial'noye strakhovaniye ot neschastnykh sluchayev na proizvodstve i professional'nykh zabolevaniy na 2006 god ot 22.12.2005 №179 [Federal Law on Insurance Tariffs for Compulsory Social Insurance against Industrial Accidents and Occupational Diseases for 2006 dated December 22, 2005 No. 179]. Retrived from the ConsultantPlus reference legal system [in Russian].

4. Order on approval of the Methodology for calculating discounts and surcharges to insurance rates for mandatory social insurance against industrial accidents and occupational diseases / Order of the Ministry of labor of the Russian Federation dated 01.08.2012 No. 39 // Access from legal-reference system "ConsultantPlus".

5. Postanovleniye ob utverzhdenii znacheniy osnovnykh pokazateley po vidam ekonomicheskoy deyatel'nosti na 2020 god / Postanovleniyem FSS RF ot 23.05.2019 N 64 [Decision on the approval of the main indicator values by type of economic activity for 2020 / Decision of the FSS of the Russian Federation of May 23, 2019 N 64. Retrieved from the consultant-plus reference system [in Russian]. 

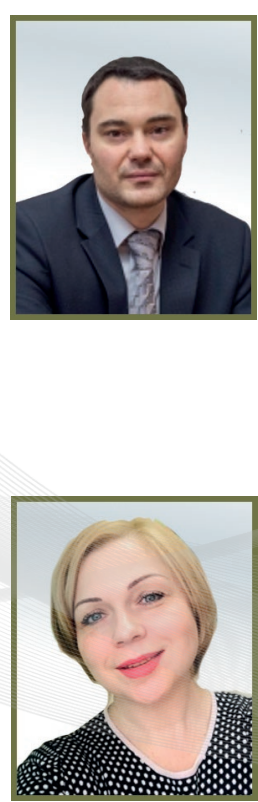

М.Г. Рублев //M. G. Rublev rumag@ngs.ru

кандидат биологических наук, доцент, ФГБОУ Сибирский государственный университет путей сообщения, кафедра «Безопасность жизнедеятельности». 630049 , г. Новосибирск, ул. Дуси Ковальчук, 191

Candidate of Biological Sciences, Associate Professor, FGBOU Siberian State University of Railway Transport. 630049, Novosibirsk, ul. Dusi Kovalchuk, 191, dpt. "BZD"

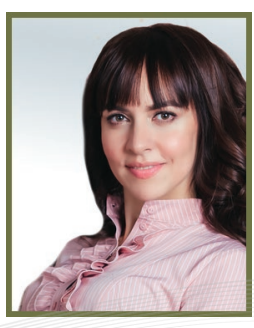

И.В. Пирумова //

I. V. Pirumova

Pirumova_777@mail.ru

кандидат биологических наук, доцент, ФГБОУ Сибирский государственный университет путей сообщения, кафедра «Безопасность жизнедеятельности». 630049, г. Новосибирск, ул. Дуси Ковальчук, 191

Candidate of Biological Sciences, Associate Professor, FGBOU Siberian State University of Railway Transport. 630049, Novosibirsk, ul. Dusi Kovalchuk, 191, dpt. "BZD"

УДК 331.453

СОВЕРШЕНСТВОВАНИЕ СИСТЕМЫ УПРАВЛЕНИЯ ОХРАНОЙ ТРУДА В ЗАПАДНО-СИБИРСКОЙ ДИРЕКЦИИ УПРАВЛЕНИЯ ДВИЖЕНИЕМ IMPROVING THE LABOR PROTECTION MANAGEMENT SYSTEM IN THE WEST SIBERIAN DIRECTORATE OF TRAFFIC

MANAGEMENT

В.Л. Павлова //V. L. Pavlova p_v_75@mail.ru

кандидат экономических наук, доцент, заведующий кафедрой ФГБОУ Сибирский государственный университет путей сообщения, кафедра «Безопасность жизнедеятельности». 630049 , г. Новосибирск, ул. Дуси Ковальчук, 191

Candidate of Economic Sciences, Associate Professor, Life Safety Department Head., FGBOU Siberian State University of Railway Transport. 630049, Novosibirsk, ul. Dusi Kovalchuk, 191, dpt. "BZD"

Повышение эфрфективности системы управления охраной труда в Западно - Сибирской дирекции управления движением достижимо за счет пересмотра существующей структуры управления охраной труда в ЗСИБ Д; выявления возможностей расширения функций действующих компьютерных программ, используемых в охране труда; поиска способов уменьшения объема бумажной работы специалиста по охране труда на всех уровнях управления с целью экономии трудозатрат и времени; повышения эфрфективность обучения работников безопасным методам и приемам работ. Совершенствование структуры достигается за счет организации «группы охраны труда и инспекционного контроля» в отделе безопасности движения и охраны труда. Интеграция в ЕК АСУТР автоматизированной системы «Оценка влияния человеческого фрактора на возникновение случая травмы на производстве и определения доли ответственности причастных работников к этому событию» позволяет оптимизировать работу специалиста и сократить риск ошибок и недочетов, которые могут возникнуть при ручном расчете и вводе данных. Перевод бумажных журналов регистрации инструктажей в электронный вид позволит сократить затраты времени на их ведение. Применение видеоинструктажей по охране труда вместо прочтения сухих инструкций позволит ознакомить работников с имеющимися опасными и вредными производственными фракторами, с безопасными методами и приемами выполнения работ в режиме 3D реальности (моделирования).

Improving the effectiveness of the labor protection management system in the West Siberian Directorate of Traffic Management by reviewing the existing structure of labor protection management in the ZSIB D; identify opportunities to expand the functions of existing computer programs used in labor protection; the search for ways to reduce the paperwork of a labor protection specialist at all levels of management in order to save labor and time; improving the effectiveness of employee training in safe working methods and techniques. The improvement of the structure is achieved through the organization of a "labor protection and inspection group" in the department of traffic safety and labor protection. The integration of the automated system "Assessing the impact of the human factor on the occurrence of an accident at work and determining the share of responsibility 
of the employees involved in this event" into the EK ASUTR allows to optimize the work of a specialist and reduce the risk of errors and shortcomings that may arise during manual calculation and data entry. The conversion of paper logs of briefings in electronic form will reduce the time spent on their maintenance. The use of video training on labor protection instead of reading dry instructions will allow employees to familiarize themselves with the existing dangerous and harmful production factors, with safe methods and techniques for performing work in $3 D$ reality mode (simulation).

Ключевые слова: ОХРАНА ТРУДА, СИСТЕМА УПРАВЛЕНИЯ ОХРАНОЙ ТРУДА (СУОТ); ЕК АСУТР; ВИДЕОИНСТРУКТАЖИ; ЧЕЛОВЕЧЕСКИЙ ФАКТОР.

Keywords: LABOR PROTECTION, LABOR PROTECTION MANAGEMENT SYSTEM (LPMS); EK ASUTR; VIDEO BRIEFINGS; HUMAN FACTOR.

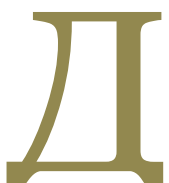

ля развития экономики страны ключевую роль играет транспортная система. В России одной из основных транспортных артерий является железная дорога. ОАО «РЖД» является крупнейшей транспортной компанией мира с колоссальными объемами грузовых и пассажирских перевозок.

Холдинг «РЖД» - социально ответственная компания, которая уделяет особое внимание вопросам безопасности труда, охраны здоровья работников, предупреждению производственных травм и профессиональных заболеваний.

Основным направлением политики ОАО «РЖД» в области охраны труда является обеспечение приоритета сохранения жизни и здоровья работников [1]. Несчастные случаи на производстве и профрессиональные заболевания не предопределены судьбой и не являются неизбежными: у них всегда есть причины и последствия в виде травм, профессиональных заболеваний и, как следствие, - страховых выплат [2]. Система управления охраной труда позволяет эти причины предотвратить и устранить, a eе постоянное развитие и совершенствование позволяет использовать самые современные методы и средства обеспечения безопасности.

ОАО "РЖД" придерживается принципа постоянного совершенствования результатов деятельности компании [3].

Непрерывное совершенствование управления охраной труда организации позволяет достичь повышения безопасности труда путем снижения опасностей и вредностей трудового процесса и сопутствующих ему рисков.

Совершенствование способствует повышению конкурентоспособности и быстрому реагированию на появление современных разработок.

Основным документом, регламентирующим деятельность системы управления охраной труда, является СТО РЖД 15.001-2016 "Система управления охраной труда в ОАО "РЖД". Общие положения".
Западно-Сибирская дирекция управления движением поставила задачу перед сотрудниками кафедры «Безопасность жизнедеятельности» СГУПС по поиску путей и возможностей совершенствования системы управления охраной труда с целью повышения ее эффрективности и результативности.

Поэтому, основной целью научной работы является повышение эффективности системы управления охраной труда в Западно - Сибирской дирекции управления движением.

Для достижения поставленной цели необходимо было решить ряд задач, вытекающих из анализа существующей системы:

- пересмотреть существующую структуру управления охраной труда в ЗСИБ Д;

- выявить возможность расширения функций действующих компьютерных программ, используемых в охране труда;

- найти способы уменьшения объема бумажной работы специалиста по охране труда на всех уровнях управления с целью экономии трудозатрат и времени;

- повысить эффективность обучения работников безопасным методам и приемам работ.

При проведении анализа структуры управления охраной труда [4] в дирекции были выявлены следующие недостатки:

1) сложная структура управления с дублированием функций на региональном и линейном уровнях управления;

2) низкая эффрективность работы специалиста по охране труда на станциях ДЦС;

3) отсутствие разграничений ответственности за исполнение функций по охране труда (рис.1).

Совершенствование структуры достигается за счет организации «группы охраны труда и инспекционного контроля» в отделе безопасности движения и охраны труда. Этим удается перестроить систему подчинения с разветвленной на вертикальную с распределением функций между специалистом по охране труда и инспектором. Функции инспекторов будут за- 


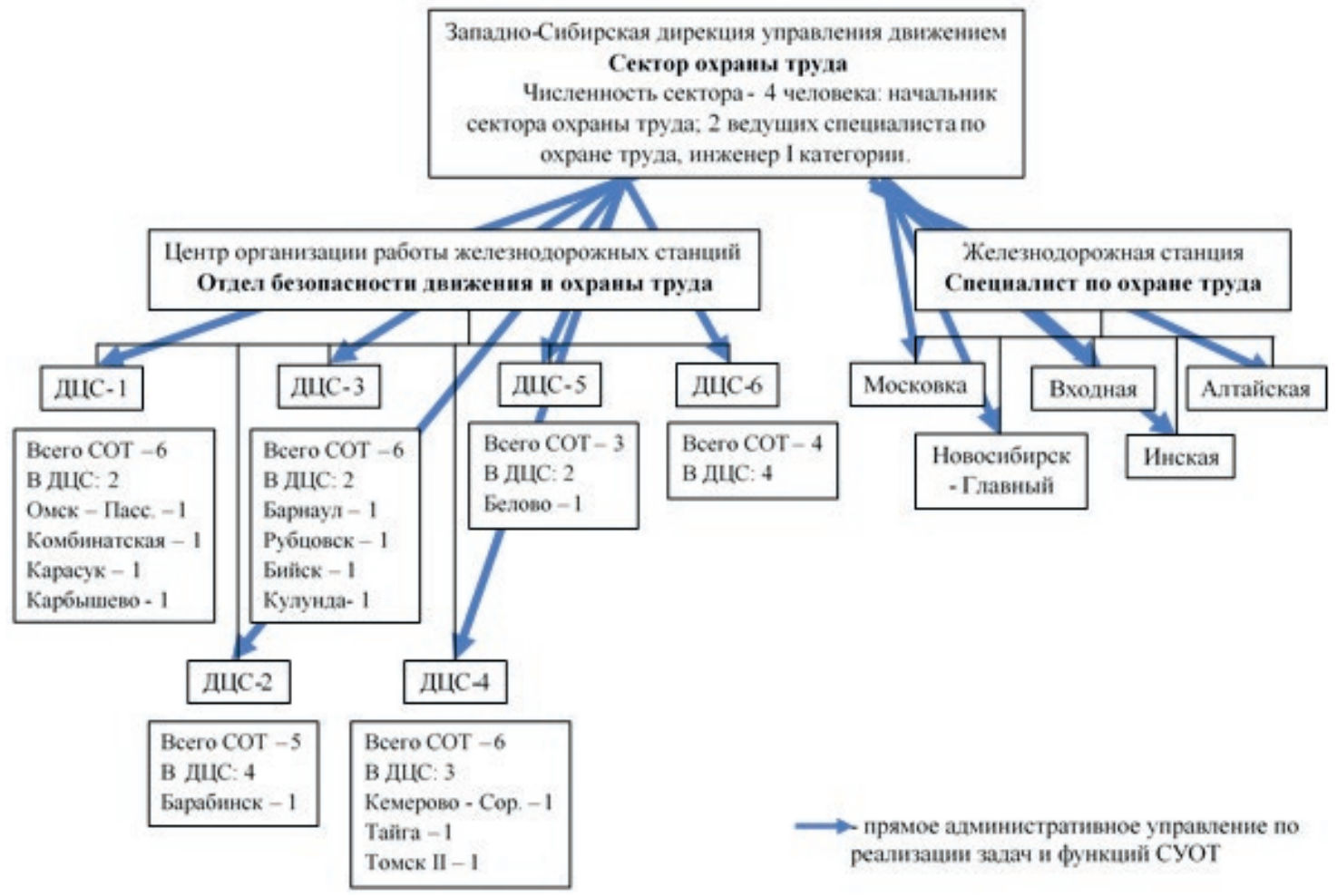

Рисунок 1 - Существующая система управления охраной труда

Figure 1 - The existing labor protection management system

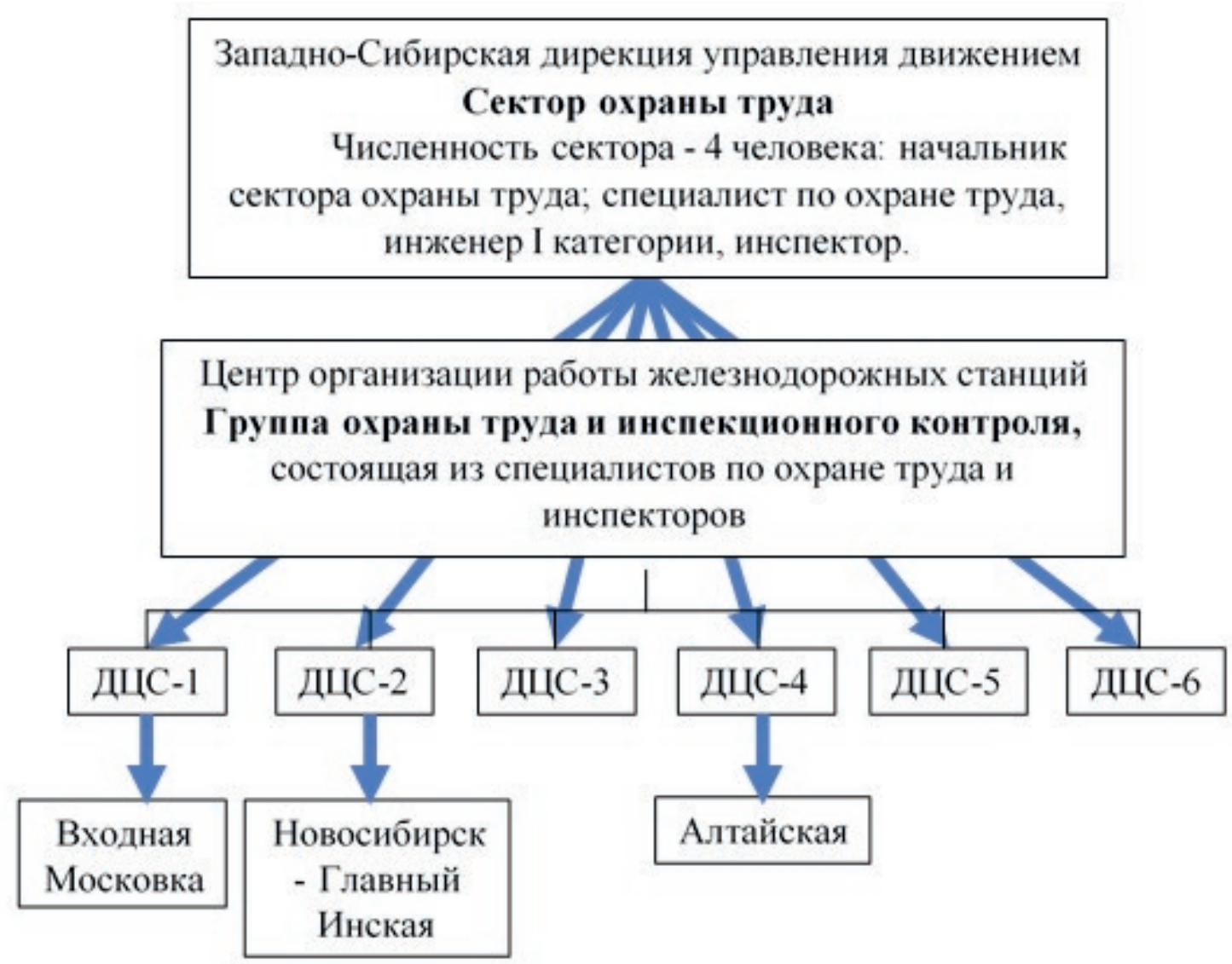

Рисунок 2 - Совершенствование структуры управления охраной труда Figure 2 - Improving the structure of labor protection management 
ключаться в работе с подразделениями, сборе информации и выезде на линию с проверкой, а специалист по охране труда будет заниматься анализом данных и разработкой мероприятий, направленных именно на профилактику производственного травматизма (рис.2).

Преимуществами этой структуры управления охраной труда является:

- уменьшение списочной численности специалистов, участвующих в системе управления охраной труда (было 39 человек, стало 37);

- упрощенная система подчинения с исключением дублирующих фрнкций.

Для уменьшения нормативно-правовой базы и исключения дублирующих документов по охране труда на линейном уровне следует остановить разработку локальных нормативных документов по охране труда на региональном уровне, так как дирекция может учесть все местные особенности своих линейных подразделений.

Для повышения эфффективности управления охраной труда можно оптимизировать некоторые действия специалистов при помощи расширения фрункциональных возможностей программы ЕК АСУТР, позволяющих исключить трудовые ресурсы.

Интегрировав в программу автоматизированную систему «Оценка влияния человеческого фактора на возникновение случая травмы на производстве и определения доли ответственности причастных работников к этому событию» [5], мы сможем оптимизировать работу специалиста и сократить риски ошибок и недочетов, которые могут возникнуть при ручном расчете и вводе данных (рис.3).

Перевод бумажных журналов регистрации инструктажей в электронный вид позволит сократить затраты времени на их ведение. К возможностям электронного журнала относят:

- создание и планирование автоматического добавления записей за один клик;

- автоматическое нахождение неподписанных записей;

- создание резервных копий базы данных, для предотвращения их утраты;

- поддержка электронной и графической подписи (рис.4).

Важнейшая составляющая часть производственной деятельности - это обучение работников по охране руда. Использование VRтехнологий в обучении откроет новые возможности для изучения теории и отработки практики. Они дают уникальную возможность работнику лично в процессе тренировок погрузиться в реальную рабочую атмосферу, оценить и устранить опасность на рабочем месте, приобрести первичный опыт правильных действий.

Применение видеоинструктажей по охране труда вместо прочтения сухих инструкций позволит ознакомить работников с имеющимися опасными и вредными производственными факторами, с безопасными методами и приемами выполнения работ в режиме 3D реальности (моделирования). Визуализирование обстоятельств и причин несчастных случаев и аварий оставит след в эмоциональной памяти работника в результате чего он будет вести себя более разумно и осторожно.

Таким образом, разработанные мероприятия по совершенствованию системы управления охраной труда в дирекции управления движением позволят исключить лишний объем работы, связанный с ненужным дублированием функций,

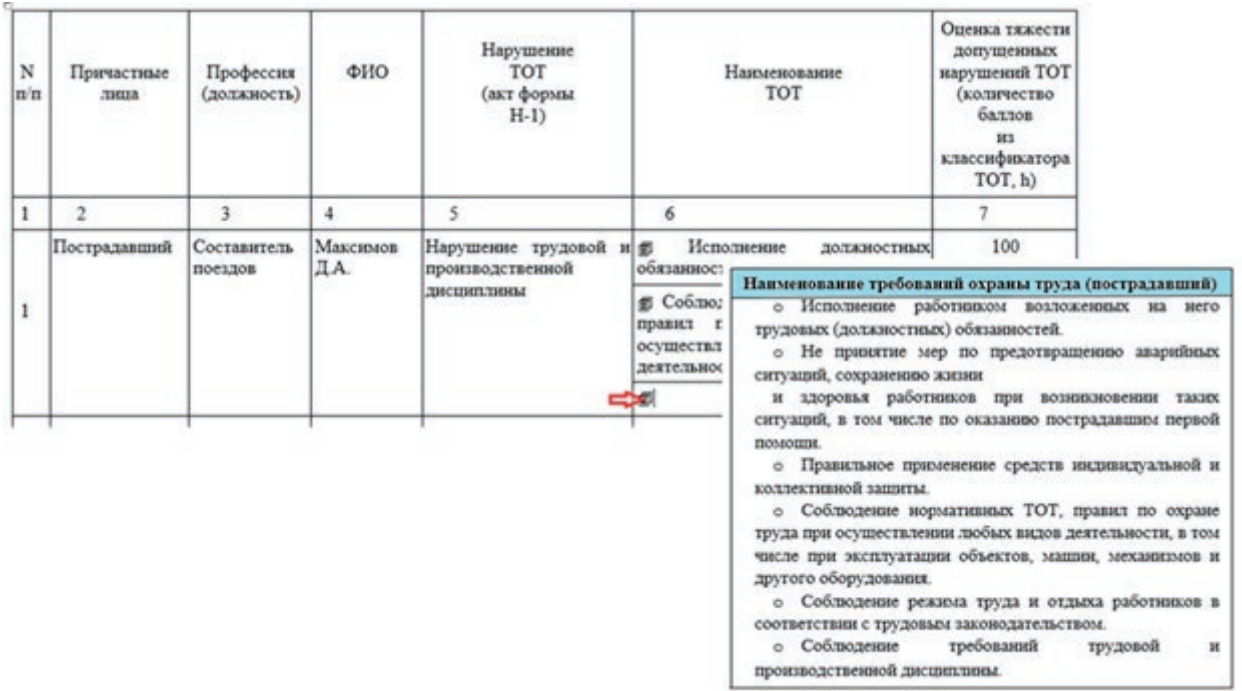

Рисунок 3 - Совершенствование программы ЕК АСУТР в части управления рисками Figure 3 - Improving the EK ASUTR program in terms of risk management 


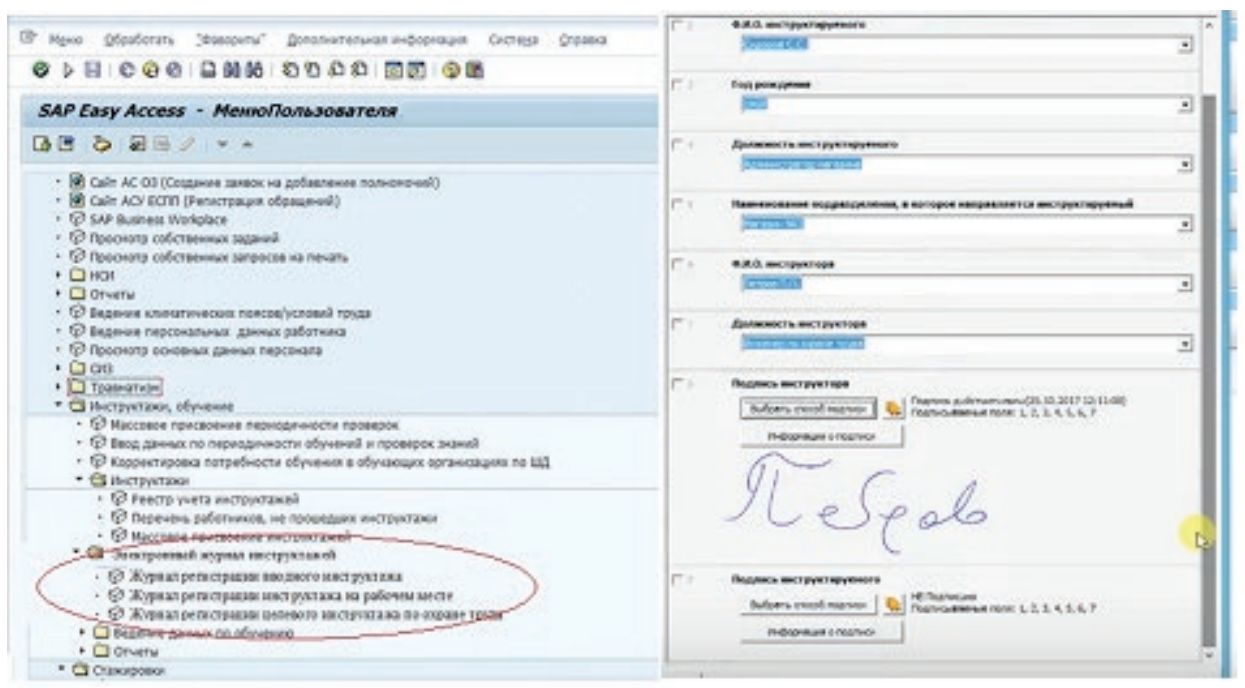

Рисунок 4 - Совершенствование ЕК СУТР в части регистрации инструктажей Figure 4 - Improving the EK SUTR regarding registration of briefings

сэкономить финансовые затраты на сокращении трудовых ресурсов, сократить время на заполнение журналов инструктажей и форм отчета по выявлению человеческого фактора, значительно повысить качество обучения персонала.
Результаты научных разработок используются на предприятиях Западно-Сибирской дирекции управления движением, что подтверждается актом о внедрении.

\section{СПИСОК ЛИТЕРАТУРЫ}

1. Политика ОАО "Российские железные дороги" в области охраны труда, защиты окружающей среды и промышленной безопасности от 10.10.2008.

2. Павлова, В.Л., Рублев, М.Г. Страхование от несчастных случаев на железнодорожном транспорте. Какие риски попадают под страховку? В.Л. Павлова // Научные проблемы транспорта Сибири и Дальнего Востока. 2017 - № 3-4. - С. 45-49.

3. СТО РЖД 15.001-2016 «Система управления охраной труда в ОАО "РжД". Общие положения» от 20.02.2017.

4. Распоряжение об утверждении структуры Западно-Сибирской дирекции управления движением - структурного подразделения Центральной дирекции управления движением - филиала ОАО «РЖД» от 28.12.2018.

5. Положение о Центральной дирекции управления движением - Филиале открытого акционерного общества «Российские железные дороги» от 15.06.2009.

\section{REFERENCES}

1. Politika OAO "Rossiyskiye zheleznyye dorogi" v oblasti okhrany truda, zashchity okruzhayushchey sredy i promyshlennoy bezopasnosti ot 10.10.2008 [The policy of Russian Railways in the field of labor protection, environmental protection and industrial safety of 10.10.2008] [in Russian].

2. Pavlova, V.L., \& Rublev, M.G. (2017). Strakhovaniye ot neschastnykh sluchayev na zheleznodorozhnom transporte. Kakiye riski popadayut pod strakhovku? [Rail accident insurance. What risks are covered by insurance?] Nauchnyye problemy transporta Sibiri i Dal'nego Vostoka - Scientific problems of transport in Siberia and the Far East, 3-4, 45-49 [in Russian].

3. STO RZHD 15.001-2016 «Sistema upravleniya okhranoy truda v OAO "RZHD". Obshchiye polozheniya» ot 20.02.2017 [STO RZD 15.001-2016 "Labor protection management system in OAO Russian Railways. General Provisions "dated 02.20.2017 [in Russian].

4. Rasporyazheniye ob utverzhdenii struktury Zapadno-Sibirskoy direktsii upravleniya dvizheniyem - strukturnogo podrazdeleniya Tsentral'noy direktsii upravleniya dvizheniyem - filiala OAO «RZHD» ot 28.12.2018 [Order on approval of the structure of the West Siberian Directorate of Traffic Management - a structural unit of the Central Directorate of Traffic Management - a branch of Russian Railways dated 12.28.2018] [in Russian].

5. Polozheniye o Tsentral'noy direktsii upravleniya dvizheniyem - Filiale otkrytogo aktsionernogo obshchestva «Rossiyskiye zheleznyye dorogi» ot 15.06.2009. [Regulation on the Central Directorate of Traffic Management - Branch of the Russian Railways Open Joint Stock Company dated 06/15/2009. [in Russian]. 


\title{
III. ТЕХНОЛОГИЧЕСКИЕ ВОПРОСЫ БЕЗОПАСНОСТИ ГОРНЫХ РАБОТ III. TECHNOLOGICAL QUESTIONS OF MINING WORK SAFETY
}
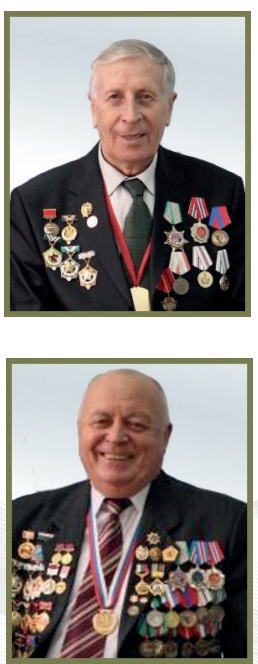

Ю. А. Масаев // Yu.A. Masaev

канд. техн. наук, профессор ФГОУ ВО КузГТУ им. Т.Ф, Горбачева

Почетный член Академии горных наук candidate of technical sciences, professor FGOU VO KuzGTU named after T.F. Gorbachev, Honorary Member of the Academy of Mining Sciences

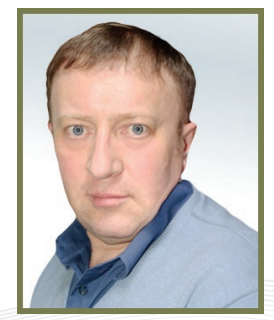

B. Ю. Масаев// V.Yu. Masaev

канд. техн. наук, доцент Кемеровская государственная сельскохозяйственная академия, кафедра ландшафтной ар хтектуры

candidate of technical sciences, associate professor Kemerovo State Agricultural Academy, Department of Landscape Architecture

\section{А. И. Копытов//}

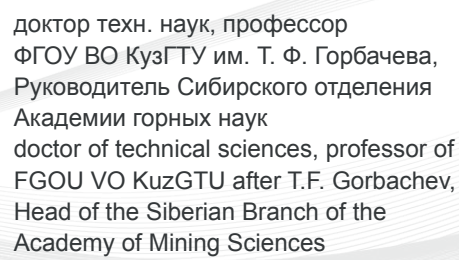

УДК $622.831,622.2,622.235$

\section{ОСОБЕННОСТИ ПРОХОДКИ КОМПЛЕКСА ГОРНЫХ ВЫРАБОТОК ПРИ РАЗРАБОТКЕ РУДНЫХ МЕСТОРОЖДЕНИЙ FEATURES OF MINE OPENING COMPLEX HEADING AT THE DEVELOPMENT OF ORE DEPOSITS}

\begin{abstract}
Рассмотрены особенности сооружения горных выработок в крепких породах с использованием глубоких скважин и многозабойной организации горнопроходческих работ при разработки рудных месторождений подземным способом. Приведены рекомендации по снижению напряженного состояния породного массива в приконтурной зоне за счет создания разгрузочных полостей, а также способов увеличения несущей способности породного массива за счет искусственного укрепления нарушенных горных пород.

The features of mine working construction in hard rocks with the use of deep boreholes and multi-face organization of mining opera-tions during the development of ore deposits with the underground method are consid-ered. Recommendations are given to reduce the stress state of the rock massif in the con-tour zone through the unloading cavities' creation, as well as ways to increase the bearing capacity of the rock massif through the artificial strengthening of disturbed rock.
\end{abstract}

КлючевЫе слова: ВЗРЫВНЫЕ РАБОТЫ; ПРИКОНТУРНЫЙ МАССИВ; БЛОК; БУРОВЫЕ ВЫРАБОТКИ; НАРЕЗНЫЕ ВЫРАБОТКИ.

Key words: BLASTING WORKS; CONTOUR MAS-SIF; BLOCK; DRILLING WORKINGS; CUT WORKINGS.

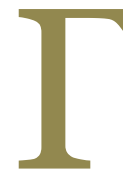
еотехнология разработки железорудных месторождений подземным способом с отличаются от угольных месторождений. Месторождения Горной Шории представлены магнетитами с примесью целого ряда других минералов - кальцитов, хлоритов, кварцитов и др. Горизонтальная мощность таких залежей изменяется от 15-20 метров до 40-60 метров, а вместе с прослоями пустых пород до- стигает 100-120 метров. Общая глубина таких залежей достигает 1500 м. С увеличением глубины залегания изменяются фризико-механические свойства горных пород, повышается горное давление, усиливаются геодинамические явления в виде горных ударов. С начала 1970 г. на рудниках Горной Шории разработана и внедрена система разработки этажного принудительного обрушения руды и вмещающих пород пучками 


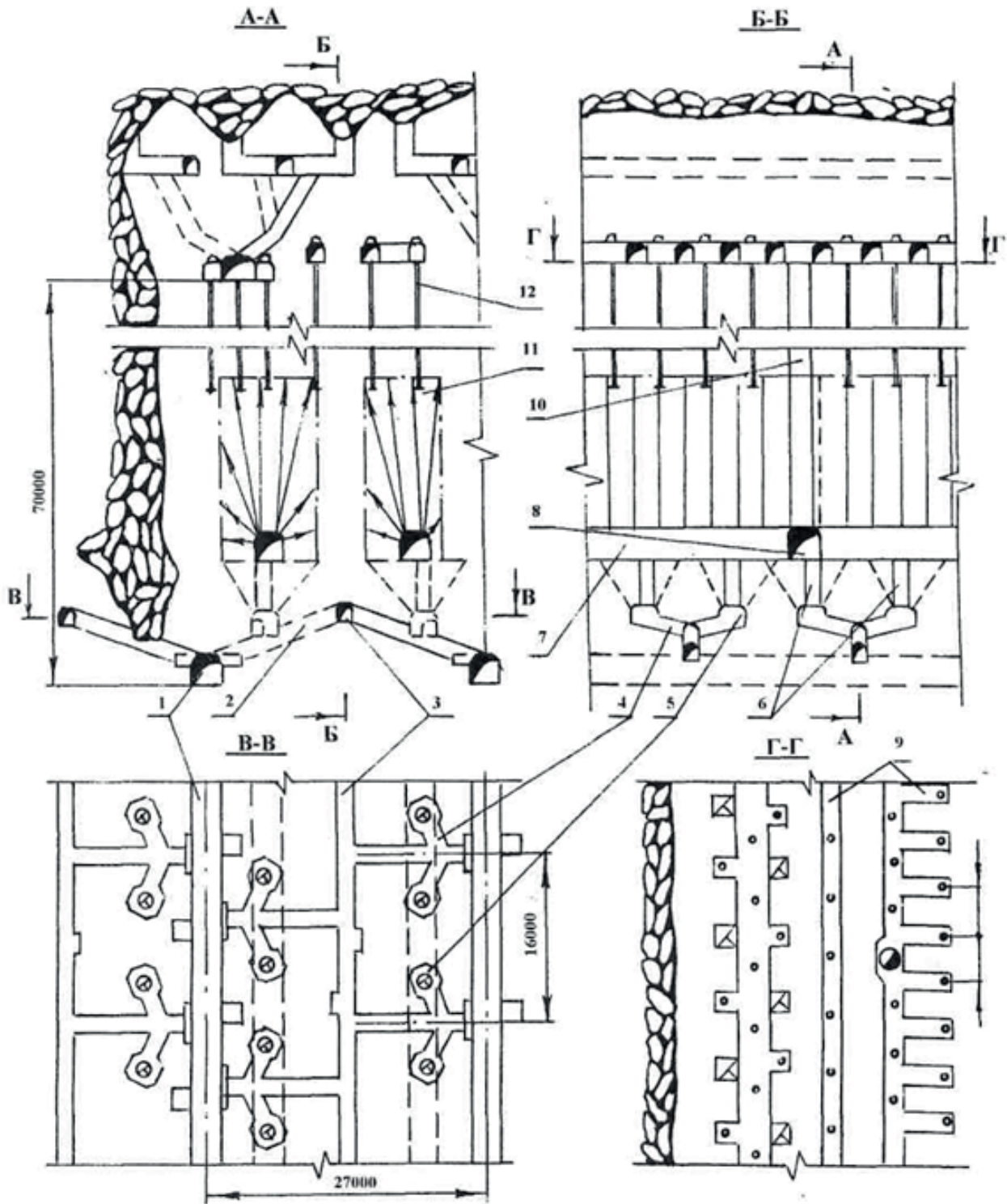

Рисунок 1. Система этажного принудительного обрушения с вибровыпуском руды. Figure 1. The system of forced roof collapse with vibration output of ore.

параллельно-сближенных скважин и выпуском погрузо-доставочными установками ВДПУ-4ТМ (рис.1).

Для вскрытия и подготовки месторождения необходимо выполнение целого комплекса работ по проходке выработок различного назначения, протяженности, направления и размеров поперечного сечения, бурению шпуров и скважин в определенном направлении с учетом устойчивости и напряженного состояния массива горных пород и руд.

Горнопроходческие работы в блоке заключаются в проходке откаточных ортов 1 на расстоянии 27 м друг от друга по осям выработок. Из откаточной выработки с размещением почвы на уровне 2,2 м от головки рельс через 16 м друг от друга проходят камеры под виброустановки 2 , которые соединяются между собой вентиля- ционно-смотровой выработкой 3. Из камер под питатели проходят заходки под дучки 4. В торцевой части заходки разделывается камера 5 размерами 3×3×3 м, из которой на высоту 3-4 м до почвы горизонта подсечки поднимаются дучки 6. Последние перед началом очистных работ разделываются в воронки. Из дучек засекаются и проходятся выработки горизонта подсечки: траншейные орты 7 и разрезные панели 8. Выработки бурового горизонта 9 (буровые орты, штреки с заходками) проходятся на уровне кровли бывшего откаточного орта. Горизонт подсечки и буровой горизонт соединяются между собой отрезными восстающими 10. Максимальную протяженность (до 300 м) имеют откаточные выработки, длина нарезных выработок в пределах блока изменяется от 4 до 100 м.

Практика применения системы этажного 
принудительного обрушения с вибровыпуском руды показывает, что наибольший объем в блоке занимают нарезные выработки сечением 3-4 $\mathrm{M}^{2}-89,0 \%$, из которых 72,0 \% составляют горизонтальные.

Наличие большого объема нарезных выработок малого сечения и высокая крепость горных пород предопределили преимущественно буровзрывной способ проходки, характеризующийся ограниченным применением высокопроизводительных буровых и погрузочных машин, а также существующую организацию труда при подготовке и нарезке блоков.

Как можно заметить, при подготовке и нарезке блоков создается густая сеть горных выработок, приводящих к изменению напряженного состояния породного массива, которое может привести к снижению устойчивости породных обнажений. Для предотвращения подобных нарушений предусматриваются следующие меры:

- расположение горных выработок с учетом соседних выработок и свойств окружающих горных пород;

- снижение напряженного состояния породного массива в приконтурной зоне за счет создания разгрузочных полостей, позволяющих снизить концентрацию действующих напряжений;

- применение способов увеличения несущей способности породного массива за счет искусственного укрепления нарушенных горных пород;

- выбор рациональной формы поперечного сечения горных выработок, обеспечивающих устойчивость породных обнажений;

- применение рациональных видов крепей горных выработок с учетом свойств породного массива.

Проведение горизонтальных выработок с применением скважинных зарядов вызывает повышенное воздействие взрыва на приконтурный массив, из-за чего создаются условия для преждевременного его разрушения во время эксплуатации данных выработок. Поэтому ограничивающими факторами для определения схемы расположения скважин при проходке выработок протяженностью менее 20 м необходимо считать назначение, условия эксплуатации и срок службы этих выработок.

Промышленные эксперименты по исследованию влияния разрушающего действия взрыва шпуровых и скважинных зарядов ВВ на приконтурный массив горизонтальных нарезных выработок в процессе их эксплуатации проводили в опытном блоке и для этой цели в скарнах с коэффрициентом крепости $\mathrm{f}=16-18$ и руде $\mathrm{f}=$ 14-15 с использованием глубоких скважин было пройдено 24 буровых заходок сечением $3,5 \mathrm{~m}^{2}$ и средней длиной 11,5 м. Из них 7 выработок - с использованием в приконтурной части взрывных скважин диаметром 70 мм, 3 выработки - с использованием в приконтурной части взрывных скважин диаметром 110 мм и 14 выработок - с применением взрывных скважин диаметром 70 и 110 мм для образования врубовой полости и последующим оконтуриванием до проектных размеров взрыванием шпуровых зарядов диаметром 43 мм. Скважины бурили заранее на полную проектную длину по направлению буровых заходок и при этом во всех выработках в комплекте вруба бурили компенсационные скважины диаметром 155 мм. Максимальная длина взрываемой секции составляла 6,0 м, общий вес заряда аммонита № 6ЖВ - 330 кг.

Наблюдения за состоянием приконтурной части выработок осуществляли ежемесячно в течение 1 года 8 месяцев, в процессе подготовки блока к массовому обрушению. Оценка состояния приконтурного массива выработок производилась с помощью маркшейдерской съемки по величине отклонения их сечения от проектных размеров $(\Delta S)$, которое определяли как отношение площади поперечного сечения выработки в момент замера $\left(S_{\phi}\right)$ к площади ее проектного поперечного сечения $\left(\mathrm{S}_{\mathrm{np}}\right)$, данные измерений фриксировались в журнале участкового маркшейдера. Затем через каждые 3 месяца производилась обработка и сравнительная оценка фрактического состояния выработок с проектным, путем нанесения на маркшейдерский планшет. Результаты этих наблюдений приведены в табл. 1.

На основании приведенных данных (табл. 1) построены зависимости изменения площади поперечного сечения буровых выработок блока от срока их службы (t) с учетом влияния технологических операций, производимых в этот период до массового обрушения запасов руды (рис. 2).

Таким образом, установлено, что лучшая устойчивость приконтурного массива обеспечивается в выработках, пройденных с использованием взрывных шпуров и компенсационных скважин диаметром 43 и 70-110 мм. Увеличение сечения этих выработок незначительное и составляет около 2,5 \% к полученному после проходки (рис. 2, а).

Устойчивость приконтурного массива выработок, пройденных с использованием оконтуривающих взрывных скважин диаметром 70 мм, удовлетворительная. Непосредственно после проходки, в некоторых случаях в районе геологи- 
Таблица 1. Результаты наблюдений за состоянием буровых выработок блока в период эксплуатации после их проходки с использованием глубоких скважин

Table 1. The block drilling workings state observation results during operation after they are drilled with deep boreholes

\begin{tabular}{|c|c|c|c|c|c|c|c|c|c|}
\hline \multirow{2}{*}{$\begin{array}{c}\text { Срок } \\
\text { службы } \\
\text { выработки, } \\
\text { мес. }\end{array}$} & \multicolumn{3}{|c|}{$\begin{array}{c}\text { Схема с оконтуривающими } \\
\text { шпурами, } d=43 \text { мм }\end{array}$} & \multicolumn{3}{|c|}{$\begin{array}{c}\text { Схема с оконтуривающими } \\
\text { скважинами, } d=70 \text { мм }\end{array}$} & \multicolumn{3}{|c|}{$\begin{array}{c}\text { Схема с оконтуривающими } \\
\text { скважинами, } d=110 \text { мм }\end{array}$} \\
\hline & $S_{n p}, M^{2}$ & $S_{\phi}, M^{2}$ & $\mathrm{~S} \%$ & $S_{n p}, M^{2}$ & $S_{\phi}, M^{2}$ & $\mathrm{~S} \%$ & $S_{n p}, M^{2}$ & $S_{\phi}, M^{2}$ & $\mathrm{~S} \%$ \\
\hline 3 & 3,5 & 3,85 & 10,0 & 3,5 & 3,87 & 10,7 & 3,5 & 3,92 & 12,0 \\
\hline 6 & 3,5 & 3,85 & 10,0 & 3,5 & 3,90 & 11,6 & 3,5 & 3,96 & 13,0 \\
\hline 9 & 3,5 & 3,86 & 10,5 & 3,5 & 3,92 & 12,0 & 3,5 & 4,02 & 15,0 \\
\hline 12 & 3,5 & 3,88 & 11,0 & 3,5 & 3,94 & 12,5 & 3,5 & 4,11 & 17,5 \\
\hline 15 & 3,5 & 3,89 & 11,3 & 3,5 & 4,07 & 16,5 & 3,5 & 4,34 & 24,6 \\
\hline 18 & 3,5 & 3,92 & 12,0 & 3,5 & 4,16 & 19,0 & 3,5 & 4,77 & 36,5 \\
\hline 20 & 3,5 & 3,94 & 12,5 & 3,5 & 4,26 & 21,8 & 3,5 & 5,07 & 45,0 \\
\hline
\end{tabular}

ческих нарушений наблюдалось повышенное заколообразование. И после уборки заколов дальнейшее заколообразование прекращалось. За период наблюдений сечение данных выработок увеличилось по отношению к проектному на 21 $\%$, а по отношению к зафиксированному после проходки на 16,8 \%, в том числе на $2 \%$ - за период обуривания блока пучками глубоких взрывных скважин, на 2 \% - за период производства массовых взрывов по образованию траншейной подсечки на высоту до 16 м и 8,8 \% - за период производства массовых взрывов по образованию двух компенсационных щелей (рис. 2, б).

В выработках, пройденных с использованием оконтуривающих взрывных скважин диаметром 110 мм во всех случаях наблюдалось повышенное разрушение приконтурного массива за счет интенсивного заколообразования. Это привело к увеличению сечения выработок за 1 год и 8 месяцев до 45\% по отношению к проектному и на $35 \%$ к зафриксированному после проходки, в том числе на $5 \%$ - за период обуривания блока пучками глубоких взрывных скважин, на 5 \% - за период производства массовых взрывов по образованию траншейной сечки блока на высоту до 16 м на и на $25 \%$ - за период производств массовых взрывов по образованию двух компенсационных щелей (рис. 2, в)

Опыты показали, что при использовании глубоких взрывных скважин диаметром 70 и 110 мм в приконтурной части нарезных выработок бурового горизонта наиболее интенсивное увеличение сечения происходит за счет заколообразования в период производства массовых взрывов по образованию компенсационных камер. В результате возрастают трудозатраты на уборку нависших кусков породы и руд с бортов и кровли выработок, а также на вскрытие пучков взрывных скважин и создаются опасные условия для труда рабочих, занятых на подготовке и проведении массовых взрывов.

Установлено, что глубина законтурного разрушения выработок, пройденных с использованием глубоких скважин, линейно зависит от диаметра оконтуривающих скважин и срока службы выработок. При диаметре скважин 70 и 110 мм эта величина достигает через 1,5-2 года (к концу отработки блока) соответственно 0,2 и 0,4 м.При проходке подготовительно-нарезных выработок протяженностью менее 20 м наиболее целесообразно применение компенсационной и взрывных скважин для образования врубовой полости и оконтуривающих шпуров для доведения контуров выработок до проектных размеров. Область применения схем образования выработок блока с использованием врубовых и оконтуривающих скважин, врубовых взрывных и компенсационных скважин и только компенсационной скважины определяется протяженностью выработок, назначением их и сроком службы.

По результатам исследований рассчитаны и построены схемы расположения шпуров и скважин для разработки технологии подготовки и нарезки очистных блоков с использованием глубоких скважин (рис. 3).

Натурные исследования, а также анализ применяемых паспортов буровзрывных работ, позволили установить основные зависимости, необходимые для расчета рациональных параметров буровзрывных работ при проходке горных выработок как мелкошпуровым способом, так и с использованием глубоких скважин. Это является основой для создания технологий проходки откаточных ортов, выработок выпуска и доставки руды, выработок горизонта подсечки и бурового горизонта при подготовке и нарезке очистных блоков в мощных залежах руд с повышенным коэффрициентом крепости. 

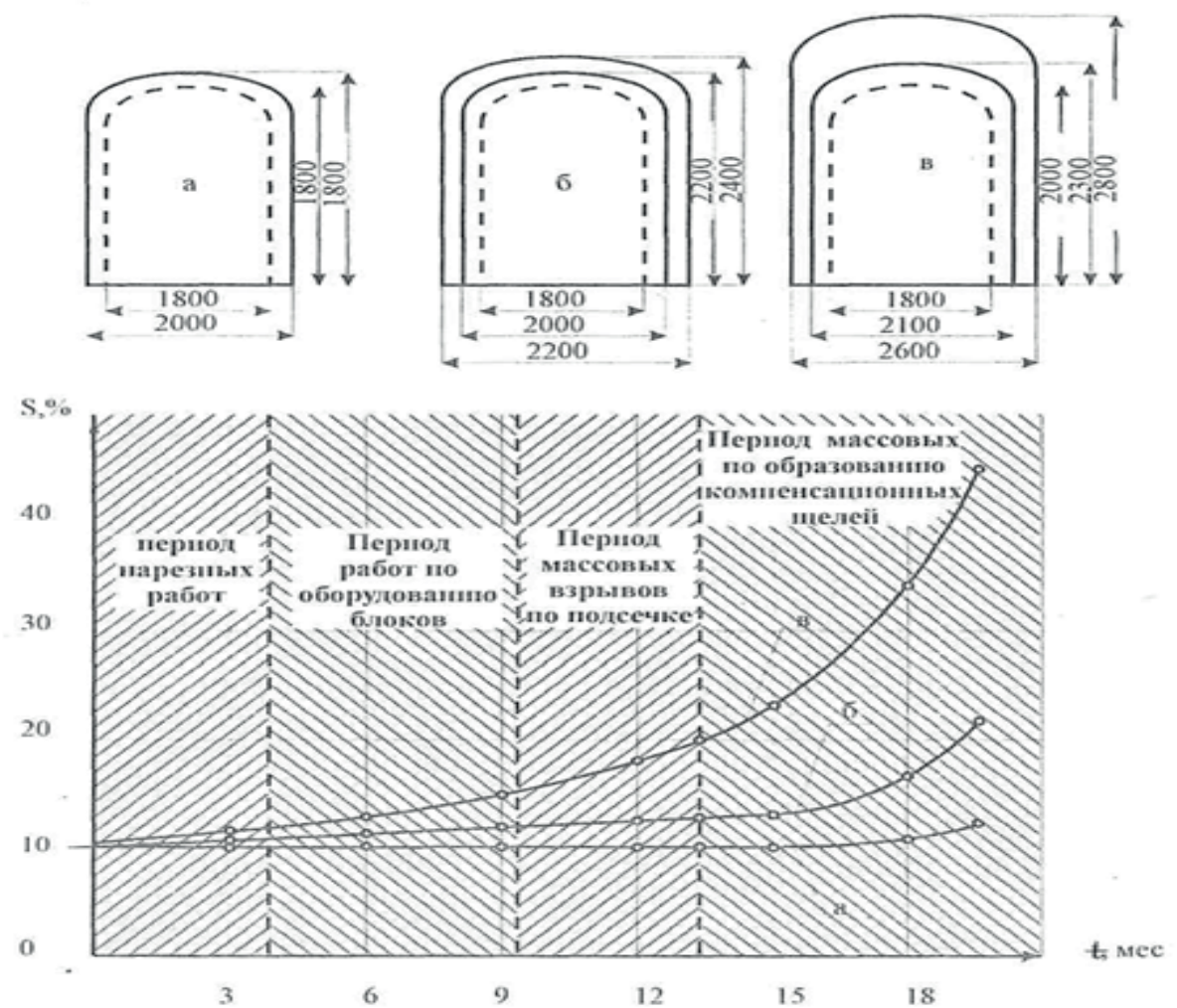

Рисунок 2. Зависимости изменения площади поперечного сечения буровых выработок блока (S) om cрока их эксплуатации (t) и способа проходки:

$a-c$ использованием компенсационной и взрывных скважин в комплекте вруба и оконтуривающих шпуров $-D=$ 43 мм; б - с использованием взрывных скважин $D=70$ мм для оконтуривания выработки; в - с использованием взрывных скважин $D=110$ мм для оконтуривания выработки.

Figure 2. Dependences of the change in cross-sectional area of the drilling workings of the block (S) on the period of their opera-tion ( $t$ ) and the method of sinking:

a - using compensation and blast holes in the set of the cut and contouring holes - $D=43 \mathrm{~mm} ; b-$ using blast holes $D=70$ $\mathrm{mm}$ for contouring the working; $c$ - using blast holes $D=110 \mathrm{~mm}$ for contouring the working.
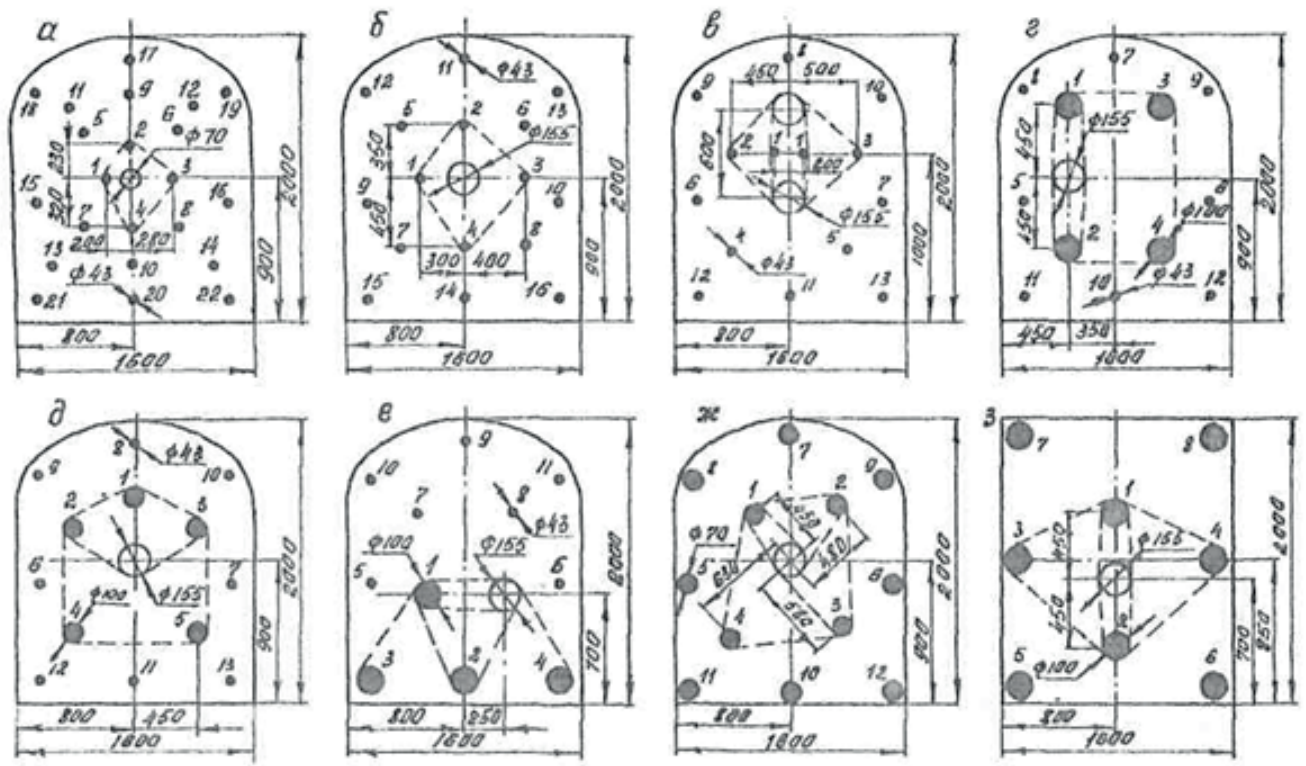

Рисунок 3. Схемы расположения шпуров и скважин для разработки технологии подготовки и нарезки очистных блоков.

Figure 3. Layouts of holes and wells for tech-nology development of extraction blocks' preparation and cutting. 


\section{СПИСОК ЛИТЕРАТУРЫ}

1. Руководство по проектированию, организации и проведению массовых взрывов на подземных рудниках фрилиалов Евразруды. - Новокузнецк, 2008. - 271 с.

2. Еременко, А. А. Совершенствование технологии буровзрывных работ на железорудных месторождениях Западной Сибири. - Новосибирск, «Наука», 2013. - 191 с.

3. Еременко, А. А. Проведение и крепление горных выработок в удароопасных зонах железорудных месторождений / А. А. Еременко, А. И. Федоренко, А. И. Копытов. - Новосибирск, «Наука», 2008. - 235 с.

4. Копытов, А. И. Экспериментально-теоретические основы совершенствования буровзрывных технологий проведения выработок на рудниках / А. И. Копытов, А. В. Ефремов, В. В. Першин. - Кемерово, 1999. - 155 с.

5. Казаков, Н. Н. Взрывная отбойка скважинными зарядами. - М.: «Недра», 1975. - 191 с.

6. Коростовенко, В. В. Технология и безопасность взрывных работ / В. В. Коростовенко, С. А. Вохмин, А. П. Андриевский. - Красноярск, 2005. - 118 с.

7. Копытов, А. И. Взрывные работы в горной промышленности / А. И. Копытов, Ю. А. Масаев, В. В. Першин. - Новосибирск, «Наука», 2013. - 510 с.

\section{REFERENCES}

1. Rukovodstvo po proyektirovaniyu, organizatsii i provedeniyu massovykh vzryvov na podzemnykh rudnikakh filialov Yevrazrudy [Guidance on the design, organization and conduct of mass explosions in the underground ore mines of Yevrazruda branches]. (2008). Novokuznetsk [in Russian]

2. Yeremenko, A.A. (2013). Sovershenstvovaniye tekhnologii burovzryvnykh rabot na zhelezorudnykh mestorozhdeniyakh Zapadnoy Sibiri [Improving the technology of drilling and blasting operations at iron ore deposits in Western Siberia]. Novosibirsk: Nauka [in Russian].

3. Yeremenko, A.A., Fedorenko, A.I., \& Kopytov, A.I. (2008). Provedeniye i krepleniye gornykh vyrabotok v pozharoopasnykh zonakh zhelezorudnykh mestorozhdeniy [Mine workings' heading and supporting in fire hazardous zones of iron ore deposits]. Novosibirsk: Nauka [in Russian].

4. Kopytov, A.I., Yefremov, A.V., \& Pershin, V.V. (1999). Eksperimental'no-teoreticheskiye osnovy sovershenstvovaniya burovzryvnykh tekhnologiy provedeniya vyrabotok na rudnikakh [Experimental and theoretical foundations for improving drilling and blasting technologies of working heading at ore mines]. Kemerovo [in Russian].

5. Kazakov, N.N. (1975). Vzryvnaya otboyka skvazhinnymi zaryadami [Explosive crushing with borehole charges]. Moscow: Nedra [in Russian].

6. Korostovenko, V.V., Vokhmin, S.A., \& Andrievsky, A.P. (2005). Tekhnologiya i bezopasnost' vzryvnykh rabot [Blasting work technology and safety]. Krasnoyarsk [in Russian].

7. Kopytov, A.I., Masaev, Yu.A., \& Pershin, V.V. (2013). Vzryvnyye raboty v gornoy promyshlennosti [Blasting works in mining industry]. Novosibirsk: Nauka [in Russian].

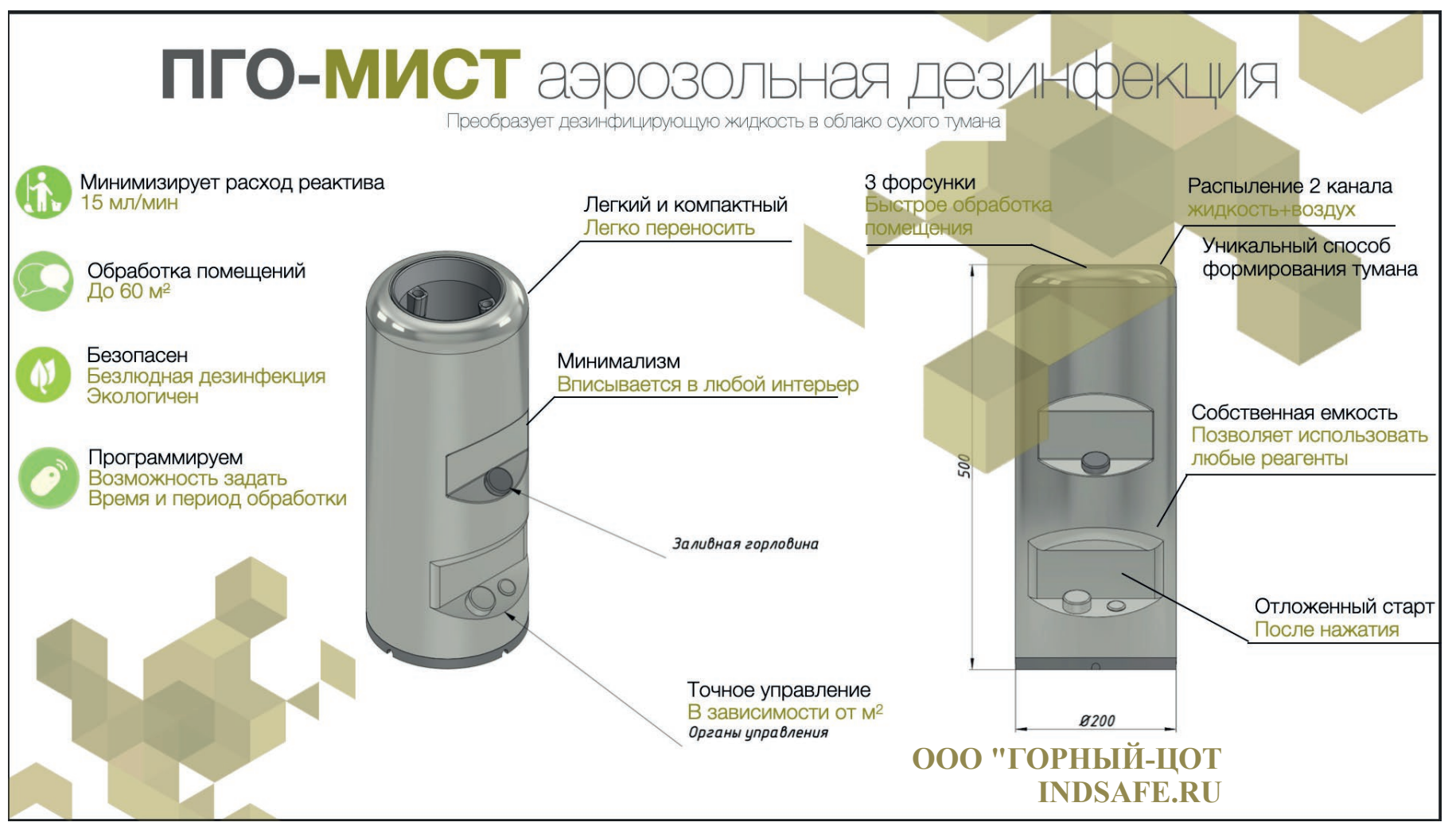




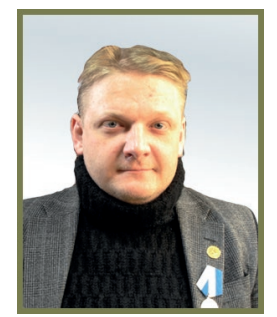

П.Б. Герике // P.B.Gerike am_besten@mail.ru

канд. техн. наук, доцент, Институт угля Федерального Исследовательского Центра угля и углехимии СО РАН, г. Кемерово пр. Ленинградский, 10 candidate of technical sciences, associate professor, chief researcher of coal engineering laboratory, FIC UUKh SB RAS. Kemerovo, Leningradsky prospect, 10

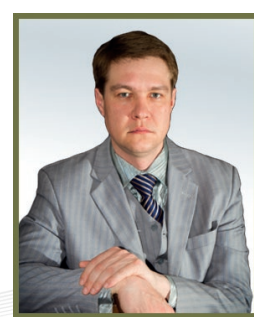

П.В. Ешеркин //

P.V.Yeshcherkin

esherkinpv@gmail.com

канд. техн. наук, доцент Кузбасский

государственный технический

университет имени Т.Ф. Горбачева,

Россия, г. Кемерово, ул. Весенняя, 28 candidate of technical sciences, associate professor of Kuzbass state technical university after T.F. Gorbachev,

Russia, Kemerovo, Vesenniaia Street, 28

Удк 681.518 .5

РАЗРАБОТКА ЕДИНОГО ДИАГНОСТИЧЕСКОГО КРИТЕРИЯ

ДЛЯ ДИАГНОСТИКИ ПОДШИПНИКОВ КАЧЕНИЯ

ЭНЕРГОМЕХАНИЧЕСКОГО ОБОРУДОВАНИЯ КАРЬЕРНЫХ

ЭКСКАВАТОРОВ

DEVELOPMENT OF A UNIFIED DIAGNOSTIC CRITERION FOR MINING

SHOVEL POWER-MECHANICAL EQUIPMENT ROLLING BEARINGS' DIAGNOSIS

В данной работе произведено обобщение некоторых результатов исследований в области анализа параметров вибрации, генерируемой при работе динамического оборудования электрических карьерныхэкскаваторов, эксплуатируемыхнапредприятияхугольнойигорноруднойпромышленности Кузбасса применительно к решению задачи по разработке единого диагностического критерия для оценки и прогнозирования процессов деградации технического состояния подшипников качения карьерных экскаваторов.

Цель работы: Выполнить классифрикацию диагностических признаков выявления дефректов подшипников качения, используемых в конструкции электрических карьерных экскаваторов и осуществить совершенствование существующих методологий нормирования параметров вибрации, а также создать алгоритм для разработки единого диагностического критерия для диагностики подшипников.

Методы исследования: $B$ настоящей работе применялись результаты комплексного диагностического подхода к анализу параметров вибрации, включая спектральный анализ в расширенном частотном и динамическом диапазоне, анализ огибающей спектра и эксцесс. Полученные результаты подтверждают эфффективность предложенного выбора диагностических методологий для создания набора признаков и правил для разработки комплексного критерия оценки и прогнозирования процессов деградации технического состояния подшипников качения.

Результаты: Полученные научные результаты доказывают принципиальную эффрективность предложенного подхода к анализу параметров вибрации и моделированию процессов деградации технического состояния оборудования карьерных экскаваторов с использованием разрабатываемого единого критерия для диагностики подшипников качения.

The discussed issue topicality. In this paper we made a generalization of some research results in the analysis of vibration parameters generated in the dynamic equipment of electric mining shovels, operated in the coal and mining industry of Kuzbass in relation to the challenge to develop a single diagnostic criterion for the rolling bearings' technical condition degradation assessing and predicting.

The main aim of the study: Classify the diagnostic signs for detecting defects in rolling bearings used in the construction of electric mining excavators and improve the existing methodologies for normalizing vibration parameters, as well as create an algorithm for developing a common diagnostic criterion for diagnosing bearings.

The methods used in the study: In this work, we used the results of an integrated diagnostic approach to the analysis of vibration parameters, including spectral analysis in the extended frequency and dynamic range, analysis of the spectral envelope, and excess. The obtained results confirm the effectiveness of the proposed choice of diagnostic methodologies for creating a set of features and rules for creating a comprehensive criterion for evaluating and predicting the rolling bearings' technical condition degradation. 
The results: The obtained scientific results prove the principal effectiveness of the proposed approach to the analysis of vibration parameters and to modeling the mining shovels'equipment technical condition degradation using the developed unified criterion for the diagnosis of rolling bearings.

КЛючевЫе слова: ВИБРОДИАГНОСТИКА, КАРЬЕРНЫЕ ЭКСКАВАТОРЫ, ПОДШИПНИКИ КАЧЕНИЯ, УПРАВЛЕНИЕ ТЕХНИЧЕСКИМ ОБСЛУЖИВАНИЕМ, МЕХАНИЧЕСКИЕ ДЕФЕКТЫ, ПРОГНОЗНОЕ МОДЕЛИРОВАНИЕ.

Key words: VIBRATION ANALYSIS, MINING SHOVELS, ROLLING BEARINGS, MAINTENANCE MANAGEMENT, MECHANICAL DEFECTS, PREDICTIVE MODELING.

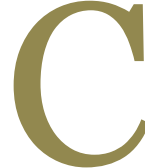

уществующие на сегодняшний день в мире единые диагностические критерии для оценки и прогнозирования процессов изменения технического состояния подшипников качения, основанные на анализе параметров вибрации, являются несовершенными и не могут в полной мере заменить собой большое количество диагностических признаков, правил и методов, таким образом упростив анализ и минимизировав затрачиваемое на него время. Именно поэтому совершенствование уже созданных и разработка новых единых диагностических критериев (ЕДК), пригодных для выполнения оценки фрактического технического состояния различных технических устройств на основе результатов анализа вибрации, является весьма актуальной научной задачей.

Очевидно, что из-за существующих ограничений на область применения ряда методов вибродиагностики набор диагностических характеристик, необходимый для создания ЕДК для каждого из конструктивных элементов сложных механических систем, будет являться уникальным. Большинство существующих ЕДК для диагностики подшипников качения имеют в своей основе два-три базовых диагностических параметра оценки, таких как: среднеквадратическое значение виброскорости в стандартном частотном диапазоне или оценку спектра огибающей по подшипниковым частотам [1, 2, 3]. Принципиальной отличительной особенностью создаваемого в рамках настоящей работы диагностического критерия является распределенный подход к оценке и выбору характеристик для описания предельного состояния подшипников качения, используемых при разработке ЕДК.

В рамках выполнения работ по гранту РФФИ № 20-48-420010ไ20 коллективом ученых из Федерального Исследовательского Центра угля и углехимии СО РАН (ФИЦ УУХ СО РАН) и ФГБОУ ВПО «КузГТУ им. Т.Ф. Горбачева» осуществляются исследования процессов формирования и распространения виброакустических волн, результатом которых должно стать создание комплекса единых диагностических критериев, пригодных для эффективного контроля фрак- тического состояния и прогнозирования деградационных процессов на энергомеханическом оборудовании электрических карьерных экскаваторов. Результаты анализа данных, полученных при проведении контроля технического состояния на выборке из двадцати единиц карьерных экскаваторов типа ЭШ и ЭКГ, эксплуатируемых на предприятиях угольной и горнорудной промышленности Кузбасса, свидетельствует о том, что в недопустимом техническом состоянии на сегодняшний день находится до $25 \%$ от общего числа обследованных технических устройств. Задачу, связанную с записью виброакустических характеристик на объектах исследования и сбором диагностической информации, существенно упростило бы использование стационарного комплекса контроля параметров вибрации, однако использование таких систем на данном технологическом оборудовании экономически не оправдано [2]. Применяемая на сегодняшний день в рамках экспертизы промышленной безопасности система оценки технического состояния горных машин по параметрам механических колебаний является несовершенной и нуждается в модернизации для эффективного выявления дефектов оборудования, в т.ч. находящихся на стадии зарождения, с возможностью выполнения оценки степени их опасности для возникновения аварийного отказа [1].

Набор диагностических методологий для решения задачи по созданию ЕДК для различных узлов и агрегатов карьерных экскаваторов будет изменяться в зависимости от типа объекта диагностирования и режимов его работы. Конкретное сочетание диагностических методологий, признаков и правил выявления дефектов меняется каждый раз при смене обследуемого объекта (подшипники, нарушение жесткости, расцентровка и т.д.). Таким образом, для каждой группы десректов диагностируемого оборудования (десекты зубчатых зацеплений в редукторах планетарного и переборного типа, подшипников качения, нарушения жесткости, дефектов электрической природы и т.д.) на основе результатов комплексного анализа параметров вибрации должен быть разработан уникальный еди- 
ный диагностический критерий, пригодный для выполнения оценки фрактического состояния и осуществления прогнозирования процессов деградации технического состояния объектов диагностирования. Создаваемые критерии должны исключить необходимость использования большого числа громоздких диагностических признаков и правил, что позволит минимизировать затраты времени на проведение обработки диагностических данных, снизить требования к квалификации специалистов, осуществляющих вибродиагностический контроль, а также повысить эффрективность анализа и прогнозирования деградационных процессов [3, 4].

Исследование большого объема диагностической информации, полученной на работающем энергомеханическом оборудовании горных машин свидетельствует о необходимости использования на практике результатов комплексного диагностического подхода к анализу параметров вибрации для получения эффрективной оценки технического состояния. В общем виде набор диагностических методологий, являющийся минимальным для виброанализа сложных механических систем, должен включать в себя результаты спектрального анализа, анализа огибающей спектра и эксцесса, в зависимости от типа оборудования и режимов его работы данный набор может быть изменен $[5,6]$.

В рамках выполнения настоящего исследования решалась задача по созданию прогнозной модели, описывающей процессы деградации технического состояния энергомеханического оборудования карьерных экскаваторов. Присутствующие сегодня на рынке специализированного программного обеспечения математические модели, предназначенные для прогнозирования процессов развития дефектов оборудования горных машин (например: дисбалансы, расцентровку и искривления валов агрегатов, дефекты подшипников качения; нарушение жесткости системы и/или структурный резонанс; повреждения элементов соединительных муфрт и т.д.) и предназначенные для осуществления кратко- и среднесрочного прогнозирования процессов деградации технического состояния объектов диагностирования на основе анализа параметров вибрации, являются несовершенными, так как область их применения зачастую очень ограничена, а апробация получаемых результатов не всегда является достаточной. Большая часть специализированного программного обеспечения, использующего алгоритмы прогностического моделирования процессов вибрации, ориентирована на описание процессов измене- ния технического состояния единичных элементов оборудования горных машин, в качестве такого элемента может выступать, например, подшипник редуктора вращателя буровой установки или подшипник генератора собственных нужд на малой генераторной группе шагающего экскаватора.

Универсальной прогностической модели, основанной на моделировании параметров вибрации и предназначенной для работы с самыми разными элементами энергомеханического оборудования горных машин, на сегодняшний день не существует. Причин для этого несколько: недостаточная изученность вопросов динамики горных машин, ограниченность существующих баз данных по параметрам вибрации однотипного механического оборудования, сложность интерпретации результатов анализа, а также трудности, возникающие при реализации математических моделей с использованием большого числа громоздких диагностических признаков и правил выявления дефектов [7, 8, 9]. Помимо перечисленного можно назвать еще одну ключевую в данном контексте причину - отсутствие устойчивой теоретической базы, учитывающей характер изменения спектрального состава получаемых данных, что крайне затрудняет создание адекватных математических моделей развития дефектов энерго-механического оборудования горной техники. Кроме того, для разработки эффективных прогнозных моделей потребуется наличие результатов комплексного подхода к анализу параметров вибрации, а также единые диагностические критерии, пригодные для осуществления оценки фактического состояния однотипных элементов оборудования горных машин.

Особенностью действующей до сих пор на предприятиях угольной и горнорудной промышленности России системы планово-предупредительных ремонтов является четкая регламентация сроков выполнения технического обслуживания эксплуатируемой техники. В этих условиях максимальный приоритет исследований должен быть отдан созданию кратко- и среднесрочных прогнозных моделей, использование которых позволит получить информацию о том, сможет ли вся эксплуатируемая техника отработать очередной период до наступления момента выхода оборудования в ремонт без возникновения аварийных ситуаций. Решение задачи по долгосрочному прогнозированию процессов деградации технического состояния обследуемых технических устройств в данных условиях является неактуальным и может представлять инте- 
рес только как теоретический элемент создания концепции обслуживания горных машин по их фактическому состоянию.

Наиболее эффективным решением данной задачи может оказаться реализация алгоритмов адаптивного краткосрочного прогнозирования деградационных процессов изменения фактического технического состояния исследуемых объектов, что при условии использования данных нескольких предыдущих измерений позволит адаптировать параметры математической модели к изменению внешних условий (например, к изменению оборотной частоты, динамических нагрузок и т.п.). Анализ ряда исследований, выполненных как отечественными, так и зарубежными авторами, позволил выявить основной недостаток существующих адаптивных прогностических деградационных моделей, основанных на результатах анализа параметров вибрации - их малую область применения, обычно ограниченную небольшой группой однотипных объектов [3, 9].

Модели такого типа, как правило, ориентированы на прогнозирование остаточного ресурса эксплуатируемого оборудования. Обычно в качестве основного диагностического критерия оценки вибронагруженности агрегатов здесь используется величина общего уровня среднеквадратического значения виброскорости в стандартном частотном и динамическом диапазонах, иногда добавляется оценка интенсивности вибрации в частотных полосах проявления дефектов, а также в частотном диапазоне, включающем частоту вращения ротора $[10,11]$. Осуществить эффективную оценку остаточного ресурса оборудования горных машин на основе анализа вибрации и дать краткосрочный прогноз изменения технического состояния объекта диагностирования возможно только при наличии высокоточных способов выделения трендов детерминированной составляющей виброакустического сигнала. При этом очень важно, чтобы результаты моделирования могли обеспечить расчет величины гарантированного остаточного ресурса и наиболее оптимального междиагностического интервала [3, 9].

Главной целью настоящего исследования является разработка и нормирование единого диагностического критерия для выявления дефректов подшипников качения, совершенствование методологических подходов к диагностике сложных механических систем и создание задела для решения задачи по созданию прогностической деградационной модели, подходящей для описания процессов изменения техническо- го состояния узлов и агрегатов энергомеханического оборудования электрических карьерных экскаваторов. Создаваемый критерий предназначен для выполнения анализа и прогнозирования процесса изменения технического состояния и должен быть одинаково эффективным на любом этапе развития дефектов - от их зарождения до стадии накопления необратимых повреждений и аварийного выхода агрегата из строя. Значительные ограничения на область применения создаваемого единого критерия для диагностики подшипников накладывают такие факторы, как: изменяющиеся во время работы агрегатов частоты, наличие тихоходных узлов (например, выходные валы редукторов напора экскаваторов ЭКГ), а также присутствие в спектре так называемых «паразитных» составляющих, наличие которых может быть вызвано ошибками при установке датчиков (неправильно выбранное место установки или неподготовленная измерительная поверхность), наличием дефректов в системе «датчик-кабель-прибор», знакопеременными ударными нагрузками, резким изменением температур и т.д. (см. пример на рисунке 1). Наилучших результатов при решении этой проблемы можно добиться с использованием гибко настроенного алгоритма фрильтрации для очистки исходных диагностических данных от «паразитных» составляющих сигнала [3, 12, 13].

Обобщение результатов исследований в области анализа параметров механических колебаний, генерируемых при работе энергомеханического оборудования электрических карьерных экскаваторов, позволило сделать вывод о том, что необходимый и достаточный минимум

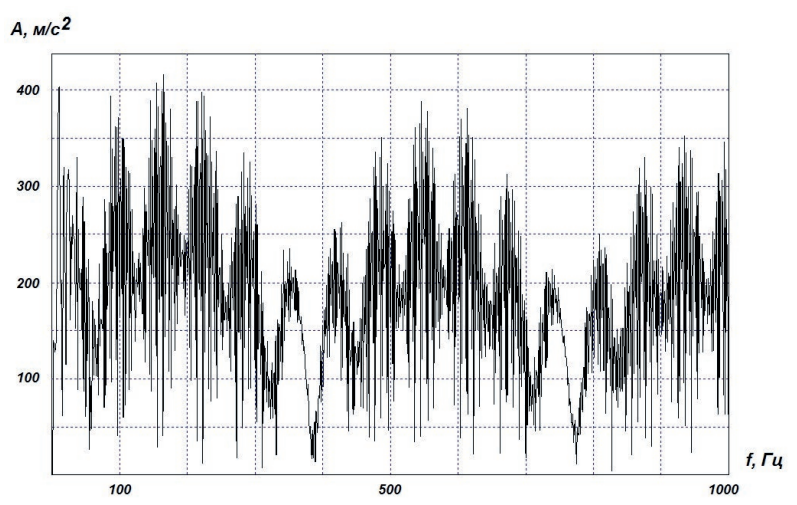

Рисунок 1. Пример искажения виброакустического сигнала, зарегистрированного на сетевом двигателе экскаватора ЭКГ-10 после запуска генераторной группы при температуре окружающего воздуха $-15^{\circ} \mathrm{C}$

Figure 1. An example of a vibro-acoustic signal distortion recorded on an EKG-10 excavator mainsoperated motor after starting a generator group at an ambient temperature of $-15^{\circ} \mathrm{C}$ 

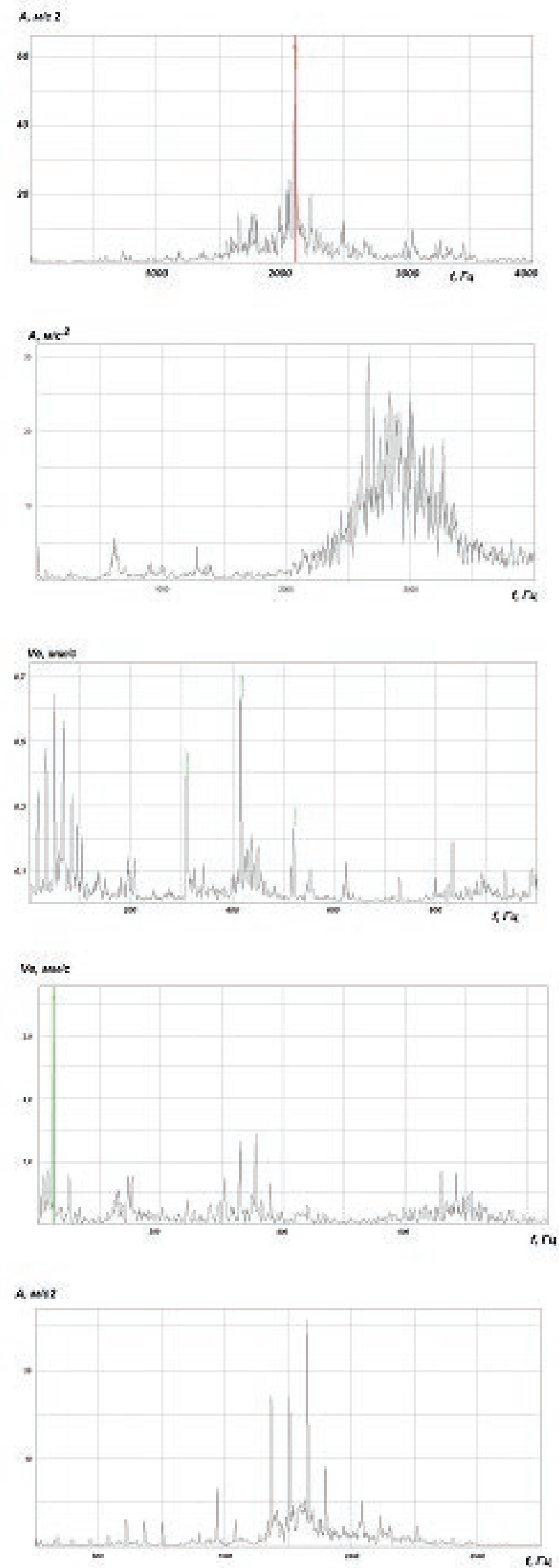

A) Недопустимое фрактическое состояние подшипника генераторной группы ЭКГ-5А, диагностируемое по общим признакам - превышению общего уровня и вклада отдельных гармоник

Б) Недопустимая степень развития множественных дефектов подшипника генератора напора экскаватора ЭКГ-8И, общий уровень сигнала по параметру виброускорения $A_{\text {СК } 3} \approx 100 \mathrm{~m} / \mathrm{c}^{2}$

В) Дефект сепаратора, повреждение внешней обоймы и множественные раковины на телах качения подшипника сетевого двигателя ЭШ $11 / 70$

Г) Износ и наклеп сепаратора, гранность тел качения подшипника входного вала редуктора поворота экскаватора ЭКГ-5А
Д) Ослабление посадки, повреждения внутреннего и внешнего кольца подшипника генератора собственных нужд ЭШ 10/70

Рисунок 2. Примеры спектров, иллюстрирующие наличие диагностических признаков некоторых дефектов подшипников

Figure 2. Spectrum examples illustrating the presence of some bearing defect diagnostic signs 
ценной диагностической информации может быть получен при помощи анализа ряда основных информативных показателей.

Для диагностики технического состояния подшипников качения такой набор диагностических критериев должен включать следующие основные показатели:

общий уровень СКЗ виброскорости и виброускорения в стандартном и расширенном частотных диапазонах;

максимумы амплитуд подшипниковых частот по параметрам виброскорости и виброускорения в стандартном и расширенном частотном диапазоне (0,5...10000 Гц);

общий уровень подшипниковых составляющих спектра по параметру виброскорости; анализ спектра огибающей в области подшипниковых частот;

расчет эксцесса.

Дефектам подшипников качения (среди которых повреждения и наклеп сепараторов, раковины и трещины колец, изменение фрормы тел качения и т.д.) соответствует около сорока базовых диагностических признаков в области вибродиагностики, большинство из которых относятся к спектральному анализу (см. примеры на рисунке 2). Данные признаки были классифицированы по типу повреждения и степени опасности, а также осуществлена их формализация для удобства дальнейшего использования при разработке ЕДК для диагностируемого оборудования по результатам анализа параметров генерируемых при его работе механических колебаний.

При разработке алгоритма создания единого диагностического критерия его неотъемлемой составляющей должна стать процедура клиппирования, необходимая для осуществления очистки исходного сигнала от присутствия составляющих иной природы, не имеющей отношения к данной рассматриваемой группе дефектов [2, 14]. Для разработки такой процедуры применяются алгоритмы фильтрации и уточнения оборотной частоты. Использованный в рамках настоящего исследования алгоритм уточнения оборотной, предложенный в работе [3], основан на принципе поиска составляющих спектра с максимальными амплитудами в области низких частот. Данный алгоритм показал высокую эффективность при осуществлении поиска оборотной частоты в спектрах по параметрам виброскорости и виброускорения даже в тех случаях, когда максимальные амплитуды гармоник априори не принадлежат оборотной частоте, он был использован при разработке спектральных масок высокой степени детализации для диагностики подшипников качения на энергомеханическом оборудовании карьерных экскаваторов. К

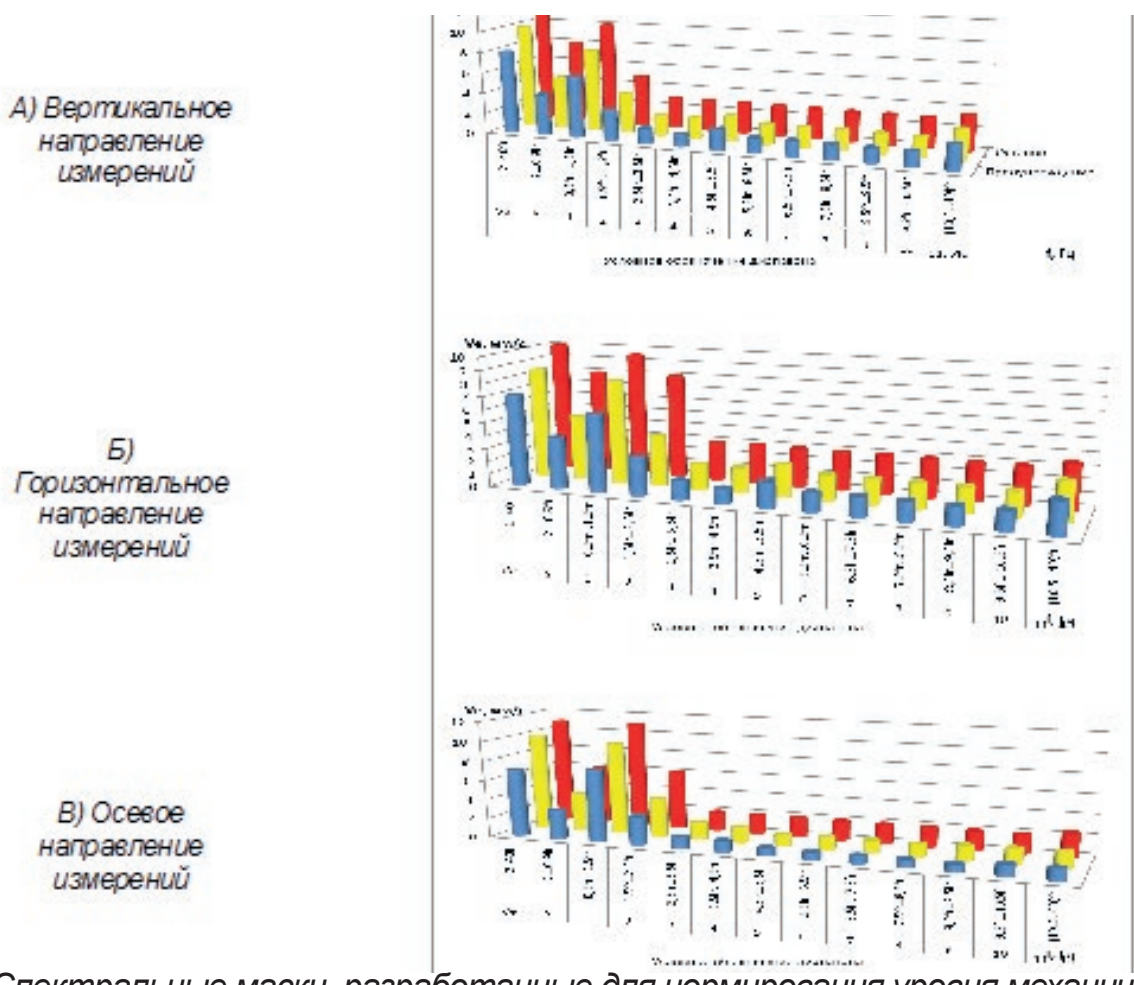

Рисунок 3. Спектральные маски, разработанные для нормирования уровня механических колебаний двигателя механизма поворота экскаватора ЭШ 10/70

Figure 3. Spectral masks designed to normalize the level of ESh 10/70 excavator rotation mechanism motor mechanical vibrations 
недостаткам этого способа нормирования относят высокую трудоемкость разработки масок, узкую область их применения (при смене объекта диагностирования работу по нормированию составляющих спектра и созданию спектральных масок необходимо начинать заново), а также сложности, возникающие при осуществлении нормирования параметров вибрации с использованием масок на оборудовании, для работы которого характерны изменяющиеся частоты (см. пример на рисунке 3).

При создании единых критериев оценки технического состояния наиболее целесообразным является использование реализации многомерного пространства диагностических признаков с применением алгоритмов скаляризации, что позволит с максимальной эфффективностью оценить процессы, свидетельствующие об изменении фрактического состояния однотипных объектов диагностирования [15]. При этом алгоритм создания единого критерия для анализа вибрации должен опираться на принципы пошаговой сегментации технических устройств на группы в зависимости от степени развития базовых дефректов диагностируемого оборудования.

В общем виде данный алгоритм создания критерия наличия дефектов подшипников качения должен включать в себя несколько основных этапов: на первом этапе - выделение значащих гармоник спектра и их нормирование; на втором - осуществляется уточнение оборотной частоты, выполняемое на основе принципа поиска гармоник с максимальными амплитудами в низкочастотной области спектра; на третьем этапе реализации алгоритма происходит фильтрация спектра, клиппирование и удаление всех составляющих, появление которых в спектре не вызвано вибрацией, генерируемой при работе подшипников, а также расчет величины общего уровня подшипниковых частот.
Использование разрабатываемого единого диагностического критерия в качестве моделируемого параметра прогнозной адаптивной математической модели позволит осуществлять краткосрочное прогнозирование на один-два интервала диагностирования, что полностью удовлетворяет требованиям системы плановопредупредительных ремонтов [16]. Реализация на практике результатов моделирования и анализа с использованием единых критериев оценки и прогнозных моделей, а также принципов комплексного подхода к анализу параметров вибрации позволит внедрить в условиях угольных предприятий России элементы системы обслуживания эксплуатируемой техники по её фрактическому техническому состоянию и отказаться от преобладающего сейчас в угольной отрасли сочетания «аварийной» схемы обслуживания оборудования и системы плановых ремонтов. Анализ полученных в рамках выполнения настоящей работы диагностических данных прямо свидетельствует о наличии острой практической необходимости в использовании результатов комплексного подхода к анализу параметров вибрации для создания группы единых критериев для осуществления быстрой и эффективной оценки технического состояния обследуемой горной техники и прогнозирования деградационных процессов. Результаты внедрения предложенной концепции позволят минимизировать риски возникновения несчастных случаев на производстве, связанных с недопустимым состоянием эксплуатируемой техники, а также оптимизировать логистику и складское хозяйство эксплуатирующих предприятий и свести к минимуму риски, возникновения аварийных простоев сложного технологического оборудования, эксплуатируемого в угольной отрасли.

\section{СПИСОК ЛИТЕРАТУРЫ}

1. Gerike P.B., Klishin V.I. Vibration analysis of electromechanical equipment of mining shovels. IOP Conference Series: Earth and Environmental Science 2019. С. 012019.

2. Неразрушающий контроль. Справочник в 7 томах под редакцией чл.-корр. РАН В.В. Клюева, т.7 - Москва, 2005. $-828 \mathrm{c}$

3. Сушко А. Е. Разработка специального математического и программного обеспечения для автоматизированной диагностики сложных систем. Дисс. ... канд. техн. наук. - М. - МИФИ. - 2007. - 170 с.

4. Puchalski A., Komorska I. Stable distributions and fractal diagnostic models of vibration signals of rotating systems. Applied Condition Monitoring. 2018, Vol. 9. Pp 91-101. https://doi.org/10.1007/978-3-319-61927-9_9

5. Pozhidaeva V. Determining the roughness of contact surfaces of the rolling bearings by the method of shock pulses. World Tribology Congress III, September 12-16, 2005, Washington, D.C., USA

6. Balducchi F., Arghir M., Gaudillere S. Experimental analysis of the unbalance response of rigid rotors supported on aerodynamic foil bearings. Proceedings of ASME Turbo Expo 2014: Turbine Technical Conference and Exposition GT2014. June 16 - 20, 2014, Düsseldorf, Germany.

7. Puchalski A. «A technique for the vibration signal analysis in vehicle diagnostics», Mechanical Systems and Signal Processing \#56-57(2015). 173-180

8. Trebuna F., Šimcak F., Bocko J., Hunady R., Pastor M. «Complex approach to the vibrodiagnostic analysis of excessive vibration of the exhaust fan», Engineering Failure Analysis \#37 (2014). 86-95 
9. Герике П.Б. Диагностика технического состояния механизмов поворота экскаваторов типа драглайн на основе анализа параметров виброакустических волн, генерируемых при их работе / Вестник Научного центра по безопасности работ в угольной промышленности, №2. - Кемерово. - 2015. С. 54-60.

10. Schreiber, R. Induction motor vibration diagnostics with the use of stator current analysis. Proceedings of the 2016 17th International Carpathian Control Conference, ICCC 2016. Pp. 668-672. https://doi.org/10.1109/ CarpathianCC.2016.7501179

11. Shardakov I., Shestakov A., Tsvetkov R., Yepin V. Crack diagnostics in a large-scale reinforced concrete structure based on the analysis of vibration processes. AIP Conference Proceedings 2053, 040090 (2018). https://doi. org/10.1063/1.5084528

12. Ширман А.Р. Практическая вибродиагностика и мониторинг состояния механического оборудования / Ширман А.Р., Соловьев А.Б. / Москва, 1996. - 276 с.

13. Барков А.В. Вибрационная диагностика машин и оборудования. Анализ вибрации. Учебное пособие. / Барков А.В., Баркова Н.А. / Издательство СПбГМТУ. Санкт Петербург, 2004. - 156 с.

14. Wang, T., Han, Q., Chu, F., Feng, Z. Vibration based condition monitoring and fault diagnosis of wind turbine planetary gearbox : A review. Mechanical Systems and Signal Processing. 2019. V.126, Pp. 662-685. https://doi.org/10.1016/j. ymssp.2019.02.051

15. Ghasemloonia A., Rideout D. G., Butt S. D. Vibration Analysis of a Drillstring in Vibration-Assisted Rotary Drilling: Finite Element Modeling With Analytical Validation. Journal of Energy Resources Technology SEPTEMBER 2013, Vol. 135 / 032902-1

16. Герике П. Б. Выбор и обоснование параметров комплексного подхода для анализа вибрации экскаваторов типа ЭКГ / Горное оборудование и электромеханика, №1. - Кемерово, 2019. С. 13-19

\section{REFERENCES}

1. Gericke, P.B., \& Klishin, V.I. (2019). Vibration analysis of electromechanical equipment of mining shovels. IOP Conference Series: Earth and Environmental Science 2019. C. 012019 [in English].

2. Nerazrushayushchiy kontrol': spravochnik. V 7-kh tomakh [Non-destructive testing: Handbook. In 7 Vol. V.7] Edited by V.V. Kliuev. Moscow: Mashinostroenie Publishers, (2005) [in Russian].

3. Sushko A. E. (2007). Razrabotka spetsial'nogo matematicheskogo i programmnogo obespecheniya dlya avtomatizirovannoy diagnostiki slozhnykh system [Development of special mathematical and software for automated diagnosis of complex systems]. Candidate's thesis. Moscow [in Russian].

4. Puchalski, A., \& Komorska, I. (2018). Stable distributions and fractal diagnostic models of vibration signals of rotating systems. Applied Condition Monitoring. Vol. 9. Pp 91-101. https://doi.org/10.1007/978-3-319-61927-9_9 [in English].

5. Pozhidaeva, V. (2005). Determining the roughness of contact surfaces of the rolling bearings by the method of shock pulses. World Tribology Congress III, September 12-16, 2005, Washington, D.C., USA [in English].

6. Balducchi, F., Arghir, M., \& Gaudillere, S. (2014). Experimental analysis of the unbalance response of rigid rotors supported on aerodynamic foil bearings. Proceedings of ASME Turbo Expo 2014: Turbine Technical Conference and Exposition GT2014. June 16 - 20, 2014, Düsseldorf, Germany. URL: http://proceedings.asmedigitalcollection.asme. org/ [in English].)

7. Puchalski, A. (2015). A technique for the vibration signal analysis in vehicle diagnostics, Mechanical Systems and Signal Processing \#56-57(2015). Pp. 173-180 [in English].

8. Trebuna F., Šimcak F., Bocko J., Hunady R., Pastor M. «Complex approach to the vibrodiagnostic analysis of excessive vibration of the exhaust fan», Engineering Failure Analysis \#37 (2014). Pp. 86-95 [in English].

9. Gericke, P.B. (2015). Diagnostika tekhnicheskogo sostoyaniya mekhanizmov povorota ekskavatorov tipa draglayn na osnove analiza parametrov vibroakusticheskikh voln, generiruyemykh pri ikh rabote [Diagnostics of dragline excavators' rotation mechanisms technical condition based on the analysis of vibro-acoustic wave parameters generated during their operation]. Vestnik nauchnogo tsentra po bezopasnosti rabot v ugolnoi promyshlennosti - Herald of Safety in Mining Industry Scientific Center, 2, 54-60 [in Russian].

10. Schreiber, R. (2016). Induction motor vibration diagnostics with the use of stator current analysis. Proceedings of the 2016 17th International Carpathian Control Conference, ICCC 2016. Pp. 668-672. https://doi.org/10.1109/CarpathianCC.2016.7501179 [in English].

11. Shardakov, I., Shestakov, A., Tsvetkov, R., \& Yepin, V. (2018). Crack diagnostics in a large-scale reinforced concrete structure based on the analysis of vibration processes. AIP Conference Proceedings 2053, $040090 \mathrm{https}: / / \mathrm{doi}$. org/10.1063/1.5084528 [in English].

12. Shirman, A.R., \& Solov'ev, A.B. (1996). Prakticheskaya vibrodiagnostika i monitoring sostoyaniya mekhanicheskogo oborudovaniya [The practical vibration analysis and monitoring of mechanical equipment] Moscow: Spectrum engineering Publishers [in Russian].

13. Barkov, A.V., \& Barkova, N.A. (2004). Vibratsionnaya diagnostika mashin i oborudovaniya. Analiz vibratsii [Vibration diagnostics of machines and equipment. Vibration analysis: Handbook]. St. Petersburg: SPbGMTU [in Russian].

14. Wang, T., Han, Q., Chu, F., Feng, Z. (2019). Vibration based condition monitoring and fault diagnosis of wind turbine planetary gearbox: A review. Mechanical Systems and Signal Processing. V.126, Pp. 662-685. https://doi.org/10.1016/j. ymssp.2019.02.051 [in English].

15. Ghasemloonia, A., Rideout, D. G., \& Butt, S. D. (2013). Vibration Analysis of a Drillstring in Vibration-Assisted Rotary Drilling: Finite Element Modeling With Analytical Validation. Journal of Energy Resources Technology SEPTEMBER 2013, Vol. 135 / 032902-1 [in English].

16. Gerike P.B. (2019). Vybor i obosnovaniye parametrov kompleksnogo podkhoda dlya analiza vibratsii ekskavatorov tipa EKG [The selection and justification of the parameters of an integrated approach for the analysis of excavators such as ECG vibration]. Gornoe oborudovanie i jelektromehanika - Mining equipment and electromechanics], 1, 13-19 [in Russian]. 


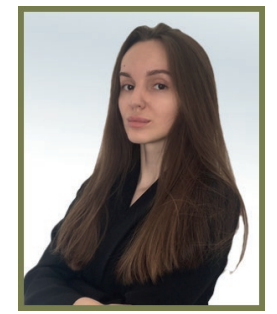

В. А. Афанасьева //

V. A. Afanasieva

afanasevavictoria176@gmail.com

студент ФГБОУ ВО «Кузбасский государственный технический университет имени Т.Ф. Горрбачева» Россия, г. Кемерово, ул. Весенняя, 28 student of FGBOU VO "Kuzbass State Technical University named after T.F. Gorbachev, Russia, Kemerovo, Vesenniaia St., 28

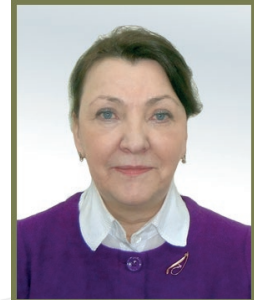

А. В. Дягилева// A. V. Diagileva

канд. техн. наук, доцент ФГБОУ ВО «Кузбасский государственный технический университет имени Т.Ф. Горрбачева», Россия, г. Кемерово, ул. Весенняя, 28 candidate of technical sciences, associate professor of FGBOU VO "Kuzbass State Technical University named after T.F. Gorbachev, Russia, Kemerovo, Vesenniaia St., 28

УДК 504.05:656.13.065

\section{ДИАГНОСТИКА ЗАГРЯЗНЕНИЯ ОКРУЯАЮЩЕЙ СРЕДЫ}

ОТРАБОТАННЫМ МАШИННЫМ МАСЛОМ В Г. КЕМЕРОВО

DIAGNOSTICS OF THE ENVIRONMENTAL POLLUTION WITH WASTE ENGINE OIL IN KEMEROVO

В начале XXI в. проблемы загрязнения окружающей среды стали актуальными для всего человечества в связи с увеличением населения планеты, быстрой урбанизацией, развитием промышленности и различных отраслей хозяйства. Мы живем в век бурного развития современных информационных технологий. Уровень автомобилизации населения растет в наше время с каждым годом, что, с одной стороны, способствует удовлетворению социальных потребностей населения, а с другой - обуславливает увеличение масштаба негативного воздействия на окружающую среду. Проблема отработанного машинного масла существует во всем мире, но далеко не все люди уделяют этой проблеме должного внимания. Отработанные масла классифицируются как опасные отходы 2 и 3 класса (т.е. высокоопасные и умеренноопасные). По данным Департамента природопользования и охраны окружающей среды, 85\% моторного масла ненадлежащим образом сливается или просачивается в канализацию и почву. Загрязнение земной поверхности каплями отработанного моторного масла может послужить причиной увеличения экологической опасности в Кузбассе. В статье представлена инфрормация о загрязнении окружающей среды города Кемерово, полученная на основе натуральных исследований, наблюдений и статистического исследования экспериментальных данных. После проведения исследования получена сводная инсрормация о загрязнении окружающей среды, наиболее загрязненных районах.

At the beginning of XXI century, the problems of environmental pollution became topical for all of humanity in connection with an increase in the world's population, the rapid urbanization, the development of industry and various sectors of the economy. We live in the century of rapid modern information technologies development and of course the level of population motorization is growing every year nowadays. On the one hand it contributes to the satisfaction of the social needs and on the other it causes an increase in the scale of negative impact on the environment. The problem of used machine oil exists all over the world, but not all people pay enough attention to this global problem. Waste oils are classified as hazardous waste of classes 2 and 3 (highly hazardous and moderately hazardous). According to the Department of Natural Resources and Environmental Protection, $85 \%$ of engine oil is improperly drained or seeped into the sewer and soil. Pollution of the earth's surface with droplets of used motor oil can cause an increase in environmental hazard in the Kuzbass. The article provides information on environmental pollution in the town of Kemerovo, obtained on the basis of field studies, observations and statistical studies of experimental data. After the study, a summary of environmental pollution and the most polluted areas was obtained.

Ключевые слова: КЕМЕРОВО, ЭКОЛОГИЯ, ОКРУЖАЮЩАЯ СРЕДА, АВТОМОБИЛЬ, ИСТОЧНИКИ ЗАГРЯЗНЕНИЙ, АНАЛИЗ СЛУЧАЙНОЙ ВЕЛИЧИНЫ, ЗАКОН РАСПРЕДЕЛЕНИЯ, ГИСТОГРАММА.

Key words: KEMEROVO, ECOLOGY, ENVIRONMENT, CAR, POLLUTION SOURCES, RANDOM VALUE ANALYSIS, DISTRIBUTION LAW, HISTOGRAM.

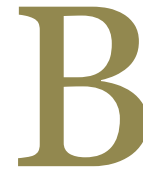

ведение

В городе Кемерово все автомобили работают в жестких городских условиях. Наиболее напряженными участка- ми по количеству вредных выбросов являются остановки, перекрестки и парковочные места. При прохождении этих пунктов увеличивается нагрузка на двигатель автомобиля (в режиме 
торможения и разгона). В этот момент капли отработанного масла срываются с двигателя. Легковые автомобили старше 10 лет, маршрутные такси, автобусы и грузовые автомобили старше 3-х лет являются самыми загрязняющими. Согласно данным “Автостата", по состоянию на начало 2019 года в России насчитывалось 25,4 млн. машин, эксплуатируемых больше 10 лет. Это составляет 58\% от общего легкового автопарка страны. Что касается грузовых автомобилей, то по состоянию на 01.01.2015 - 75\% эксплуатируется больше 10 лет.

\section{Механизм загрязнения:}

В зимних условиях капля срывается с двигателя и, затвердевая, падает на снег. В летних условиях при соприкосновении капли с асфальтом площадь пятна, получаемого в результате контакта, увеличивается в два раза. Если поверхность влажная (например, в дождливую погоду), то масло с потоками дождевой воды уходит в канализацию, а твердые частицы вдавливаются в асфральт. Отработанное машинное масло может стать одним из крупнейших источников загрязнения грунтовых вод и водотоков.

Вероятные последствия действительно серьезны: литр масла может стать источником масляного пятна площадью почти 1 га или загрязнить миллион литров питьевой воды.

Несмотря на то что в летний сезон высокие температуры оказывают свое влияние на капли отработанного масла, скорость их испарения не увеличивается, что и является одной из главных проблем. Пятна отработанного масла довольно трудно испаряются из-за наличия в своем составе различных примесей.

После попадания отработанного моторного масла в почву происходит её окисление, повышается содержание углерода. Это приводит к замедлению реакций, происходящих в почве. Из-за образования масляной пленки корни не

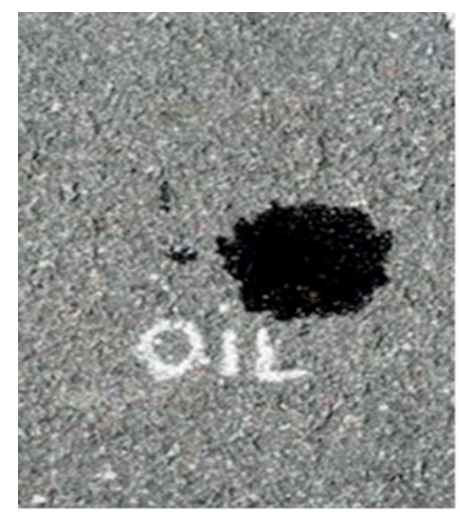

Рисунок 1 - Вид капли отработанного машинного масла на асфральте

Figure 1 - View of a waste engine oil drop on asphalt получают достаточного количества воды. Антропогенное загрязнение уже привело к тому, что $27 \%$ земель планеты подвержены эрозии (разрушению почвы).

Исходя из этого, можно сделать вывод, что загрязнение окружающей среды отработанным моторным маслом зависит от следующих факторов:

1) Среднего количества автомобилей.

2) Состояния двигателя.

3)Режима эксплуатации и погодных условий.

Для того чтобы провести диагностику загрязнения окружающей среды, мы выбрали один из достаточно загруженных участков по количеству проходящих автомобилей - перекресток на улице Автозаводской.

В качестве исходных данных выступает среднее количество автомобилей (случайная величина X), зафиксированное на данном участке в период с 6:00 до 22:00 (кроме интервала с 12:00 до 13:00) каждые 15 минут: 105, 150, 270, $475,650,890,820,740,850,790,1100,960,580$, $790,1100,960,580,790,800,330,410,650,830$, 510, 400, 200, 490, 510, 850, 430, 435, 585, 870, 648, 935, 947, 797, 857, 856, 990, 360, 695, 510, $335,310,330,519,141,250,319,296,235,163$, 189, 155, 93.

Учитывая тот факт, что более 50\% автомобилей в РФ эксплуатируется более 10 лет, движение на рассматриваемом нами участке тройное и с двигателя одного старого автомобиля срывается одна капля отработанного масла, нам удалось посчитать предположительное количество капель, попавших в окружающую среду в данный промежуток времени (случайная величина Y): 70, 100, 180, 317, 433, 593, 547, 493, $567,527,733,681,387,527,533,220,273,433$, $553,478,267,133,327,340,567,287,290,390$,

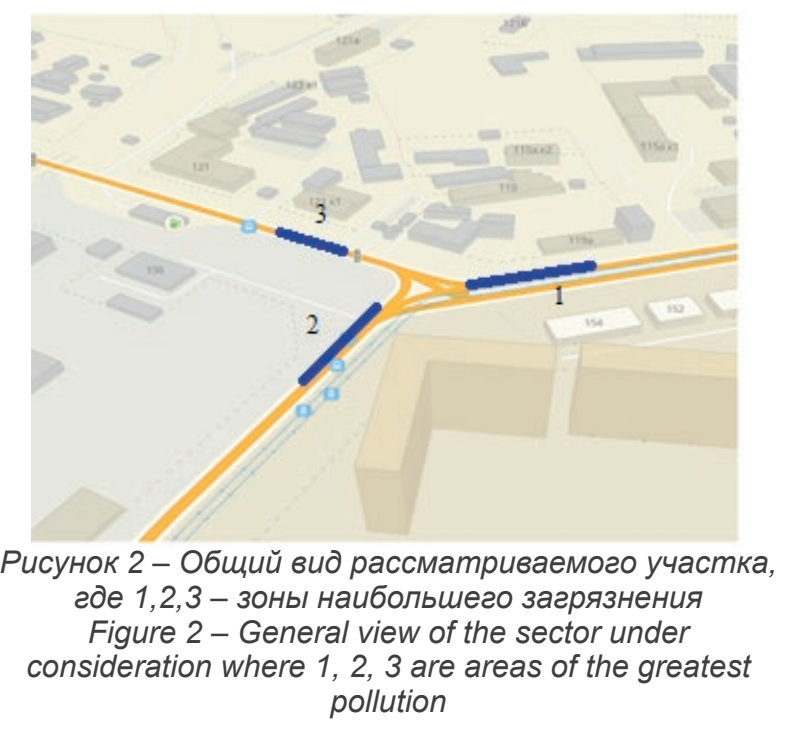


$580,432,623,631,531,571,570,660,240,463$, $340,223,207,220,346,94,167,213,197,157$, 109, 126, 103, 62.

\section{Анализ случайных величин $\mathrm{X}$ и $\mathrm{Y}$}

Предположим, что рассматривается некоторая случайная величина X, закон распределения которой неизвестен. Необходимо, опираясь на результаты опыта, определить приблизительный закон, которому подчиняется данное распределение, а для того чтобы не допустить ошибку в принятии гипотезы, провести ряд проверок по различным критериям.

Составим вариационный ряд, определив величину интервала (шага) по фрормуле Стёрджесса (1926 г.):

$$
h=\frac{x_{\max }-x_{\min }}{1+3,2 \lg n}
$$

где $n$ - количество измерений случайной величины, $x_{\max }$ и $x_{\min }$ - максимальное и минимальное значение в выборке. Если при вычислении шага получаем дробную величину, то за $h$ принимаем ближайшее целое значение.

Для того чтобы выдвинуть нулевую гипотезу о предполагаемом законе распределения $\left(H_{0}\right)$, необходимо построить и проанализировать гистограмму и полигон распределения. Кроме того, проводится анализ и числовых характеристик (выборочное среднее $\bar{x}_{\mathrm{b}}$, средний линейный разброс $d_{b}$ выборочную дисперсию $D_{b}(x)$, среднее квадратичное отклонение $\tau_{b}(x)$.

Опираясь на вид гистограммы (Рисунок 3), можно предположить, что данное распределение является равномерным $\left(\mathrm{H}_{0}\right)$.

Рассчитаем выборочную среднюю величи-

$$
\text { ну: } \quad \bar{x}_{b}=\frac{\sum n_{i} x_{i}}{n}
$$

и среднее квадратичное отклонение:

$$
\sigma_{b}(x)=\sqrt{D_{b}(x)}
$$

Далее найдем примерные значения числовых характеристик, соответствующих равно-

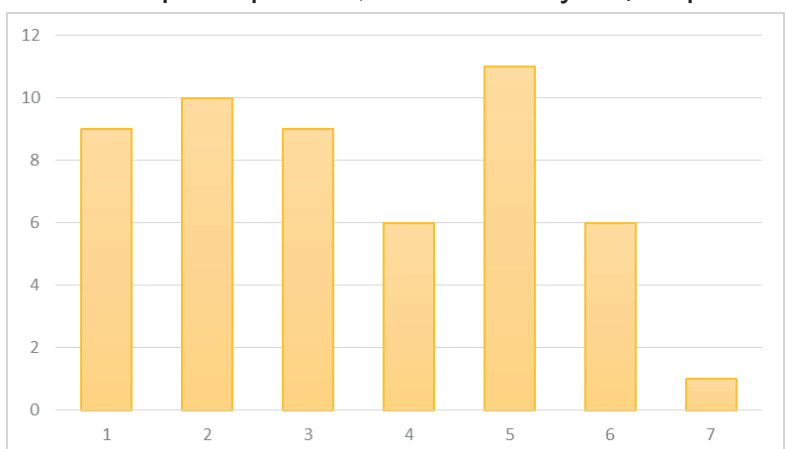

Рисунок 3 - Гистограмма распределения случайной величины X

Figure 3- Histogram of the distribution of random variable $X$ мерному распределению:

$$
\begin{gathered}
\bar{x}_{b}=\frac{x_{\max }+x_{\min }}{2}, \\
\sigma_{b}(x)=\frac{x_{\max }-x_{\min }}{3}
\end{gathered}
$$

В нашем случае разница между данными характеристиками получается весьма значительная, следовательно, гипотеза о равномерном распределении подвергается сомнению.

Предположим, что наше распределение является нормальным $\left(H_{1}\right)$.

При нормальном распределении отношение среднеквадратического отклонения $\sigma_{b}(x)$ к среднему линейному разбросу $d_{b}$ должно стремиться к 1,25.

Кроме того, проверяют сообразность гипотезы по критерию Пирсона, наблюдаемое значение которого определяется по выборке:

$$
\chi_{\text {набл. }}^{2}=\sum_{i=1}^{r} \frac{\left(n_{i}-n_{i}^{T}\right)^{2}}{n_{i}^{T}}
$$

где $n_{i}^{T}$ - теоретическая частота, полученная на основании расчётов по предполагаемому закону распределения, $r$ - число интервалов вариационного ряда после предварительного объединения, если это потребуется.

Помимо этого, нам необходимо владеть числом степеней свободы:

$$
k=r-S-1
$$

где $S$ - число параметров, которые описывают предполагаемое распределение. Используя таблицу «Критические точки распределения $\chi^{2}$ можем определить $\chi_{\text {критич. }}^{2}$ соответствующее определенному уровню значимости $\alpha$ и числу $k$. Если выполняется условие $\chi_{\text {набл. }}^{2} \leq \chi_{\text {критич. }}^{2}$, то гипотеза $H_{0}$ принимается, в противном же случае - отвергается.

По обоим критериям, приведённым выше, распределение получилось предположительно нормальным. Далее используем следующие критерии для подтверждения гипотезы о нормальности распределения: числа Вестергарда, Пирсона, Романовского, Колмогорова, а также найдем моду, медиану, коэффициент вариации, доверительный интервал, асимметрию и эксцесс.

Асимметрия - это показатель симметричности или скошенности кривой распределения, определяющийся по формуле:

$$
A_{S}=\frac{\sum\left(x_{i}-\bar{x}\right)^{8} \cdot n_{i}}{\sum n_{i} \cdot \sigma^{s}}
$$

Коэфффициент эксцесса представляет собой меру остроты пика распределения случайной величины. Определяется по следующей фрормуле:

$$
E_{S}=\frac{\sum\left(x_{i}-\bar{x}\right)^{4}}{\sum n_{i} \cdot \sigma^{4}}-3
$$


Доверительный интервал для оценки математического ожидания нормального распределения при неизвестной дисперсии генеральной совокупности определяется по формуле:

$$
\bar{x}-\frac{s}{\sqrt{n}} \cdot t_{\gamma}<a<\bar{x}+\frac{s}{\sqrt{n}} \cdot t_{\gamma} 3
$$

где $S$ - исправленная дисперсия, значение $t_{\gamma}$ находим, используя таблицу значений функции $t_{\gamma}=$ $t_{n, \gamma}$.

Анализ полученных результатов показывает, что большинство критериев подтверждает выдвинутую теорию о нормальности данного распределения.

Аналогично исследуем случайную величину $\mathrm{Y}$.

После исследования случайных величин найдем выборочный коэффрициент корреляции между ними:

$$
r=\frac{\overline{x y}-\bar{x} \cdot \bar{y}}{\sigma_{x} \sigma_{y}} \cdot 100 \%
$$

В нашем случае коэффрициент корреляции составляет 98\%, что говорит нам о наличии тесной связи между признаками $X$ и $Y$. Теперь оценим надежность полученного коэфффициента корреляции. Вычислим среднее квадратичное отклонение коэффициента корреляции:

$$
\sigma_{r}=\frac{1-r^{2}}{\sqrt{n}}
$$

Поскольку условие $\frac{\left|r_{b}\right|}{\sigma_{r_{b}}}>3$ выполняется, мы имеем право полагать, что полученный коэффициент корреляции отражает действительно существующую связь.

В заключение можно сказать: представленное исследование показывает, что посчитанное нами предположительное количество капель отработанного моторного масла, попавших в окружающую среду, справедливо и имеет место быть, поскольку полученный коэффицциент корреляции очень близок к 100\%. Вместе с тем путем лабораторных исследований нам удалось выявить, что вес капли трансмиссионного масла составляет 0,05 г. Общее предполагаемое количество капель отработанного масла составляет 19111, следовательно, на данном участке произошел выброс более 1 л. отработанного масла. Ежедневный выброс такого объема опасных отходов наносит существенный урон экологии. Для того чтобы избежать такой ситуации, людям необходимо развивать в себе экологическую осознанность и своевременно проводить диагностику своего автомобиля, устранять неисправности двигателя.

\section{СПИСОК ЛИТЕРАТУРЫ}

1. Акимова Т.А., Хаскин В.В. Основы экоразвития. - М.: Изд-во Рос. экон. акад., под редакцией В.И. Видяпина, 1994. - 312 c.

2. Стуканов В.А. Автомобильные эксплуатационные материалы: Учебное пособие. Лабораторный практикум. М.: ФОРУМ: ИНФРА-М, 2003. - 208 с.

3. Гмурман В.Е., Руководство к решению задач по теории вероятностей и математической статистике: Учебное пособие для студентов вузов/ В.Е. Гмурман. - 9-е изд., стер. - М: Высш. шк., 2004. - 404 с.

4. Кобзарь А.И. Прикладная математическая статистика. Для инженеров и научных работников. - М.: ФИЗМАТлИТ, 2006. - 816 с.

\section{REFERENCES}

1. Akimova, T.A., Haskin, V.V. (1994). Osnovy ekorazvitia [Basics of Eco-Development]. Moscow: Russian Academy of Economics [in Russian].

2. Stukanov, V.A. (2003). Avtomobil'nyye ekspluatatsionnyye materialy: Uchebnoye posobiye. Laboratornyy praktikum [Automotive Maintenance Materials: Study Guide. Laboratory workshop]. Moscow: FORUM: INFRA-M [in Russian].

3. Gmurman, V.E. (2004). Rukovodstvo k resheniyu zadach po teorii veroyatnostey i matematiche-skoy statistike: Uchebnoye posobiye dlya studentov vuzov [Guide to solving problems in probability theory and mathematical statistics: a textbook for University students]. Moscow: Vysshaia shkola [in Russian].

4. Kobzar, A. I. (2006). Prikladnaya matematicheskaya statistika. Dlya inzhenerov i nauchnykh rabotnikov [Applied mathematical statistics. For engineers and scientists]. Moscow: FIZMATLIT [in Russian] 


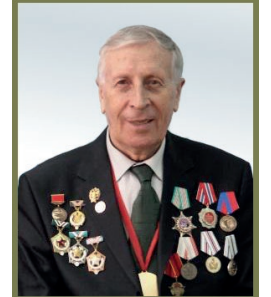

Ю. A. Macaeв // Yu.A. Masaev

канд. техн. наук, профессор ФГОУ ВО КузГТУ им. Т.Ф, Горбачева

Почетный член Академии горных наук candidate of technical sciences, professor FGOU VO KuzGTU named after T.F. Gorbachev, Honorary Member of the Academy of Mining Sciences

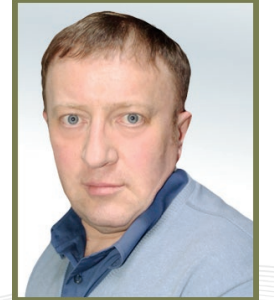

B. Ю. Масаев// V.Yu. Masaev

канд. техн. наук, доцент Кемеровская государственная сельскохозяйственная академия, кафедра ландшафтной архтектуры

candidate of technical sciences, associate professor Kemerovo State Agricultural Academy, Department of Landscape Architecture

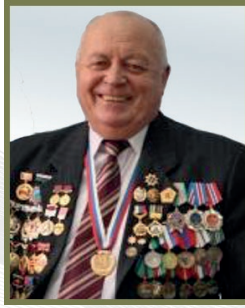

\section{А. И. Копытов//}

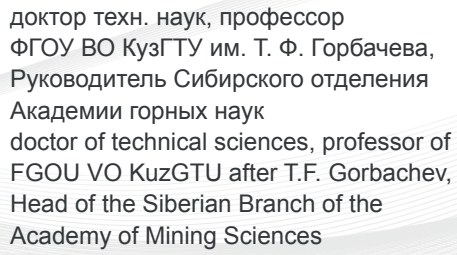

УДК 622.831, 622.235

\section{ИССЛЕДОВАНИЯ ПО УСТАНОВЛЕНИЮ РАЦИОНАЛЫНЫХ ПАРАМЕТРОВ БВР ПРИ ПОДГОТОВКЕ И НАРЕЗКЕ ОЧИСТНЫХ БЛОКОВ В МОЩНЫХ ЗАЛЕЖАХ КРЕПКИХ РУД RESEARCHES TO ESTABLISH RATIONAL DRILL AND BLAST PARAMETERS DURING THE PREPARATION AND CUTTING OF EXTRACTION BLOCKS IN THICK DEPOSITS OF HARD ORES}

Рассмотрены проблемы строительства и эффрективной эксплуатации рудных месторождений, связанных с выполнением большого объема горнопроходческих работ. Установлены закономерности влияния организационно-технических фракторов и технологических параметров буровзрывных работ и необходимости разработки на их основе новых технических и технологических решений интенсифрикации горнопроходческих работ на рудниках, обеспечивающих ограничение действия ударных воздушных волн при применении глубоких взрывных и компенсационных скважин в крепких породах.

The problems of construction and efficient operation of ore deposits related to the carrying out of a large amount of mine heading operations are considered. The regularities of the influence of organizational and technical factors and technological parameters of drilling and blasting operations, and the need to develop on their basis new technical and technological solutions for the intensification of mining operations in mines that limit the shock air waves effect when using deep blasting and compensatory hard rock wells.

КлючевЫе слова: МАССОВЫЙ ВЗРЫВ; КОМПЕНСАЦИОННЫЕ СКВАЖИНЫ; ВЫЕМОЧНЫЙ БЛОК; УДАРНАЯ ВОЗДУШНАЯ ВОЛНА; ОЧИСТНОЙ БЛОК; ГОРИЗОНТ ПОДСЕЧКИ.

Key words: MASS EXPLOSION; COMPENSATION WELLS; EXTRACTION BLOCK; SHOCK AIR WAVE; CLEAR OUT BLOCK; UNDERMINING LEVEL.

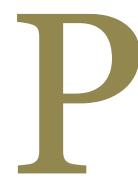
азработка железорудных месторождений Кузбасса по сравнению с угольными месторождениями отличается сложностью подготовки выемочных блоков из-за необходимости проведения различных по назначению, расположению и габаритам горных выработок, в которых требуется бурить шпуры и скважины различного диаметра, глубины и направления. Разработка рудных месторождений осложняется условиями залегания горных пород и рудных тел.

Как правило, рудые тела и горные породы пересекаются крупными тектоническими раз- ломами с амплитудой смещения более 120 м, сопровождающимися зонами смятия. Вмещающие породы состоят из скарнов, альбитафиров, порфиритов, сиенитов, мраморизованных известняков и гранитов. Рудные тела залегают на больших глубинах, до 1000 и более метров, и с увеличением глубины осложняется геомеханическая обстановка за счет перераспределения поля напряжений, а при нарушении сплошности породного массива фрормируется зона сжимающих напряжений, которые действуют вблизи периметра обнажения отрабатываемого рудного блока. В породных зонах, удаленных от вырабо- 
танного пространства, происходят смещения и изменения напряженного состояния, и наибольшая их концентрация наблюдается на расстояниях 20-60 м от выработанного пространства, а в породном массиве происходят механические процессы в виде смещений, деформаций, расколов, вызванные действием высокого горного давления. Помимо этого, при разработке месторождений в сложных горно-геологических условиях на больших глубинах повышается сейсмоактивность и удароопасность. Так, например, на Таштагольском месторождении на глубине 300 м были зафиксированы стреляния, заколообразования горных пород, а с повышением глубины разработок стали регистрироваться горные удары, микроудары и толчки различной интенсивности. Исследованиями Института горного дела им. И. А. Чинакала СО РАН было зафиксировано, что за 24 года произошло 19000 толчков различных классов, 20 горных ударов, из них 7 горно-тектонического типа, 67 микроударов.

Сложность залегания рудных тел и разработки таких месторождений требует особого подхода к проектированию и подготовке массовых взрывов. Подготовка и проведение технологических массовых взрывов осуществляется по типовым проектам, на основании которых составляется технический расчет, в котором приводятся следующие сведения:

- объем разрушаемой горной массы с указанием типа применяемых ВВ и требуемого общего количества;

- общая длина скважин с указанием их диаметров и номеров по отдельным веерам и рядам;

- способы заряжания и взрывания скважин с указанием длины заряжаемых и недозаряжаемых частей скважин, вместимости ВВ в 1 м скважины и выхода руды с 1 м скважины;

- порядок заряжания и взрывания шпуров и скважины, конструкция зарядов с указанием мест установки патронов-боевиков, электродетонаторов, СИНВ-Ш, ДШ с интервалами замедления, схем монтажа взрывных сетей;

- геолого-маркшейдерскую документацию, на которой указываются необходимые планы и разрезы с нанесенными контурами взрываемого блока, фрактическое положение горных выработок и скважин для отбойки массива и скважин для уточнения контуров рудного тела или плоскости обнажения отбиваемого массива;

- на плане горизонтов наносятся границы запретной и опасной зон, а при необходимости и на поверхности.

Современные тенденции развития систем и технологий подземной разработки мощных рудных месторождений выражаются в широком внедрении комплексной механизации процессов добычи, устранения трудоемких ручных работ, переходе на массовую одностадийную выемку руды.

Одним из главных фракторов в обеспечении производственной мощности рудников при условии увеличения глубины разработки до 600 метров и более, осложнения геомеханической обстановки и опасности по горным ударам служит принимаемая система разработки и ее конструктивное оформление.

Проведенные ранее исследования позволили сделать вывод, что технология проходки подготовительных и нарезных выработок с использованием глубоких скважин позволяет увеличить производительность труда и интенсивность подготовки блоков к очистной выемке. При этом максимальная эффективность от применения этой технологии может быть достигнута при условии концентрации выработок на строго определенных горизонтах, обеспечивая тем самым единый многозабойный фронт работ и создавая условия для независимого выполнения операций по бурению, взрыванию и уборке горной массы. На основе этого был разработан вариант конструктивного оформления системы этажного принудительного обрушения с вибровыпуском руды, обеспечивающий максимальное использование глубоких скважин при проведении подготовительно-нарезных работ в блоке (рис. 1).

Участок мощной рудной залежи разрезается подготовительными и нарезными выработками, которые размещены преимущественно на трех горизонтах. Доставочные и выпускные выработки 2 проходят на уровне откаточного горизонта. При этом боковое расположение дучек позволяет осуществить перекрытие выхода руды на платформу питателя и при необходимости демонтировать его. Таким образом, доставочные выработки используются в качестве буровых при подготовке очистного блока нижележащего этажа.

Дополнительные буровые выработки 6 (заходки) располагаются взаимно перпендикулярно и опущены на уровень почвы откаточного орта 1. Количество буровых заходок определяют из условия размещения пучков глубоких взрывных скважин 9 в соответствии с сеткой, обеспечивающей удовлетворительное дробление руды.

Выработки горизонта подсечки 4 размещены на одном уровне, образуя единую сеть по всему рудному массиву. 
Таким образом, обеспечивается независимость ведения подготовительных и нарезных работ одновременно.

В блоке 5 (на рис. 1 условно не показан) после проходки откаточного орта 1 и настилки капитальных рельсовых путей по направлению буровых доставочных выработок 2 самоходным буровым агрегатом «Шория-1 Б» бурят наклонные взрывные и компенсационные скважины в соответствии с разработанной схемой.

Одновременно на вышележащем горизонте по направлению буровых заходок 6 самоходной буровой установкой «Шория-3» бурят комплекты взрывных и компенсационных скважин по заданной схеме и нисходящие глубокие взрывные скважины для проходки отрезного восстающего 5.

В блоке 4 осуществляется проходка доставочных выработок 2, выработок горизонта подсечки 4 по предварительно обуренным скважинам и отрезного восстающего 5 методом секционного взрывания глубоких скважин.

В блоке 3 после окончания работ по проходке доставочных выработок производят монтаж питателей. В первую очередь монтируются питатели под отрезным восстающем и дучками для отгрузки горной массы из забоев выработок горизонта подсечки. Затем осуществляют проходку заходок под дучки, самих дучек и обуривание разворотов. Параллельно проходят буровые заходки 6 с уборкой горной массы в отрезной восстающий 5 и агрегатом «Шория-2Г» бурят восходящие глубокие скважины веерного расположения 12 для образования траншейной подсечки.

В блоке 2 ведут работы по подготовке к массовому взрыву, которые заключаются в бурении пучков глубоких скважин 9, образовании разворотов рудоулавливающих воронок 10 , подсечки блока и компенсационной камеры 7.

Опытно-промышленная проверка разработанной технологии подготовки и нарезки очистных блоков с использованием глубоких скважин, проведенная в условиях ОАО «Шерегешское рудоуправление» показала, что с ее применением увеличивается производительность труда и интенсивность подготовки блоков к очистной выемке в 1,5-2,0 раза.

Одним из проблемных вопросов при подготовке блоков к очистной выемке является вопрос обеспечения четкого прямолинейного контура подготавливаемого блока к массовой отбойке полезного ископаемого, исключающего неуправляемое разрушение контура горного массива следующего блока.

Нами был предложен способ повышения эфрфективности и качества оконтуривания подготавливаемого выемочного блока без дополнительных трудовых и экономических затрат за счет направленного разрушения горных пород при подготовке выемочного блока.

На рисунке приведен блок 2 подготавливаемый к очистной выемке рудного тела (схема расположения горных выработок и пробуриваемых скважин приведен на рис. 1). На границе со следующими блоком 3 пробуривают контурные пучки скважин таким образом, чтобы устья пучков скважин располагались в форме полуокружностей в направлении образуемого контура подготавливаемого блока 2.

После заряжания всех пучков скважин в подготавливаемом блоке 2 осуществляют их

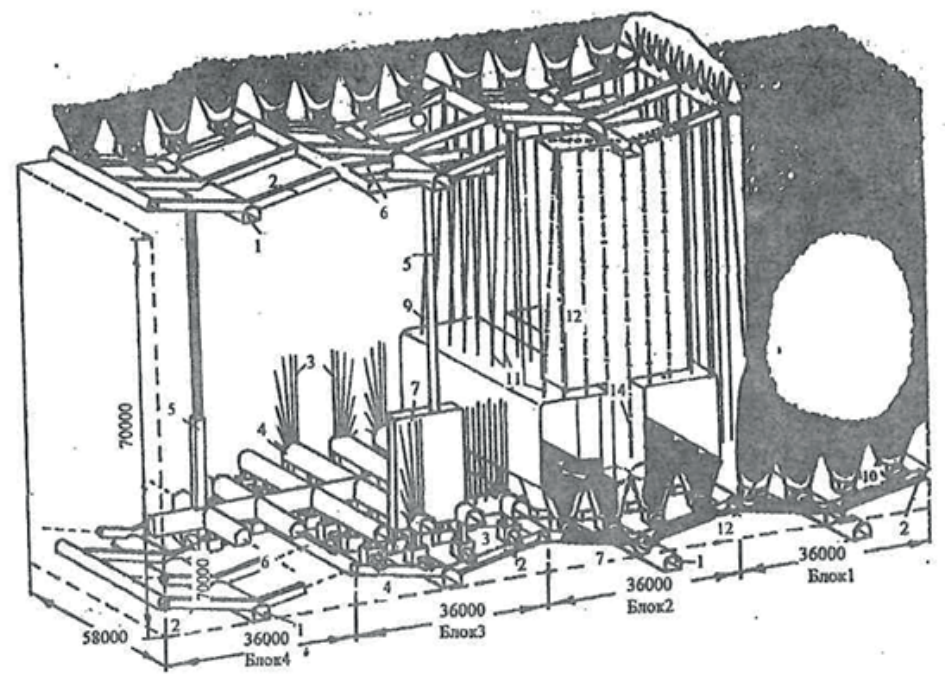

Рисунок 1. Технология подготовки и нарезки очистных блоков с использованием глубоких скважин в мощных залежах крепких руд.

Figure 1. The technology of preparation and cutting of extraction blocks using deep wells in thick deposits of hard ores. 


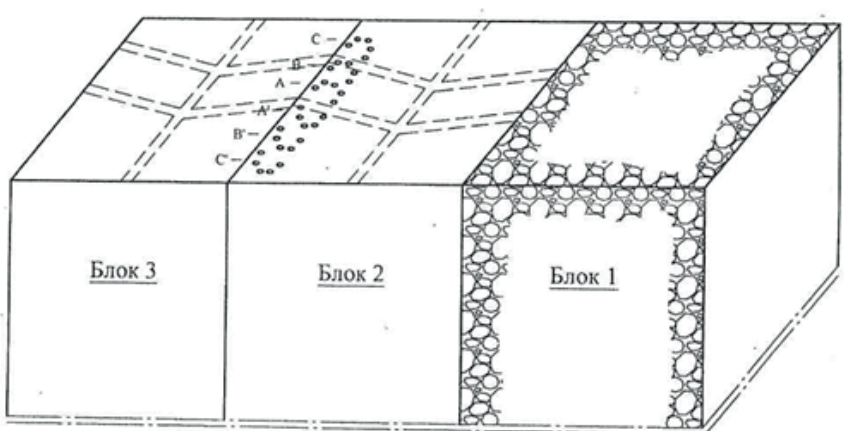

Рисунок 2. Схема расположения выемочного и подготавливаемых блоков

Figure 2. The layout of the extraction and preparation blocks

взрывание, при этом контурный ряд пучков скважин взрывают первой очередью. А в пределах контурного ряда первой серией взрывают центральные пучки скважин А-А', второй серией с замедлением пучки скважин B-B', затем C-C' и т.д. Расположение скважин в пучке в форме полуокружностей при взрывании зарядов ВВ в них создает принцип кумулятивного воздействия на разрушаемый породный массив. В этом случае волны напряжений в породе при взрыве зарядов BВ аккумулируются в направлении раскрытия полуокружностей, и на породный массив в контурном ряду создается усиленное направленное взаимодействие энергии взрыва (рис. 3).

Граница контура выемочного блока

При взрыве первой серии пучков скважин A и $A^{\prime}$ аккумулированные равнодействующие волны напряжения действуют навстречу друг другу, их взаимное воздействие на породный массив усиливается, и за счет этого происходит эффрективное разрушение участка породы между пучками скважин А и А', при этом образуется подобие врубовой щели. Второй серией взрываются пучки скважин В и В', возбуждаемые при этом аккумулированные волны напряжений достигают поверхностей от взрыва пучков скважин

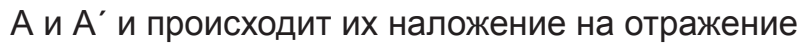
волны, что формирует усиление действия взрыва на разрушаемый породный массив. По такому же механизму разрушаются участки породы от взрыва пучков скважин C-C', D-D' и т.д. По- сле завершения взрыва пучков скважин контурного ряда формируется четкий контур границы блоков 2 и 3, что в конечном итоге повышает качество подготовки и эфффективности разрушения следующего блока.

Одним из основных факторов, определяющим способ или схему применения скважин при подготовке и нарезке блоков является протяженность и условия проветривания выработок, назначение и срок их эксплуатации.

При системе этажного принудительного обрушения с вибровыпуском руды длина блока составляет 84 м, ширина 27 м, высота 70 м, запасы сырой руды 565 тыс. т. и для подготовки к выемке полезного ископаемого необходимо проведение более 20 горных выработок протяженностью от 0,8 до 130 м и площадью поперечного

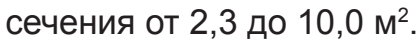

При большом количестве горных выработок различного поперечного сечения, длины и направления значительно осложняется процесс проветривания. Согласно требованиям правил безопасности выработки протяженностью до 20 м можно проветривать за счет общешахтной депрессии, во всех остальных случаях при протяженности выработок более 20 м требуется применение средств проветривания с применением нагнетательных трубопроводов. Число выработок протяженностью более 20 м составляет около 41 \% и это, главным образом, откаточные орты сечением 9,2-10,0 м2 и выработки единого горизонта подсечки сечением 7,3-7,7 м². Ведение взрывных работ с применением скважинных зарядов ВВ приводит к разрушению призабойной части вентиляционного трубопровода и, как следствие, ухудшению проветривания. Таким образом, для откаточных выработок и выработок горизонты подсечки, протяженность которых более 20 м, главным ограничивающим фактором способа применения взрывных и компенсационных скважин является условие проветривания, которое ухудшается в связи с увеличением одновременно взрываемого ВВ. Исследованиями было установлено, что в зависимости от горно-геологических и горнотехнических условий

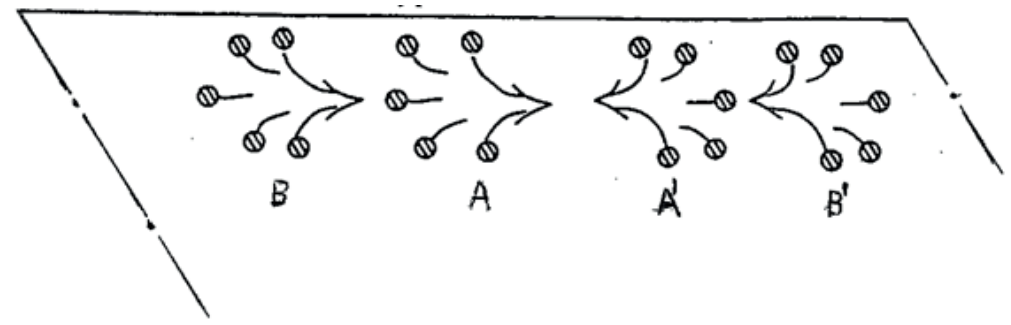

Рисунок 3. Схема направленного аккумулированного действия взрыва пучков контурного ряда скважинных зарядов ВB.

Figure 3. The scheme of the directed accumulated action of contour row borehole explosive charge bunch explosion. 
при производстве массовых взрывов по отбойке руды, эффективное снижение интенсивности воздушной ударной волны может быть получено регулированием объема компенсации. Поэтому, для проходки подготовительно-нарезных выработок протяженностью более 20 м схема расположения взрывных и компенсационных скважин (шпуров) и их диаметры в комплекте должны быть такими, чтобы за счет соответствующего объема компенсации обеспечить максимальную эффективную глубину отбойки в забое выработки и снизить воздушную ударную волну от взрыва зарядов ВВ увеличенной мощности до величины, не оказывающей разрушающего действия на средства вентиляции и призабойное оборудование.

\section{СПИСОК ЛИТЕРАТУРЫ}

1. Патент 2564716 РФ: МПК F42D 3/04. Способ направленного разрушения горных пород при подготовке выемочного блока / Копытов А. И., Масаев Ю. А. - № 2014132415/03; заявл. 05.08.2014; опубл. 10.10.2015.

2. Масаев, Ю. А. Методические разработки для выбора эфффективной геотехнологии разработки опасных по горным ударам железорудных месторождений Кузбасса / Ю. А. Масаев, А. И. Копытов // Научно-технический журнал «Вестник Научного центра по безопасности работ в угольной промышленности». Выпуск 3. - Кемерово, ООО «ВостЭКО», 2016. - С. 28-36.

3. Руководство по проектированию, организации и проведению массовых взрывов на подземных рудниках фрилиалов Евразруды. - Новокузнецк, 2008. - 271 с.

4. Еременко А. А. Совершенствование технологии буровзрывных работ на железорудных месторождениях Западной Сибири. - Новосибирск, «Наука», 2013. - 191 с.

5. Копытов, А. И. Взрывные работы в горной промышленности / А. И. Копытов, Ю. А. Масаев, В. В. Першин. Новосибирск, «Наука», 2013. - 510 с.

6. Копытов А. И. Опыт строительства подземных объектов особого назначения в условиях железорудных месторождений Кузбасса / А. И. Копытов, Ю. А. Масаев // Проектирование, строительство и эксплуатация комплексов подземных сооружений: Труды V Международной конференции - Екатеринбург, 2016. - С. 216-221.

7. Масаев, Ю. А. Новые технологии безопасной разработки рудных месторождений в условиях Кузбасса / Ю. А Масаев, В. В. Першин, А. И. Копытов // Вестник КузГТУ, №3. - Кемерово, 2012. - С. 77-83.

8. Масаев, Ю. А. Оценка сейсмического действия массового взрыва / Ю. А. Масаев, В. Ю. Масаев // Сб. Проблемы и перспективы комплексного освоения и сохранения земных недр. Междунар. научная школа акад. К. Н. Трубецкого. Ин-т комплексного освоения недр. РАН. - Москва, 2014. - С. 129-132.

9. Еременко, А. А. Проведение и крепление горных выработок в удароопасных зонах железорудных месторождений / А. А. Еременко, А. И. Федоренко, А. И. Копытов. - Новосибирск, «Наука», 2008. - 235 с.

\section{REFERENCES}

1. Patent 20141324115/03 A.I. Kopytov \& Yu.A. Masaev Sposob napravlennogo razrusheniya gornykh porod pri podgotovke vyyemochnogo bloka [The method of directed destruction of rocks in the preparation of an extraction block]. Russian Federation (2015) [in Russian].

2. Masaev, Yu.A., \& Kopytov, A.I. (2016). Metodicheskiye razrabotki dlya vybora effektivnoy geotekhnologii razrabotki opasnykh po gornym udaram zhelezorud-nykh mestorozhdeniy Kuzbassa [Methodological developments for the selection of effective geotechnology for the development of iron ore deposits in Kuzbass dangerous for rock shocks]. Vestnik nauchnogo tsentra po bezopasnosti rabot v ugolnoi promyshlennosti - Herald of Safety in Mining Industry Scientific Center, 3, 28-36 [in Russian].

3. Rukovodstvo po proyektirovaniyu, organizatsii i provedeniyu massovykh vzryvov na podzemnykh rudnikakh filialov Yevrazrudy [Guidance on the design, organization and conduct of mass explosions in the underground mines of the Yevrasruda branches. - Novokuznetsk, 2008 [in Russian].

4. Yeremenko, A.A. (2013). Sovershenstvovaniye tekhnologii burovzryvnykh rabot na zhelezorudnykh mestorozhdeniyakh Zapadnoy Sibiri [Improving the technology of drilling and blasting at iron ore deposits in Western Siberia]. Novosibirsk: Nauka [in Russian].

5. Kopytov, A.I., Masaev, Yu.A., \& Pershin, V.V. (2013). Vzryvnyye raboty v gornoy promyshlennosti [Blasting works in mining industry]. Novosibirsk: Nauka [in Russian].

6. Kopytov, A.I., \& Masaev, Yu.A. (2016). Opyt stroitel'stva podzemnykh ob"yektov osobogo naznacheniya v usloviyakh zhelezorudnykh mestorozhdeniy Kuzbassa [Experience in the construction of underground special-purpose facilities in the conditions of iron ore deposits of Kuzbass]. Proceedings from: Design, construction and operation of underground facilities: V Mezhdunarodnaya konferentsia - V International Conference. (pp. 216-2210. Yekaterinburg [in Russian].

7. Masaev, Yu.A., Pershin, V.V., \& Kopytov, A.I. (2012). Novyye tekhnologii bezopasnoy razrabotki rudnykh mestorozhdeniy $v$ usloviyakh Kuzbassa [New technologies for the safe development of ore deposits in the conditions of Kuzbass]. Vestnik KuzGTU - KuzGTU Herald, 3, 77-83 [in Russian].

8. Masaev, Yu.A., \& Masaev, V.Yu. (2014). Otsenka seysmicheskogo deystviya massovogo vzryva [Assessment of a mass explosion seismic effect]. Sbornik. Problemy i perspektivy kompleks-nogo osvoyeniya i sokhraneniya zemnykh nedr. Mezhdunar. nauchnaya shkola akad. K. N. Trubetskogo - Collection. Problems and prospects of the complex development and conservation of the Earth's interior. Int. academic school of acad. K.N. Trubetskoy. Moscow: Institute of integrated subsoil development. RAS. [in Russian].

9. Yeremenko, A.A., Fedorenko, A.I., \& Kopytov, A.I. (2008). Provedeniye i krepleniye gornykh vyrabotok v pozharoopasnykh zonakh zhelezorudnykh mestorozhdeniy [Carrying out and supportinging of mine workings in rock shock hazardous zones of iron ore deposits]. Novosibirsk: Nauka [in Russian]. 


\title{
IV. ПРОБЛЕМЫ И СУЖДЕНИЯ IV. PROBLEMS AND OPINIONS
}

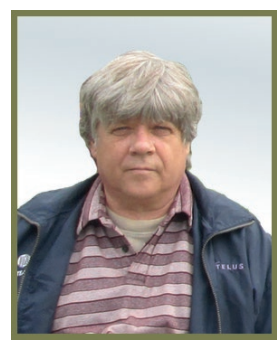

С.Б. Бычков// S.V. Bychkov sergueibychkov@gmail.com

горный инженер, Университет

Британской Колумбии, Ванкувер, Канада

mining engineer University of British

Columbia, Vancouver, Canada

УДК 622:831.322

КРУПНОМАСШТАБНЫЕ ОБВАЛЫ КАК ГЕОФИЗИЧЕСКИЙ ПРОЦЕСС ГОРНОГО УДАРА ИЛИ ВНЕЗАПНОГО ВЫБРОСА ПОРОД И ГA3A

\author{
LARGE-SCALE COLLAPSES AS A GEOPHYSICAL PROCESS OF \\ ROCK BUMP OR SUDDEN OUTBURST OF ROCKS AND GAS
}

Миллионылетатмосферные, биохимические, катагенетические, метаморфические, радиоактивные и иные газы под действием горного давления и других фризико-химических фракторов, год за годом внедрялись в породы земной коры и мантии. В процессе сорбции происходило деформирование кристаллических решёток пород с изменением их размеров и фрормы, а молекулы пород и газов образовывали устойчивые химические соединения - твёрдые растворы [1-3]. Практика показывает, что в обычных условиях обратный процесс дегазации пород, растягивается на тысячи лет, что позволяет кристаллическим решёткам без разрушения пластично изменять свои размеры и фрорму. Но, как показывает практика, в какой-то случайный момент, возможен запуск процесса лавинообразной дегазация блока пород. После внезапного исхода газов кристаллические решётки пород обязаны принять естественную конфицурацию, но в следствии высокой скорости деформаций, процесс релаксации не успевает за ростом напряжений. Происходит коллапс решёток с выделением энергии затраченной природой на их деформирование и возникновение упругих ударов - импульсов, которые известны в практике горного дела как горные удары и внезапные выбросы пород и газа. Данный процесс возможен при возникновении в горном массиве цепной химической реакции, запускаемой высокоэнергетическими молекулами, ионами и свободными радикалами по типу так называемого процесса Холодного взрыва, который был открыт в 1980 году в Институте химической фризики АН СССР. Механизм реакции Холодного взрыва объясняется возникновением в образце гигантских деформационных нагрузок, возникающих при быстром охлаждении образца. В процессе обвала в роли охлаждения выступает процесс высокоскоростной дегазации, а сам механизм цепной химической реакции объясняется взаимодействием свободных радикалов, высокоэнергетических молекул и других заряженных частиц в соответствии с постулатами Н.Бора. Описанию механизма крупномаситабного обвала и процесса образования высокоэнергетических молекул, ионов, свободных радикалов по принципиальной схеме $X \rightarrow X \cdot++e^{-} / Y+e^{-} \rightarrow Y$ необходимых для старта цепной химической реакции в горном массиве и сопутствующих процессу фризикохимических условий, посвящена данная статья.

Millions of years of atmospheric, biochemical, catagenetic, metamorphic, radioactive and other gases under the influence of rock pressure and other physico-chemical factors, were introduced into the rocks of the earth's crust and mantle year after year. In the process of sorption, the crystal lattices of the rocks were deformed with a change in their size and shape, and the rock and gas molecules formed stable chemical compounds - solid solutions [1-3]. Practice shows that under normal conditions, the reverse process of rock degassing stretches for thousands of years, which allows the crystal lattices to plasticize their sizes and shapes without breaking. But, as practice shows, at some random moment, it is possible to start the process of avalanche-like degassing of a block of rocks. After a sudden outflow of gases, the crystal lattices of the rocks must take on a natural configuration, but due to the high strain rate, the relaxation process does not keep up with the increase 
in stress. The lattice collapses with the release of energy expended by nature for their deformation and the occurrence of elastic impacts - impulses, which are known in mining practice as rock bumps and sudden outbursts of rocks and gas. This process is possible in the event of a chain chemical reaction in a rock massif triggered by high-energy molecules, ions and free radicals, similar to the so-called cold explosion process, which was discovered in 1980 at the Institute of Chemical Physics of the USSR Academy of Sciences. The reaction mechanism of the cold explosion is explained by the occurrence of giant deformation loads in the sample arising from the rapid cooling of the sample. During the collapse, the process of high-speed degassing plays the role of cooling, and the mechanism of the chain chemical reaction is explained by the interaction of free radicals, high-energy molecules, and other charged particles in accordance with N. Bohr's postulates. This article is devoted to the description of large-scale collapse mechanism and the formation of high-energy molecules, ions, free radicals according to the principle scheme $X \rightarrow X \cdot++e^{-} / Y+e^{-} \rightarrow Y$ necessary for starting a chain chemical reaction in a rock massif and the physical and chemical conditions associated with the process.

КлючевЫе слова: ОБВАЛ, ГОРНЫЙ УДАР, ВНЕЗАПНЫЙ ВЫБРОС ПОРОДИГАЗА, ТВЁРДЫЙ РАСТВОР, "БЕШЕНАЯ МУКА", ВЫСОКОЭНЕРГЕТИЧЕСКАЯ МОЛЕКУЛА, ЦЕПНАЯ ХИМИЧЕСКАЯ РЕАКЦИЯ. Key words: COLLAPSE, ROCK BUMP, SUDDEN OUTBURST OF ROCKS AND GAS, SOLID SOLUTION, "RABID FLOUR", HIGH-ENERGY MOLECULE, CHAIN CHEMICAL REACTION.

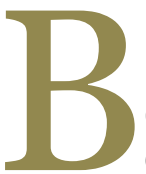

\section{ведение}

Горным ударам и внезапным выбросам пород и газа в шахтах посвящена обширная научная и горная литература. Обвалам “повезло" меньше, хотя их изучение представляет не меньший научный интерес для безопасности людей проживающих в горных районах Анд, Альп, Памира, Кавказа, Гималаев. В настоящий момент возможности учёных значительно расширились. Космическая съемка местности и система GPS представляют исследователям отличную возможность для обнаружения подобных деформаций горных образований. У учёных появилась возможность не выходя из кабинетов изучать обстановку в горах, что дает значительную экономию времени и трудозатрат при районировании территории. Используя систему GPS можно с ювелирной точностью произвести привязку крупных обвалов к геологическим образованиям отражающим современный рельефр, что даёт неоценимый материал для изучения и установления связи обвалов с различными природными явлениями. При строительстве в горных районах большое значение имеет оценка степени устойчивости склонов и возникающие здесь обвалы приводят к значительным фринансовым потерям, и необратимым изменениям ландшафрта. Опасность возникновения обвалов и необходимость изучения условий их образования многократно увеличиваются в сейсмически активных областях. Согласно определению Геологических справочников [4-7] - обвалы относится к гравитационным движениям без участия воды, происходящим на склоне больше угла естественного откоса, вследствие потери сцепления с горным массивом блока горных пород результате выветривания или потери временной опоры в результате природных или техногенных причин. Крупные блоки пород обрушаются внезапно и согласно геофизикам - этот процесс большей частью генерируется сейсмическими событиями. Размеры обвалов достигают объемов в сотни миллионов и даже миллиарды кубических метров, а экономический ущерб исчисляется миллиардами долларов, не говоря уже о тысячах человеческих жизнях.

\section{Теоретическая часть}

Согласно современным утверждениям геофизиков, растворённые в породах газы, постепенно, день, за днём дегазируясь из горного массива, создают в трещинах и кавернах породных блоков избыточное давление, которое при ослаблении горного массива проявляется в виде горных ударов, внезапных выбросов пород и газов. Механизм такого процесса геофизики сравнивают с процессом внезапного разрушения ёмкости находящейся под высоким давлением газа. При пристальном рассмотрении этого утверждения возникает парадокс. С одной стороны многочисленные опыты показали, что процесс дегазации пород занимает длительное время измеряемое сутками и годами и никогда в лабораторных условиях процессы дегазации не происходили лавинообразно. Но с другой стороны, это противоречит фрактам многочисленных горных ударов и внезапных выбросов газа и пород в подземных шахтах. К примеру, на калийной шахте Менценграбен В Германии 07.07.1953 года, произошёл внезапный выброс газа $\mathrm{CO}_{2}$. Тогда точное количество выброшенного $\mathrm{CO}_{2}$ определить не удалось, но то, что он с шумом и под давлением выходил из шахты по двум стволам в течение 25 минут, говорит за то, что его количество было не меньше нескольких сотен тысяч кубометров. Известен внезапный выброс газа более милли- 
она м ${ }^{3} \mathrm{CH}_{4}$ на шахте Санхуба в Китае [8], что эквивалентно суточному дебиту высокопродуктивной скважины на богатых месторождениях горючих газов (!). Существует ли решение этого парадокса? Из школьного курса химии известно, что наиболее распространенными физико-химическими системами являются растворы. Характерная особенность раствора состоит в том, что растворенное вещество находится в виде атомов, ионов или молекул, равномерно окруженных атомами и молекулами растворителя, то есть в них отсутствует граница раздела между растворителем и растворенным веществом. Растворы могут существовать в любом из агрегатных состояний: газообразном, жидком или твердом виде. Нас в данном случае интересуют твёрдые растворы в которых молекулы газов хаотично распределены среди молекул твердого вещества. Например, водород охотно растворяется в некоторых породах и элементах. В природе не существуют чистых кристаллических минералов, а следовательно и пород. Знание природы процессов смесимости имеет огромное значение для минералогии, геологии и общей геохимии, ибо взаимной смесимостью определено количественное распределение химических элементов горных пород в земной коре, мантии и ядре. Растворимость большинства твердых веществ с увеличением температуры увеличивается, а растворимость газов, наоборот, уменьшается. Это связано, прежде всего, с тем, что газы при тепловом движении способны покидать раствор гораздо легче, чем молекулы твердых веществ. Увеличение окружающего давления повышает растворимость газов. По своей сути любая порода является раствором переменного состава, имеющим возможность непрерывно изменять соотношение растворенного вещества и растворителя в зависимости от горных условий. Подводя краткий итог экскурса в химию, можно уверенно сказать, что газоносность зависит от геохимии горной пород и условий их залегания, возрастая с повышением горного давления, пористости и уменьшаясь с ростом температуры и водонасыщенности. Основываясь на этих знаниях, горные инженеры по фризической сути (упрощенно) сравнивают добываемый депозит полезного ископаемого с бутылкой минеральной воды, в котором под давлением растворёны различные газы. Как только бутылку открывают, давление в ней падает и тут же уменьшается растворимость газа, который начинает лавинообразно выделяться из раствора в виде пузырьков. Официальная версия обвалов, это потеря механической устойчивости консолей массива. Естественно, никто не сбрасывает со счетов возрастание консольных нагрузок за счёт деструктивных сил природы, которые несомненно могут привести к обвалу, но не они являются источниками процесса, а цепная химическая реакция (ЦХР), которая приводит к почти мгновенному превращению твёрдого раствора газа в свободное состояние. В этом случае возникает закономерный вопрос - имеет ли горный массив физическую и химическую возможность лавинообразно дегазировать газов из блока пород? До 1980 года это было неизвестно, когда в Институте химической фризики АН СССР был открыт эффрект под названием Холодный взрыв [9], который показал реальность процесса лавинообразного исхода газов при дегазации горного массива в результате цепной химической реакции. Если в цепных ядерных реакциях инициаторами реакции служат нейтроны, то в цепных химических реакциях эту роль выполняют свободные радикалы, ионы и высокоэнергетические молекулы, которые образуются при различных физических, химических, ядерных и механических процессах в горном массиве, в том числе при резком изменении горного давления. Например, в результате процесса радиолиза под действием альфа излучения происходит распад молекулы воды, которой более чем предостаточно в земной коре, по следующей схеме: из молекулы воды выбивается электрон и образуется положительно заряженный ион воды: $\gamma \rightarrow \mathrm{H}_{2} \mathrm{O} \rightarrow e^{-}+\mathrm{H}_{2} \mathrm{O}^{+}$«Вырванный» электрон присоединяется к нейтральной молекуле воды, образуя отрицательный ион воды: $e^{-}+\mathrm{H}_{2} \mathrm{O} \rightarrow \mathrm{H}_{2} \mathrm{O}$. Ионы воды, которые при этом образовались, в свою очередь диссоциируют, с образованием свободных радикалов водорода и гидроксила $\left(\mathrm{H}^{\cdot} \mathrm{OH}\right): \mathrm{H}_{2} \mathrm{O}^{+} \rightarrow \mathrm{H}^{+}+\mathrm{OH}^{\cdot} ; \mathrm{H}_{2} \mathrm{O}^{-} \rightarrow \mathrm{H}^{*}+$ $\mathrm{OH}$. Срок жизни свободных радикалов - доли секунды, в течение которых наступает рекомбинация и восстановление нормальных молекул воды. Однако в результате исключительной реактивной способности в эти короткие промежутки своего существования свободные радикалы воды дают толчок другим реакциям, развивающимся по цепному типу, а также, что особо важно для нас, к нарушению кристаллической структуры. Общая формула образования свободных радикалов имеет следующий вид: $X \rightarrow X \bullet^{+}+e^{-} / Y$ $+e^{-} \rightarrow Y^{\bullet^{-}}$. Классические примеры прохождения ЦХР изложены в работах нобелевского лауреата Н.Н. Семёнова [10-11], других учёных. Например, показательна реакция $\mathrm{H}_{2}+\mathrm{O}_{2} \rightarrow 2 \mathrm{OH}$ [ [12], из которой видно, что одна активная частица превращается в три активных частицы: атомы кислоро- 
да $O \bullet$, водорода $H \bullet$ и свободный радикал $O H \bullet$. Более подробная схема этой реакции включает более двух десятков элементарных реакций с участием свободных радикалов в реагирующей смеси, но при наличии в системе соединений азота, углерода и других примесей число ветвей реакций существенно увеличивается и может составить несколько сотен! Но не в этом суть, а том, что даже одного радикала $\mathrm{OH} \bullet$ с мизерной энергией может хватить, чтобы число активных центров начало расти в геометрической прогрессии и реакция перешла в лавинообразный режим. Для реакции каждой активной частицы с молекулой исходного вещества требуются миллиардные (!) доли секунды. Конечно, скорость реакции в твёрдом растворе будет меньше, чем в других состояниях, но тем не менее достаточно высокой для лавинообразной дегазации. Из практического опыта наблюдения и изучения горных ударов и внезапных выбросов хорошо известно, что в этом процессе могут принимать участие такие газы как: водород $H_{2}$, моноксид и диоксид углерода $\mathrm{CO}$ и $\mathrm{CO}_{2}$, азот $\mathrm{N}_{2}$, метан $\mathrm{CH}_{4}$, сероводород $H_{2} S$, аргон $A r$, гелий Не или смеси указанных газов. Что касается поглощения газов породами, то как показывает практика, все представленные в земной коре породы в процессе метаморфизма могут стать абсорбентами газов. Даже основные породы земной коры - базальты, обладающие высокой крепостью и плотностью и, казалось бы, неспособные служить адсорбентом, в процессе метаморфизма становятся идеальными абсорбентами. Так результаты [13] бурения сверхглубокой Тюменской скважины, полностью подтверждают этот вывод. С глубины 6424 метра скважина вскрыла толщу базальтов, которые в отличие от аналогичных по возрасту и составу пород, оказались сверх пористыми и превратились в идеальные адсорбенты.

\section{Энергия и механизм обвала}

В геологических словарях существует единство мнений об обвалах, как об обрушении блока пород со склона, скольжении вниз, сдвига и оседания горных пород с малыми скоростями перемещения обусловленное силой гравитации, а само явление обвала трактуется, как разрядка потенциальной энергии горных масс полученная ими в процессе тектогенеза. Казалось бы в процессе обвала нет ничего загадочного и сложного - неожиданно пришедшие в движение огромные блоки пород отделившись от материнского геологического тела, в соответствии с законом гравитации устремляются отвесно вниз. При этом скорости перемещения обвальных масс находятся в прямой зависимости от массы обвального тела, высоты ниши отрыва над местностью, коэффициентов трения, сцепления, пластичности и углов наклона поверхностей скольжения транзитной зоны, т.е. ни о каком значительном перемещении блоков пород в воздухе по наклонной дуге не может быть и речи и противоречит фундаментальным законам физики. Данные определения, являясь в настоящее время общепринятыми в геофизике и не позволяют объяснить некоторые зафиксированные фракты, которые никаким образом не вписываются в общепринятые схемы: дальность выброса, большие начальная скорости, ускорения и энергетические потенциалы отделившегося блока пород, высокие температуры обвальных масс, образование больших объёмов "бешеной муки" и стремительное поступательное движение блока пород без вращения. К настоящему времени в научной литературе задокументированы и описаны катастрофрические обвалы блоков пород, которые нарушая закон гравитации, словно огромные каменные птеродактили, вместо того, чтобы отвесно упасть в долину и разбиться о землю пролетали по пологой дуге несколько километров (!). Ярким примерам такого необычного и загадочного процесса является Кариухохский обвал на Памире, рис. 1, когда блок скальных

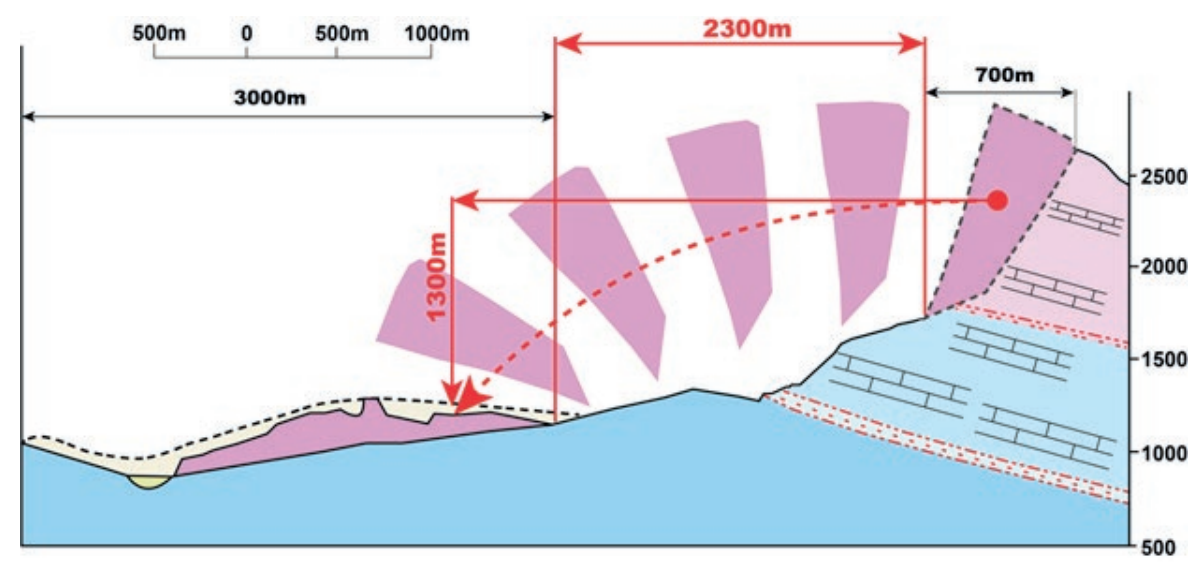

Рисунок1. Схема Кариухохского обвала. Реконструкция рис. И.М.Васькова [14], стр.250

Figure 1. Scheme of the Kariukhokh collapse. Reconstruction of I.M. Vaskov figure [14], p. 250 
пород шириной 1500 м, высотой 800 м и толщиной 300 м, объемом до 3,6 $\cdot 10^{8} \mathrm{M}^{3}$, массой $9.1 \cdot 10^{11}$ т. при удельной плотности пород $2.6 \mathrm{~T} /$ $\mathrm{M}^{3}$ отделился от материнского массива и вместо того, чтобы под действием силы тяжести сползти вниз по склону горы, пролетел по наклонной дуге 2.3 (!) километра.

Не найдя объяснения причин столь “дальнего полёта" каменных блоков современная геофризика оставила решение этой загадки на потом, а в качестве основной причины механизма обвалов рассматривает резкое увеличение консольных нагрузок за счёт потери механического сцепления блока пород с материнским телом в результате экзогенного процесса выветривания, где главным разрушителем является вода проникающая в массив по трещинам. В период перепада температур и фазовых переходов водалёд-вода происходит пульсация напряжений упругих деформаций породного блока, что ведёт к разрядке геостатических напряжений и к ослаблению сил взаимного сцепления и возникновению зоны разгрузки, для которой характерно разуплотнение, возникновение и развитие трещин бокового отпора, которые постоянно увеличиваются и в какой-то момент времени отторгают породный блок от массива. Мы согласны с такой трактовкой процесса частично, ибо для некоторых обвалов начальное движение блоков пород не может трактоваться ни как скольжение масс по поверхности отрыва, ни как разрушение массива и обвал обломков по склону ввиду наличия зоны транзита, где оторвавшиеся массы горных пород, словно снаряды выпущенные из миномёта, перемещались по пологой дуге над поверхностью склона. Изучая приведённый выше рисунок становится очевидным, что для такого перемещения блока пород необходим значительный

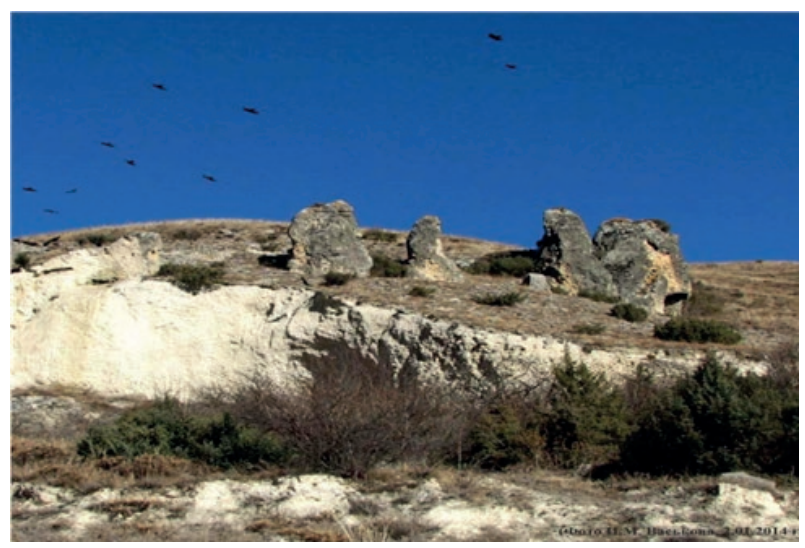

Рисунок 2а. Зона обвальных отложений Кариухохского обвала- обломки известняков и доломитов перемешанные "бешеной мукой» Figure 2a. The zone of landslides of the Kariukhokh collapse - fragments of limestone and dolomites mixed with "rabid flour".. начальный энергетический импульс, который согласно расчёту в работе [14] составляет 1,5 - 1016 Дж., или примерно 3.6 Мт.ТНТ. На основании расчёта автор делает вывод: Выделение большого количества энергии, наличие «бешеной муки» рис.2a,b, обжиг известняков и другие факты свидетельствуют о проявлении процесса типа горного удара при отрыве обвального блока.

Мы хотели бы обратить особое внимание на один из продуктов обвалов, горных ударов и внезапных выбросов пород и газа - "бешеную муку", или породную пыль тончайшего помола. Исследования с помощью электронных микроскопов [15] показали, что каждая такая пылинка имеет размер в пределах от нескольких микрон, до кластера из нескольких молекул (!). Так называемая шахтёрами “бешеная мука"является обязательным атрибутом и индикатором любого горного удара и внезапного выброса пород, которую невозможно получить никаким видом дробления, взрывными работами или другими способами, за исключением помола породы в шаровых мельницах. Этот замечательный фракт позволяет приоткрыть секрет механизма обвалов и горных ударов, ибо тончайший помол пыли указывает на то, что горные породы были разрушены на уровне кристаллических решёток и нам необходимо исходить из этого практического фракта. В горной литературе имеются многочисленные описания выделений “бешеной муки” при горных ударах и подземных выбросах [16]. Например, в результате обвала, произошедшего 12 ноября 2007 г. на северной стене Айнсера в Сикстинских Доломитах (Италия) было задокументировано [17], что обвальная масса и приле-

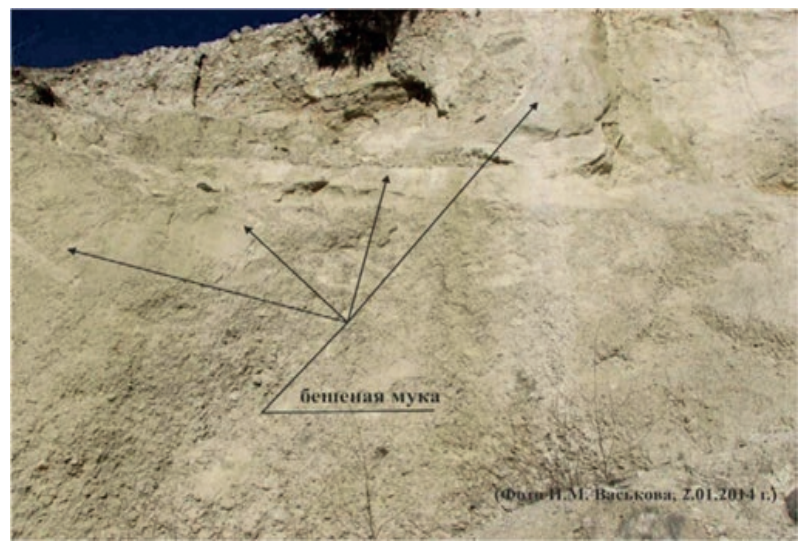

Рисунок 2b. Зона обвальных отложений (аккумуляции) Кариухохского обвала- брекчи из обломков известняков и доломитов размерами от полуметра перемешанные «бешеной мукой».

Figure $2 b$. The zone of landslide deposits (accumulation) of the Kariukhokh collapse - breccias from fragments of limestone and dolomites, half a meter in size, mixed with "rabid flour". Figure 2a is enlarged. 
гающая территория были покрыты слоем бешеной муки толщиной $~ 100$ мм. Согласно горным словарям, внезапный выброс, это часто встречающиеся в горной практики газодинамическое явление, возникающее вследствие внезапного изменения напряжённого состояния части участка ведения горных работ с внезапным выбросом из рабочей зоны породы и газа и бешеной муки, выброс которой служит веским доказательством того, что горный массив разрушился по причине лавинообразного исхода внутримолекулярного газа из кристаллических решёток пород массива. Внезапные выбросы и горные удары представляют огромную угрозу для жизни людей. Одним из наиболее опасных регионов, по данным ВНИМИ [18], является Кузбасс, на угольных и рудных шахтах которого в период с 1943 по 2005 гг. зарегистрировано 5470 динамических и газодинамических явления, в том числе: 207 внезапных выбросов, 222 горных и горно-тектонических удара, 42 микроудара, 3599 толчков и более 1400 стреляний [19]. Только на шахтах Украины за период с 1951 по 2005 гг. произошло 7230 внезапных выбросов, а в период с 1971 по 1980 гг. погибло 259 шахтёров. Это явление зафриксировано в подземных шахтах с 1738 г. (первый горный удар) и с 1834 г. (первый внезапный выброс) и хорошо изучено ввиду его доступности для исследователей и огромного статистического материала, накопленного за многие годы изучения. Самым мощным подземным выбросом пород считается выброс 14 тысяч тонн угля и около $600000 \mathrm{~m}^{3}$ газа $\mathrm{CH}_{4}$, который произошёл в 1969 г. в Украине. Горную выработку засыпало выброшенным углём на протяжении 650 м. Говоря о сейсмическом характере обвалов, мы должны заметить, что точное время Кариухохского обвала неизвестно, поэтому привязать его к сейсмическому событию в регионе нельзя. Но на наше счастье, у нас есть Усойский гигантский обвал на Памире, рис.3, время которого точно зафиксировано. Обвал произошёл 18 февраля 1911 г., 23 часа 15 минут при котором отторгнутый блок объёмом $1.3-1.5$ км $^{3}$ (!) пролетел по наклонной дуге более 5 км (!).

Вот сообщение известного русского сейсмолога того времени В.Б. Голицына от 13 мая 1915 года: - "Землетрясение силою в VIII баллов 18-го Февраля 1911 года около 11 1/4 часа вечера имело место на Памире, около Сареза и было отмечено на целом ряде сейсмических станций. В результате обвала образовалась огромная плотина, перекрывшая речку Мургаб. В результате этого возникло Сарезкое озеро длиной 75 км и шириной до 3,4 км, с глубиной 505 м. На Памирском посту землетрясение продолжалось не менее 2-х минут...". То есть В.Б.Голицын еще в 19 веке заметил связь между обвалами и сейсмической активностью. И хотя он говорит об одном землетрясении, на самом деле произошло два типа совершенно разных по механике землетрясений - первый в виде Горного удара и второй в виде Обвального землетрясения в момент удара обвального тела об землю. В расчётах автора [14 стр.280] при объёме отторгнутого блока 1.3 - 1.5 км$^{3}$ указаны такие параметры энерговыделения Усойского обвала: 1.1•1017 Дж. при отрыве блока и $1,7 \cdot 10^{17}$ Дж. при обрушении горной массы на землю, то есть в течении 20.5 секунд произошло два сейсмических события, которые идеально укладываются в картину записанных сейсмограмм ближайших станций. При перерасчёте этих цифрр в ТНТ мы получим мощность обвала равную 26.3 Мт.ТНТ и 40.6 Мт.ТНТ, что равно мощности взрыва примерно 2000 и 3000 атомных бомб сброшенных на Хиросиму!

Исходя из изложенных фактов попробуем определить механизм образования энергии крупномасштабных обвалов. Ясно, что сила гравитации в описанных выше случаях играют второстепенную роль, являясь не причиной, а лишь следствием сил процессов эрозии и служит сти-

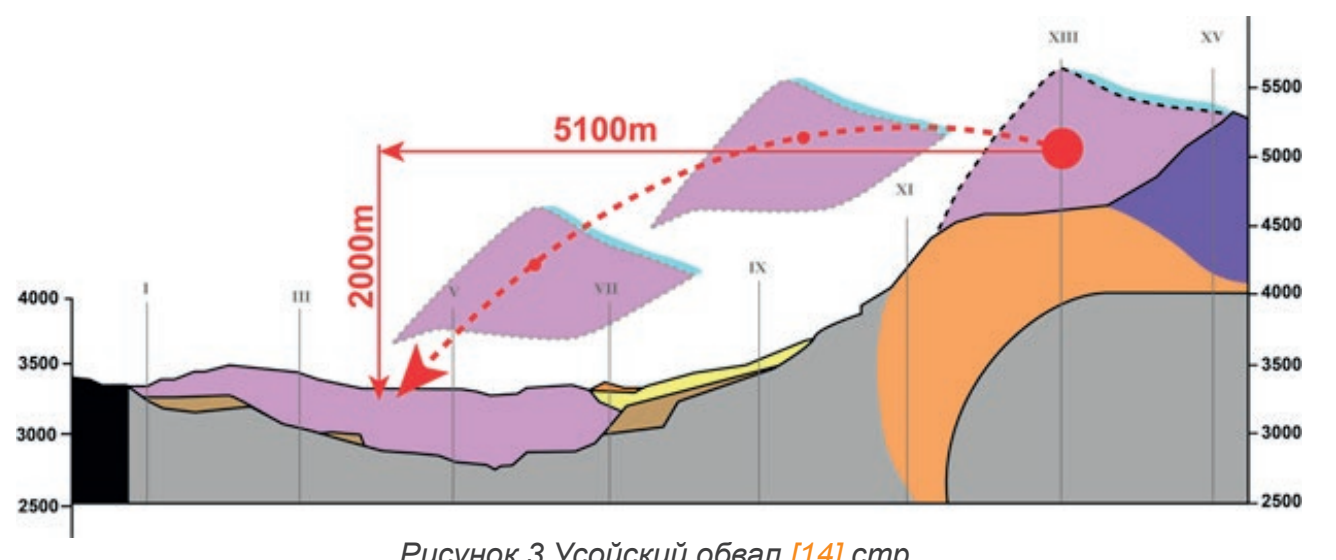

Рисунок 3 Усойский обвал [14] cmp.

Figure 3 Usoi collapse [14] p. 
мулятором процесса обвала - чем выше консольные нагрузки, тем больше разность упругих деформаций в горном массиве и следовательно, выше вероятность образования свободных радикалов и других высокоэнергетических молекул и тонов, способных запустить механизм ЦХР и вызвать горный удар в виде внезапного выброса горных пород. С точки зрения фундаментальных законов фризики ничем другим объяснить “летающие” блоки пород не представляется возможным.

\section{Нильс Бор и механизм обвалов}

В самом начале XX века, строя квантовую модель атома и формулируя свои знаменитые постулаты [20], Нильс Борн и не догадывался, что его постулаты послужат фундаментом в объяснении механизма "летающих" обвалов. Известно, что атом содержит ядро из протонов и нейтронов, и электронов, которые обращаются по орбитам вокруг ядра. С точки зрения классической электродинамики, такой атом будет неустойчив, так как при движении электроны должны излучать энергию в виде электромагнитных волн и, следовательно, терять энергию. Постепенно электроны должны упасть на ядро, что привело бы к коллапсу Вселенной. Но этого не происходит! Чтобы разрешить этот парадокс, мистер Бор предложил два постулата:

1. Атомы и атомные системы могут длительно пребывать только в определенных состояниях - стационарных состояниях, - в которых, несмотря на происходящие в них движения заряженных частиц, они не излучают и не поглощают энергию. В этих состояниях атомные системы обладают энергиями, образующими

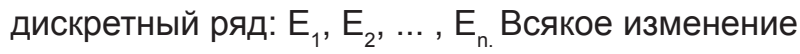
энергии в результате поглощения или испускания электромагнитного излучения может происходить только при полном переходе (скачком) из одного стационарного состояния в другое стационарное состояние.

2. При переходе из одного стационарного состояния в другое атомы испускают или поглощают излучение только строго определенной частоты. Постулаты Нильса Бора были триумфально подтверждены опытами [21] Д. Франка и Г. Герца. Предлагаем рассмотреть энергетического состояние блока пород с точки зрения квантовой теории строения атома по Н.Бору. В момент фрормирования пород земной коры и перемещений какого-то отдельно взятого блока на какую-то глубину и обратно на поверхность в виде горных систем, атомам блока была сообщена энергия сил объёмного давления и кристаллические решётки пород блока интенсивно сорбировалась различными газами. То есть геофизические силы совершили работу по формированию массива. Электроны атомов пород получили потенциальную энергию упругих деформаций и согласно постулатам Бора перешли на внешнюю орбиту с поглощением кванта энергии, рис.1а. Породный массив в таком состоянии может находиться сколько угодно долго в зависимости от величины будущих сил деформаций и некоторых физических (например, РТ) и химических параметров (например, растворимости газов), от которых напрямую зависит величина критического потенциала (первый потенциал возбуждения).

При каких-то подвижках геологических тел, изменении их физического или химического состояния, теплового фактора, резкого увеличения консольной нагрузки и т.д. произойдёт перераспределения напряжений в горном массиве. Электроны в соответствии с принципом минимума энергии и постулатом Бора постараются сбросить запасённую ими потенциальную энергию и сделают скачок к ядру и займут стационар-
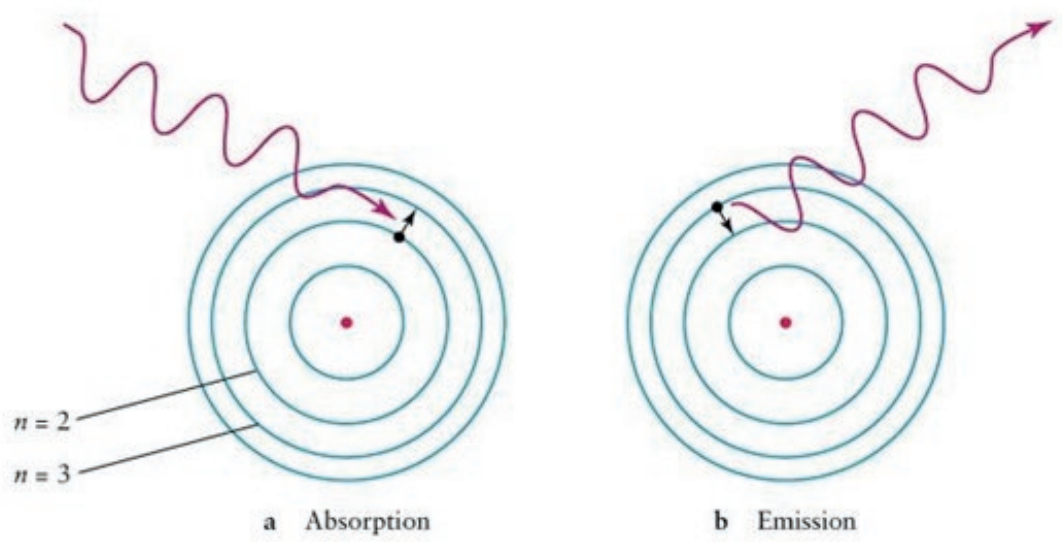

Рисунок 4. Графрический смысл постулатов Бора. Figure 4. The graphic meaning of Bohr's postulates. 
ную орбиту в соответствии с величиной критического потенциала, излучив квант энергии, рис.1 b. Мгновенный сброс энергии атомами приведёт к резкому скачку температуры в месте ниши отрыва обвала (на это указывают оплавленные породы обвалов), зональному снижению давления и как следствие к скачкообразному уменьшению растворимости газов, которые постараются перейти в свободное состояние. Из физики известно, что при движении заряда (электрона) возникает электрический ток, то есть горный массив станет проводником. Но, так как появившиеся области с разной величиной горного давления будут генерировать разную полярность, то возникнет разность потенциалов. Так как движение электронов в горном массиве будет происходить с ускорением, а сила тока будет меняться, то электрический ток будет носить переменный характер, значит вокруг заряда возникнут электрические и магнитные поля и ток самоиндукции. Разгоняясь в появившимся электромагнитном поле на расстоянии свободного пробега, электроны могут приобретать кинетическую энергию, достаточную для ударной ионизации атомов или молекул материала при соударениях с ними. В результате каждого такого столкновения с достаточной для ионизации энергией возникает пара противоположно заряженных частиц, одна или обе из которых также начинают разгоняться электрическим полем и могут далее участвовать в процессе ударной ионизации, который приведёт к появлению высокоэнергетических ионов и молекул и свободных радикалов. Как результат возникнет цепная химическую реакции по образцу описанного выше Холодного взрыва. Плюс, в результате возникновения электрического и магнитного полей, фазовых переходов и механических деформаций массива в следствии изменения консольных и других нагрузок, в обвальном блоке пород, по аналогии с выбросами пород в подземных шахтах, обязательно возникнут явления различных стрикций [22] (электро, механо, термо, магнито). Процессы стрикций начнут "раскачивать" горный массив, что приведёт к микроударам в виде пульсаций предваряющих главный удар. В этот момент может начаться другой разрушительный процесс, известный, как цепной процесс магнитопластичности, хорошо изложенный в работе академика РАН А.Л.Бучаченко [23], который дополнит и усилит картину обвала. Согласно теории мистера Бора, электрон, в зависимости от величины критического потенциала и дискретного ряда, может прыгнуть сразу через несколько стационарных орбит, что естественно значительно увеличит дальность полёта камен- ного монстра.

\section{Дискуссия}

Наличие значительных транзитных зон обвальных тел и энергия выброса соответствует физическим, химическим и механическим параметрам и условиям внезапных выбросов пород и газов в подземных шахтах, а их производная - бешеная мука, однозначно указывает на идентичность процессов, причём тончайший помол бешеной муки также однозначно указывает на разрушение пород на кристаллической уровне. Так как случайными совпадениями эти фракты объяснить нельзя, следовательно, крупномасштабные обвалы и внезапные выбросы пород в шахтах имеют одну природу и один механизм и в этом не должно быть никаких сомнений. Трудность изучаемого вопроса состоит в том, что природа внезапных выбросов [24] до сих пор не понятна до конца, а существующие современные теории не могут объяснить суть явления за исключением, пожалуй, гипотезы Деформационного взрыва пород [25]. Авторитетный исследователь внезапных выбросов и горных ударов, Член-корреспондент РАН Г.Грицко отметил [26]: "Современные научные представления о происходящих процессах при горных ударах и внезапных выбросах в шахтах не соответствуют реальным процессам". Другой сложный вопрос возникающий при рассмотрении обвалов состоит в явной связи обвалов и землетрясений. Некоторые учёные это категорически отрицают: [27, 28], а другие учёные согласны в наличие такой связи, но не раскрывают при этом механизма процесса [29]. Мы надеемся, что наша гипотеза прольёт свет, как на процесс обвалов, так и на процесс внезапных выбросов и горных ударов.

\section{Заключение}

Из представленной работы вытекают несколько выводов:

1. Потенциальная энергия деформированных кристаллических решёток пород горного массива основывается на энергии кулоновского взаимодействия атомов и молекул.

2. Стартом и движущей силой обвала, как вида внезапного выброса пород, служит потенциальная энергия деформированных кристаллических решёток пород горного массива, который по каким-то причинам начал выходить их равновесного состояния с излучением энергии электронами при переходе с одной стационарной орбиты на другую, согласно постулатам Н.Бора.

3. Процесс выделения энергии упруги деформаций кристаллических решёток влечёт за собой образование высокоэнергетических моле- 
кул, ионов и свободных радикалов, которые могут вызвать химическую цепную реакцию, так и цепную реакцию магнитопластичности. Вместе с возникшими процессами различного рода стрикций, все эти явления могут привести к крупномасштабному обвалу.

4. Согласно теории мистера Бора, электрон, в зависимости от величины критического потенциала и дискретного ряда, может прыгнуть сразу через несколько стационарных орбит, что значительно увеличит мощность обвала. Мо- дель обвала будет выглядеть так:

Изменение ландшафота $\rightarrow$ Растрескива-

ние массива $\rightarrow$ Резкое изменение горного давления внутри горной системы $\rightarrow$ Образование высокоэнергетичных молекул, ионов и свободных радикалов $\rightarrow$ Cтарт цепной химической реакции $\rightarrow$ Лавинообразный исход газов из кристаллических решёток пород $\rightarrow$ Лавинообразное выделение потенциальной энергии электронов и энергии ЦХР $\rightarrow$ Образование ударной волны $\rightarrow$ Отброс горного блока.

\section{СПИСОК ЛИТЕРАТУРЫ}

1. ТВЕРДЫЕ РАСТВОРЫ. — Текст : электронный // Химик : [сайт]. — URL: http://www.xumuk.ru/encyklopedia/2/4329. html (дата обращения: 18.06.2020).

2. ТВЕРДЫЕ РАСТВОРЫ. - Текст : электронный // Энциклопедия фризики и техники : [сайт]. — URL: http://femto. com.ua/articles/part_2/3986.html (дата обращения: 18.06.2020).

3. Solid solution. - Текст : электронный // Encyclopaedia Britannica : [сайт]. — URL: https://www.britannica.com/ science/solid-solution (дата обращения: 18.06.2020).

4. Геологический словарь, 2011. - Текст : электронный // Геокнига : [сайт]. — URL: http://www.geokniga.org/ bookfiles/geokniga-geologicheskiy-slovar-tom-2-k-p.pdf (дата обращения: 18.06.2020).

5. Географическая энциклопедия. - Текст : электронный // academic.ru : [caйт]. — URL: http://dic.academic.ru/dic. nsf/enc_geo (дата обращения: 18.06.2020).

6. What is a landslide?. - Текст : электронный // BGS : [сайт]. — URL: http://www.bgs.ac.uk/research/ engineeringGeology/shallowGeohazardsAndRisks/landslides/whatls.html (дата обращения: 18.06.2020).

7. Whittow, John (1984). Dictionary of Physical Geography. London: Penguin, 1984. ISBN 0-14-051094-X.

8. Внезапный выброс. - Текст : электронный // MiningWiki : [сайт]. — URL: http://miningwiki.ru/wiki/\%D0\%92\%D0\% BD\%D0\%B5\%D0\%B7\%D0\%B0\%D0\%BF\%D0\%BD\%D1\%8B\%D0\%B9_\%D0\%B2\%D1\%8B\%D0\%B1\%D1\%80\%D0 \%BE\%D1\%81 (дата обращения: 18.06.2020).

9. Кожушнер, М. А. Холодный взрыв / М. А. Кожушнер. - Текст : электронный // Кванта : [caйт]. — URL: http://kvant. mccme.ru/1983/02/p20.htm (дата обращения: 18.06.2020).

10. SEMENOV, N. N. Some problems relating to chain reactions and to the theory of combustion / N. N. SEMENOV. Текст : электронный // College of Earth and Mineral Sciences personal pages : [сайт]. — URL: https://personal.ems. psu.edu/ radovic/Semenov Nobel_1956.pdf (дата обращения: 18.06.2020).

11. Semenov N. N. Chain reactions. Moscow: Nauka 1986

12. University of Toronto. - Текст : электронный // College of Earth and Mineral Sciences personal pages : [caйт]. URL: https://arrow.utias.utoronto.ca/ ogulder/ClassNotes3.pdf (дата обращения: 18.06.2020).

13. Попов, В. С. ГЛУБОКОЕ И СВЕРХГЛУБОКОЕ НАУЧНОЕ БУРЕНИЕ НА КОНТИНЕНТАХ / В. С. ПопОВ. - ТеКСт : электронный // Наука о Земле : [сайт]. — URL: http://popovgeo.sfedu.ru/sites/default/files/library/\%D0\%9F\%D0\%B E\%D0\%BF\%D0\%BE\%D0\%B2,\%20\%D0\%9A\%D1\%80\%D0\%B5\%D0\%BC\%D0\%B5\%D0\%BD\%D0\%B5\%D1\%86\% D0\%BA\%D0\%B8\%D0\%B9\%201999_11_2.pdf (дата обращения: 18.06.2020).

14. Vaskov, I. M. Large-scale landslides: geodynamics and forecas / I. M. Vaskov. - Текст : электронный // ФГБОУ ВО «Северо-Кавказский горно-металлургический институт (государственный технологический университет)» [сайт]. — URL: ttp://www.skgmi-gtu.ru/Portals/0/_Monographs/2266-\%D0\%BC.pdf?ver=2019-02-13-162736-707 (дата обращения: 18.06.2020).

15. Kiryukov V.V. Electron-microscopic studies of vitrinite of Donetsk coals in order to predict sudden emissions of coal and gas. Coal Magazine. 1994. N 5. p. 44-47.

16. Xia-Ting Feng Rockburst: Mechanisms, Monitoring, Warning, and Mitigation. University of Wollongong Research Online 2018 https://pdfs.semanticscholar.org/f406/6399174b22547eb48a8c333bbf879a29a39b.pdf

17. Так умирают горы. Огромный обвал в Доломитах.. - Текст : электронный // Risk.ru : [caйт]. — URL: https://risk. ru/blog/2157 (дата обращения: 18.06.2020).

18. Главная. - Текст : электронный // Научно-исследовательский институт горной геомеханики и маркшейдерского дела — межотраслевой научный центр "ВНИМИ" : [сайт]. — URL: http://vnimi.ru/ (дата обращения: 18.06.2020).

19. Вернигор, В. М. ПРЕДУПРЕЖДЕНИЕ ГОРНЫХ УДАРОВ И ВНЕЗАПНЫХ ВЫБРОСОВ В ГОРНОДОБЫВАЮЩЕЙ ПРОМЫШЛЕННОСТИ / В. М. Вернигор. — Текст : электронный // Горная Промышленность : [сайт]. — URL: https://mining-media.ru/ru/article/newtech/1071-preduprezhdenie-gornykh-udarov-i-vnezapnykh-vybrosov-vgornodobyvayushchej-promyshlennosti (дата обращения: 18.06.2020).

20. Introduction to the Bohr Model. - Текст : электронный // BYJU'S : [сайт]. — URL: https://byjus.com/chemistry/bohrsmodel/ (дата обращения: 18.06.2020).

21. Physics 42 Spring 1995 Lab 1 - The Franck-Hertz Experiment and the Critical Potentials of Неlium. — Текст : электронный // Dartmouth : [сайт]. — URL: http://www.dartmouth.edu/ physics/labs/descriptions/franck.hertz.critical. potentials/franck.hertz.critical.potential.writeup.pdf (дата обращения: 18.06.2020).

22. Magnetostriction. - Текст : электронный // LibreTexts : [сайт]. - URL: https://eng.libretexts.org/Bookshelves/ Materials_Science/Supplemental_Modules_(Materials_Science)/Magnetic_Properties/Magnetostriction (дата обращения: 18.06.2020).

23. Buchachenko, A. L. Magnetoplasticity and the physics of earthquakes. Can a catastrophe be prevented? / A. L. Buchachenko. - Текст : электронный // IOPscience : [сайт]. — URL: https://iopscience.iop.org/article/10.3367/ 
UFNe.0184.201401e.0101 (дата обращения: 18.06.2020).

24. Lama, R. Overview of Gas Outbursts and Unusual Emissions / R. Lama. - Текст : электронный // University of Wollongong Research Online : [сайт]. — URL: https://pdfs.semanticscholar.org/f406/6399174b22547eb48a8c333bbf 879a29a39b.pdf (дата обращения: 18.06.2020).

25. БЫЧкОВ, С. В. МОДЕЛЬ ОЧАГА ВНЕЗАПНОГО ВЫБРОСА ПОРОД И ГАЗА ИЗ ГОРНОГО МАССИВА / С. В. Бычков. - Текст : электронный // Index Copernicus : [сайт]. — URL: https://journals.indexcopernicus.com/api/file/ viewByFileld/717032.pdf (дата обращения: 18.06.2020).

26. Грицко, Г. ВНЕЗАПНЫЕ ВЫБРОСЫ МЕТАНА В ШАХТАХ / Г. Грицко. - Текст : электронный // Наука в Сибири : [сайт]. — URL: http://www.nsc.ru/HBC/article.phtml?nid=428\&id=17 (дата обращения: 18.06.2020).

27. Scheidegger A.E. Earth-Science Reviews, 1984 A review of recent work on mass movements on slopes and on rock falls

28. Fedorenko V.S. Mountain landslides and landslides, their forecast. M .: Publishing House of Moscow State University, 1988

29. НАЦИОНАЛЬНЫЙ ОТЧЕТ МеждУНародНОЙ ассоциации сейсмологии и физики недр Земли Международного геодезического и геофизического Союза 2003 - 2006. - Текст : электронный // РОССИЙСКАЯ АКАДЕМИЯ НАУК НАЦИОНАЛЬНЫЙ ГЕОФИЗИЧЕСКИЙ КОМИТЕТ : [саЙТ]. — URL: http://www.iugg.org/members/nationalreports/ russia07.pdf (дата обращения: 18.06.2020).

\section{REFERENCES}

1. SOLID SOLUTIONS. (n.d.). Retrieved from http://www.xumuk.ru/encyklopedia/2/4329.html

2. Solid solutions. (n.d.). Retrieved from http://femto.com.ua/articles/part_2/3986.html

3. Perkowitz, S. (2016, September 14). Solid solution. Retrieved from https://www.britannica.com/science/solid-solution

4. Геологический словарь, 2011. - Текст : электронный // Геокнига : [сайт]. — URL: http://www.geokniga.org/ bookfiles/geokniga-geologicheskiy-slovar-tom-2-k-p.pdf (дата обращения: 18.06.2020).

5. Geophysical Dictionary. (2011). Retrieved from http://www.geokniga.org/bookfiles/geokniga-geologicheskiy-slovartom-2-k-p.pdf

6. British Geological Survey 1998 - 2017 (c)NERC mailto:www-bgs@bgs.ac.uk. (n.d.). What is a landslide? Retrieved from http://www.bgs.ac.uk/research/engineeringGeology/shallowGeohazardsAndRisks/landslides/whatls.html

7. Whittow, J. B. (1988). The Penguin dictionary of physical geography. London, Eng.: Penguin.

8. Внезапный выброс. - Текст : электронный // MiningWiki : [сайт]. — URL: Sudden surge. (n.d.). Retrieved from http://miningwiki.ru/wiki/Внезапный_выброс

9. Kozhuhner, M. A. (n.d.). Cold explosion. Retrieved from http://kvant.mccme.ru/1983/02/p20.htm.

10. SEMENOV, N. N. (1956). Some problems relating to chain reactions and to the theory of combustion. Retrieved from https://personal.ems.psu.edu/ radovic/Semenov_Nobel_1956.pdf

11. Semenov, N. N. (1986). Chain reactions. Moscow: Nauka

12. Combustion Chemistry. (n.d.). Retrieved from https://arrow.utias.utoronto.ca/ ogulder/ClassNotes3.pdf.

13. Popov, V. S. (n.d.). DEEP AND ULTRA DEEP SCIENTIFIC DRILLING ON CONTINENTS. Retrieved from http:// popovgeo.sfedu.ru/sites/default/files/library/Попов, Кременецкий 1999_11_2.pdf

14. Vaskov, I. M. (n.d.). Large-scale landslides: Geodynamics and forecas. Retrieved from ttp://www.skgmi-gtu.ru/ Portals/0/_Monographs/2266-M.pdf?ver=2019-02-13-162736-707

15. Kiryukov, V.V. (1994). Electron-microscopic studies of vitrinite of Donetsk coals in order to predict sudden emissions of coal and gas. Coal Magazine, 5, 44-47.

16. Xia-Ting Feng. (2018). Rockburst: Mechanisms, Monitoring, Warning, and Mitigation. Retrieved from https://pdfs. semanticscholar.org/f406/6399174b22547eb48a8c333bbf879a29a39b.pdf

17. So the mountains die. Huge landslide in the Dolomites. (n.d.). Retrieved from https://risk.ru/blog/2157.

18. Home. (n.d.). Retrieved from http://vnimi.ru/

19. Vernigor, V. M. (n.d.). Prevention of rock blows and sudden emissions in the mining industry. Retrieved from https://mining-media.ru/ru/article/newtech/1071-preduprezhdenie-gornykh-udarov-i-vnezapnykh-vybrosov-vgornodobyvayushchej-promyshlennosti

20. Admin. (2020, January 21). Bohr's Model of an Atom with Postulates and Limitations: BYJU'S. Retrieved from https:// byjus.com/chemistry/bohrs-model/

21. Lab 1 - The Franck-Hertz Experiment and the Critical Potentials of Helium. (1995). Retrieved from http://www. dartmouth.edu/ physics/labs/descriptions/franck.hertz.critical.potentials/franck.hertz.critical. potential.writeup.pdf

22. Libretexts. (2020, May 31). Magnetostriction. Retrieved from https://eng.libretexts.org/Bookshelves/Materials_Science/ Supplemental_Modules_(Materials_Science)/Magnetic_Properties/Magnetostriction

23. Buchachenko, L. A. (n. .d.). Magnetoplasticity and the physics of earthquakes. Can a catastrophe be prevented? Retrieved from https://iopscience.iop.org/article/10.3367/UFNe.0184.201401e.0101

24. Lama, R. (2002). Overview of Gas Outbursts and Unusual Emissions. Retrieved from https://pdfs.semanticscholar. org/f406/6399174b22547eb48a8c333bbf879a29a39b.pdf.

25. Bychkov. S.V.. (2018). FOCUS MODEL OF ROCK AND GAS SUDDEN OUTBURST FROM ROCK MASSIF. Retrieved from https://journals.indexcopernicus.com/api/file/viewByFileld/717032.pdf

26. Gritsko, G. (2007). Sudden Methane Emissions in Mines. Retrieved from http://www.nsc.ru/HBC/article. phtml? nid=428\&id=17

27. Scheidegger. A.E (1984). Earth-Science Reviews\& A review of recent work on mass movements on slopes and on rock falls

28. Fedorenko, V.S. (1988). Mountain landslides and landslides, their forecast. Mpscow - Publishing House of Moscow State University,

29. RUSSIAN ACADEMY OF SCIENCES NATIONAL GEOPHYSICAL COMMITTEE. (2007). NATIONAL REPORT to the International Association of Seismology and Physics of the Earth's Interior of the International Union of Geodesy and Geophysics 2003 - 2006. Retrieved from http://www.iugg.org/members/nationalreports/russia07.pdf 


\section{ТРЕБОВАНИЯ К РАЗМЕЩЕНИЮ РЕКЛАМНЫХ МАТЕРИАЛОВ}

Научно-технический журнал «Вестник Научного центра по безопасности работ в угольной промышленности» приглашает научные институты, организации и промышленные предприятия разместить информацию о конференциях, выставках, разрабатываемой и выпускаемой продукции в области охраны труда, безопасности в чрезвычайных ситуациях, пожарной и промышленной безопасности в угольной промышленности, контроля природной среды, веществ, материалов и изделий, а также приборостроения.

\section{РАЗМЕРЫ РЕКЛАМНЫХ МОДУЛЕЙ:}

- размер для 1 полосы: 216*303 мм, включая по 3 мм на обрезку с каждой стороны внешнего периметра, на корешок допуск ставить не нужно.

- 1/2 полосы вертикальная: 103*303 мм,

- 1/2 полосы горизонтальная: 216*151 мм

- 1/3 полосы горизонтальная: 216*92 мм

- 1/4 полосы горизонтальная: $216^{*} 67$ мм

- 1/4 полосы вертикальная в верхнем или нижнем внешнем углу страницы: 103*151 мм

ТРЕБОВАНИЯ К РЕКЛАМНЫМ СТАТЬЯМ

1. Текст для статьи предоставляется тольков текстовом редакторе Word.

2. Объем статьи: не более 4500 печатных знаков с пробелами (без изображений). При использовании фотографий объем текста пропорционально уменьшается.

3. Требования к фотографиям: формат .eps или .tiff с разрешением $300 \mathrm{dpi}$.

4. Логотип-в форматах.cdr, .eps, приэтом шрифтыдолжныбыть переведены в кривые.

5. Текст рекламной статьи должен включать заголовок (подзаголовок), выходные данные заказчика: название, адрес, телефон, электронный адрес компании.

\section{ТРЕБОВАНИЯ К РЕКЛАМНЫМ МАКЕТАМ}

1. Размер электронного макета должен соответствовать размерам рекламного модуля.

2. Растровые фрайлы должны быть в форматах .tif, .psd, .eps с разрешением 300 dрі , векторные .ai, .eps u .cdr.

3. Оригинал-макетыпередаются в цветовой модели СМҮК без компрессии.

4. Верстка может быть в форматах Adobe illustrator, Corel Draw, Adobe Indesign (в этом случае должны предоставляться все связанные элементы, а также все используемые шрифты, обязательно макет должен так же прилагаться в pdf).

5. В макете, подготовленном в пакете Corel Draw не допускается наличие следующих эффектов: shadow, transparency, gradient fill, lens, texture fill и postscript fill. Все вышеперечисленные эфректы Corel Draw должны быть конвертированы в bitmap $300 \mathrm{dpi.}$

6. Черный цвет текста должен состоять только из черного канала - С:0, М:0, Y:0, K:100 или 100 Black в одноцветной шкале Grayscale.

7. Все текстовые элементы оригинал-макета должны быть переведены в кривые.

8. Текст и важные изображения (логотип и т. п.) не должны располагаться ближе 5 мм к обрезному краю.

Информация о расценках на размещение рекламы размещена на сайте www.ind-saf.ru. риалов.

Редакция журнала оставляет за собой право отбора поступивших рекламных мате- 


\section{ТРЕБОВАНИЯ, УСЛОВИЯ И ПОРЯДОК ПРЕДСТАВЛЕНИЯ РУКОПИСЕЙ В НТЖ «Вестник Научного центра по безопасности работ в угольной промышленности»}

\section{I. Порядок представления материалов в редакцию}

1. В журнал принимаются статьи, соответствующие его тематике - охрана труда, безопасность в чрезвычайных ситуациях, пожарная и промышленная безопасность в угольной промышленности, приборы и методы контроля природной среды, веществ, материалов и изделий.

2. Статья должна быть оригинальной, не представленной в других изданиях.

3. На основании положений части четвертой Гражданского кодекса Российской Федерации (раздел VII «Права на результаты интеллектуальной деятельности и средства индивидуализации») представляемые в журнал статьи должны сопровождаться лицензионным договором о передаче ООО «ВостЭКО» (издатель журнала) простой (неисключительной) лицензии. Договор заполняется на бланках по образцам лицензионных договоров с одним или коллективом авторов (при написании статьи несколькими авторами). Лицензионный договор является договором присоединения. Необходимо заполнить и подписать договор, отсканированный вариант отправить по e-mail: yarosh_mv@mail.ru, два первых экземпляра офрормленного договора отправить в редакцию по почте: $65000 \overline{2}$, Кемерово, Сосновый бульвар, д. 1, ООО «ВостЭКО». Договор, подписанный автором/авторами и направленный по электронной почте, признается равнозначным документу на бумажном носителе, подписанному собственноручной подписью, порождающим права и обязанности сторон. Скачать бланки договора можно на сайте www.indsafe.ru.

\section{II. Форма представления рукописи}

1. Рукопись представляется отпечатанной в текстовом редакторе Word через 1,5 интервала на одной стороне стандартного листа белой бумаги фрормата A4 и в электронном виде (передается по электронной почте yarosh_mv@mail.ru или на магнитном носителе).

2. Все страницы рукописи, включая таблицы, список литературы, рисунки должны быть пронумерованы. Рекомендуемый объем статьи 5-7 страниц. Статья должна быть подписана всеми авторами.

3. Плата с аспирантов за публикацию рукописей не взимается.

\section{Подготовка электронной версии материалов}

1. Текст набирается шрифтом Times New Roman, размер шрифта 12, для заголовка 16, полуторный интервал, абзацный отступ 1,25 см, фрормат листа А4. Поля с левой стороны 3 см, сверху и снизу и справа 2 см;

2. Электронная версия должна быть идентична распечатанному тексту. В случае расхождения за основу берется печатный вариант.

\section{Структура статьи}

1. Индекс УДК.

2. Фотографрии всех авторов (форматы: TIF, Jpeg, Png, не сканированные, не ретушированные, не обрезанные, разрешение $300 \mathrm{dpi)}$.

3. Инициалы и фамилия автора (ов).

4. Место работы.

5. Название статьи.

6. Рефрерат. Реферат должен быть инфрормативным, отражать основное содержание статьи и результаты исследований, следовать логике описания результатов в статье, укладываться в объем от 100 до 250 слов. Возможно краткое повторение структуры статьи, включающей введение, цели и задачи, методы, результаты, заключение.

7. Ключевые слова.

8. Текст статьи с таблицами, иллюстрациями, фрормулами.

9. Список литературы (оформленный в соответствии с ГОСТ Р 7.0 .5 - 2008 «Библиографическая ссылка. Общие требования и правила составления»). жать:

На отдельном листе или в конце статьи размещается «Список авторов», который должен содер-

- публикуемые сведения об авторах (название организации указывается в соответствии с учредительными документам));

- служебные или домашние адреса с указанием почтового индекса;

- адрес электронной почты (e-mail).

Обращаем ваше внимание, что представление оригинальной статьи к публикации в НТЖ означает согласие авторов на передачу права на воспроизведение, распространение и доведение произведения до всеобщего сведения любым способом. 


\title{
СЛОВО РЕДАКТОРА // EDITORIAL
}

\section{5 Трубицына H. Trubitsyna N.}

5 Трубицына H. Trubitsyna N.

\section{AKTYAЛЫHO // IMPORTANT}

6 С.Б. Романченко, Е.А. Губина, Д.В. Ушаков, Ю.К. Нагановский

Термогравиметрический анализ угольной пыли и инертных добавок в системах пылевзрывозащиты

S. B. Romanchenko, E. A. Gubina, D. V. Ushakov, Yu. K. Naganowskiy

Thermogravimetric analysis of coal dust and inert additives in dust and explosion protection systems

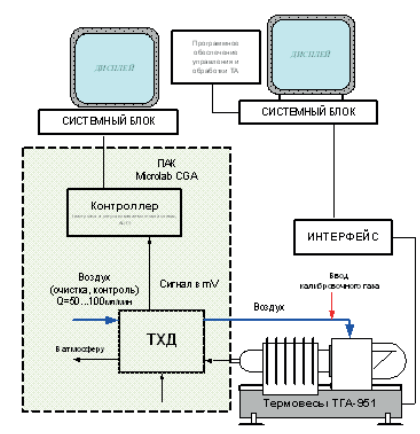

\section{І. ПРОМЫШЛЕННАЯ БЕЗОПАСНОСТЬ И ГЕОМЕХАНИКА // INDUSTRIAL SAFETY AND GEOMECHANICS}

13 С.Б. Романченко, А. А. Трубицын, В.В. Соболев, В.В. Вдовина Теоретические аспекты определения плотности угольной пыли и сыпучих материалов

S. B. Romanchenko, A.A. Trubitsyn, V.V. Sobolev, V.V. Vdovina. Theoretical aspects of determining the density of coal dust and bulk materials

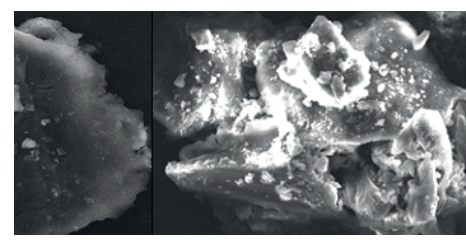

21 А.В. Шадрин, А.С. Телегуз Структура подсистемы прогноза выбросоопасности многофункциональной системы безопасности угольной шахты

A.V. Shadrin, A.S. Teleguz Coal mine multifunctional safety outburst hazard forecast subsystem structure

32 В. С. Зыков Обоснование показателя степени выбросоопасности призабойной части угольного пласта

V.S. Zykov Coal seam face area outburst hazard degree factor justification

38 К.Х. Ли, В.В. Иванов Кинетические представления о разрушении горных пород при подготовке горных ударов

K.Kh. Li, V. V. Ivanov. Kinetic conceptions of rock destruction during rock bump preparation

\section{II. ПОЖАРНАЯ И ПРОМЫШЛЕННАЯ БЕЗОПАСНОСТЬ // FIRE AND INDUSTRIAL SAFETY}

\begin{abstract}
41 К. А. Кольвах Обоснование ключевого статистического показателя применительно к оценке индивидуального риска работников угольных шахт вследствие обрушения горных пород К. A. Kolvakh Substantiation of a key statistical indicator for assessing the individual risk of coal mine workers due to rock collapse
\end{abstract}

45 А. И. Фомин, Д. А. Бесперстов Проблемы и пути их решения, возникающие при эксплуатации и консервации угольных предприятий и шламоотстойников

A. I. Fomin , D. A. Besperstov Problems and ways of their solution arising when operating and maintaining coal enterprises and sludge pits

50 И. М. Анисимов, А. И. Фомин. Анализ потерь при получении работником травмы I.M. Anisimov, A.I. Fomin. Analysis of losses in case when an employee has injury

54 М.Г. Рублев, И.В. Пирумова, В.Л. Павлова Совершенствование системы управления охраной труда в западно-сибирской дирекции управления движением

M. G. Rublev, I. V. Pirumova, V. L. Pavlova Improving the labor protection management system in the west siberian directorate of traffic management 


\section{III. ТЕХНОЛОГИЧЕСКИЕ ВОПРОСЫ БЕЗОПАСНОСТИ ГОРНЫХ PABOT // TECHNOLOGICAL QUESTIONS OF MINING WORK SAFETY}

59 Ю. А. Масаев, В. Ю. Масаев, А. И. Копытов. Особенности проходки комплекса горных выработок при разработке рудных месторождений

Yu.A. Masaev, V.Yu. Masaev, A.I. Kopytov. Features of mine opening complex heading at the development of ore deposits

65 Герике П.Б., П.В. Ещеркин. Разработка единого диагностического критерия для диагностики подшипников качения энергомеханического оборудования карьерных экскаваторов

P.B. Gerike, P.V.Yeshcherkin Development of a unified diagnostic criterion for mining shovel powermechanical equipment rolling bearings' diagnosis

73 В.А.Афранасьева, Дягилева А.В. Диагностика загрязнения окружающей среды отработанным машинным маслом в г. кемерово

V. A. Afanasieva, A.V .Diagileva. Diagnostics of the environmental pollution with waste engine oil in kemerovo

77 Ю. А. Масаев, А. И. Копытов, В. Ю. Масаев. Исследования по установлению рациональных параметров бвр при подготовке и нарезке очистных блоков в мощных залежах крепких руд

Yu.A. Masaev, A.I. Kopytov, V.Yu. Masaev. Researches to establish rational drill and blast parameters during the preparation and cutting of extraction blocks in thick deposits of hard ore

\section{IV. ПРОБЛЕМЫ И СУЖДЕНИЯ // PROBLEMS AND OPINIONS}

82 Бычков С. Крупномасштабные обвалы как геофизическмй процесс горного удара или внезапного выброса пород и газа

S.V. Bychkov Large-scale collapses as a geophysical process of rock bump or sudden outburst of rocks and gas

92 ТРЕБОВАНИЯ К РЕКЛАМНЫМ МАТЕРИАЛАМ // ADVERTISING MATERIALS REQUIREMENTS

93 TРЕБОВАНИЯ К СТАТЬЯМ // DEMANDS TO ARTICLES

94 СОДЕРЖАНИЕ // CONTENT 
Подписано в печать 24.06.2020. Тираж 1000 экз. Формат 60х90 1/8.

Выпуск 2-2020, дата выхода в свет 25.06.2020

Объем 10 п. л. Заказ № 12020 г. Цена свободная.

Типография ООО «ИНТ».

650065, Россия, Кемеровская область, г. Кемерово, пр-т Октябрьский, 28 офис 215 Тел. 8 (3842) 657889. 